\title{
Retinoic acid metabolism blocking agents (RAMBAS) in hyperkeratotic disorders
}

Citation for published version (APA):

Verfaille, C. J. (2007). Retinoic acid metabolism blocking agents (RAMBAS) in hyperkeratotic disorders. [Doctoral Thesis, Maastricht University]. Datawyse / Universitaire Pers Maastricht. https://doi.org/10.26481/dis.20070427cv

Document status and date:

Published: 01/01/2007

DOI:

$10.26481 /$ dis.20070427cv

Document Version:

Publisher's PDF, also known as Version of record

\section{Please check the document version of this publication:}

- A submitted manuscript is the version of the article upon submission and before peer-review. There can be important differences between the submitted version and the official published version of record.

People interested in the research are advised to contact the author for the final version of the publication, or visit the DOI to the publisher's website.

- The final author version and the galley proof are versions of the publication after peer review.

- The final published version features the final layout of the paper including the volume, issue and page numbers.

Link to publication

\footnotetext{
General rights rights.

- You may freely distribute the URL identifying the publication in the public portal. please follow below link for the End User Agreement:

www.umlib.nl/taverne-license

Take down policy

If you believe that this document breaches copyright please contact us at:

repository@maastrichtuniversity.nl

providing details and we will investigate your claim.
}

Copyright and moral rights for the publications made accessible in the public portal are retained by the authors and/or other copyright owners and it is a condition of accessing publications that users recognise and abide by the legal requirements associated with these

- Users may download and print one copy of any publication from the public portal for the purpose of private study or research.

- You may not further distribute the material or use it for any profit-making activity or commercial gain

If the publication is distributed under the terms of Article $25 \mathrm{fa}$ of the Dutch Copyright Act, indicated by the "Taverne" license above, 


\author{
Retinoic Acid Metabolism \\ BLOCKING AGENTS (RAMBAS) \\ IN HYPERKERATOTIC DISORDERS
}


Lay-out: C.J. Verfaille

Cover illustration: Fiji Mermaid by Takeshi Yamada (see page 239)

Printing: Datawyse / Universitaire Pers Maastricht

ISBN $978-90-5278-620-9$

(C) Copyright C.J. Verfaille, Beerse 2007

All rights reserved. No part of this thesis may be reproduced or transmitted in any form or by any means, electronic or mechanical, including photocopying, recording or any information appropriate, without the prior written permission of the publishers of the publications. 


\title{
Retinoic Acid Metabolism BLOCKING AGENTS (RAMBAS) IN HYPERKERATOTIC DISORDERS
}

\author{
Proefschrift \\ ter verkrijging van de graad van doctor \\ aan de Universiteit van Maastricht \\ op gezag van de Rector Magnificus, \\ Prof. Mr. G.P.M.F. Mols \\ volgens het besluit van het College van Decanen \\ in het openbaar te verdedigen \\ op vrijdag 27 april 2007 om 14.00 uur \\ door
}

\section{Christel Jeanne Verfaille}

geboren te Menen, België op 19 maart 1969

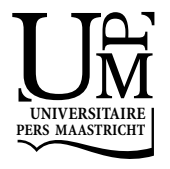




\section{Promotor}

Prof. Dr. M. Borgers

Prof. Dr. F.C.S. Ramaekers

Prof. Dr. P.M. Steijlen

\section{Co-promotor}

Dr. M.A.M. van Steensel

\section{Beoordelingscommissie}

Prof. Dr. J.P.M. Geraedts (voorzitter)

Prof. Dr. M.J.A.P. Daemen

Prof. Dr. H. Degreef (Katholieke Universiteit Leuven)

Prof. Dr. A.P. Oranje (Erasmus MC, Rotterdam)

Prof. Dr. H. van Loveren

The work presented in this thesis as well as the printing was financially supported by Barrier Therapeutics, Geel, Belgium. 
Aan mijn ouders

En mijn familie

Family, family, center of our lifes,

No one wants a broken circle

Hands together

Bound

(The Innocent Mission) 


\section{Abbreviations}

ACTH

ADIV

AD

$\mathrm{ADH}$

ALDH

AE

All-trans-RA

APL

ARAT

AUC

b.i.d.

BPE

BSA

CBIE

CCA

CRABP

CRBP

CTCL

CYP

DR

ECG

EGF

ELI

ELISA

FDA

FLG

$\mathrm{FSH}$

$\mathrm{HDFa}$

HLA

HuMVEC

IBS

IC50

IFN- $\gamma$

IL-1 $\alpha$

ITT

IU

i.v.

KRT

KSFM

LI

LH

LOR
Adrenocorticotropic Hormone

Autosomal Dominant Ichthyosis Vulgaris

Atopic Dermatitis

Alcohol Dehydrogenase

Retinal Dehydrogenase

Adverse Event

All-trans-Retinoic Acid

Acute Promyelocytic Leukemia

Acyl-CoA:Retinol Acyltransferase

Area under the Curve

Bis in diem

Bovine Pituitary Extract

Bovine Serum Albumine

Congenital Bullous Ichthyosiform Erythroderma of Brocq

Complete Case Analysis

Cellular Retinoic Acid Binding Protein

Cellular Retinol Binding Protein

Cutaneous T-Cell Lymphoma

Cytochrome P-450

Direct Repeat

Electrocardiogram

Epidermal Growth Factor

Erythrodermic Lamellar Ichthyosis

Enzyme-Linked ImmunoSorbent Assay

U.S. Food and Drug Administration

Filaggrin Gene

Follicle-Stimulating Hormone

Human Adult Dermal Fibroblasts

Human Leucocyte Antigen

Human Microvascular Endothelial Cells

Ichthyosis Bullosa of Siemens

$50 \%$ Inhibitory Concentration

Interferon $\gamma$

Interleukin- $1 \alpha$

Intent-to-Treat

International Units

Intravenous

Keratin Gene

Keratinocyte Serum-free Medium

Lamellar Ichthyosis

Luteïnizing Hormone

Loricrin Gene 


$\begin{array}{ll}\text { LRAT } & \text { Lecithin:Retinol Acyltransferase } \\ \text { LSC } & \text { Liquid Scintillation Counting } \\ \text { LSGS } & \text { Low Serum Growth Supplement } \\ \text { MHC } & \text { Major Histocompatability Complex } \\ \text { MRP-8 } & \text { Migration inhibitory factor-Related Protein } \\ \text { MTT } & \text { 3-[4,5-dimethyl-thiazol-2-yl]-2,5-diphenyl tetrazolium bromide } \\ \text { MVGS } & \text { Microvascular Growth Supplement } \\ \text { n-CIE } & \text { non-Bullous Congenital Ichthyosiform Erythroderma } \\ \text { NELI } & \text { Non-Erythrodermic Lamellar Ichthyosis } \\ \text { NHEK } & \text { Normal Human Epidermal Keratinocytes } \\ \text { 9-cis-RA } & \text { 9-cis-Retinoic Acid } \\ \text { OD } & \text { Optical Density } \\ \text { ODC } & \text { Ornithine Decarboxylase } \\ \text { PASI } & \text { Psoriasis Area Severity Index } \\ \text { PBS } & \text { Phosphate Buffered Saline } \\ \text { p.o. } & \text { Per Os } \\ \text { PP } & \text { Per Protocol } \\ \text { PPAR } & \text { Peroxisome Proliferator-activated Receptor } \\ \text { PSORS } & \text { Psoriasis Susceptibility Locus } \\ \text { PUVA } & \text { Psoralen plus UVA-irradiation } \\ \text { RA } & \text { Retinoic Acid } \\ \text { RAL } & \text { Retinal } \\ \text { RAMBA } & \text { Retinoic Acid Metabolism Blocking Agent } \\ \text { RAR } & \text { Retinoic Acid Receptor } \\ \text { RBP } & \text { Retinol Binding Protein } \\ \text { RE } & \text { Retinyl Ester } \\ \text { RHE } & \text { Reconstituted Human Epidermis } \\ \text { ROL } & \text { Retinol } \\ \text { RXR } & \text { Retinoid X Receptor } \\ \text { SAE } & \text { Serious Adverse Event } \\ \text { s.c. } & \text { Subcutaneous } \\ \text { SDR } & \text { Short-chain Dehydrogenase/Reductase } \\ \text { STS } & \text { Steroid Sulfatase } \\ \text { 13-cis-RA } & \text { 13-cis-Retinoic Acid } \\ \text { TG-1 } & \text { Transglutaminase -1 } \\ \text { TGM-1 } & \text { Transglutaminase-1 gene } \\ \text { TPA } & \text { Tetradecanoyl-phorbol-13-acetate } \\ \text { TR } & \text { Thyroid Receptor } \\ \text { TSH } & \text { Thyroid Stimulating Hormone } \\ \text { TTR } & \text { Transthyretin } \\ \text { UGT2B7 } & \text { Human Liver Glucuronyl Transferase } \\ \text { UVA } & \text { Ultraviolet A } \\ \text { UVB } & \text { Ultraviolet B } \\ \text { VDR } & \text { Vitamin D Receptor } \\ \text { XRI } & \text { X-linked Recessive Ichthyosis } \\ & \end{array}$





\section{Contents}

$\begin{array}{ll}\text { Chapter } 1 \text { General introduction } & 11\end{array}$

$\begin{array}{ll}\text { Hyperkeratotic skin disorders } & 12\end{array}$

$\begin{array}{ll}\text { Ichthyosis } & 14\end{array}$

$\begin{array}{ll}\text { Psoriasis } & 20\end{array}$

Acne $\quad 22$

Treatment of hyperkeratotic disorders $\quad 23$

$\begin{array}{ll}\text { General treatments } & 23\end{array}$

$\begin{array}{ll}\text { Retinoids } & 25\end{array}$

Retinoic Acid Metabolism Blocking Agents $\quad 37$

Aim and outline of the thesis $\quad 39$

Chapter 2 In vitro comparison of 3 generations RAMBAs $\quad 55$

Chapter 3 Effects of R115866 on Reconstituted Human Epidermis 69

Chapter 4 In vivo pharmacology of liarozole $\quad 85$

$\begin{array}{lll}\text { Chapter } 5 \text { Topical liarozole in ichthyosis } & 103\end{array}$

$\begin{array}{lll}\text { Chapter } 6 \text { Oral liarozole in ichthyosis } & 119\end{array}$

$\begin{array}{llr}\text { Chapter } 7 \text { Retinoids and RAMBAs in psoriasis } & 139\end{array}$

$\begin{array}{lll}\text { Chapter } 8 \text { Oral R115866 in psoriasis } & 171\end{array}$

$\begin{array}{lll}\text { Chapter } 9 \text { Oral R115866 in acne } & 193\end{array}$

$\begin{array}{ll}\text { Chapter } 10 \text { General discussion } & 207\end{array}$

$\begin{array}{ll}\text { Summary } & 221\end{array}$

$\begin{array}{ll}\text { Samenvatting } & 225\end{array}$

$\begin{array}{lr}\text { Colour figures } & 229\end{array}$

$\begin{array}{lr}\text { Fiji Mermaid by Takeshi Yamada } & 239\end{array}$

$\begin{array}{ll}\text { Dankwoord } & 241\end{array}$

$\begin{array}{ll}\text { Curriculum vitae } & 245\end{array}$

$\begin{array}{ll}\text { List of publications } & 248\end{array}$ 



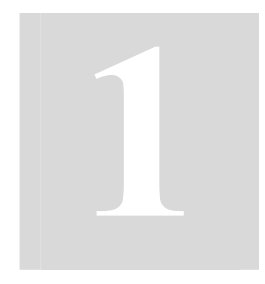

\section{General Introduction}

Partly based on:

Verfaille $C J^{1,4}$, van Steensel MAM ${ }^{2}$, van de Kerkhof $P C M^{3}$ and Steijlen $P M^{1}$. Use of liarozole in ichthyosis.

Submitted

\footnotetext{
${ }^{1}$ Departments of Dermatology and Molecular Cell Biology, GROW, Maastricht University, The Netherlands.

${ }^{2}$ Department of Dermatology, AZM, University Hospital Maastricht, The Netherlands.

${ }^{3}$ Department of Dermatology, Radboud University Nijmegen Medical Center, Nijmegen, The Netherlands.

${ }^{4}$ Barrier Therapeutics $n v$, Geel, Belgium
} 


\section{Hyperkeratotic skin disorders}

The outer layer of the skin, called "the epidermis", is the largest organ in the human body. It is at its thinnest on the eyelids, at $.05 \mathrm{~mm}$, and at its thickest on the palms and soles at $1.5 \mathrm{~mm}$. As a specialized non-vascularised stratifying epithelium, consisting of successive layers (strata) of keratin producing cells (keratinocytes), the epidermis is a dynamic, continually renewing structure that functions as an essential barrier to the environment. The keratinocytes gradually migrate through the different strata up to the surface (keratinocyte maturation) and are sloughed off in a process known as desquamation. ${ }^{1-3}$ Keratinocyte maturation can be divided into five sequences:

1. The bottom layer of the epidermis, the stratum basale, consists of undifferentiated keratinocytes shaped like columns. These cells are attached by hemi-desmosomes to a non-cellular basement membrane that separates the epidermis from the underlying dermis. In the basal layer, the keratinocytes divide continuously and push already formed cells into higher layers. Half of these cells progress upwards and differentiate, while the other half remain behind to divide again. In addition to the differentiating keratinocytes, the stratum basale also houses other cells with stem celllike properties, Merkel cells (with apparent sensory functions) and melanocytes (pigment producing cells that protect us against ultraviolet radiation damage).

2. In the middle inner layers, the stratum spinosum (8-10 sheets of keratinocytes with limited dividing capacity), the shape of the keratinocytes changes from columnar to polygonal. Differentiating keratinocytes synthesize keratins which aggregate to form the tonofilaments that make up the cell skeleton. Condensations of these tonofilaments insert into desmosomes which connect keratinocytes and serve to disperse structural stresses through the epidermis. Also found here are bone marrow-derived sentinel cells of the immune system called Langerhans cells.

3. The next layer, the stratum granulosum, consists of 3-5 sheets of non-dividing keratinocytes producing granules of a protein called keratinohyalin and enzymes which induce degradation of nuclei and organelles. The formation of an anuclear keratin layer is called orthokeratosis. Keratohyalin granules mature the keratin and provide an amorphous protein matrix for the tonofilaments. Membrane coating granules attach to the cell membrane and release impenetrable lipid-containing cement which contributes to cell adhesion and to the cornified envelope which ultimately will form the epidermal barrier. 
4. The outermost layer of the epidermis, the stratum corneum, consists of 15-26 layers of highly cross-linked dead but biochemically active, flat skin cells or corneocytes that are organized into 'bricks-and-mortar' arrays and shed about every 2 weeks. Corneocytes are afforded extra protection via a uniform peripheral envelope of several highly cross-linked, cytosolic proteins, the cornified envelope. The flattened sheets are packed with keratin filaments and embedded within a matrix of filaggrin and interconnected via junctions (corneo-desmosomes). The stratum corneum is important in preventing all manner of agents from entering the skin, including micro-organisms, water and particulate matter. It also prevents loss of vital body fluids. Barrier function in human epidermis depends on transglutaminase (TGase)mediated cross-linking of structural proteins and lipids during this terminal stage of keratinocyte differentiation. Such cross-linking yields high molecular mass proteins highly resistant to mechanical perturbation and proteolysis. Several mutations in genes encoding the barrier's structural components, its enzymes and lipid processing can result in skin diseases.

5. Corneocytes are shed from the skin surface.

The dividing basal cell replicates on average every 200 to 400 hours, and the resulting cell takes 14 days to differentiate and 14 days to be shed again, which results in a normal human epidermal cell turn-over of 28 days. Increased proliferation of the basal cells or increased retention of the keratinocytes within the epidermis, or both, results in increased thickness of the epidermis, also called 'hyperkeratosis', a typical feature of keratinisation disorders. Many such diseases have been discovered to date, but this work will only focus on 3 of them: ichthyosis, psoriasis and acne.

Genetic abnormalities in structural cytoskeleton proteins or in enzymes responsible for the formation of the cornified cell envelope or the metabolism of the intercellular lipids are among the main causes of keratinization disorders such as ichthyosis. These, however, are relatively rare.

Hyperkeratosis as a result of an abnormal cell turnover is much more common. Abnormal cell-turn over is caused by abnormalities in the keratinocyte life-cycle, which may or may not be immune-mediated. The best known example is psoriasis, where hyperkeratosis is associated with aberrant differentiation and inflammation caused by the release of cytokines into the epidermis by keratinocytes and lymphocytes. Mitotic activity of basal keratinocytes is increased almost 50-fold, with keratinocytes migrating from the basal to the cornified layers in only 3-5 days compared to the normal 28-30 
days. With hyperproliferation of skin cells, the epidermis becomes thickened or acanthotic in appearance and an increase in size of the rete ridges is observed. Abnormal keratinocyte differentiation is noted throughout the psoriatic plaques, as manifested by the loss of the granular layer. The stratum corneum is also thickened, and the retention of cell nuclei in this layer is referred to as parakeratosis.

Hyperkeratosis is also one of the factors involved in the pathogenesis of acne. The keratinocytes lining the inside of a hair follicle normally detach from the lining, attach to the growing hair and die, while converting themselves into corneocytes and forming the hair cuticle. In acne, a number of the keratinocytes in the follicle convert too fast (=hyperkeratinization), clumping together instead of attaching to the cuticle. When such a clump of keratinocytes blocks the follicle exit, it induces comedogenesis and contributes to acne.

\section{Ichthyosis}

'Ichthyosis' is a descriptive term used for a clinically and genetically heterogeneous group of keratinisation disorders caused by abnormal differentiation and/or desquamation of the epidermis. Ichthyosis is derived from the Greek word 'ichthys' which means fish, as it is characterized by visible scales all over the body surface and excessively dry skin. ${ }^{4}$ These dermatoses are rarely life-threatening but they can be debilitating, cause social isolation and may require life-long treatment. The quality of life of these patients is severely affected. ${ }^{5}$

The group is classified on the basis of clinical appearance and the underlying gene defect. Classification has been refined over the years due to spectacular advances in molecular genetics. Today, more than 20 different subtypes have been described and as more mutations are discovered, more surely will follow over the next years. An overview of the molecular genetics and geno/phenotypes of the different ichthyosis subtypes described in this thesis is given in Table 1.1. More information on the different ichthyosis subtypes can be found in the works of H.Traupe and Judge and Harper. ${ }^{4,6}$ More recently, the molecular genetics have been reviewed by Richard et al. and Segre et al. ${ }^{7,8}$

\section{Autosomal dominant ichthyosis vulgaris (ADIV)}

ADIV, with an incidence in $1 / 250$ individuals, is the most common form of ichthyosis. Although inherited in an autosomal dominant pattern, it differs in many ways from the rest of the ichthyosis. Being a lot milder than the other types, it responds well to hydra- 
tion, lubrication and keratolytics and is considered a separate clinical entity by dermatologists. It is often classified as an excessive dryness, which is not present at birth but develops during the first years of life. There is a marked seasonal variation and the dryness worsens in dry climate.

In 2005-2006, Irwin McLean et al. and other experts on genetic skin disorders have discovered that ADIV is caused by mutations in the filaggrin (FLG) gene located on chromosome 1. The FLG gene encodes profilaggrin, a protein that is needed for the formation of the stratum corneum. ${ }^{9}$ During epidermal differentiation profilaggrin is cleaved into multiple filaggrin peptides that aggregate keratin filaments. ADIV is semidominant meaning that heterozygous mutations in the $F L G$ gene result in either no discernible phenotype or a very mild form of ADIV whilst homozygous mutations result in moderate to severe ADIV. An additional major discovery by the same experts was that mutations in the FLG gene are also held responsible for the development of atopic dermatitis (AD) and asthma. ${ }^{10}$ Thus, patients with ADIV are predisposed to develop AD (or eczema) later in life, which is of a greater concern that the ADIV itself. ${ }^{10,11}$

The other ichthyosis subtypes, of which only a few will be described in more detail, are far rarer and far more severe than ADIV and can be considered orphan diseases. Therefore patients are often referred to specialized academic centres for diagnosis and treatment. The only effective drugs available today for the treatment of severe ichthyosis are retinoic acid (RA) and its synthetic analogues.

\section{X-linked recessive ichthyosis (XRI)}

XRI is caused by a defect in the STS gene (steroid sulfatase) which leads to an accumulation of cholesterol-3-sulfate in the epidermis. ${ }^{12,13}$ The result is a defect in desquamation. The skin is covered with small, dark, firmly adherent scales accentuated on sides of the neck and on the trunk. Face, palms and soles are generally spared. As it is an Xlinked recessive trait, the disorder is only manifested in males and has an incidence of $1 / 6000$. It may be present at birth but is often not noticed for months or years. The overall severity does not change with time but distinctively worsens in dry weather.

\section{Autosomal recessive congenital ichthyosis: Lamellar ichthyosis (LI)}

LI is, with an incidence of 1/300,000-600,000, one of the most severe forms of ichthyosis. Inherited in an autosomal recessive trait, it is already apparent at birth and persists unremittingly throughout life. Many LI patients are born encased in a tight, shiny, translucent membrane with underlying erythroderma and are called 'collodion babies', because the membrane resembles collodion, which is a syrupy solution that was 
once used to coat photographs. ${ }^{4,14}$ The "collodion membrane" is gradually replaced over the first weeks of life by generalized large, dark brown and plate-like scales with minimal to no erythema. Increased susceptibility to bacterial and fungal skin infections, as well as heat intolerance, may be a common problem in this group.

Mutations in the transglutaminase-1 gene, TGM-1, have been found in about $30 \%$ of patients with features of the 'classical' non-erythrodermic LI, in the past also referred to as non-erythrodermic lamellar ichthyosis or NELI. ${ }^{15-18}$ Transglutaminase-1 is a crucial epidermal enzyme expressed in the upper differentiated layers. It facilitates the formation of an insoluble protein envelope by cross-linking numerous structural proteins (e.g. loricrin, keratin intermediate filaments, and others) as well as the attachment. ${ }^{19,20}$ Only few patients carrying TGM-1 defects have mild to moderate erythroderma with white, gray or small scales. ${ }^{21-23}$ Today this group is classified as congenital ichthyosiform erythroderma. In the past they were assigned to the LI group and referred to as erythrodermic lamellar ichthyosis or ELI. ${ }^{4,24}$

In other individuals with LI, misense mutations have been reported in a novel gene namely $A B C A 12$, which belongs to the large super-family of ATP-binding casette transporter genes. ${ }^{25} A B C A 12$ is hypothesized to be involved in epidermal lipid trafficking. Complete loss of $A B C A 12$ function results in harlequin ichthyosis, the most severe form of congenital ichthyosis often lethal in the neonatal period. ${ }^{26,27}$ In 2006 , Lefevre et al. reported mutations in a new cytochrome $\mathrm{P} 450$ gene (encoding for CYP4F2) in lamellar ichthyosis. ${ }^{28}$

\section{Autosomal recessive congenital ichthyosis: non-bullous congenital ichthyosi- form erythroderma (n-CIE)}

The clinical features of n-CIE, a usually severe inflammatory ichthyosis occurring in about 1/200.00 individuals, are somewhat milder than in lamellar ichthyosis. In contrast to classical LI, the skin is always red and scales are usually white, fine and powdery. In some subtypes of $\mathrm{n}$-CIE, the palms and soles are severely hyperkeratotic. ${ }^{6}$ Ninety percent of the patients are born as collodion babies. Shedding of the collodion membrane within the first weeks of life reveals persistent, generalized scaly erythroderma. Pruritus is characteristic for n-CIE and in most patients sweating is compromised and markedly reduced from infancy onwards. Heat intolerance and increased susceptibility to infections of the skin is common.

Although inherited as an autosomal recessive trait in the vast majority of families, autosomal dominant transmission has occasionally been reported. Several genes have been implicated it its pathogenesis, including TGM-1 as discussed above, the lipoxy- 
genase genes $A L O X E 3$ and $A L O X 12 B$ and the ichthyin gene which encodes a protein of unknown function localized in the plasma membrane with homologies to both transporters and G-protein coupled receptors. ${ }^{29,30}$ Occasionally, the related Chanarin-Dorfman disease, caused by mutations in the ABHD5 gene, may be confused with n-CIE. ${ }^{31}$

\section{Autosomal dominant epidermolytic ichthyoses}

The epidermolytic ichthyoses $(<1 / 100,000)$ i.e. congenital bullous ichthyosiform erythroderma of Brocq (CBIE) and ichthyosis bullosa of Siemens (IBS) are autosomal dominant disorders of keratinisation which are associated in younger patients with blistering. ${ }^{32,33}$ At least half of the cases have no family history and thus are presumed to represent new mutations. ${ }^{34}$ Genetic defects in the keratin genes KRT1 and KRT10 have been described for CBIE and in KRT2e for IBS, which clinically appears as a mild variant of CBIE ${ }^{35-37}$ Apart from generalized erythroderma, the skin may appear normal immediately at birth. However, within a few hours of life, extensive blisters and peeling are apparent.

Progressive hyperkeratosis, predominantly in the flexures, scalp, anterior neck, abdominal wall and infragluteal folds is obvious from early childhood. Yellow-brown waxy scales tend to form parallel rows of spines or ridges especially near large joints. The scaling remains a life long while the blistering improves significantly with age. Infection of blisters is common. Colonization with bacteria and yeast cause an embarrassing body odour. 


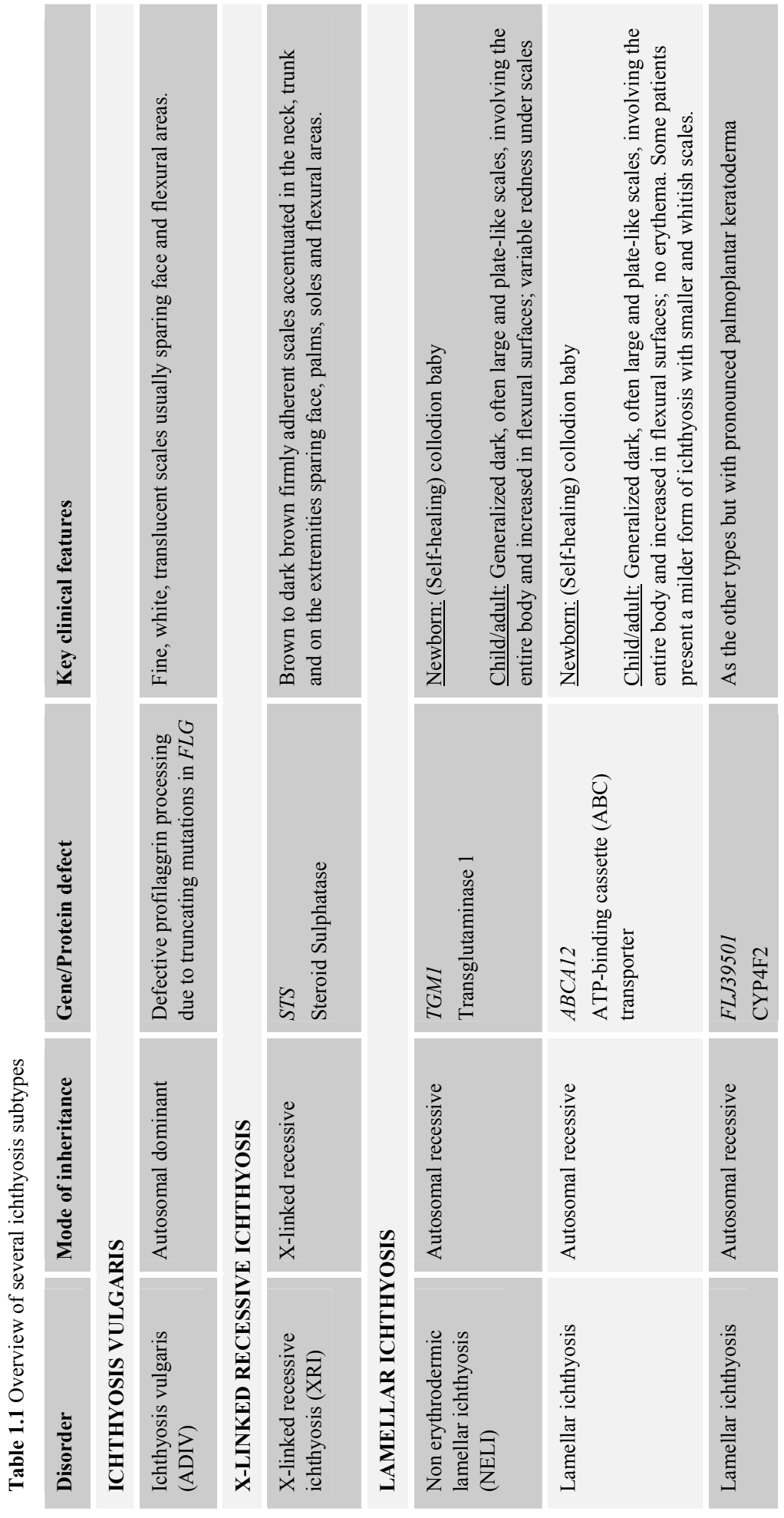




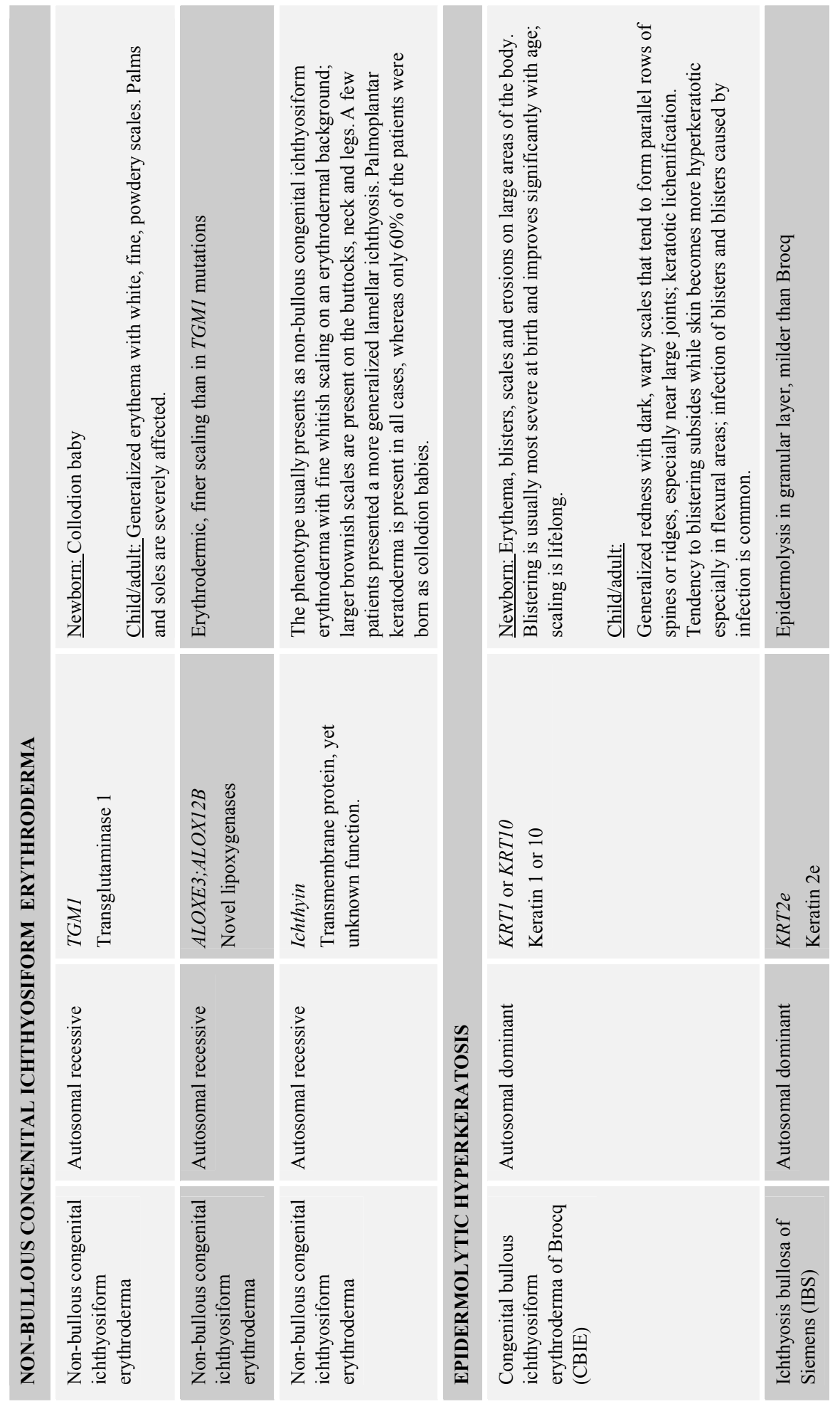




\section{Psoriasis}

Psoriasis is a chronic, multi-factorial and complex skin disorder affecting 1 to $3 \%$ of the world's population. There are several variations of psoriasis, but this thesis deals only with the most common form, psoriasis vulgaris or plaque-type psoriasis, which accounts for $90 \%$ of all cases. Because the manifestations of the disorder are visible and obvious, the disease has a profound psychosocial impact. ${ }^{38,39}$ A symmetrical distribution of skin lesions is the rule in plaque-type psoriasis. Any part of the body skin may be involved, but the face is frequently spared. The most commonly involved areas are the elbows, knees, scalp, sacrum, umbilicus, intergluteal cleft, and genitalia. A typical fully developed lesion is a sharply demarcated, red-violet, round or oval plaque of $1 \mathrm{~cm}$ or larger in diameter surmounted by white silvery scales. In darkly pigmented patients, lesions are hyperpigmented with various shades of brown or black. About $70 \%$ of patients complain of pruritus, skin pain, or burning, especially when the scalp is involved. The course is chronic, with exacerbations and remissions.

Histological examination of psoriatic lesions reveals the following abnormalities: epidermal hyperproliferation, premature keratinisation resulting in a depleted number of granular cells and infiltration of immune cells and polymorphonuclear leukocytes. ${ }^{40-42}$ The cause of psoriasis is unknown. Manifesting itself as a skin disorder, it was considered until the 1980's to be a disease resulting from abnormal regulation of keratinocytes growth and differentiation. Mueller et al. had provided the first evidence of T-cell involvement. ${ }^{43}$ Over time, more evidence is gathered that impaired or defective cell mediated immunity (T-cell driven) plays a critical role in the pathogenesis. ${ }^{44-48}$ The same counts for the involvement of a genetic component. Supporting evidence includes the fact that psoriasis runs in some families; secondly, the increased incidence of psoriasis in children when one of both parents has psoriasis; thirdly, analysis of concordance rates amongst monozygotic and dizygotic twins; and fourthly, a higher than expected frequency of certain white cell antigens (Class I human leucocyte antigens or HLAs) on T-cells in patients with early-onset psoriasis and their close relatives.

The mode of inheritance is still uncertain. Based upon analyses of family pedigrees, polygenic inheritance probably provides the best model for the complex genetics of psoriasis. Genome-wide linkage scans have demonstrated several genetic loci that are associated with susceptibility for psoriasis; these studies have recently been reviewed by Rahman and Elder. ${ }^{49}$ A number of HLA class I and II antigens were found to be associated with psoriasis, such as HLA-B13, -B17, -B37 and -Cw6. ${ }^{50}$ Further studies revealed that these latter associations were secondary to an association with HLA-Cw6. The locus that includes the HLA-C gene, now known as PSORS1, is the major susceptibility 
locus for psoriasis. ${ }^{51-53} \mathrm{PSORS1}$, mapped to chromosome $6 \mathrm{p} 21.3$ by independent groups, was found to be involved in about $50 \%$ of psoriatic patients. PSORS1 is situated within the major histocompatibility complex (MHC) region of chromosome 6, which contains human lymphocyte antigen genes and various interleukin genes. ${ }^{54-56}$ At present, 8 different psoriasis susceptibility loci have been suggested on different chromosomes ${ }^{57}$ like $6 \mathrm{p}^{58}, 17 \mathrm{q}^{59}$ and $20 \mathrm{p}^{60}$. The alpha-antitrypsin gene locus and a polymorphism of the IL-1 receptor antagonist gene have also been associated with psoriasis. ${ }^{61,62}$ The probability that genes found to be associated with psoriasis may or may not cause the disease in an individual, depends on the activity of the genes in relation to one another, which is determined by the inheritance pattern.

Also, other factors such as injury, infection or stress are involved in triggering the onset of the disease which leads us to the latest hypothesis reported by Boss et al. that psoriasis is probably a genetically determined triggered state of otherwise dormant innate immunity. ${ }^{47}$

Psoriasis has several morphological expressions. ${ }^{39}$ The form that psoriasis takes in a patient depends on a combination of genetics, environmental factors, associated diseases and concomitant medications. Psoriasis cannot be cured nor prevented. Symptomatic treatment is the only treatment currently available. 


\section{Acne}

Acne vulgaris is a very common skin disease affecting most people at some point in their life between 11 and 30 years. Of the 15-30\% that needs medical treatment due to the severity of the condition, $2-7 \%$ of the patients are left with post-acne scars. ${ }^{63} \mathrm{Al}-$ though the disease is not life-threatening, it can have serious adverse effects on a person's psychosocial development and the quality of life leading to emotional problems and even depression. ${ }^{64,65}$

Limited to the sebaceous follicles of the head and upper trunk, acne vulgaris is a skin disorder with a very complex aetiology involving 4 major factors: increased sebum production, hyperkeratosis of the pilosebaceous duct, colonization with Propionibacterium acnes and, finally, inflammation. The primary lesion in acne is the "microcomedo" that may evolve over time into a non-inflammatory one, i.e., an open comedone (blackhead) or a closed one (whitehead) and further to an inflammatory lesion (pustule, papule or nodulocystic lesion). ${ }^{66}$ Yet, the exact sequence and precise interdependence of the pathogenic factors in acne, and especially their point of origin have remained unclear. The conventional concepts have recently been critically reviewed and discussed by Zouboulis et al. ${ }^{63}$

Oral isotretinoin, developed more than 20 years ago, is the only drug currently available that affects all four before mentioned pathogenic factors of acne. ${ }^{67-69}$ Although not directly affecting $P$. acnes, its inhibitory effect on sebum production leads to alteration of the follicular microclimate and indirect fall of $P$. acnes counts reducing its ability to induce inflammation.

Acne can be graded according to Cunliffe into mild, moderate and severe based on the total number of comedones, inflamed lesions and a total lesion count. ${ }^{70,71}$ Correct grading of acne is important, ensuring patients are not under or over-treated.

Acne may be triggered or worsened by external factors such as mechanical obstruction (i.e. helmets, shirts and collars), medications, occupational exposures, cosmetics and emollients. 


\section{Treatment of hyperkeratotic disorders}

\section{General treatments}

The treatment of ichthyosis, psoriasis and acne is purely symptomatic. The choice of treatment depends on the severity of the disease and the response of the patient. Mild to moderate forms are usually treated with topical agents whereas the severe forms require oral treatment. ${ }^{4,71-74}$

In ichthyosis and psoriasis, emollients are usually tried first followed by keratolytic lotions containing salicylic acid or urea. However, these ointments are of limited value in ichthyosis as they are only effective in ADIV, whereas the more severe ichthyosis subtypes do not markedly improve. ${ }^{4}$

Anti-inflammatory agents can be used when an immune or inflammatory component is involved. As a prototype of this class of drugs, topical corticosteroids are quite effective in the treatment of both acne and psoriasis. ${ }^{71-73}$ However, long-term use of topical corticosteroids can cause side effects, ranging from cutaneous atrophy to systemic adrenal suppression. ${ }^{73}$

Topical and oral antimicrobials (e.g. azaleic acid, benzoyl peroxide, antibiotics) have been a mainstay of acne treatment for more than 30 years. For optimizing results, they are often used as a combination therapy in more inflammatory forms of acne. However, the potential for bacterial resistance limits their long-term use. ${ }^{71,75}$

Hormonal therapy with oral anti-androgens is an excellent treatment option for women suffering from severe acne when oral contraception is desirable. ${ }^{76,77}$

Cyclosporin A, a systemically active T-cell suppressor (calcineurin antagonist), is an efficient immunosuppressant but it is reserved for the more severe cases of psoriasis due to its toxicity profile (especially hypertension and renal impairment). ${ }^{43,78}$

Recently, antibodies ("biologics") that modify immune signalling have been introduced for the treatment of psoriasis. These agents must be administered intramuscularly or intravenously, are accompanied by various systemic adverse effects and have yet unknown long-term safety profiles. ${ }^{79}$

Agents that block cell division are also helpful in psoriasis, but they have to be administered systemically and are accompanied by significant toxicity, limiting their use to severe cases. Methotrexate is a good example of such a drug. While very effective, its use is limited by its hepatotoxicity and bone marrow toxicity. ${ }^{74,80}$

Phototherapy, which comprises PUVA (psoralen plus UVA-irradiation), and small- and broad-spectrum UVB, is the treatment of choice for psoriasis when larger areas are 
involved and topical treatments are insufficient. ${ }^{73}$ Short-term use of phototherapy is relatively safe but cumulative sessions increase the risk for skin cancer. Phototherapy is frequently combined with topical or systemic treatments in order to enhance the therapeutic effect whilst using reduced cumulative UVA/UVB doses (cfr. chapter 7). ${ }^{81-87}$

Another attractive concept for the treatment of keratinization disorders is modulation of the keratinization process at the level of gene regulation. The vitamin A and D derivatives all-trans-RA and 1 $\alpha, 25$-dihydroxyvitamin $\mathrm{D}_{3}$, respectively are steroid hormones that modulate the expression of genes essential for keratinocyte growth and differentiation. They exert most of their biological activities through binding to specific nuclear receptors (the VDR and the RARs/RXRs, belonging to the superfamily of nuclear receptors), which act as ligand-inducible transcriptional factors. Vitamin D3 analogues such as calcipotriol, calcitriol (1,25-dihydroxy vitamin $\left.\mathrm{D}_{3}\right)$, tacalcitol (1,24-dihydroxy vitamin $\mathrm{D}_{3}$ ) are only available as topical treatments for psoriasis because systemic administration is accompanied by significant disturbances in calcium homeostasis. ${ }^{73,88,89}$ A 2-compound ointment of calcipotriol and betamethasone dipropionate, a potent corticosteroid, has recently been developed and proven to be efficacious in treating moderately severe forms of plaque psoriasis. A good clinical improvement of lamellar and epidermolytic ichthyosis with topical calcipotriol has been demonstrated. However, the limited maximum weekly amount of $100 \mathrm{~g}$ constitutes a restriction for its use, as in these patients, a substantial part of the total body surface is affected..$^{90}$

The retinoids, a group of natural and synthetic compounds that share structural and/or functional similarity with vitamin A, have been used widely for oral and topical treatment of ichthyosis, psoriasis and acne..$^{71,73,74,91,92}$ Their long history and mechanism of action will be discussed in greater detail below. Topical retinoids are often used in the treatment of mild to moderate forms, despite being associated sometimes with significant irritation. ${ }^{72,73,93,94}$ Systemic retinoids are reserved for patients with more severe and recalcitrant types because of their toxicity such as long lasting teratogenicity, hypertriglyceridemia, liver abnormalities and skeletal malformations. ${ }^{69,95-99}$

In conclusion, there is ample room for alternative therapies that are at least as effective as the established ones but have a more favourable side-effect profile. ${ }^{100-102} \mathrm{~A}$ new and promising approach is a pathway-based therapy, which increases the endogenous alltrans-RA levels only in tissues that actively metabolize all-trans-RA by blocking retinoic acid metabolizing enzymes. Compounds that can do this are available and are called retinoic acid metabolism blocking agents, or RAMBAs. The RAMBA approach as a treatment to ichthyosis, psoriasis and acne is the subject of this thesis. 


\section{Retinoids}

\section{History}

Retinoids are a group of natural and synthetic compounds that share structural and/or functional similarity with vitamin A (retinol, ROL). The importance of retinoids in the skin was first noted in 1925 by Wolbach and Howe, who showed that vitamin A (retinol)-deficiency, or the absence of compounds with vitamin A activity, leads to keratinizing metaplasia and hyperkeratosis. ${ }^{103}$ Numerous studies followed, focusing on the metabolism and pharmacological action of retinoids in the skin and the development of retinoid treatment for various skin diseases. The chemical structures of the natural occurring retinoids are presented in Figure 1.1.

Vitamin A was initially investigated at non-physiological doses in acne and psoriasis. Megadoses of vitamin A (2-4 million IU) resulted only in a slight improvement of psoriasis, but the symptoms of a vitamin A intoxication, such as intracranial hypertension with nervous disturbances, dryness of the mucous membranes and skin peeling were unacceptable to patients. ${ }^{104}$ Thousands of analogues have since been synthesized, out of which 3 successive generations have been established for topical and systemic treatment of hyperkeratotic disorders.

The first generation comprises the non-aromatic retinoids: $\beta$-carotene (pro-vitamin $\mathrm{A}$ ), all-trans-RA (tretinoin) and 13-cis-RA (isotretinoin). All-trans-RA as well as isotretinoin proved to be of use for the topical treatment of acne but their use was hampered by their irritating potential. ${ }^{72,105}$ Besides, they had no anti-psoriatic potential following topical application. Systemic treatment with all-trans-RA and isotretinoin requires high doses in order to be effective which produces unacceptable side effect restricting their use. For more than 20 years, isotretinoin is the only oral retinoid effective in the treatment of acne but it is reserved for the more severe forms due to its toxicity profile (increased liver enzymes, hypertriglyceridaemia, teratogenicity, cutaneous side effects,...). ${ }^{106}$ Today, it is a first line treatment in severe nodular acne and is commonly used for recalcitrant acne resistant to oral antibiotics. ${ }^{67,69}$

Because the efficacy of orally administrated vitamin A and all-trans-RA was insufficient, the search for synthetic analogues with a better efficacy and safety profile went on and resulted in the synthesis of the mono-aromatic retinoid derivative etretinate and, later, of its free active carboxylic acid metabolite acitretin. ${ }^{107,108}$ Etretinate and acitretin are highly (and equally) effective systemic treatments for psoriasis with adverse events that appear to be similar in severity and incidence. ${ }^{109,110}$ Today acitretin is the preferred systemic retinoid for psoriasis because of its better pharmacokinetic profile. ${ }^{111}$ The 
mean elimination half-life of acitretin is about two days, whereas the mean elimination half-life of etretinate, the ethyl ester of acitretin, is 120 days but can still be detected in the subcutis as long as 18 months after treatment. ${ }^{112-113}$ Acitretin was developed because it was thought to be cleared from the body more rapidly than etretinate. However, reesterification of acitretin to etretinate in the human body has found to be possible, especially if the patient has a substantial alcohol intake. ${ }^{114}$ Therefore, in view of the teratogenic effect, women of childbearing potential who have been treated with acitretin have to continue contraception for 2 years in Europe and for 3 years in the US after stopping the therapy which puts a real burden on its use. ${ }^{115}$ Next to its teratogenicity, the use of acitretin is also hampered by a serious toxicity profile which is discussed more into detail in chapter $7 .^{102,116-118}$

So the search for new analogues offering at least the same efficacy and a better risk/benefit ratio as the previous ones resulted in the development of a third generation: the polyaromatic retinoid derivatives or arotenoids: e.g. tazarotenic acid, adapalene and the specific RXR-ligands (rexinoids) like bexarotene. Topical adapalene is on the market for the treatment of acne whilst topical tazarotene has been approved for both the treatment of acne and psoriasis. ${ }^{119-126}$ Nevertheless, subjects treated with one of those compounds are not free from cutaneous irritation at the site of application. Oral tazarotene and bexarotene have been proven effective treatments in acne and/or psoriasis, respectively, but they are not without potentially serious side effects (see also chapter 7). ${ }^{127-129}$ Today, the search for more efficacious and less toxic retinoids continues.

\section{Retinoid sources and metabolism}

\section{All-trans-RA sources}

All-trans-retinoic acid (all-trans-RA), the naturally occurring derivative of vitamin A (retinol; ROL) regulates the expression of genes involved in cell proliferation, differentiation and apoptosis and is essential for normal embryonic development and general health in the adult. ${ }^{130}$ The chemical structures of the naturally occuring retinoids are presented in Figure 1.1. Ultimately, all retinoids in the body are derived from the diet, where they are ingested either as retinyl esters (RE) derived from animal fat or as carotenoids ( $\beta$-carotene) derived from yellow and green vegetables; see Figure 1.2. ${ }^{131,132}$

Ingested RE are converted to ROL in the intestinal lumen by enteral hydrolases, allowing absorption of free ROL by the mucosa. $\beta$-carotene enters the enterocytes by passive diffusion where it is converted to 2 retinal (RAL) molecules through central cleavage by 
$\beta$-carotene-15,15'-dioxygenase. ${ }^{131,133-135}$ In addition, an eccentric cleavage pathway was proposed, based on in vitro work, in which $\beta$-carotene is cleaved into RAL and apocarotenals with different chain lengths, but this has not been confirmed in vivo.

RAL binds to cellular retinol binding protein II (CRBPII) and is reduced to ROL by a microsomal retinal reductase. ${ }^{136}$ The fact that CRBPII is highly expressed in the absorptive cells of the small intestine and comprises up to $1 \%$ of the soluble proteins suggests that CRBPII has an essential role in the initial processing of ROL from food. In the enterocytes, also free ROL forms complexes with CRBPII. ${ }^{137}$ This ROL-CRBPII complex serves as a substrate for a lecithin:retinol acyltransferase (LRAT). LRAT is responsible for the re-esterification of ROL to RE which will be incorporated into chylomicrons (tri-acylglycerol-rich lipoproteins) together with phospholipids, cholesterol and triglycerides during absorption of normal loads of vitamin A. ${ }^{138-140}$ However, when large amounts of ROL are rapidly absorbed into enterocytes (due to a vitamin A rich meal or high pharmacological doses) it will accumulate in the cell membranes as CRBPII and LRAT become saturated leading to an increased activity of another enzyme, the acyl-CoA:retinol-acyltransferase (ARAT). The excessive amount of free ROL will then be esterified by ARAT and temporarily stored in lipid droplets. ${ }^{141}$

The chylomicrons containing the RE travel through the intestinal lymphatic system where they undergo lypolysis to give rise to chylomicron remnants, which are primarily cleared by the liver. ${ }^{142}$ Also, extra-hepatic chylomicron uptake has been shown in bone marrow and spleen and to a lesser extent in testes, lung, kidney, fat and skeletal muscle. ${ }^{132,143}$ The uptake of the chylomicron remnants by the parenchymal cells in the liver (endocytosis) is mediated by the apolipoprotein E receptor. ${ }^{144-146}$ In the parenchymal cells, RE are hydrolyzed and free ROL is released into the blood together with retinolbinding protein (RBP). ${ }^{147}$ In the blood, $95 \%$ of the ROL-RBP complex associates with transthyretin (TTR) which transports the complex to extra-hepatic tissue. TTR is a serum protein which has the ability to bind and transport simultaneously but independently both the ROL-RBP complex and the thyroid hormone. ${ }^{132}$ Excess ROL in the hepatocytes undergoes a paracrinic transfer to the stellate cells in the liver where it will form a complex with cellular binding protein I (CRBPI) who facilitates the esterification of ROL by LRAT to form RE for storage. ${ }^{148}$ Fifty to $80 \%$ of the total body ROL is thus stored as RE in the stellate cells of the liver, from which it can be released to maintain constant ROL concentrations in the plasma. Extra-hepatic tissues also play a role in storage and mobilization of ROL and contribute to vitamin A homeostasis. ${ }^{149}$ ROL is the most abundant retinoid in blood. Under normal dietary conditions, the plasma ROL concentrations are relatively high $(2 \mu \mathrm{mol} / \mathrm{L})$, making ROL available throughout the body for potential conversion to all-trans-RA. 


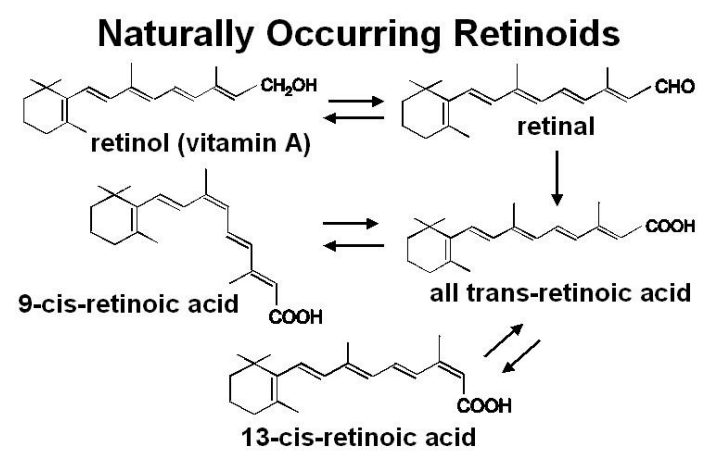

Figure 1.1 Chemical structures of naturally occurring retinoids.

\section{Tissue uptake of ROL and intracellular metabolism}

The specific mechanism by which ROL is transferred from ROL-RBP or ROL-RBPTTR to the target cells is not yet fully understood. Several possible mechanism have been proposed, like a specific RBP receptor-mediated uptake, a non-specific spontaneous transfer of ROL (and all-trans-RA) and fluid-phase endocytosis. ${ }^{132,150,151}$ Based on the available evidence, a receptor-mediated uptake of ROL is believed to be the most important mechanism to deliver ROL to cells that require it. Beginning 2007, Kawaguchi R. and co-workers published the discovery of the long-sought membrane receptor for RBP which mediates cellular uptake of ROL. ${ }^{291}$ STRA6, a previously discovered but uncharacterized multitransmembrane domain protein, has now been identified in bovine retinal pigment epithelium cells as a specific membrane receptor for RBP. STRA6 binds to RBP with high affinity and has robust ROL uptake activity from the ROL-RBP complex. STRA6 is widely expressed in embryonic development and in adult organ systems where a RBP receptor would be expected such as RAL pigmented epithelium of the adult eye, placenta, brain, spleen, female genital tract, testis, lung and skin. The $\mathrm{RBP}$ receptor represents a major physiological mediator of cellular vitamin A uptake.

Once inside the cell, ROL can associate with CRBPI and serve either as a substrate for esterification by LRAT (note: in the intestine substrate for LRAT is ROL-CRBPII) or it can be converted to all-trans-RA depending on the ratio freeCRBPI/boundCRBPI. ${ }^{152}$ It has been postulated that the quantity of free CRBPI present in the target cell also determines the amount of ROL that is taken up by the cell. ${ }^{153}$ 
The basic cellular pathway leading to the conversion of ROL to all-trans-RA consists of 2 steps which are mediated by numerous dehydrogenases. The first step is a reversible oxidation/reduction of ROL-CRBPI to RAL-CRBPI, which can be catalysed by three different enzyme families: the alcohol dehydrogenases (ADH), the short-chain dehydrogenases/reductases (SDR) and the cytochrome P450s. ${ }^{154}$ The second step is mediated by tissue specific retinal dehydrogenases (ALDH) and is an irreversible oxidation of RAL or RAL-CRBPI to all-trans-RA, which will form a complex with a cellular retinoic acid binding protein (CRABPI or II). ${ }^{152,155,156}$ Some all-trans-RA will bind to specific retinoic acid receptors for signaling, while the rest will be subjected to oxidative degradation to more polar metabolites by various CYP450 enzymes (including CYP26A1, CYP26B1, CYP26C1: see below).

\section{CRABPI and II}

Intracellularly, all-trans-RA is bound to either CRABPI or CRABPII with high affinity; CRABPI binds it with a higher affinity than does CRABPII. ${ }^{157}$ Natural metabolites of all-trans-RA, including 4-hydroxy-RA, 4-oxo-RA, 18-hydroxy-RA, 3,4-didehydro-RA can also bind to CRABPS. Binding of 9-cis-RA to CRABPs occurs with a lower affinity than all-trans-RA and there is only little, if any binding, of 13-cis-RA or 9,13-dicisRA. ${ }^{158-160}$ CRABPI is expressed almost ubiquitously whereas CRABPII is only expressed in certain tissues e.g. skin, liver, bone, uterus, ovary and choroid plexus. Although both CRABPI and II are widely expressed in the embryo, they don't coexist in the same cells. Both CRABP isoforms are present in the cytosol and the nuclei of cells. In general, expression of CRABPII has been associated with cells that synthesize large amounts of all-trans-RA. ${ }^{161-163}$ Neither the exact functions nor the distinct roles of the 2 CRABP isoforms are completely understood at present. ${ }^{164}$ In general, retinoid binding proteins act to solubilize and stabilize their hydrophobic and labile ligands in aqueous solutions. Nowadays, a growing body of evidence indicates that each binding protein also has a distinct function in the transport, metabolism and action of the retinoid they associate with. However, CRABPI and CRABPII null mutant mice have a normal phenotype and so does the double knockout, which challenges the hypothesis that CRABPs would facilitate the catabolism of all-trans-RA. ${ }^{165-166}$

In human skin, the intracellular levels of CRABPI protein are similar in the dermis and the epidermis, whereas CRABPII levels are much higher in the epidermis. ${ }^{167-169}$ Melanocytes are the primary source for CRABPI, whereas keratinocytes and fibroblasts are sources of CRABPII. ${ }^{170}$ Differentiation of human epidermal keratinocytes in vitro is accompanied by increased cellular all-trans-RA concentration and increased expression of CRABPII. ${ }^{171}$ Moreover, newly synthesized retinoic acids are retained by CRABPII. It 
should be mentioned here, that in psoriasis and other hyperproliferative skin diseases, retinoid binding proteins display atypical patterns which adds to the above suggestion that they are involved in the regulation of intracellular retinoid concentrations. ${ }^{172-173}$

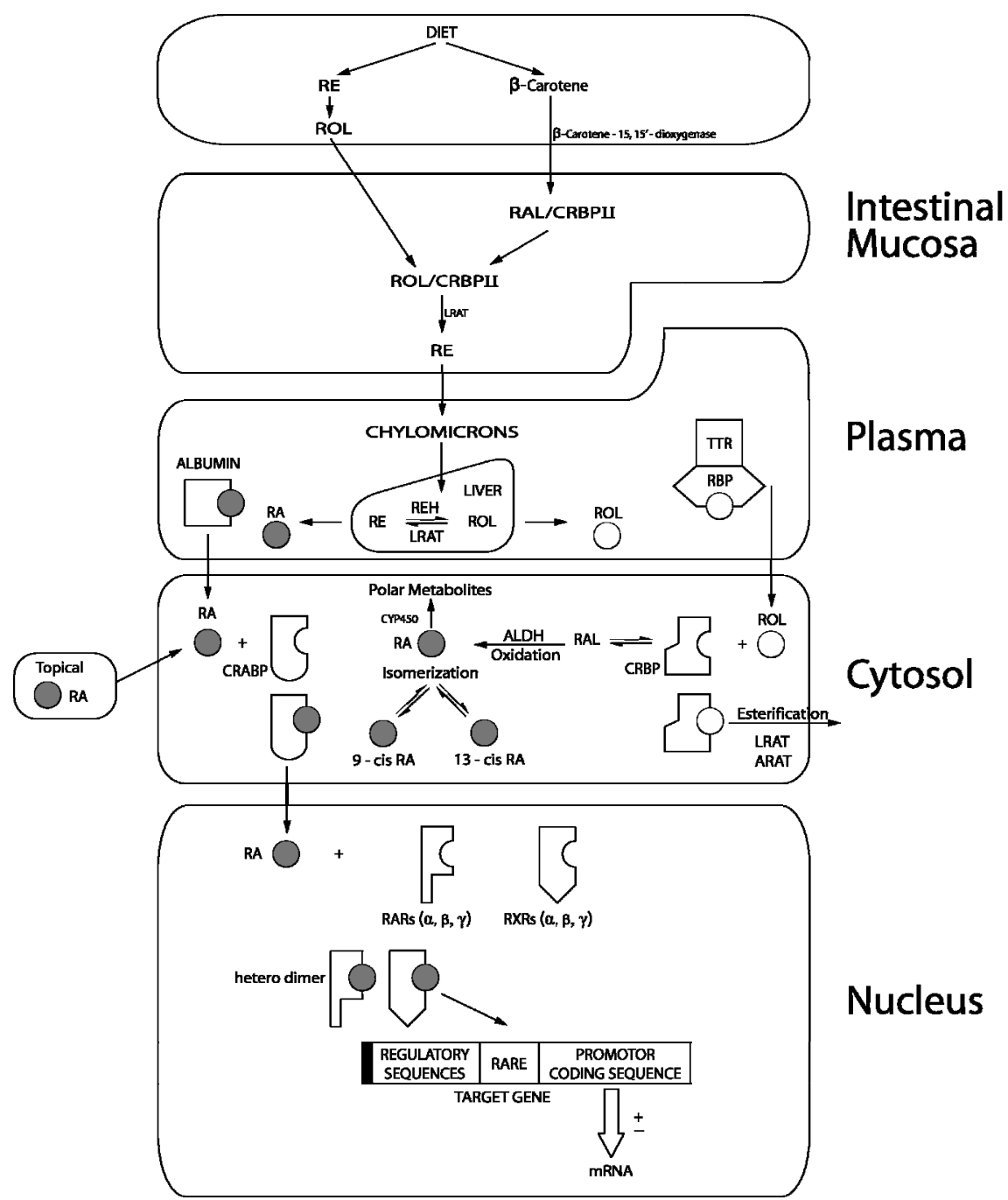

Figure 1.2 Generalized ans simplified scheme of RA uptake and metabolism. RE: Retinylester; ROL: Retinol; RAL: Retinal, RA: All-trans-Retinoic Acid; LRAT: Lecithin Retinol Acyl Transferase; ARAT: Acyl-CoA Retinol Transferase; CRBP: Cellular Retinol Binding Protein; CRABP: Cellular Retinoic Acid Binding Protein; ALDH: Retinal Dehydrogenase; CYP450 Cytochrome P450-dependent enzymes (e.g. CYP26). 


\section{Hydroxylation via CYP26: one route of all-trans-RA metabolism}

All-trans-RA homeostasis is maintained by regulation of its rate of synthesis (from ROL) and its rate of degradation. RA catabolism governs tissue sensitivity to RA.

All-trans-RA is metabolized via hydroxylation at the $\mathrm{C} 4$ or $\mathrm{C} 18$ position of its cyclohexenyl moiety, which gives rise to 4-OH-RA that further oxidizes to 4-oxo-RA and other polar metabolites, or to 18-OH-RA. ${ }^{174-175}$ That these reactions are cytochrome P450 dependent (CYP) was already hypothesized in 1979 by Roberts et al. ${ }^{176-177}$, based on the observation that all-trans-RA metabolism occurred in microsomal fractions, required NADPH and oxygen and was inhibited by carbon monoxide and wellestablished CYP inhibitors like ketoconazole, liarozole and clotrimazole. ${ }^{178-184}$

The CYP superfamily of heme-binding mono-oxygenases catalyses lipid-soluble substrates i.e. the non-specific oxidative conversion of a large number of endobiotics (fatty acids, sterols and steroids), a variety of xenobiotics and environmental toxins. ${ }^{185}$ The term P450 derives from the observation that this cytochrome has an unusual absorption spectrum with a peak at about $450 \mathrm{~nm}$ when the iron atom is reduced and the sixth coordination position is occupied by carbon monoxide. ${ }^{186}$ Although generally expressed in the liver, CYPs have also been found in extra-hepatic tissue like kidney, mucosa of the gut, lung, skin, placenta, reproductive organs, embryonic tissue and the brain. Several CYPs have been described to catalyze the 4-hydroxylation of all-trans-RA but their specificity is generally low. ${ }^{187-193}$ In the late nineties, a novel CYP was first cloned and characterized in zebrafish and later in mouse, human, chicken and frog (Xenopus) displaying high specificity towards all-trans-RA. ${ }^{194-198}$ This enzyme, designated P450RA1 but known officially as CYP 26A1, is expressed in a number of adult tissues like liver, heart, hypophyse, adrenals, duodenum and colon and is inducible by all-transRA both in vivo and in cell lines. This indicates that regulation of all-trans-RA catabolism may include a positive feedback loop. ${ }^{199-201}$ CYP26A1 is also differentially expressed in mammalian embryos and inducible by all-trans-RA. ${ }^{202}$ Here too, this autoregulatory mechanism is believed to protect certain tissues for all-trans-RA overload (fluctuations in maternal RA which could result in teratogenesis) by oxidizing it to more polar metabolites. $^{203}$ In the adult liver, the principal site of retinoid metabolism, CYP26A1 expression and all-trans-RA metabolism are not only acutely regulated by all-trans-RA administration (cfr. retinoid therapy) but also chronically depending upon the dietary intake of ROL. ${ }^{204}$ In cell cultures CYP 26A1 gene regulation and expression is highly dependent on the cell type. Four different situations have been reported in various human cell lines: 1) no CYP26 expression and no induction by all-trans-RA; 2) 
no CYP 26 expression but inducible by all-trans-RA; 3) basal CYP 26 expression and induction by all-trans-RA is observed; and 4) CYP 26 is expressed in a constitutive way and is not inducible by all-trans-RA, thus forming a barrier for all all-trans-RA exposure.

Today four members of the CYP26 family have been cloned and characterized sharing sequence similarity but distinct catalytic activity. CYP26A1 and CYP26B1catabolize all-trans-RA both in the embryo and the adult but does not appreciably metabolize the 9-cis and 13-cis isomers. ${ }^{205,206}$ CYP 26B1 is broadly expressed at very low levels in most human tissues and predominantly in a constitutive way in adult brain , the cerebellum and pons, in particular. ${ }^{206-209}$ This is in contrast to CYP26A1 which did not show appreciable expression in any of the brain tissues, suggesting a unique role for CYP26B1 in brain development and functioning. ${ }^{202,206}$ During mouse embryogenesis, CYP26B1 was also specifically expressed in dermis surrounding the developing hair follicles. CYP26B1 appears to be inducible by all-trans-RA in several cell lines. The catalytic activity of CYP26C1, cloned by Taimi et al. in 2004, appears to be distinct from the other CYP26 members as it can metabolize also 9-cis-RA and it is much less sensitive (5 times) to the inhibitory effects of ketoconazole, a 4-hydroxylase inhibitor. ${ }^{180,182,187}$ CYP26C1 is not widely expressed in the adult and has so far only be detected in a small number of human cell lines. Comparison of the distribution of Cyp26C1 with that of Cyp26A1 and Cyp26B1 in the chick and mouse embryo shows that they generally occupy non-overlapping sites of expression suggesting individual roles for each of the CYP enzymes in the developing embryo. ${ }^{205,210,211}$ Only recently, a fourth CYP26 member involved in the metabolism of all-trans-RA has been cloned in zebrafish namely CYP26D1. ${ }^{212-213}$

What about the skin? Vanden Bossche et al. have shown that skin epidermal microsomes from neonatal rats 4-hydroxylate all-trans-RA in a CYP-dependent way. ${ }^{180,187}$ Isoenzymes of CYP families 1, 2, 3 and 4 were shown by other groups to be present in human epidermal foreskin keratinocytes. ${ }^{214-216}$ A 4.5 fold increase in metabolism of alltrans-RA to 4-oxo-RA has been described in skin treated with all-trans-RA but the principal CYP enzyme responsible for this conversion in human skin has not been defined yet. $^{217}$

Smith et al. identified CYP2S1 in human skin and showed its capacity to metabolize alltrans-RA into 4-hydroxy and 5,6-epoxy-RA; remarkably, no 4-oxo-RA was detected as a metabolite. ${ }^{218,219}$ They also showed an induction of CYP2S1 expression by all-transRA, ultraviolet radiation, PUVA and coal tar. Furthermore, there was a higher cutane- 
ous CYP2S1 expression than CYP26 which suggests a functional role of CYP2S1 in the cutaneous catabolism of all-trans-RA. The fact that no 4-oxo-RA was formed adds to the suggestion that another CYP may be responsible for oxidization of 4-OH in skin. Of the CYP26 family, only CYP26A1 has been detected in human epidermis and keratinocytes. ${ }^{20,221}$ Very recent work by Heise et al. revealed no basal levels of CYP26A1 mRNA expression in monolayer cultures of normal human epidermal keratinocytes (NHEK) and dermal fibroblasts. Only a weak CYP26A1 expression was detected in NHEK and it could be enhanced by stimulation with all-trans-RA. However, in contrast to the cultured monolayers, a constitutive expression of CYP26A1 was found in vivo and in organotypic 3D skin models but it was restricted to basal epidermal keratinocytes as well as to eccrine sweat glands and sebaceous glands. To the best of my knowledge neither CYP26B1 nor CYP26C1 have been detected so far in human skin.

\section{Glucuronidation: a second route of all-trans-RA metabolism}

All-trans-RA has a short elimination half-life in vivo and in cultured cells (6-7 hours), except for B-lymphocytes. ${ }^{222-226}$ Glucuronidation and enterohepatic circulation serves as another route of elimination/recirculation in vivo. ${ }^{227-231}$ Human liver glucuronyl transferase UGT2B7 has been identified as responsible for the glucuronidation of all-transRA, 4-oxo-RA, 5,6-epoxy-RA (via their carboxyl group) and of 4-OH-RA (via the hydroxyl group). ${ }^{232-233}$

UGT2B7 that catalyzes retinoyl- $\beta$-glucuronide synthesis from all-trans-RA does not recognize all-trans-RA bound to CRABPI as a substrate which leads to the hypothesis that glucuronidation in vivo would preferentially occur in cells that do not express CRABPI like hepatocytes and small intestinal mucosal cells. ${ }^{234}$ Retinoyl- $\beta$-glucuronide is, unlike other all-trans-RA derivatives, water-soluble and is considered a product of detoxification. Retinoyl- $\beta$-glucuronide is biologically active but does not bind to cellular binding proteins or nuclear receptors. ${ }^{235-236}$ Glucuronide formation may provide a water-soluble pool of all-trans-RA in times of vitamin A need.

\section{Other all-trans-RA sources}

First, all-trans-RA can be generated in the cells following the uptake and metabolism of plasma ROL. Secondly all-trans-RA is present in the circulation, originating from eccentric cleavage of $\beta$-carotene from the diet or formed in the intestine. ${ }^{198}$ Unlike ROL and RAL, all-trans-RA and its isomers, 13-cis-RA and 9-cis-RA can not be stored so it circulates in plasma, bound to serum albumin, and as such contributes significantly to all-trans-RA pools in several tissues. ${ }^{237}$ The molecular mechanisms for cellular uptake are not clear. However, the processes used are tissue and cell type specific and also 
responsive to the physiological state. Under normal physiological dietary conditions, both ROL and all-trans-RA are present in plasma but at different concentrations. In contrast to ROL $(2 \mu \mathrm{mol} / 1)$, the plasma concentration of all-trans-RA and 13-cis-RA is approximately 100 -fold lower: $7-14 \mathrm{nmol} / 1$ (=1.2-4.2 ng/ml) and 3.7-6.3 nmol/1, respectively. ${ }^{145,238-240} 9$-cis-RA has also been shown to occur naturally in vivo, although the levels found were a lot lower. ${ }^{241}$ Importantly, although 13-cis- and all-trans-RA have an identical chemical structure their elimination half-lives are quite different due to a different molecular geometry: around 20 versus 0.9 hours respectively. ${ }^{242-244}$ The difference in elimation rate is believed to be responsible for the fact that 13-cis-RA (isotretinoin) is more active than all-trans-RA in treating acne. All-trans-RA can substitute for ROL in growth, morphogenesis and epithelial differentiation but not completely in reproductive function. Most important is that all-trans-RA can not replace RAL in the visual cycle. $^{245}$

The fact that all-trans-RA can be easily detected in many adult and embryonic tissues, whereas 9-cis-RA can not be detected in the same tissue, could mean that all-trans-RA is the only ligand needed physiologically for RA signaling. ${ }^{246}$

\section{Mechanism of Action}

Retinoids exert most of their biological activities through binding to specific retinoid receptors, belonging to the superfamily of nuclear receptors which also include the steroid, vitamin D (VDR), thyroid (TR), the peroxisome proliferator-activated (PPAR) and a number of orphan receptors. Nuclear receptors regulate transcription of genes by acting as ligand-inducible transcription factors.

Two classes of retinoid receptors have been discovered: RAR and RXR, each containing three subtypes: $\alpha, \beta$ and $\gamma \cdot{ }^{247-251}$ Each subtype is encoded by a different gene which is located on a different chromosomes being 17q21.1 (RAR- $\alpha$ ), 3p24 (RAR- $\beta$ ), 12q13 (RAR- $\gamma$ ), 9q34.3 (RAR- $\alpha$ ), 6p21.3 (RXR- $\beta$ ) and 1q22-23 (RXR- $\gamma$ ). There are also multiple isoforms of these subtypes that are generated by alternative splicing and by differential use of promotors. All-trans-RA has been identified as a potent activator and high affinity ligand for the RARs, whilst its 9-cis isomer (9-cis-RA) appears to be the natural ligand for RXRs in vitro. ${ }^{252-254} 9$-cis-RA not only binds and activates all 3 RXR subtypes at physiological concentrations $(\mathrm{Kd} \sim 15 \mathrm{nM})$ but also the 3 RAR subtypes at lower Kd values (0.2-0.7 nM) ${ }^{255,256}$ However, since tissue concentrations of 9-cis-RA tested up to now, appear to be in the low nanomolar range [3-5 fold lower than all- 
trans-RA], the question on the availability of 9-cis-RA at high enough concentrations to stimulate RXRs in vivo has been raised and is still unanswered. ${ }^{252}$

RARs function as a heterodimer complex with RXRs, whereas the RXRs may act either as homodimers or as a heterodimer complex with a variety of other nuclear receptors that play an important role in cell function and physiology. This means that the biological activities of specific RXR ligands could be broader than that of compounds that specifically activate RARs. The expression pattern of the retinoid receptors shows cell and tissue specificity and is dependent upon variable factors such as state of differentiation, inflammation and diseases. ${ }^{257-258}$ The expression patterns of the various RAR and RXR isoforms indicate that most, if not all, tissues are potential targets of retinoid action, although different RXR homodimer and RAR-RXR heterodimer complexes will transduce the retinoid signal in different tissue. ${ }^{259}$

In adult human skin, the predominant RAR protein expressed is RAR- $\gamma$ whilst only minimal but detectable levels are found for RAR- $\alpha$; RAR- $\beta$ is undetectable. ${ }^{260}$ The concentration of RXRs is five times as high as the total concentration of RARs, with RXR $\alpha$ being the most abundantly expressed; RXR- $\beta$ is minimally detectable and RXR$\gamma$ undetectable. ${ }^{260}$ The mRNA levels of the receptors are compatible with the protein levels. The predominant receptor complexes in the human skin are RAR $\gamma$-RXR $\alpha$ and the RXR-VDR, the latter one being of major importance in RXR-signaling. ${ }^{261}$

Each retinoid receptor exists of 6 functional domains of which the 2 most important are the ligand binding domain (where the ligand binds to the receptor) and the DNA binding domain (where the receptor binds to the DNA of the target genes). ${ }^{262}$ Dimers of retinoid receptors are localized in the nucleus of the cell where they bind, even in the unliganded state, to specific DNA regulatory sequences termed retinoid response elements (RARE or RXRE) in the promotors of retinoid-responsive genes. As such they can regulate genes involved in processes as cell differentiation, cell proliferation, apoptosis, etc. A comparison of the in vitro DNA binding repertoires of RAR and RXR homodimers and of RXR/RAR heterodimers indicates that heterodimers bind more efficiently and more selectively than homodimers. RAR-RXR heterodimers are suggested to be the functional units in vivo that transduce the retinoid signal. ${ }^{247}$

Retinoid response elements are usually located within the 5'-regulatory region of retinoid regulated genes, sometimes they are found within introns. RAREs consist of a direct repeat (DR) of a core hexameric sequence, $\mathrm{PuG}(\mathrm{G} / \mathrm{T})$-TCA, separated by either 1 , 2 or 5 base-pairs (DR1, DR2 and DR5) depending of the genes. ${ }^{247}$ A large number of 
genes contain 1 or more RARE and therefore are potentially responsive to RA. More than 500 genes with diverse functions are regulated by retinoic acid, and RAREs have been localized in many of these genes including $R A R \beta, C R B P I, C R A B P I I$ and members of the Hox and $H N F$ gene families. ${ }^{263}$ Because the RXR functions as a partner for several nuclear receptors other than RAR, it has the potential together with the ligands that bind to them, to influence an even wider variety of genes than are regulated by RARs. $^{264}$

According to a current model of transcriptional activation, the unliganded receptor dimers, when bound to DNA, recruit proteins with histone deacetylase activity (corepressors), which results in chromatin condensation and gene silencing. ${ }^{265}$ Ligand binding causes the receptors to undergo a conformational change that favours the dissociation of co-repressors and the recruitment of other proteins (co-activators) with histone acetylase activity, which opens up the chromatin, making it accessible to transcriptional machinery to initiate transcription. This results in the induction of retinoidmediated expression. ${ }^{266-268}$

\section{Cellular effects}

The cellular effects of all-trans-RA also largely depend upon the presence of cellular retinoid-binding proteins and upon the activity of all-trans-RA metabolizing enzymes. The molecular mechanisms underlying the action of retinoids are still intensively investigated and not yet fully understood. On one hand, retinoids have been shown to act as an antiproliferative agent in hyperproliferative systems and on the other hand cause an induction of hyperproliferation in systems with a normal proliferation. ${ }^{269}$ Retinoids have also been shown to contain immunomodulating properties like modulation of T-cell responses ${ }^{270}$, inhibition of chemotactic responses, activation of polymorphonuclear leukocytes $^{271}$ and immunostimulation of natural killer lymphocytes. Furthermore retinoid treatment has been shown to induce an increase of the number of Langerhans cells in normal as well as in psoriatic skin. It has also been described that retinoid receptor activation inhibits the induction of migration inhibitory factor-related protein (MRP-8) a marker for hyperproliferation and abnormal keratinisation by interferon $\gamma($ IFN- $\gamma){ }^{272}$ 


\section{Retinoic Acid Metabolism Blocking Agents: RAMBAs}

\section{Mechanism of action}

Clinically, the RA-mediated induction of Cyp26A1, as discussed above, may be significant when using retinoids as pharmacological agents. In APL (acute promyelocytic leukaemia), where all-trans-RA is often used as a treatment, a high proportion of patients start exhibiting all-trans-RA resistance after an initial remission. ${ }^{273}$ Cyp26A1 induction may be responsible for this acquired retinoid resistance as Cyp26A1 mRNA has been shown inducible by all-trans-RA in APL cell lines. ${ }^{274}$ Cyp $26 A 1$ is also inducible in skin where retinoids have been used extensively to treat conditions such as acne, psoriasis and ichthyosis. ${ }^{275}$ Prolonged treatment of skin with retinoids can induce Cyp26A1-mediated metabolism leading to reduced responsiveness, higher effective therapeutic doses and consequently unwanted side-effects.

An alternative approach to administering retinoids has emerged i.e. modulating retinoic acid concentrations at the tissue level by using Retinoic Acid Metabolism Blocking Agents or RAMBAs sometimes referred to as retinoic acid 4-hydroxylase inhibitors. As discussed earlier, one of the pathways by which intracellular all-trans-RA is metabolized occurs by 4-hydroxylation at the $\mathrm{C} 4$ position of the cyclohexenyl ring to form 4hydroxy-all-trans-RA which is converted by a reductase into 4-keto-all-trans-RA that is in turn further transformed into more polar metabolites. Both the 4-hydroxylation process of all-trans-RA and the further oxidation of 4-keto-all-trans-RA to more polar metabolites involve microsomal cytochrome P-450 (CYP) dependent enzymes. ${ }^{152,276}$ RAMBAs are non-retinoid drugs that block the CYP dependent enzyme i.e. the RA-4hydroxylase (CYP26) responsible for the intracellular catabolism of all-trans-RA in specific target cells which results in an increase of the intracellular all-trans-RA concentration (see Figure 7.2, Chapter 7). ${ }^{187,277}$ This selective and targeted modulation of alltrans-RA concentration at the tissue level should hypothetically enhance the efficacy and limit toxicity compared to oral retinoids.

Unlike existing therapies where high amounts of exogenous retinoids, natural or synthetic, are administered to the body, a RAMBA modulates the body's own production of all-trans-RA to achieve the same therapeutic effects. Once treatment is stopped, a RAMBA is quickly eliminated from the body returning the metabolism of retinoic acid back to normal and declining the elevated all-trans-RA tissue levels back to physiological levels. The rapid clearance of the RAMBAs is important as it decreases the potential for side effects in contrast to the available synthetic retinoids, which may stay in some 
organs for a long time, and which can cause retinoid related chronic toxicity and birth defects for months after discontinuation of therapy.

\section{History of RAMBAs}

The first azole shown to display RAMBA properties was the antifungal ketoconazole. Besides its antifungal activity, ketoconazole was shown to inhibit in an apparently competitive manner the CYP mediated metabolism of all-trans-RA by hamster liver microsomes. ${ }^{180,182}$ The search for more selective CYP inhibitors of all-trans-RA metabolism led to the identification of liarozole.

Liarozole is an imidazole derivative that is lacking anti-fungal activity but shares with ketoconazole its inhibitory effects on epidermal all-trans-RA metabolism $\left(\mathrm{IC}_{50}=2 \mu \mathrm{M}\right)$ and on the CYP mediated 17-hydroxylase-17,20-lyase in testes microsomes. Like ketoconazole, administration of liarozole to rats enhances endogenous plasma concentrations of endogenous all-trans-RA and reduces the elimination rate of intravenously injected all-trans-RA from plasma. ${ }^{183,184}$ Liarozole also inhibits several other cytochrome P450-dependent steroid biosynthesis reactions-mainly the conversion of androgens to estrogens (aromatase) and of 11-deoxycorticosterone to corticosterone (11-hydroxylase). ${ }^{278,279}$

Developed in the 90's as a non-hormonal agent in the treatment of prostate cancer and various other cancers, liarozole was considered to be of potential benefit in the treatment of skin disorders like psoriasis and ichthyosis based on the fact that the reported adverse events in the cancer trials were mainly cutaneous reactions showing a striking similarity with vitamin A-related symptoms. A total of 6 clinical trials assessing the efficacy and safety of oral liarozole in psoriasis have been conducted. ${ }^{280-284}$ Currently, liarozole is in development as an orphan drug for ichthyosis. ${ }^{285-287}$ An overview of liarozole's in vivo pharmacology related to dermatology will be presented in Chapter 4. Two clinical studies in ichthyosis, one with topical and one with oral liarozole are part of this work and are discussed in Chapters 5 and 6.

Whereas the first RAMBAs where non-selective CYP inhibitors, a thorough screening of hundreds of molecules against different CYP-isozymes yielded a very selective and highly active retinoic acid 4-hydroxylase inhibitor namely R115866 (Rambazole ${ }^{\mathrm{TM}}$ ), representing a third generation. ${ }^{288,289} \mathrm{R} 115866$ is a substituted benzyl-1, 2, 4,- triazole derivative which is a stable, enantiomerically pure base. R115866 inhibits all-trans RA catabolism in the nanomolar range $\left(\mathrm{IC}_{50}=4 \mathrm{nM}\right.$, human CYP26 transfected yeast microsomes) and is about three orders of magnitude more powerful than liarozole $\left(\mathrm{IC}_{50}=3 \mu \mathrm{M}\right)$. At concentrations needed to inhibit all-trans-RA catabolism, R115866 
displays only trivial inhibitory effects $\left(\mathrm{IC}_{50}=1.2-2.6 \mu \mathrm{M}\right)$ on the CYP-dependent biosynthesis of steroids (testosterone and oestradiol). Furthermore, consistent with its ability to enhance endogenous RA content in tissues and plasma, R115866 was found to generate retinoid-mimetic biological activities in various retinoid sensitive animal models of keratinisation. ${ }^{288-290}$ In these studies no major effects other than its primary pharmacodynamic effect were evidenced.

By virtue of this property and the modulating effects of all-trans-RA on epithelial growth and differentiation, R115866 is currently under clinical investigation for both oral and topical treatment of psoriasis and acne. The results of the first exploratory studies with R115866 in these patient populations will be presented in this work.

\section{Aim and outline of the thesis}

It is well known by now that hyperkeratotic disorders like ichthyosis, psoriasis and acne are retinoid-sensitive diseases. These chronic conditions are rarely life-threatening but they may cause major physical, psychosocial and cosmetic disability, and require ongoing treatment. For decades, topical as well as oral retinoids have been widely used as treatments. Amongst the systemic treatments available today, only the vitamin A derivatives are efficacious for all these keratinization disorders. Psoriasis and acne respond to a broader variety of agents because of the principal inflammatory component. However, considering the serious toxicity associated with existing systemic therapies and the limited choice within the topical armamentarium, there is need for safe systemic and alternative topical agents for the treatment of keratinization disorders. The capability of RAMBAs to enhance and sustain pharmacologically active skin tissue levels of endogenous RA by blocking its CYP-mediated metabolic inactivation would represent a new attractive therapeutic approach. The question whether this new class of compounds can have a potential in these difficult-to-treat skin disorders is addressed in this work.

Chapter 1 describes the main hyperkeratotic diseases and the current treatment modalities.

The first part of the thesis deals with the pharmacology of the RAMBAs focusing on dermatology. The effect of 3 generations RAMBAs on cell proliferation and viability in 3 major skin cell types i.e. keratinocytes, fibroblasts and endothelial cells is described in Chapter 2. In Chapter 3 the effect of topical R115866 on cell viability and skin permeability is studied in vitro using human reconstituted epidermis as an alternative for 
animal testing. Chapter 4 gives an overview of the in vivo pharmacology of liarozole, the first RAMBA that has ever been in clinical development for dermatology.

The second part summarizes and discusses the therapeutic applications of liarozole in patients with ichthyosis (XRI, LI and CBIE) as interest in this molecule has received a boost because of its received orphan drug status for congenital ichthyosis by the European Commission and the U.S. Food and Drug Administration. Chapter 5 covers a short and long-term clinical study with topical liarozole. In Chapter 6 the efficacy, safety and tolerability of oral liarozole is compared to acitretin, the only oral retinoid and systemic treatment approved in some EU countries for the treatment of ichthyosis. The third part of this work is dedicated to psoriasis, starting with a review of the use of retinoids and RAMBAs in psoriasis; see Chapter 7. The results of an exploratory study with R115866, a new generation RAMBA in moderate to severe psoriasis is presented in Chapter 8.

The fourth part of the thesis is about acne. Chapter 9, covers the results of an exploratory clinical study with oral R115866 in moderate to severe facial acne.

Finally, in the last part i.e. Chapter 10, the implications of the major findings in this thesis are discussed and future perspectives are given. 


\section{References}

1. Candi E, Schmidt R, Melino G. The cornified envelope: a model of cell death in the skin. Nat Rev Mol Cell Biol 2005; 6: 328-40.

2. Chuong CM, Nickoloff BJ, Elias PM, et al. What is the 'true' function of skin? Exp Dermatol 2002; 11: 159-87.

3. Eckert RL, Crish JF, Robinson N. The epidermal keratinocyte as a model for the study of gene regulation and cell differentiation. Phys Rev 1997; 77: 397-424.

4. Traupe $\mathrm{H}, e d$. The Ichthyoses. A guide to clinical diagnosis, genetic counselling and therapy. Berlin: Springer-Verlag; 1989.

5. Gånemo A, Lindholm $\mathrm{C}$, Lindberg $\mathrm{M}$, et al. Quality of life in adults with congenital ichthyosis. $J A d v$ Nurs 2003; 44: 412-9.

6. Judge MR, Harper JI. The ichthyoses. In: Inherited Skin Disorders; The genodermatoses (Harper JI, ed). Oxford: Butterworth-Heinemann. Ltd, 1996: 69-96

7. Richard G. Molecular genetics of the ichthyosis. Am J Med Genet 2004: 131C: 32-44.

8. Segre JA. Epidermal barrier formation and recovery in skin disorders. J Clin Invest 2006; 16: 1150-8.

9. Smith FJD, Irvine AD, Terron-Kwiatkowski A, et al. Loss-of-function mutations in the gene encoding filaggrin cause ichthyosis vulgaris. Nat Genet 2006; 38: 337-42.

10. Palmer CN, Irvine AD, Terron-Kwiatkowski A, et al. Common loss-of-function variants of the epidermal barrier protein filaggrin are a major predisposing factor for atopic dermatitis. Nat Genet 2006; 38: 441-6.

11. Sandilands A, O'Regan GM, Liao H, et al. Prevalent and rare mutations in the gene encoding filaggrin cause ichthyosis vulgaris and predispose individuals to atopic dermatitis. J Invest Dermatol 2006; 126: $1770-5$.

12. Lykkesfeldt G, Høyer H, Ibsen H, et al. Steroid sulphatase deficiency disease. Clin Genet 1985; 28: 231-7.

13. Hernandez-Martin A, Gonzalez-Sarmiento R, De Unamuno P. X-linked ichthyosis: an update. $B r J$ Dermatol 1999; 141: 617-27.

14. Sandler B, Hashimoto K. Collodion baby and lamellar ichthyosis. J Cutan Pathol 1998; 25: 116-21.

15. Huber M, Rettler I, Bernasconi K, et al. Mutations of keratinocyte transglutaminase in lamellar ichthyosis. Science 1995; 267: 525-8.

16. Parmentier L, Blanchet-bardon C, Nguyen S, et al. Autosomal recessive lamellar ichthyosis: identification of a new mutation in transglutaminase 1 and evidence for genetic heterogeneity. Hum Mol Genet 1995; 4: 1391-5.

17. Russell LJ, DiGiovanna JJ, Rogers GR, et al. Mutations in the gene for transglutaminase 1 in autosomal recessive lamellar ichthyosis. Nat Genet 1995; 9: 279-83.

18. Krebsová A, Küster W, Gilles G, et al. Identification, by homozygosity mapping, of a novel locus for autosomal recessive congenital ichthyosis on chromosome $17 \mathrm{p}$, and evidence for further genetic heterogeneity. Am J Hum Genet 2001; 69: 216-22.

19. Jeon $\mathrm{S}$, Djian $\mathrm{P}$, Green $\mathrm{H}$. Inability of keratinocytes lacking their specific transglutaminase to form crosslinked envelopes: absence of envelopes as a simple diagnostic test for lamellar ichthyosis. Proc Natl Acad Sci U.S.A. 1998; 95: 687-90.

20. Eckert RL, Sturniolo MT, Broome AM, et al. Transglutaminase function in epidermis $J$ Invest Dermatol 2005; 124: 481-92.

21. Hennies HC, Kuster W, Wiebe V, et al. Genotype/phenotype correlation in autosomal recessive lamellar ichthyosis. Am J Hum Genet 1998; 62: 1052-61. 
22. Laiho E, Niemi KM, Ignatius $\mathrm{J}$, et al. Clinical and morphological correlations for transglutaminase 1 gene mutations in autosomal recessive congenital ichthyosis. Eur J Hum Genet 1999; 7: 625-32.

23. Shevchenko YO, Comptom JG, Toro JR, et al. Splice-site mutation in TGM1 in congenital recessive ichthyosis in American families: molecular, genetic, genealogic, and clinical studies. Hum Genet 2000; 106: 492-9.

24. Akiyama M, Sawamura D, Shimizu H. The clinical spectrum of nonbullous congenital ichthyosiform erythroderma and lamellar ichthyosis. Clin Exp Dermatol 2003; 28: 235-40.

25. Lefevre C, Audebert S, Jobard, F, et al. Mutations in the transporter ABCA12 are associated with lamellar ichthyosis type 2. Hum Mol Genet 2003; 12: 2369-78.

26. Hovnanian A. Harlequin ichthyosis unmasked: a defect of lipid transport. J Clin Invest 2005; 115: 1708-10.

27. Akiyama M, Sugiyama-Nakagiri Y, Sakai K, et al. Mutations in lipid transporter ABCA12 in harlequin ichthyosis and functional recovery by corrective gene transfer. J Clin Invest 2005; 115: 1777-84.

28. Lefevre C, Bouadjar B, Ferrand V, et al. Mutations in a new cytochrome P450 gene in lamellar ichthyosis type 3. Hum Mol Genet 2006; 15: 767-76.

29. Jobard F, Lefèvre C, Karaduman A, et al. Lipoxygenase-3 (ALOXE3) and 12(R)-lipoxygenase (ALOX12B) are mutated in non-bullous congenital ichthyosiform erythroderma (NCIE) linked to chromosome 17p13.1. Hum Mol Genet 2002; 11: 107-13.

30. Lefevre C, Bouadjar B, Karaduman A, et al. Mutations in ichthyin a new gene on chromosome $5 \mathrm{q} 33$ in a new form of autosomal recessive congenital ichthyosis. Hum Mol Genet 2004; 13: 2473-82.

31. Lefevre C, Jobard F, Caux F, et al. Mutations in CGI-58, the gene encoding a new protein of the esterase/lipase/thioesterase subfamily, in Chanarin-Dorfman syndrome. Am J Hum Genet 2001; 69: 1002-12.

32. Barker LP, Sachs W. Bullous congenital ichthyosiform erythroderma. Arch Dermatol syphilol 1953; 67: 443-55.

33. Traupe H, Kolde G, Hamm H, et al. Ichthysos bullosa of Siemens: a unique type of epidermolytic hyperkeratosis. J Am Acad Dermatol 1986; 14: 1000-5.

34. Fuchs E. Genetic skin disorders of keratin. J Invest Dermatol 1992; 99: 671-4.

35. Ishida-Yamamoto A, Mc Grath JA, Judge MR, et al. Selective involvement of keratin 1 and 10 in the cytoskeletal abnormality of epidermolytic hyperkeratosis. J Invest Dermatol 1992; 99: 19-26.

36. McLean IWH, Eady RAJ, Dopping-Hepenstal PJC, et al. Mutations in the rod 1A domain of keratin 1 and 10 in bullous congenital ichthyosiform erythroderma (BCIE). J Invest Dermatol 1994; 102: 24-30.

37. McLean IWH, Morley SM, Lane EB, et al. Ichthyosis bullosa of Siemens (IBS)- a disease involving keratin 2e. J Invest Dermatol 1994; 103: 277-81.

38. Kreuger G, Koo J, Lebwohl M, et al. The impact of psoriasis on quality of life. Results of a 1998 National Psoriasis Foundation patient-membership survey. J Am Acad Dermatol 2001; 137: 280-4.

39. Langley RGB, Krueger GG, Griffths CEM. Psoriasis: epidemiology, clinical features, and quality of life. Ann Rheum Dis 2005; 64: ii18-ii23

40. Mueller W, Hermann B. Cyclosporin for psoriasis. N Engl J Med 1979; 303: 555.

41. van de Kerkhof PC, Van Erp PE. The role of epidermal proliferation in the pathogenesis of psoriasis. Skin Pharmacol 1996; 9: 343-54.

42. van Ruissen F, de Jongh GJ, Van Erp PE, et al. Cell kinetic characterization of cultured human keratinocytes from normal and psoriatic individuals. J Cell Physiol 1996; 168: 684-94.

43. van de Kerkhof PC, Lammers AM. Intraepidermal accumulation of polymorpholnuclear leukocytes in chronic stable plaque psoriasis. Dermatologica 1987; 174: 224-7. 
44. Ortonne JP. Recent developments in the understanding of the pathogenesis of psoriasis. Br J Dermatol 1999; 140: 1-7.

45. Nickoloff BJ. The immunologic and genetic basis of psoriasis. Arch Dermatol 1999; 135: 1104-10.

46. Krueger G, Ellis C. Psoriasis-recent advances in understanding its pathogenesis and treatment. $J \mathrm{Am}$ Acad Dermatol 2005; 53: S94-S100.

47. Bos JD, de Rie MA, Teunissen MB, et al. Psoriasis: dysregulation of innate immunity. Br J Dermatol 2005; 152: 1098-107.

48. Bowcock AM, Krueger JG. Getting under the skin: the immunogenetics of psoriasis. Nature Rev 2005; 5: 699-711.

49. Rahman P, Elder JT. Genetic epidemiology of psoriasis and psoriatic arthritis. Annals of the Rheumatic Diseases 2005; 64: 1137-9.

50. Henseler T, Christophers E. Psoriasis of early and late onset: characterization of two types of psoriasis vulgaris. J Am Acad Dermatol 1985; 13: 450-6.

51. Russell TJ, Schultes LM, Kuban DJ. Histocompatibility (HLA) antigens associated with psoriasis. $N$ Engl J Med 1972; 287: 738-40.

52. Brenner W, Gnschait F, Mayr WR. HLA B13, B17, B37 and Cw6 in psoriasis vulgaris: association with the age of onset. Arch Dermatol Res 1978; 262: 337-9.

53. White SH, Newcomer VD, Mickey MR, et al. Disturbance of HLA antigen frequency in psoriasis. $N$ Engl J Med 1972; 287: 740-3.

54. Asumalahti K, Veal C, Laitinen T, et al. Coding haplotype analysis supports HCR as the putative susceptibility gene for psoriasis at the MHC PSORS1 locus. Hum Mol Genet 2002; 11: 589-97.

55. Capon F, Trembath RC, Barker JN. An update on the genetics of psoriasis. Dermatol Clin 2004; 22: 339-47.

56. The international Psoriasis Genetics Consortium. The International Psoriasis Genetics Study assessing linkage to 14 candidate susceptibility loci in a cohort of 942 affected sib pairs. Am J Hum Genet 2003; 73: 430-7.

57. Bowcock AM, Shannon W, Du F, et al. Insight into psoriasis and other inflammatory diseases from large-scale gene expression studies. Hum Mol Genet 2001; 10: 1793-1805.

58. Enlund F, Samuelsson L, Enerback C, et al. Analysis of three suggested psoriasis susceptibility loci in a large Swedish set of families: confirmation of linkage to chromosome 6p (HLA region), and to 17q, but not to 4q. Hum Hered 1999; 49: 2-8.

59. Thomforde J, Silverman A, Barnes R, et al. Gene for familial psoriasis susceptibility mapped to the distal end of human chromosome 17q. Science 1994; 264: 1141-5.

60. Nair RP, Henseler T, Jenisch S, et al. Evidence for two psoriasis susceptibility loci (HLA and 17q) and two novel candidate regions (16q and 20p) by genome-wide scan. Hum Mol Genet 1997; 6: 1349-56.

61. Beckman G, Beckman L, Liden S. Association between psoriasis and the alpha-1-antitrypsin deficiency gene Z. Acta Derm Venereol 1980; 60: 163-4.

62. Tarlow JK, Cork MJ, Clay FE, et al. Association between interleukin-1 receptor antagonist (IL-1 ra) gene polymorphism and early and later-onset psoriasis. Br J Dermatol 1997; 136: 147-8.

63. Zouboulis CC, Eady A, Philpott M, et al. What is the pathogenesis of acne? Exp Dermatol 2005; 14: $143-52$.

64. Tan JK. Psychosocial impact of acne vulgaris: evaluating the evidence. Skin Therapy Lett 2004; 9: 1-3.

65. Magin P, Pond D, Smith W. Isotretinoin, depression and suicide: a review of the evidence. Br J Gen Pract 2005; 55: 134-8.

66. Pawin H, Beylot C, Chivot M, et al. Physiopathology of acne vulgaris: recent data, new understanding of the treatments. Eur J Dermatol 2004; 14: 4-12. 
67. Strauss JS, Rapini RP, Shalita AR, et al. Isotretinoin therapy for acne: results of a multicenter doseresponse study. J Am Acad Dermatol 1984; 10: 490-6.

68. Orfanos CE, Zouboulis CC. Oral retinoids in the treatment of seborrhoea and acne. Dermatology 1998; 196: $140-7$.

69. Thielitz A, Krautheim A, Gollnick H. Update in retinoid therapy of acne. Dermatol Ther 2006; 9: 272-9.

70. Pochi PE, Shalita AR, Straus JS, et al. Report of the Consensus Conference on Acne Classification. Washington, D.C., March 24 and 25, 1990. J Am Acad Dermatol 1991; 24: 495-500.

71. Gollnick H, Cunliffe W, Berson D, et al. Management of acne: a report from a Global Alliance to Improve Outcomes in Acne. J Am Acad Dermatol 2003; 49: S1-37.

72. Gollnick H, Schramm M. Topical drug treatment in acne. Dermatology 1998; 196: 119-25.

73. Lebwohl M, Ali S. Treatment of psoriasis. Part 1. Topical therapy and phototherapy. J Am Acad Dermatol 2001; 45: 487-98.

74. Lebwohl M, Ali S. Treatment of psoriasis. Part 2. Systemic therapies. J Am Acad Dermatol 2001; 45: 649-61.

75. Eady EA. Bacterial resistance in acne. Dermatology 1998; 196: 59-66.

76. Beylot C, Doutre MS, Beylot-Barry M. Oral contraceptives and cyproterone acetate in female acne treatment. Dermatology 1998; 196: 148-52.

77. Thiboutot D. Endocrinological evaluation and hormonal therapy for women with difficult acne. $J$ Eur Acad Dermatol Venereol 2001; 15: 57-61.

78. Lebwohl M, Ellis C, Gottlieb A, et al. Cyclosporine consensus conference: with emphasis on the treatment of psoriasis. J Am Acad Dermatol 1998; 39: 464-75.

79. Pariser DM. Management of moderate to severe plaque psoriasis with biologic therapy. Managed Care 2003; April: 36-44.

80. Roenigk HH Jr, Auerbach R, Maibach H, et al. Methotrexate in psoriasis: consensus conference. $J$ Am Acad Dermatol 1998; 38: 478-85.

81. Koo JY. Tazarotene in combination with phototherapy. J Am Acad Dermatol 1998; 3: S144-8.

82. Behrens S, Grundmann-Kollman M, Schiener R, et al. Combination phototherapy of psoriasis with narrow-band UVB irradiation and topical tazarotene gel. J Am Acad Dermatol 2000; 42: 493-5.

83. Koo JY, Lowe NJ, Lew-Kaya DA, et al. Tazarotene plus UVB phototherapy in the treatment of psoriasis. $J$ Am Acad Dermatol 2000; 43: 821-8.

84. Lowe N, Prystowski JH, Bourget T, et al. Acitretin plus UVB therapy for psoriasis: comparisons with placebo plus UVB and acitretin alone. J Am Acad Dermatol 1991; 24: 591-4.

85. Spuls PI, Rozenblit M, Lebwohl M. Retrospective study of the efficacy of narrowband UVB and acitretin. J Dermatol Treat 2003; 14: 17-20.

86. Tanew A, Guggenbichler A, Honigsmann H, et al. Photochemotherapy for severe psoriasis without or in combination with acitretin: a randomized, double-blind comparison study. J Am Acad Dermatol 1991; 26: $682-4$.

87. Laurahanta J, Geiger JM. A double-blind comparison of acitretin and etretinate in combination with bath PUVA in the treatment of extensive psoriasis. Br J Dermatol 1989; 121: 107-12.

88. Fogh K, Kragballe K. Recent developments in vitamin D analogs. Curr Pharm Des 2000; 6: 961-72.

89. Van De Kerkhof PC. Reduction of epidermal abnormalities and inflammatory changes in psoriatic plaques during treatment with vitamin D3 analogs. J Invest Dermatol Symp Proc 1996; 1: 78-81.

90. Lucker GPH, Kerkhof PCM van de, Dijk MR van, et al. Effect of topical calcipotriol on congenital ichthyoses. Br J Dermatol 1994; 131: 546-50.

91. Orfanos C, Zouboulis C, Almond-Roesler B, et al. Current use and future potential role of retinoids in dermatology. Drugs 1997; 53: 358-88. 
92. Pilkington T, Brogden RN. Acitretin. A review of its pharmacology and therapeutic use. Drugs 1992; 43: 597-627.

93. Lucker GPH, Kerkhof PCM van de, Castelijns FACM, et al. Topical treatment of ichthyosis with 13-cisretinoic acid. A clinical and immunohistochemical study. Eur J Dermatol 1995; 5: 566-71.

94. Hofmann B, Stege H, Ruzicka T, et al. Effect of topical tazarotene in the treatment of congenital ichthyoses. Br J Dermatol 1999; 141: 642-6.

95. Blanchet-Bardon C, Nazzaro V, Rognin C, et al. Acitretin in the treatment of severe disorders of keratinization. Results of an open study. JAAD 1991; 24: 982-6.

96. Lee CS, Koo JA. Review of acitretin, a systemic retinoid for the treatment of psoriasis. Expert Opin Pharmacother 2005; 6: 1725-34.

97. Yamauchi PS, Rizk D, Lowe NJ. Retinoid therapy for psoriasis. Dermatol Clin 2004, 22: 467-76.

98. Kunynetz RA. A review of systemic retinoid therapy for acne and related conditions. Skin Therapy Lett 2004; 9: 1-4.

99. David M, Hodak E, Lowe NJ. Adverse effects of retinoids. Medical Toxicology 1988; 3: 273-88.

100. Nijsten T, Margolis DJ, Feldman SR, et al. Traditional systemic treatments have not fully met the needs of psoriasis patients: results from a national survey. $J$ Am Acad Dematol 2005; 52: 434-4.

101. Tiboutot D. New treatments and therapeutic strategies for acne. Arch Fam Med 2000; 9: 179-87.

102. Naldi L, Griffiths CME. Traditional therapies in the management of moderate to severe chronic plaque psoriasis: an assessment of the benefits and risks. Br J Dermatol 2005; 152: 597-615.

103. Wolbach SB, Howe PR. Tissue changes following deprivation of fat-soluble vitamin A. J Exp Med 1925; 47: 753-77.

104. Frey JR, Schoch MA. Therapeutische Versuche bei Psoriasis mit Vitamin A, zugleich ein Beitrag zur AHypervitaminose. Dermatologica 1952; 104: 80.

105. Kligman AM, Fulton JE Jr, Plewig G. Topical vitamin A acid in acne vulgaris. Arch Dermatol 1969; 99: 469-76.

106. http://www.fda.gov/cder/foi/label/2005/018662s056lbl.pdf: Accutane (Oral isotretinoin capsules) prescribing information: accessed on July $31^{\text {st }} 2006$.

107. Lassus A, Geiger JM, Nyblom M, et al. Treatment of severe psoriasis with etretin (R0-10-1670). Br J Dermatol 1987; 117: 333-41.

108. Gollnick H, Bauer R, Brindley C, et al. Acitretin versus etretinate in psoriasis. Clinical and pharmacokinetic results of a German Multicenter study. J Am Acad Dermatol 1988; 19: 458-69.

109. Kragballe K, Jansen CT, Geiger JM, et al. A double-blind comparison of acitretin and etretinate in the treatment of severe psoriasis. Results of a Nordic multicentre study. Acta Derm Venereol 1989; 69: 3540.

110. Murray HE, Anhalt AW, Lessard R, et al. A 12-month treatment of severe psoriasis with acitretin: Results of a Canadian open multicenter trial. J Am Acad Dermatol 1991; 24: 598-602.

111. Geiger JM. Efficacy of acitretin in severe psoriasis. Skin Therapy Lett 2003; 8: 1-3.

112. Wiegand UW, Chou RC. Pharmacokinetics of acitretin and etretinate. J Am Acad Dermatol 1998; 39: S25-S33.

113. Rollmann O, Vahlquist A. Retinoid concentrations in skin, serum and adipose tissue of patients treated with etretinate. Br J Dermatol 1983; 109: 439-47.

114. Larsen FG, Jakobsen P, Knudsen J, et al. Conversion of acitretin to etretinate in psoriatic patients is influenced by ethanol. J Invest Dermatol 1993; 100: 623-7.

115. Geiger JM, Baudin M, Saurat JH. Teratogenic risk with etretinate and acitretin treatment. Dermatology 1994; 189: 109-16. 
116. Valquist C, Selinus I, Vessby B. Serum lipids changes during acitretin (etretin) treatment of psoriasis and palmo-plantar pustulosis. Acta Derm Venereol 1988; 6: 300-5.

117. Roenigk HH Jr, Callen JP, Guzzo CA, et al. Effects of acitretin on the liver. J Am Acad Dermatol 1999; 41: $584-8$.

118. Mills CM, Marks R. Adverse reactions to oral retinoids. An update. Drug Saf 1993; 9: 280-90.

119. Weiss JS, Shavin JS. Adapalene for the treatment of acne vulgaris. J Am Acad Dermatol 1998; 39: S50-4.

120. Millikan LE. Adapalene: an update on newer comparative studies between the various retinoids. Int $J$ Dermatol 2000; 39: 784-8.

121. Shalita AR, Chalker DK, Griffith RF, et al. Tazarotene gel is safe and effective in the treatment of acne vulgaris: a multicenter, double-blind, vehicle-controlled study. Cutis 1999; 63: 349-54.

122. Kakita L. Tazarotene versus tretinoin or adapalene in the treatment of acne vulgaris. J Am Acad Dermatol 2000; 43: S51-4.

123. Weinstein GD, Krueger GG, Lowe NJ, et al. Tazarotene gel, a new retinoid, for topical therapy of psoriasis: vehicle-controlled study of safety, efficacy and duration of therapeutic effect. J Am Acad Dermatol 1997; 37: 85-92.

124. Weinstein GD, Koo JY, Krueger GG, et al. Tazarotene cream in the treatment of psoriasis: Two multicenter, double-blind, randomized, vehicle-controlled studies of the safety and efficacy of tazarotene creams $0.05 \%$ and $0.1 \%$ applied once daily for 12 weeks. J Am Acad Dermatol 2003; 48: 760-7.

125. Allergan (US). Tazorac $\mathbb{B}$ (tazarotene topical cream): prescribing information 2001

126. Allergan (US). Tazorac ${ }^{\circledR}$ (tazarotene topical gel): prescribing information $2003 \mathrm{Dec}$.

127. http://www.fda.gov/ohrms/dockets/ac/04/slides/2004-4062S1_02_Allergan-Presentation_files/frame.htm (Accessed 15 Feb.2006)

128. Smit JV, Franssen ME, de Jong EM, et al. A phase II multicenter clinical trial of systemic bexarotene in psoriasis. J Am Acad Dermatol 2004; 51: 249-56.

129. Farol LT, Hymes KB. Bexarotene: a clinical review. Expert Rev Anticancer Ther 2004; 4: 180-8.

130. Ross SA, McCafferty PJ, Drager, et al. Retinoids in embryonal development. Physiol Rev 2000; 80: 1021-54.

131. Olson JA. Provitamin A function of carotenoids: the conversion of beta-carotene into vitamin A. $J$ Nutr 1989; 119: 105-8.

132. Blomhoff R, Green MH, Green JB, et al. Vitamin A metabolism: new perspectives on absorption, transport, and storage. Physiol Rev 1991; 71: 951-90.

133. Lakshman MR. Alpha and omega of carotenoid cleavage. J Nutr 2004; 134: 241S-5S.

134. Wang XD, Tang GW, Fox JG, et al. Enzymatic conversion of $\beta$-carotene into $\beta$-apo-carotenals and retinoids by human, monkey, ferret and rat tissue. J Nutr Biochem Biophys 1991; 285: 8-16.

135. Nagao A. Oxidative conversion of carotenoids to retinoids and other products. $J$ Nutr 2004; 134: 237S-40S.

136. Kakkad BP, Ong DE. Reduction of retinaldehyde bound to cellular retinol-binding protein (type II) by microsomes from rat small intestine. J Biol Chem 1988; 263: 12916-9.

137. Herr FM, Wardlaw SA, Kakkad B, et al. Intestinal vitamin A metabolism: coordinate distribution of enzymes and CRBP(II). J Lipid Res 1993; 34: 1545-54.

138. MacDonald PN, Ong DE. Evidence for a lecithin-retinol acyltransferase activity in the rat small intestine. J Biol Chem 1988; 263: 12478-82.

139. Ong DE, MacDonald PN, Gubitosi AM. Esterification of retinol in rat liver. Possible participation by cellular retinol-binding protein and cellular retinol-binding protein II. $J$ Biol Chem 1988; 263: 5789-96.

140. Blomhoff R, Green MH, Berg T, et al. Transport and storage of Vitamin A. Science 1990; 250: 399-404. 
141. Harrison EH, Hussain MM. Mechanisms involved in the intestinal digestion and absorption of dietary vitamin A. J Nutr 2001, 131: 1405-8.

142. Nayak N, Harrison EH, Hussain MM. Retinyl ester secretion by the intestinal cells is a specific and regulated process that is dependent on the assembly and secretion of chylomicrons. J Lipid Res 2001; 42: 272-80.

143. Blomhoff R. Transport and metabolism of vitamin A. Nutr Rev 1994; 52: S13-23.

144. Mahley RW, Hussain MM. Chylomicron and chylomicron remnant catabolism. Curr Opin Lipidol 1991; 2: $170-6$.

145. Blaner WS, Olson JA. Retinol and retinoic acid metabolism. In The Retinoids: Biology, Chemistry, and Medicine, $2^{\text {nd }}$ edn. (Sporn MB, Roberts AB, Goodman DS. eds.). New York: Raven Press, 1994; 283-318.

146. Chang S, Maeda N, Borensztajn J. The role of lipoprotein lipase and apolipoprotein E in the recognition of chylomicrons and chylomicron remnants by cultured isolated mouse hepatocytes. Biochem J 1996; 318: 29-34.

147. Ong DE. Cellular transport and metabolism of vitamin A: roles of the cellular retinoid-binding proteins. Nutr Rev 1994; 52: S24-S31.

148. Vogel S, Gamble MV, Blaner WS. Biosynthesis, absorption, metabolism and transport of retinoids. In Retinoids: The Biochemical and Molecular Basis of Vitamin A and Retinoid Action (Nau H, Blaner WS, eds), Vol.139. Berlin: Springer-Verlag, 1999; 31-96.

149. Soprano DR, Blaner WS. Plasma retinol-binding protein. In: The Retinoids, Biology, Chemistry, and Medicine, $2^{\text {nd }}$ edn. (Sporn MB, Roberts AB, Goodman DS, eds). New York: Raven Press, 1994; 257-82.

150. Dew SE, Ong DE. Specificity of the retinol transporter of the rat small intestine brush border. Biochemistry 1994; 33: 12340-5.

151. Noy N, Xu ZJ. Thermodynamic parameters of the binding of retinol to binding proteins and to membranes. Biochemistry 1990; 29: 3888-92.

152. Napoli JL. Retinoic acid: its biosynthesis and metabolism. Prog Nucl Acid Res Mol Biol 1999; 6: 139-88.

153. Noy N, Blaner WS. Interactions of retinol with binding proteins: studies with rat cellular retinol-binding protein and with rat retinol-binding protein. Biochemistry 1991; 30: 6380-6.

154. Raner GM, Vaz AD, Coon MJ. Metabolism of all-trans, 9-cis, and 13-cis isomers of retinal by purified isozymes of microsomal cytochrome P450 and mechanism-based inhibition of retinoid oxidation by citral. Mol Pharmacol 1996; 49: 515-22.

155. Noy N. Retinoid-binding proteins: mediators of retinoid action. Biochem J 2001; 348: 481-95.

156. Duester G. Families of retinoid dehydrogenases regulating vitamin A function: production of visual pigment and retinoic acid. Eur J Biochem 2000; 267: 4315-24

157. Gaub MP, Lutz Y, Ghyselinck NB, et al. Nuclear detection of cellular retinoic acid binding proteins I and II with new antibodies. J Histochem Cytochem 1998; 46: 1103-11.

158. Fiorella PD, Giguere V, Napoli JL. Expression of cellular retinoic acid-binding protein (type II) in Escherichia coli. Characterization and comparison to cellular retinoic acid-binding protein (type I). J Biol Chem 1993; 68: 21545-52.

159. Ong DE. Cellular transport and metabolism of vitamin A: roles of the cellular retinoid-binding proteins. Nutr Rev 1994; 52: S24-S31.

160. Li E, Norris AW. Structure/function of cytoplasmic vitamin A-binding proteins. Ann Rev Nutr 1996; 16: 205-34

161. Zheng WL, Bucco RA, Schmitt MC, et al. Localization of cellular retinoic acid-binding protein (CRABP) II and CRABP in developing rat testis. Endocrinology 1996; 137: 5028-35. 
162. Bucco RA, Zheng WL, Davis JT, et al. Cellular retinoic acid-binding protein(II) presence in rat uterine epithelial cells correlates with their synthesis of retinoic acid. Biochemistry 1997; 36: 4009-14.

163. Yamamoto M, Drager UC, Ong DE, et al. Retinoid-binding proteins in the cerebellum and choroid plexus and their relationship to regionalized retinoic acid synthesis and degradation. Eur J Biochem 1998; 257: 344-50.

164. Noy N. Retinoid-binding proteins: mediators of retinoid action. Biochem J 2000; 348: 481-95.

165. Lampron C, Rochette-Egly C, Gorry P, et al. Mice deficient in cellular retinoic acid binding protein II (CRABPII) or in both CRABPI and CRABPII are essentially normal. Development 1995; 121: 539-48.

166. Fawcett D, Pasceri P, Fraser R, et al. Postaxial polydactyly in forelimbs of CRABP-II mutant mice. Development 1995; 121: 671-9.

167. Siegenthaler G, Saurat JH, Morin C, et al. Cellular retinol- and retinoic acid-binding proteins in the epidermis and dermis of normal human skin. Br J Dermatol 1984; 111: 647-54.

168. Siegenthaler G, Saurat JH, Ponec M. Terminal differentiation in cultured human keratinocytes is associated with increased levels of cellular retinoic acid-binding protein. Exp Cell Res 1988; 178: $114-26$

169. Siegenthaler G, Tomatis I, Chatellard-Gruaz D, et al. Expression of CRABP-I and -II in human epidermal cells. Alteration of relative protein amounts is linked to the state of differentiation. Biochem J 1992; 287: 383-9.

170. Sanquer S, Gilchrest BA. Characterization of human cellular retinoic acid-binding proteins-I and -II: ligand binding affinities and distribution in skin. Arch Biochem Biophys 1994; 311: 86-94.

171. Chatellard-Gruaz D, Randolph RK, Hagens G, et al. Differentiation of human epidermal keratinocytes is accompanied by increased expression of CRABP-II and increased cellular concentration of retinoic acids: retention of newly synthesized retinoic acids by CRABP-II. J Lipid Res 1998; 39: 1421-9.

172. Siegenthaler G, Saurat JH, Salomon D, et al. Skin cellular retinoid-binding proteins and retinoidresponsive dermatoses. Dermatologica 1986; 173: 163-73.

173. Siegenthaler G, Tomatis I, Didierjean L, et al. Overexpression of cellular retinoic acid-binding protein type II (CRABP-II) and down-regulation of CRABP-I in psoriatic skin. Dermatology 1992; 185: 251-6.

174. White JA, Guo YD, Baetz K, et al. M. Identification of the retinoic acid-inducible all-trans-retinoic acid 4-hydroxylase. J Biol Chem 1996; 271: 29922-7.

175. Fiorella PD, Napoli JL. Microsomal retinoic acid metabolism. Effects of cellular retinoic acid-binding protein (Type 1) and C18- hydroxylation as an initial step. J Biol Chem 1994; 269: 10538-44.

176. Roberts AB, Frolik CA, Nichols MD, et al. Retinoid-dependent induction of the in vivo and in vitro metabolism of retinoic acid in tissues of the vitamin-A-deficient hamster. $J$ Biol Chem 1979; 254: 6303-9.

177. Frolik CA, Roberts AB, Tavela TE, et al. Isolation and identification of 4-hydroxy and 4-oxoretinoic acid: in vitro metabolites of all-trans-retinoic acid in hamster trachea and liver. Biochemistry 1979; 18: 2092-7.

178. Leo MA, Iida S, Lieber CS. Retinoic acid metabolism by a system reconstituted with cytochrome P450. Arch Biochem Biophys 1984; 234: 305-11.

179. Leo MA, Lieber CS. New pathway for retinol metabolism in liver microsomes. J. Biol Chem 1985; 260: 5228-31.

180. Vanden Bossche H, Willemsens G, Janssen PAJ. Cytochrome P450- dependent metabolism of retinoic acid in rat skin microsomes: inhibition by ketoconazole. Skin Pharmacol 1988; 1: 176-85.

181. Williams JB, Napoli JL. Imidazole antimycotics inhibit the metabolism of retinoic acid in F9 embryonal carcinoma cells. Biochem Pharmacol 1987; 36: 1386-8. 
182. Van Wauwe JP, Coene MC, Goossens J, et al. Ketoconazole inhibits the in vitro and in vivo metabolism of all-trans- retinoic acid. J Pharmacol Exp Ther 1988; 245: 718-22.

183. Van Wauwe J, Coene MC, Goossens J, et al. Effects of cytochrome P-450 inhibition on the in vivo metabolism of all-trans-retinoic acid in rats. J Pharmacol Exp Ther 1990; 252: 365-69.

184. Van Wauwe J, Van Nyen G, Coene MC, et al. Liarozole, an inhibitor of retinoic acid metabolism, exerts retinoid-mimetic effects in vivo. J Pharmacol Exp Ther 1992; 261: 773-8.

185. Nelson DR, Koymans L, Kamataki T, et al. P450 superfamily: update on new sequences, gene mapping, accession numbers and nomenclature. Pharmacogenetics 1996; 6: 1-42.

186. White RE, Coon MJ. Oxigen activation by cytochrome P-450. Ann Rev Biochem 1986; 49: 315-56.

187. Vanden Bossche H, Willemsens S. Retinoic acid and cytochrome P-450. Retinoids 1991; 10: 79-88.

188. Roberts ES, Vaz ADN, Coon MJ. Role of isozymes of rabbit microsomal cytochrome P-450 in the metabolism of retinoic acid, retinol and retinal. Mol Pharmacol 1992; 41: 427-33.

189. Leo MA, Lasker JM, Raucy JL, et al. Metabolism of retinol and retinoic acid by human liver cytochrome P450 IIC8. Arch Biochem Biophys 1989; 269: 305-12.

190. Nadin L, Murray M. Participation of CYP2C8 in retinoic acid 4-hydroxylation in human hepatic microsomes. Biochem Pharmacol 1999; 58: 1201-8.

191. McSorley LC, Daly AK. Identification of human cytochrome P450 isoforms that contribute to all-transretinoic acid 4-hydroxylation. Biochem Pharmacol 2000; 60: 517-26.

192. Chen H, Fantel AG, Juchau MR. Catalysis of the 4-hydroxylation of retnoic acids by CYP3A7 in human fetal hepatic tissues. Drug Metab Dispos 2000; 28: 1051-57.

193. Marill J, Capron CC, Idres N, et al. Human cytochrome P450s involved in the metabolism of 9-cis- and 13-cis-retinoic acids. Biochem Pharmacol 2002; 63: 933-43.

194. White JA, Beckett-Jones B, GuoYD, et al. cDNA cloning of human retinoic acid-metabolizing enzyme (hP450RAI) identifies a novel family of cytochromes P450. J Biol Chem 1997; 272: 18538-41.

195. Ray WJ, Baion G, Yao M, et al. Cyp26, a novel mammalian cytochrome P450, is induced by retinoic acid and defines a new family. J Biol Chem 1997; 272: 18702-8.

196. Swindell EC, Thaller C, Sockanathan S, et al. Complementary domains of retinoic acid production and degradation in the early chick embryo. Dev Biol 1999; 216: 282-96.

197. Hollemann T, Chen Y, Grunz H, et al. Regionalized metabolic activity establishes boundaries of retinoic acid signalling. EMBO J 1998; 17: 7361-72.

198. Wang Y, Zolfaghari R, Ross AC. Cloning of rat cytochrome P450RAI (CYP26) cDNA and regulation of its gene expression by all-trans-retinoic acid in vivo. Arch Biochem Biophys 2002; 401: 235-43.

199. Iulianella A, Beckett B, Petkovich M, et al. A molecular basis for retinoic acid-induced axial truncation. Dev Biol 1999; 205: 33-48.

200. Abu-Abed SS, Beckett BR, Chiba H, et al. Mouse P450RA1 (CYP26) expression and retinoic acidinducible retinoic acid metabolism in $\mathrm{F} 9$ cells are regulated by retinoic acid receptor $\gamma$ and retinoid X $\alpha . J$ Biol Chem 1998; 273: 2409-15.

201. Loudig O, Babichuk C, White J, et al. Cytochrome P450RAI (CYP26) promoter: a distinct composite retinoic acid response element underlies the complex regulation of retinoic acid metabolism. Mol Endocrinol 2000; 14: 1483-97.

202. Abu-Abed S, MacLean G, Fraulob V, et al. Differential expression of the retinoic acid-metabolizing enzymes CYP26A1 and CYP26B1 during murine organogenesis. Mech Dev 2002; 110: 173-7.

203. McCaffery PJ Adams J, Maden M, et al. Too much of a good thing: retinoic acid as an endogenous regulator of neural differentiation and exogenous teratogen. Eur J Neurosci 2003; 18: 457-72. 
204. Yamamoto Y, Zolfaghari R, Ross C. Regulation of CYP26 (cytochrome P450RAI) mRNA expression and retinoic acid metabolism by retinoids and dietary vitamin A in liver of mice and rats. FASEB J 2000; 14: 2119-27.

205. Taimi M, Helvig C, Wisniewsky J, et al. A novel human cytochrome P450, CYP26C1, involved in metabolism of 9-cis and all-trans isomers of retinoic acid. J Biol Chem 2004; 279: 77-85.

206. White JA, Ramshaw H, Taimi M, et al. Identification of the human cytochrome P450, P450RAI-2, which is predominantly expressed in the adult cerebellum and is responsible for all-trans-retinoic acid metabolism. Proc Natl Acad Sci USA 2000; 97: 6403-8.

207. Nelson DR. A second CYP26 P450 in humans and zebrafish: CYP26B1. Arch Biochem Biophys 1999; 371: $345-7$.

208. MacLean G, Abu-Abed S, Dolle P, et al. Cloning of a novel retinoic-acid metabolizing cytochrome P450, Cyp26B1, and comparative expression analysis with Cyp26A1 during early murine development. Mech Dev 2001; 107: 195-201.

209. Trofimova-Griffin ME, Juchau MR. Developmental expression of cytochrome CYP26B1 (P450RAI-2) in human cephalic tissues. Brain Res Dev Brain Res 2002; 136: 175-8.

210. Tahayato A, Dollé P, Petkovich M. Cyp26C1 encodes a novel retinoic acid-metabolizing enzyme expressed in the hindbrain, inner ear, first branchial arch and tooth buds during murine development. Gene Expr Patterns 2003; 3: 449-54.

211. Reijntjes S, Gale E, Maden M. Generating gradients of retinoic acid in the chick embryo: Cyp26C1 expression and a comparative analysis of the Cyp26 enzymes. Dev Dyn 2004; 230: 509-17.

212. Gu X, Xu F, Wang X, et al. Molecular cloning and expression of a novel CYP26 gene (cyp26d1) during zebrafish early development. Gene Expr Patterns 2005; 5: 733-9.

213. Gu X, Xu F, Song W, et al. A novel cytochrome P450, zebrafish Cyp26D1, is involved in metabolism of all-trans-retinoic acid. Mol Endocrinol 2006; 20: 1661-72.

214. Van Pelt FN, Meierink YJ, Blaauboer BJ, et al. Immunohistochemical detection of cytochrome P450 isoenzymes in cultured human epidermal cells. J Histochem Cytochem 1990; 38: 1847-51.

215. Uchida Y, Oda Y, Sun P, et al. Cytochrome P450 isoenzyme responsible for $\alpha$-hydroxylation of very long-chain fatty acids in mammalian epidermis. J Invest Dermatol 1997; 108: 606A

216. Zhu Z, Hotchkiss SA, Boobis AR, et al. Expression of P450 enzymes in rat whole skin and cultured epidermal keratinocytes. Biochem Biophys Res Commun 2002; 297: 65-70.

217. Duell EA, Astrom A, Griffiths CE, et al. Human skin levels of retinoic acid and cytochrome P-450derived 4-hydroxyretinoic acid after topical application of retinoic acid in vivo compared to concentrations required to stimulate retinoic acid receptor-mediated transcription in vitro. J Clin Invest 1992; 90: 1269-74.

218. Smith G, Wolf CR, Deeni YY, et al. Cutaneous expression of cytochrome P450 CYP2S1: individuality in regulation by therapeutic agents for psoriasis and other skin diseases. The Lancet 2003; 361: 1336-43.

219. Rylander T, Neve EP, Ingelman-Sundberg M, et al. Identification and tissue distribution of the novel human cytochrome P4502S1 (CYP2S1). Biochem Biophys Res Commun 2001; 281: 529-35.

220. Popa C, Dicker AJ, Dahler AL, et al. Cytochrome P450, CYP26A1, is expressed at low levels in human epidermal keratinocytes and is not retinoic acid-inducible. Br J Dermatol 1999; 141: 460-8.

221. Heise R, Mey J, Neis MM, et al. Skin Retinoid Concentrations Are Modulated by CYP26AI Expression Restricted to Basal Keratinocytes in Normal Human Skin and Differentiated 3D Skin Models. J Invest Dermatol 2006; 126: 2473-80.

222. Buck J, Myc A, Garbe G, et al. Differences in the action and metabolism between retinol and retinoic acid in B lymphocytes. J Cell Biol 1991; 115: 851-9. 
223. Williams JB, Napoli JL. Metabolism of retinoic acid and retinol during differentiation of F9 embryonal carcinoma cell. Proc Natl Acad Sci USA 1985; 82: 4658-62.

224. Chen AC, Gudas LJ. An analysis of retinoic acid induced gene expression and metabolism in AB1 embryonic stem cells. J Biol Chem 1996; 271: 14971-80.

225. Randolph RK, Simon M. Metabolism of all-trans-retinoic acid by cultured human epidermal keratinocytes. J Lipid Res 1997; 38: 1374-83.

226. Napoli JL. Retinol metabolism in LLC-PK1 cells: characterization of retinoic acid synthesis by an established mammalian cell line. J Biol Chem 1986; 261: 13592-7.

227. Zachman RD, Dunagin PE Jr, Olson JA. Formation and enterohepatic circulation of metabolites of retinol and retinoic acid in bile duct-cannulated rats. J Lipid Res 1966; 7: 3-9.

228. Lippel K, Olson JA. Origin of some derivatives of retinoic acid found in rat bile. J Lipid Res 1968; 9: 580-6.

229. Janick-Buckner D, Barua AB, Olson JA. Induction of HL-60 cell differentiation by water-soluble and nitrogen-containing conjugates of retinoic acid and retinol. FASEB J 1991; 5: 320-5.

230. Formelli F, Barua AB, Olson JA. Bioactivities of N-(4-hydroxyphenyl) retinamide and retinoyl betaglucuronide. FASEB J 1996; 10: 1014-24.

231. Becker B, Barua AB, Olson JA. All-trans-retinoyl beta-glucuronide: new procedure for chemical synthesis and its metabolism in vitamin A-deficient rats. Biochem J 1996; 314: 249-52.

232. Czernik PJ, Little JM, Barone GW, et al. Glucuronidation of estrogens and retinoic acid and expression of UDP-glucuronosyltransferase 2B7 in human intestinal mucosa. Drug Metab Dispos 2000; 28: 1210-6.

233. Samokyszyn VM, Gall WE, Zawada G, et al. 4-hydroxyretinoic acid, a novel substrate for human liver microsomal UDP-glucuronosyltransferase(s) and recombinant UGT2B7. J Biol Chem 2000; 275: 6908-14.

234. Genchi G, Napoli JL, Olson JA. Kinetic studies on retinoyl-B-glucuronide formation in the presence and absence of cellular retinoic acid binding protein, FASEB J 1998; 12: A519.

235. Zile MH, Cullum ME, Simpson RU, et al. Induction of differentiation of human promyelocytic leukemia cell line HL-60 by retinoyl glucuronide, a biological active metabolite of vitamin A. Proc Natl Acad Sci USA 1987; 84: 2208-19.

236. Mehta RG, Barua AB, Olson JA, et al. Retinoid glucuronides do not interact with retinoid binding proteins. Int J Vit Nutr Res 1992; 62: 143-7.

237. Kurlandsky SB, Gamble MV, Rajesekhar R, et al. Plasma delivery of retinoic acid to tissues in the rat. J Biol Chem 1995; 270: 17850-7.

238. De LeenHeer AP, Lambert WE, Claeys I. All-trans-retinoic acid: Measurement of reference values in human serum by high performance liquid chromatography. J Lipid Res 1982; 23: 1362-7.

239. Napoli JL, Pramanik BC, Williams JB, et al. Quantification of retinoic acid by gas-liquid chromatography-mass spectrometry: total versus all-trans-retinoic acid in human plasma. J Lipid Res 1985; 26: 38792.

240. Eckhoff C, Nau H. Identification and quantitation of all-trans- and 13-cis-retinoic acid and 13-cis-4oxoretinoic acid in human plasma. J Lipid Res 1990; 31: 1445-54.

241. Tang G, Russell RM. 13-cis Retinoic acid is an endogenous compound in human serum. J Lipid Res 1990; 31: 175-82.

242. Allen JG, Bloxham DP. The pharmacology and pharmacokinetics of the retinoids. Pharmacol Ther 1989; 40: $1-27$.

243. Lucek RW, Colburn WA. Clinical pharmacokinetics of the retinoids. Clin Pharmacokinet 1985; 10: 38-62. 
244. Lefevre A, Astraudo C, Finaz C. Inhibition of luteinizing hormone-human chorionic gonadotropin binding by retinoids in a Leydig cell line. Mol Cell Endocrinol 1991; 76: 115-23.

245. Saari JC. In: Progress in Retinal Research (Osporne NN, Chader JG, eds), 9. Oxford: Pergamon Press, 1990; 363-81.

246. Mic FA, Molotkov A, Benbrook DM, et al. Retinoid activation of retinoic acid receptor but not retinoid $\mathrm{X}$ receptor is sufficient to rescue lethal defect in retinoic acid synthesis. Proc Natl Acad Sci USA 2003; 100: $7135-40$.

247. Chambon P. A decade of molecular biology of retinoic acid receptors. FASEB J 1996; 10: 940-54.

248. Giguère $\mathrm{V}$, Ong $\mathrm{S}$, Segui $\mathrm{P}$, et al. Identification of a receptor for the morphogen retinoic acid. Nature 1987; 330: 624-9.

249. Petkovich M, Brand NJ, Krust A, et al. A human retinoic acid receptor which belongs to the family of nuclear receptors. Nature 1987; 330: 444-50.

250. Brand N, Petkovich A, Krust A, et al. Identification of a second human retinoic acid receptor. Nature 1988; 332: 850-3.

251. Giguère V, Evans RM. Identification of receptors for retinoids as members of the steroid and thyroid hormone receptor family. In: Retinoids. Part A: Molecular and Metabolic Aspects. Methods in Enzymology (Packer L, ed.), Vol.189. San Diego, CA: Academic Press, 1990; 223-32.

252. Heyman RA, Mangelsdorf DJ, Dyck JA, et al. 9-cis retinoic acid is a high affinity ligand for the retinoid X receptor. Cell 1992; 68: 397-406.

253. Levin AA, Sturzenbecker LJ, Kazmer S, et al. 9-cis retinoic acid stereoisomer binds and activates the nuclear receptor RXR $\alpha$. Nature 1992; 355: 359-61.

254. Mangelsdorf DJ, Borgmeyer U, Heyman RA, et al. Characterization of three RXR genes that mediate the action of 9-cis-retinoic acid. Genes Dev 1992; 6: 329-44.

255. Allenby G, Bocquel M-T, Saunders M, et al. Retinoic acid receptors and retinoic X receptors: interactions with endogenous retinoic acids. Proc Natl Acad Sci USA 1993; 90: 30-4.

256. Fogh K, Voorhees JJ, Aström A. Expression, purification and binding properties of human cellular retinoic acid-binding protein type I and type II. Arch Biochem Biophys 1993; 300: 751-5.

257. Dolle P, Fraulob V, Kastner P, et al. Developmental expression of murine retinoid X receptor (RXR) genes. Mech Dev 1994; 45: 91-104.

258. Mollard R, Viville S, Ward SJ, et al.Tissue-specific expression of retinoic acid receptor isoform transcripts in the mouse embryo. Mech Dev 2000; 94: 223-32.

259. Giguere V. Retinoic acid receptors and cellular retinoid binding proteins: complex interplay in retinoid signaling. Endoc Rev 1994; 15: 61-79.

260. Fisher GJ, Talwar HS, Xiao JH, et al. Immunological identification and functional quantification of retinoic and retinoid X receptor protein in human skin. J Biol Chem 1994; 269: 20629-35.

261. Xiao JH, Durand B, Chambon P, et al. Endogenous retinoic acid receptor (RAR) - retinoid X-receptor (RXR) heterodimers are the major functional forms regulating retinoid-responsive elements in adult human keratinocytes. Binding of ligands to RAR only is sufficient for RAR-RXR heterodimers to confer ligand-dependent activation of hRAR beta 2/RARE (DR5). J Biol Chem 1995; 270: 3001-11.

262. Moras D, Gronemeyer H. The nuclear receptor ligand-binding domain: structure and function. Curr Opin Cell Biol 1998; 10: 384-91.

263. Balmer JE, Blomhoff R. Gene expression regulation by retinoic acid. J Lipid Res 2002; 43: 1773-1808.

264. Chawla A, Repa J, Evans RM, et al. Nuclear receptors and lipid physiology: opening the X-files. Science 2001; 294: 1866-70.

265. McKenna NJ, Lanz RB, O’Malley BW. Nuclear receptor coregulators: cellular and molecular biology. Endocr Rev 1999; 20: 321-44. 
266. Xu L, Glass CK, Rosenfeld MG. Coactivator and corepressor complexes in nuclear receptor function. Curr Opin Genet Dev 1999; 9: 140-7.

267. Dilworth FJ, Chambon P. Nuclear receptors coordinate the activities of chromatin remodeling complexes and coactivators to facilitate initiation of transcription. Oncogene 2001; 20: 3047-54.

268. Jenuwein T, Allis CD. Translating the histone code. Science 2001; 293: 1074-80.

269. Harper RA. Specificity in the synergism between retinoic acid and EGF on the growth of adult human skin fibroblasts. Exp Cell Res 1988; 178: 254-63.

270. Dupuy P, Bagot M, Heslan M, et al. Synthetic retinoids inhibit the antigen presenting properties of epidermal cells in vitro. J Invest Dermatol 1989; 93: 455-9.

271. Bauer R, Orfanos CE. Effects of synthetic retinoids on human peripheral blood lymphocytes and polymorphonuclears in vivo. In: Retinoid Therapy: a review of clinical and laboratori research (WJ Cunliffe, ed). Boston: MTP Press. 1984; 101-18.

272. Di Sepio D, Malhotra M, Chandraratna AS, et al. Retinoic acid receptor-nuclear factor-interleukin 6 antagonism. J Biol Chem 1997; 41: 25555-9.

273. Gallagher RE. Retinoic acid resistance in acute promyelocytic leukemia. Leukemia 2002; 16: 1940-58.

274. Ozpolat B, Mehta K, Tari AM, et al. All-trans-retinoic acid-induced expression and regulation of retinoic acid 4-hydroxylase (CYP26) in human promyelocytic leukemia. Am J Hematol 2002; 70: 39-47.

275. Winterfield L, Cather J, Menter A. Changing paradigms in dermatology: nuclear hormone receptors. Clin Dermatol 2003; 21: 447-54.

276. Petkovich PM. Retinoic acid metabolism. J Am Acad Dermatol 2001; 45: S136-42.

277. Kang S, Duell E, Kim K, et al. Liarozole inhibits human epidermal retinoic acid 4-hydroxylase activity and differentially augments human skin responses to retinoic acid and retinol in vivo. J Invest Dermatol 1996; 107: 183-7.

278. De Coster R, Wouters W, van Ginckel R, et al. Experimental studies with liarozole (R75251): an antitumoral agent which inhibits retinoic acid breakdown. J Steroid Biochem Mol Biol 1992; 43: 197-201.

279. Bryson HM, Wagstaff AJ. Liarozole. Drugs Aging 1996; 9: 478-84.

280. Vandeplassche G, Verfaille CJ, Beger B, et al. Safety of oral liarozole in subjects with ichthyosis or psoriasis. J Eur Acad Dermatol Venereol 2004; 18 (Suppl. 2): 395-6.

281. Dockx P, Decree J, Degreef H. Inhibition of the metabolism of endogenous retinoic acid as treatment for severe psoriasis: an open study with oral liarozole. Br J Dermatol 1995; 133: 426-32.

282. Berth-Jones J, Todd G, Hutchinson P, et al. Treatment of psoriasis with oral liarozole: a dose-ranging study. Br J Dermatol 2000; 143: 1170-6.

283. Bhushan M, Burden AD, McElhone K, et al. Oral liarozole in the treatment of palmoplantar pustular psoriasis: a randomized, double-blind, placebo-controlled study. Br J Dermatol 2001; 145: 546-53.

284. Vandeplassche G, Beger B, Staszak J, et al. Long-term safety of oral liarozole, a new retinoic acid metabolism blocking agent. J Eur Acad Dermatol Venereol 2005; 19 (Suppl. 2): FC13.14.

285. Lucker G, Heremans A, Boegheim P, et al. Oral treatment of ichthyosis by the cytochrome P-450 inhibitor liarozole. Br J Dermatol 1997; 136: 71-5.

286. Lucker G, Verfaille CJ, Heremans A, et al. Topical liarozole in ichthyosis: a double-blind, left-right comparative study followed by a long-term open maintenance study. Br J Dermatol 2005; 152: 566-9.

287. Verfaille CJ, Steijlen PM, Blanchet-Bardon C, et al. Phase II and III studies to evaluate the efficacy and safety of oral liarozole and acitretin in the treatment of severe ichthyosis. J Eur Acad Dermatol Venereol 2004; 18 (Suppl. 2): 145.

288. Stoppie P, Borgers M, Borghgraef P, et al. R115866 inhibits all-trans-retinoic acid metabolism and exerts retinoidal effects in rodents. J Pharmacol Exp Ther 2000; 293: 304-12. 
289. Rambazole ${ }^{\mathrm{TM}}$ (R115866) Investigational Drug Brochure; version 3.0.; Oct. 2005. Data on file at Barrier Therapeutics.

290. Stoppie P, Van Wauwe J, Wouters L, et al. Rambazole ${ }^{\mathrm{TM}}$, a potent inhibitor of all-trans-retinoic acid metabolism, applied topically to mouse tail skin exerts retinoid mimetic activity. J Invest Dermatol 2004; 122: A70 (\#420)

291. Kawaguchi R, Yu J, Honda J, et al. A Membrane Receptor for Retinol Binding Protein Mediates Cellular Uptake of Vitamin A. Science 2007; 315: 820-5. 


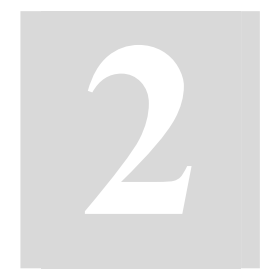

\section{In vitro comparison of three generations RAMBAs}

Partly based on:

Verfaille $C J^{1,2}$, Bols $L^{3}$, Borgers $M^{1,2}$, Franssen $K^{2}$, Govaerts $B^{3}$, Moeremans $M^{3}$, Stoppie $P^{2}$ and Geysen $J^{3}$.

Analyse comparative de l'activité de 3 générations d'agents inhibiteurs du métabolisme de l'acide rétinö̈que dans des cultures de kératinocytes épidermiques humains normaux.

Published in Actualités en Ingénierie Cutanée, 4, 287-9, 2006.

\footnotetext{
${ }^{1}$ Departments of Dermatology and Molecular Cell Biology, GROW, Maastricht University, The Netherlands.

${ }^{2}$ Barrier Therapeutics, Geel, Belgium.

${ }^{3}$ MAIA Scientific, Geel, Belgium.
} 


\section{Introduction}

All-trans-RA is a key regulator of epithelial homeostasis as it modulates the expression of genes which are essential for keratinocyte growth and differentiation. ${ }^{1}$ It exerts most of its biological activities through binding to specific nuclear receptors RARs and RXRs (belonging to the superfamily of steroid/thyroid nuclear receptors), which act as ligandinducible transcriptional factors. ${ }^{2}$ The cellular effects of all-trans-RA also largely depend upon the presence of cellular retinoid-binding proteins, which may be involved in all-trans-RA metabolism and the activity of all-trans-RA metabolizing enzymes. ${ }^{3}$ All-trans-RA and retinoids in general have been proven efficacious in many keratinisation disorders. ${ }^{4}$

Ketoconazole, liarozole and R115866 are azole derivatives representing 3 generations Retinoic Acid Metabolism Blocking Agents (RAMBAs), each with increasing potency and selectivity. ${ }^{5-8}$ R115866 is the most potent and selective RAMBA. RAMBAs inhibit the 4-hydroxylase, a cytochrome P450 (CYP)-dependent enzyme involved in the intracellular metabolic inactivation pathway of endogenous all-trans retinoic acid (all-transRA). ${ }^{9-11}$ Blocking the metabolism of all-trans-RA, results in a transient increase of alltrans-RA levels within the cells. As such, RAMBAs could represent a novel alternative in the treatment of keratinization disorders. ${ }^{12-14}$

Transglutaminase-1 (TG-1), a member of the transglutaminase family, is a crucial $\mathrm{Ca}^{2+}$ dependent enzyme expressed in vivo in the upper differentiated layers of the epidermis where it facilitates the formation of the insoluble protein envelope by cross-linking numerous structural proteins (e.g. loricrin, keratin intermediate filaments, and others) as well as the attachment of the lipid envelope. ${ }^{15,16}$ This cross-bridging produces stable structures composed of polymerized proteins which are essential in a wide variety of biological processes to maintain cell and tissue integrity. The cell envelope is a highly insoluble structure; it retards water loss through the epidermis and protects the internal milieu of the body against external mechanical stimuli, chemical injury and biological invasion. Calcium $\left(\mathrm{Ca}^{2+}\right)$ promotes the differentiation of epidermal keratinocytes both in vitro and in vivo. ${ }^{17,18}$ When normal human epidermal keratinocytes (NHEK) are cultured in vitro under high calcium conditions (1.8-2 $\mathrm{mM})$ they differentiate and express the membrane-bound TG-1. All-trans-RA has been shown in vitro to modulate this $\mathrm{Ca}^{2+}$ induced differentiation by downregulating the expression of TG-1. ${ }^{19}$

The aim of the present study was two-fold. First to compare, in vitro, the effects of R115866 and its predecessors ketoconazole and liarozole with all-trans-RA on cell viability and cell proliferation of normal human keratinocytes (NHEK), human adult dermal fibroblasts (HDFa) and Human Microvascular Endothelial Cells (HuMVEC). 
Secondly, to compare the effect of all-trans-RA alone and in combination with the different RAMBAs on $\mathrm{Ca}^{2+}$ induced differentiation in NHEK using TG-1 as a biomarker. ${ }^{20}$

\section{Materials \& Methods}

\section{Materials}

All-trans-RA, gentamycin, $\mathrm{Ca}^{2+} / \mathrm{Mg}^{2+}$ - free PBS and 3-[4,5-dimethyl-thiazol-2-yl]-2,5diphenyl tetrazolium bromide or MTT were purchased from Sigma. Ketoconazole, liarozole and R115866 are compounds from Barrier Therapeutics nv, their chemical structures are presented in Figure 2.1. All-trans-RA, ketoconazole, liarozole and R115866 were dissolved in $100 \%$ DMSO to a concentration of $10^{-2} \mathrm{M}$ and further diluted in culture medium. All dilutions were prepared separately for the different cell types in their corresponding culture medium. Final DMSO concentrations in working solutions were $0.1 \%$ or less. All culture manipulations or preparations of solutions containing all-trans-RA were performed under yellow light conditions. MTT was dissolved in $\mathrm{Ca}^{2+} / \mathrm{Mg}^{2+}$ - free PBS to a concentration of $5 \mathrm{mg} / \mathrm{ml}$.

\section{Cell culture}

Normal human epidermal keratinocytes (NHEK) derived from foreskin of a 9 year-old donor were supplied by MAIA Scientific as cryopreserved third-passage cells. Cells were cultured in keratinocyte serum-free medium (KSFM, Gibco-Life Technologies) supplemented with epidermal growth factor (EGF), bovine pituitary extract (BPE) and gentamycin (Sigma) according to the supplier's instructions. For all experiments $4^{\text {th }}$ passage cells were used.

Human Dermal Fibroblasts (adult) (HDFa) isolated from a 17 year old female donor were purchased from Cascade Biologics as well as the medium and supplements. Cells were grown in Medium 106 supplemented with Low Serum Growth Supplement (LSGS) and gentamycin according to the manufacturer's instructions. LSGS contains fetal bovine serum, basic fibroblast growth factor, epidermal growth factor, heparin, and hydrocortisone. For all experiments $5^{\text {th }}$ passage cells were used.

Human Microvascular Endothelial Cells (HMVECad) deriving from the dermis of a 30 year old female donor were purchased from Cascade Biologics as well as the medium and supplements. Cells were grown in Medium 131 supplemented with Microvascular 
Growth Supplement (MVGS) and gentamycin according to the manufacturer's instructions. MVGS contains fetal bovine serum, basic fibroblast growth factor, epidermal growth factor, heparin, hydrocortisone and dbcAMP. Culture surfaces were coated with Attachment Factor (containing gelatin) which was provided with the medium. For all experiments $5^{\text {th }}$ passage cells were used.

Ketoconazole

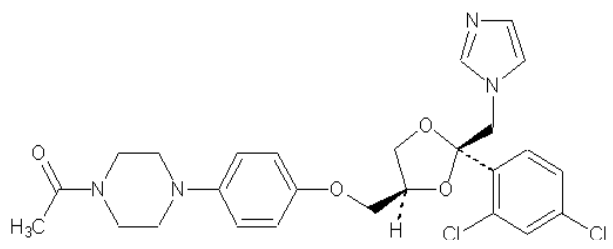

Liarozole<smiles>Clc1cccc(C(c2ccc3[nH]cnc3c2)n2ccnc2)c1</smiles>

R115866

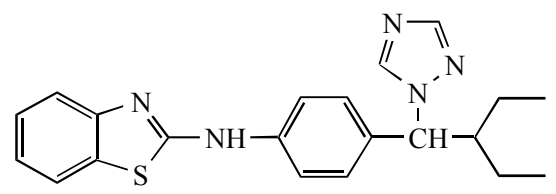

Figure 2.1 Molecular structures of the RAMBAs: ketoconazole, liarozole and R115866.

\section{Growth inhibition and cell viability assay}

NHEK were seeded at 2000 cells/well, HDFa at 4000 cells/well and HMVECad at 4000 cells/well in 96 well plates and grown in their respective medium at $37^{\circ} \mathrm{C}, 5 \% \mathrm{CO}_{2}$ for 24 hours. 
Growth Inhibition Assay. Twenty-four hours after seeding, cells were exposed to investigational compounds ketoconazole, liarozole, R115866 and all-trans-RA using 10-fold dilution series $\left(10^{-5}-10^{-10} \mathrm{M}\right)$ for the time needed to reach $100 \%$ confluent monolayers in control solution (medium $+0.1 \%$ DMSO). After this incubation time, $25 \mu 1$ MTT per well was added to the cultures and further incubated for 2.5 hours at $37^{\circ} \mathrm{C}$. The medium was then aspirated and isopropanol was added to dissolve the formazan crystals. Optical densities (OD) were measured at 540-650 $\mathrm{nm}$.

Cell viability Assay. Cells were cultured until 100\% confluence was reached and subsequently exposed to the investigational compounds (ketoconazole, liarozole, R115866) or to all-trans-RA using 10-fold dilution series $\left(10^{-5}-10^{-10} \mathrm{M}\right)$ for 96 hours with replenishment of the medium \pm compound after 48 hours. After the incubation time, $25 \mu 1$ MTT /well was added to the cultures which were then further incubated for another 2.5 hours at $37^{\circ} \mathrm{C}$. Thereafter the medium was aspirated and isopropanol was added to dissolve the formazan crystals. Optical densities were measured at 540-650 nm.

\section{TG-1 in situ ELISA for NHEK}

NHEK were cultured in KSFM under low $\mathrm{Ca}^{2+}$ conditions $(0.088 \mathrm{mM})$ until they reached $\pm 60 \%$ confluence. The medium was then replaced by KSFM with high $\mathrm{Ca}^{2+}$ $(1.8 \mathrm{mM})$ and cells were treated with either a RAMBA (ketoconazole, liarozole, R115866, R116010 alone (at $10^{-6}-10^{-8} \mathrm{M}$ ), all-trans-RA alone (at $10^{-8}-10^{-12} \mathrm{M}$ ) or alltrans-RA/RAMBA combinations for 5 more days. At day 5, after monitoring cell viability with MTT, cells were processed for TG-1 measurement using an in situ ELISA.

Cell viability. MTT was added to the cultures and after incubation of 2.5 hours at $37^{\circ} \mathrm{C}$, the reaction was stopped by removing the medium and freeze-thawing the monolayers twice. Formazan precipitates were dissolved in ethanol/aceton $\left(60 / 40 ; \mathrm{v} / \mathrm{v},-20^{\circ} \mathrm{C}\right)$ resulting at the same time in fixation of the monolayers. Cell viability was measured by reading the OD at $540-650 \mathrm{~nm}$.

In situ ELISA for TG-1. After measuring cell viability, the fixed monolayers were washed once with ethanol/aceton $(60 / 40 ; \mathrm{v} / \mathrm{v})$ to remove the formazan. Subsequently, they were dried, rehydrated and blocked with $1 \%$ bovine serum albumine (BSA). Immunostaining of TG-1 was performed with a mouse monoclonal antibody to TG-1 
(clone B.C1) and a secondary peroxidase-labeled goat-anti-mouse antibody. After incubation with o-phenylenediamine, the OD was measured at $490 \mathrm{~nm}$.

\section{Results and discussion}

\section{Growth inhibition and cell viability}

Mitochondrial activity-based assays were set-up and implemented for the evaluation of the cell isolates and of the effects of compounds on cell growth and cell viability in the 3 different cell types.

The viability of the cells was determined by a colorimetric MTT assay. The test is based on the reduction of yellow MTT by mitochondrial dehydrogenases from living cells into blue/purple formazan crystals, which are insoluble in culture medium. The amount of formazan generated is proportional to the number of viable cells after exposure to the test agent and is expressed as the percentage (\%) to the untreated control using the following formula:

$$
\% \text { of surviving cells }=\frac{\text { O.D. }{ }_{540 \mathrm{~nm}} \text { of test dilution }}{\text { O.D. }{ }_{540 \mathrm{~nm}} \text { of untreated control }} \times 100
$$

Growth inhibition and cell viability curves of the different compounds for the different cell types are shown in Figures 2.2-2.4. Estimated $\mathrm{IC}_{50}$ and $\mathrm{TC}_{50}$ values are tabulated in Table 2.1.

The data point out that the different cells display a different sensitivity towards the compounds tested. In both assays, keratinocytes are more sensitive to the compounds tested than fibroblasts. No effects on cell growth or cell viability were seen in endothelial cells at the concentration range of $10^{-10}$ to $10^{-5} \mathrm{M}$ for any of the tested compounds.

When comparing the different RAMBAs, it is clear that liarozole does not affect cell growth or cell viability, in any of the cell types, not even at $10^{-5} \mathrm{M}$, the highest concentration tested.

Like all-trans-RA, R115866 dose-dependently inhibits keratinocyte growth $\left(\mathrm{IC}_{50} \sim 2.2 \times 10^{-6} \mathrm{M}\right)$ and affects cell viability $\left(\mathrm{TC}_{50}\right.$ ranging between $\left.3.3-10 \times 10^{-6} \mathrm{M}\right)$ at micromolar concentrations. Ketoconazole, here only tested in keratinocytes, is even more potent than $\mathrm{R} 115866$ in inhibiting cell growth $\left(\mathrm{IC}_{50}=10^{-6} \mathrm{M}\right)$. Effects on cell viability are seen at concentrations higher than $10^{-6} \mathrm{M}$.

In HDF, R115866 doesn't seem to affect the cell growth up to concentrations of $10^{-6} \mathrm{M}$ but at only a 10 -fold higher concentration growth is inhibited by almost $80 \%$. Also the 
cell viability is affected at concentrations above $10^{-6} \mathrm{M}$ but the estimated $\mathrm{TC}_{50}$ $\left(2.5 \times 10^{-5} \mathrm{M}\right)$ is higher than the estimated $\mathrm{IC}_{50}\left(7.5 \times 10^{-6} \mathrm{M}\right)$. All-trans-RA displays a linear dose-dependent inhibitory effect on cell growth. Forty $\%$ growth inhibition is reached at the highest concentration tested. At physiological concentrations (from $10^{-10}$ to $5 \times 10^{-8} \mathrm{M}$ ) no effect is observed on cell viability. A $20-30 \%$ inhibition of mitochondrial activity is observed at $10^{-5} \mathrm{M}$, the highest concentration tested.

Table 2.1 Overview of the effects on cell growth (estimated $\mathrm{IC}_{50}$ ) and cell viability (estimated $\mathrm{TC}_{50}$ ) by alltrans-RA and RAMBAs measured in the different cell lines.

\begin{tabular}{|c|c|c|c|}
\hline Compound & $\begin{array}{l}\text { Cell growth } \\
\operatorname{IC}_{50}(\mathrm{M})^{*}\end{array}$ & $\begin{array}{l}\text { Cell viability } \\
\mathrm{TC}_{50}(\mathrm{M})^{*}\end{array}$ & $\begin{array}{c}\text { Concentration range } \\
\text { (M) }\end{array}$ \\
\hline \multicolumn{4}{|l|}{ NHEK } \\
\hline Ketoconazole & $10^{-6}$ & $>10^{-5}$ & $10^{-10}-10^{-5}$ \\
\hline Liarozole & $>10^{-5}$ & $>10^{-5}$ & $10^{-10}-10^{-5}$ \\
\hline R115866 & $5 \times 10^{-6}$ & $5 \times 10^{-6}$ & $10^{-10}-10^{-5}$ \\
\hline All-trans-RA & $5 \times 10^{-6}$ & $7.5 \times 10^{-6}$ & $10^{-10}-10^{-5}$ \\
\hline \multicolumn{4}{|l|}{ HDFa } \\
\hline Liarozole & $>10^{-5}$ & $>10^{-5}$ & $10^{-10}-10^{-5}$ \\
\hline R115866 & $7.5 \times 10^{-6}$ & $2.5 \times 10^{-5}$ & $10^{-10}-10^{-5}$ \\
\hline All-trans-RA & $>10^{-5}$ & $>10^{-5}$ & $10^{-10}-10^{-5}$ \\
\hline \multicolumn{4}{|l|}{ HMVECad } \\
\hline Liarozole & $>10^{-5}$ & $>10^{-5}$ & $10^{-10}-10^{-5}$ \\
\hline R115866 & $>10^{-5}$ & $>10^{-5}$ & $10^{-10}-10^{-5}$ \\
\hline All-trans-RA & $>10^{-5}$ & $>10^{-5}$ & $10^{-10}-10^{-5}$ \\
\hline
\end{tabular}

\section{Inhibition of $\mathrm{Ca}^{2+}$ induced TG-1 expression in NHEK}

An assay format for analysing the effect of all-trans-RA alone or in combination with RAMBAs on $\mathrm{Ca}^{2+}$-induced keratinocyte differentiation using TG-1 as a biomarker has been set up, optimized and validated. Two endpoints were sequentially measured in each well using a mitochondrial activity-based assay followed by an in situ ELISA. This assay not only combines the advantage of simultaneous monitoring of effects of compounds on cell growth, viability and differentiation but is next to that also a more economic assay.

Prior to analysing the (potentiating) effect of RAMBAs on the all-trans-RA-induced down-regulation of TG-1 expression in cultured keratinocytes, main efforts have been put on the characterization of diverse keratinocyte isolates. Primarily, the keratinocyte isolates were assessed on their capacity to respond to calcium-dependent differentiation 
by using an in situ ELISA for TG-1. Secondly, concentration titration experiments for the inhibition of TG-1 expression by all-trans-RA were carried out, allowing the identification and selection of all-trans-RA-sensitive keratinocyte isolates. (Data not shown) Concentration-response curves for the inhibition of TG-1 expression by all-trans-RA or in combination with each of the RAMBAs in NHEK are displayed in Figure 2.5. Corresponding estimated $\mathrm{IC}_{50}$ values by linear interpolation are represented in Table 2.2. The rate of potentiation of the retinoid-induced inhibition of TG-1 expression by the RAMBAs was assessed by calculating the ratio of the $\mathrm{IC}_{50}$ of all-trans-RA divided by the $\mathrm{IC}_{50}$ of all-trans-RA+RAMBA and is presented in Table 2.2.

Table 2.2 Inhibition of $\mathrm{Ca}^{2+}$-induced TG-1 expression by all-trans-RA alone and in combination with a RAMBA.

\begin{tabular}{|c|c|c|c|c|c|}
\hline & All-trans-RA & + & + & + & + \\
\hline & RAMBA & - & $10^{-8} \mathrm{M}$ & $10^{-7} \mathrm{M}$ & $10^{-6} \mathrm{M}$ \\
\hline \multirow[t]{3}{*}{$I C_{50}(n M)$} & Ketoconazole & $2-3$ & 2 & 0.04 & $<0.001$ \\
\hline & Liarozole & $3-4$ & 2 & 0.2 & 0.001 \\
\hline & R115866 & $4-5$ & 0.03 & 0.02 & $<0.001$ \\
\hline \multirow[t]{3}{*}{ Potentiation } & Ketoconazole & - & $1-1.5$ & $50-75$ & $>2000-3000$ \\
\hline & Liarozole & - & $1.5-2$ & $15-20$ & $3000-4000$ \\
\hline & R115866 & - & $133-160$ & $200-250$ & $>4000-5000$ \\
\hline
\end{tabular}

As expected all-trans-RA dose-dependently down-regulated TG-1 expression with an $\mathrm{IC}_{50}=2.10^{-9} \mathrm{M}$ to $5.10^{-9} \mathrm{M}$. When all-trans-RA was combined with each of the RAMBAs, dose-response curves shifted to the left. Minor differences in potency amongst the different RAMBAs were observed at a concentration of $10^{-6} \mathrm{M}$; all 3 lowered the $\mathrm{IC}_{50}$ of all-trans-RA at least 2000-fold. The decrease in TG-1 expression by ketoconazole could partially be due to its effect on proliferation. At $10^{-7} \mathrm{M}$, R115866 was 4 to 10 times more potent than ketoconazole and liarozole respectively and at $10^{-8} \mathrm{M}$ even a 100 times. 

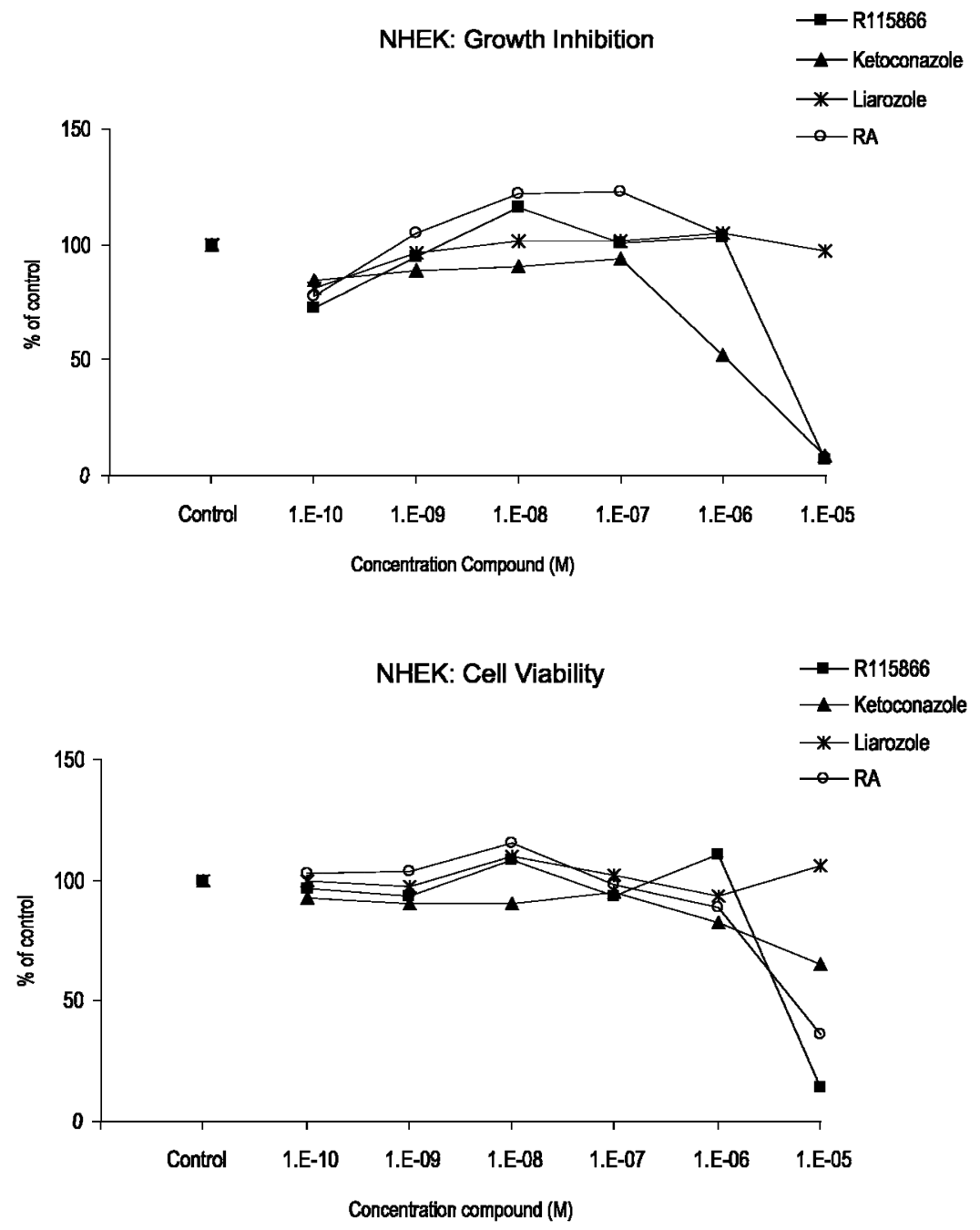

Figure 2.2 Dose-dependent growth inhibition and cell viability curves of all-trans-RA and the RAMBAs in NHEK. 

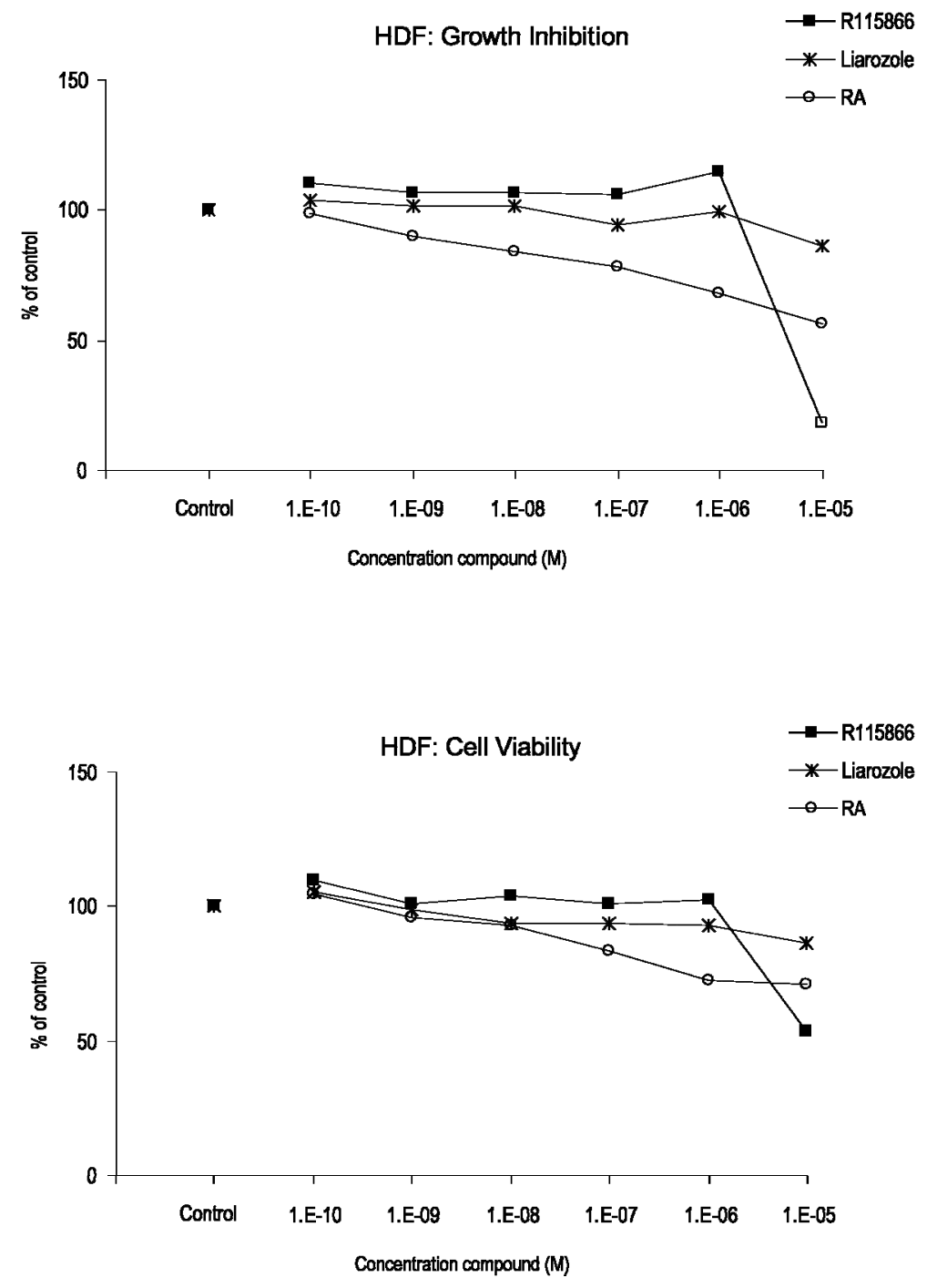

Figure 2.3 Dose-dependent growth inhibition and cell viability curves of all-trans-RA and the RAMBAs in HDF. 

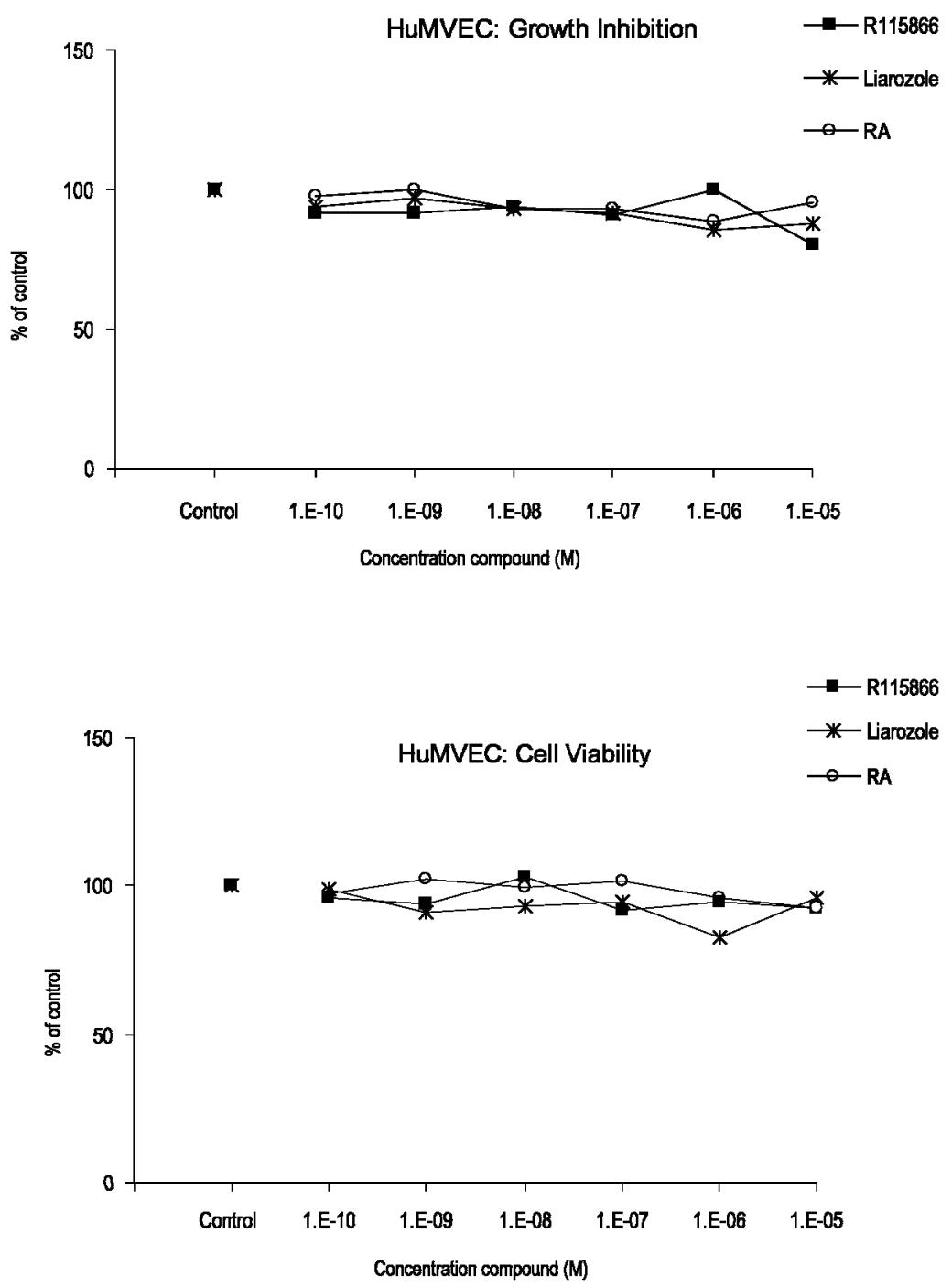

Figure 2.4 Dose-dependent growth inhibition and cell viability curves of all-trans-RA and the RAMBAs in HuMVEC. 
Ketoconazole

MTT

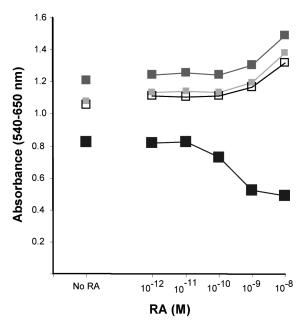

TG-1

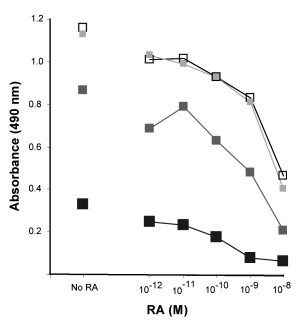

TG-1/MTT

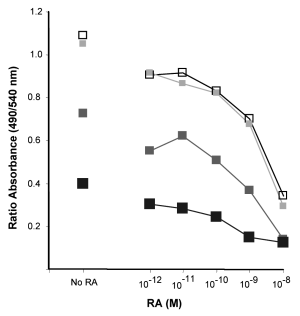

Liarozole
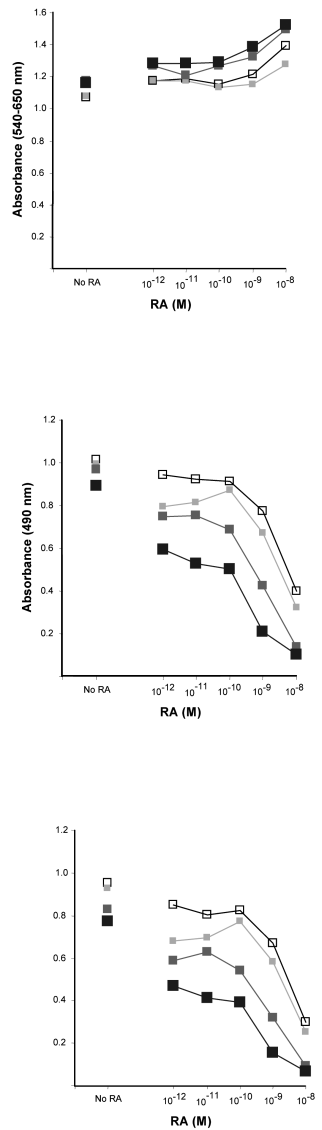

R115866
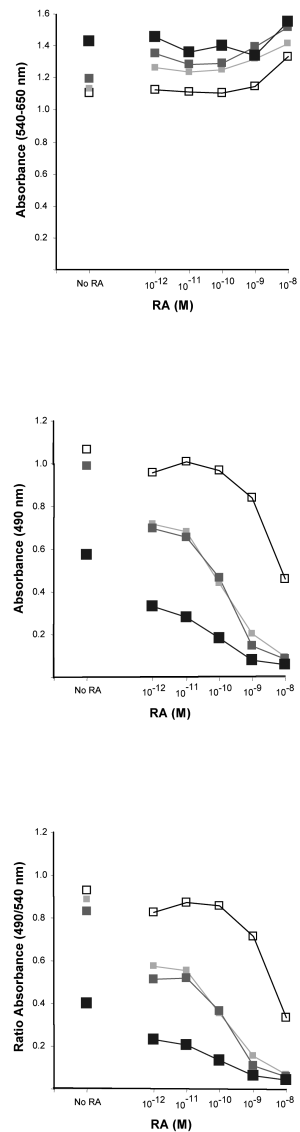

$\square-$ No compound $\longrightarrow-0.01 \mu \mathrm{M} \rightarrow-0.1 \mu \mathrm{M} \rightarrow-1 \mu \mathrm{M}$

Figure 2.5 Inhibition of TG-1 expression by all-trans-RA $\left(10^{-8}\right.$ to $\left.10^{-12} \mathrm{M}\right)$ alone and in combination with a RAMBA $\left(10^{-6}\right.$ to $\left.10^{-8} \mathrm{M}\right)$ in NHEK. TG-1 was measured with an in situ ELISA (absorbance 490nm) and values were corrected for cell number as measured with MTT (absorbance 540nm). Values represent mean of intra-assay quadruplicates 
In conclusion, in line with their proposed mechanism of action, the RAMBAs potentiated the inhibitory effect of all-trans-RA on TG-1 expression in differentiating keratinocytes with R115866 being superior to ketoconazole and liarozole. This is in concordance with their intrinsic potency to inhibit CYP 26, a cytochrome P450 dependent hydroxylase.

Although $\mathrm{IC}_{50}$ values for all-trans-RA were reproducible and the potentiating effects for RAMBAs, measured using the method published by Svendsen et al. (1997), were statistically significant, the TG-1 measurement by in situ ELISA was shown to have a rather high variability. ${ }^{21}$ This could be attributed to plate position effects and to the variable stages of keratinocyte differentiation, already visibly present in the preconfluent monolayers at the start of incubation. This variation results from the fact that as soon as keratinocytes experience a state of confluency in the centre of a growing colony, they are already primed to differentiate, even in low $\mathrm{Ca}^{2+}$ culture conditions. For this reason, the TG-1 assay design/ in situ ELISA can still be considered for further optimization. 


\section{References}

1. De Luca L, Darwiche N, Jones CS, et al. Retinoids in differentiation and neoplasia. Sci Am Sci Med 1995; 2: 28-37.

2. Napoli JL. Retinoic acid: its biosynthesis and metabolism. Prog Nucleic Acid Res Mol Biol 1999; 63: $139-88$

3. Napoli JL. Interactions of retinoid binding proteins and enzymes in retinoid metabolism. Biochim Biophys Acta 1999; 1440:139-62.

4. Van Wauwe J, Coene MC, Goossens G, et al. Ketoconazole inhibits the in vitro and in vivo metabolism of all-trans-retinoic acid. J Pharmacol Exp Ther 1987; 245: 718-22.

5. Van Wauwe J, van Nijen G, Coene MC, et al. Liarozole, an inhibitor of retinoic acid metabolism, exerts retinoid-mimetic activities in vivo. Exp Ther 1992; 261: 773-9.

6. Van Wauwe J, Coene MC, Goossens J, et al. Effects of cytochrome P-450 inhibition on the in vivo metabolism of all-trans-retinoic acid in rats. J Pharmacol Exp Ther; 1990: 252: 365-9.

7. Stoppie P, Borgers M, Borghgraef P, et al. R115866 inhibits all-trans-retinoic acid metabolism and exerts retinoidal effects in rodents. J Pharmacol Exp Ther 2000; 293: 304-12.

8. White JA, Guo Y-D, Baetz K, et al. Identification of the retinoic acid-inducible all-trans-retinoic acid 4hydroxylase. J Biol Chem 1996; 271: 29922-7.

9. White JA, Beckett-Jones B, Guo YD, et al. cDNA cloning of human retinoic acid-metabolizing enzyme (hP450RAI) identifies a novel family of cytochromes P450. J Biol Chem 1997; 272: 18538-41.

10. Ray WJ, Bain G, Yao M, et al. CYP26, a novel mammalian cytochrome P450, is induced by retinoic acid and defines a new family. J Biol Chem 1997; 272: 18702-8.

11. Orfanos CE, Zouboulis CC, Almond-Roesler B, et al. Current use and future potential role of retinoids in dermatology. Drugs 1997; 53: 358-88.

12. Berth-Jones J, Todd G, Hutchinson P, et al. Treatment of psoriasis with oral liarozole: a dose-ranging study. Br J Dermatol 2000, 143: 1170-6.

13. Bhushan M, Burden AD, McElhone $\mathrm{K}$, et al. Oral liarozole in the treatment of palmoplantar pustular psoriasis: a randomized, double-blind, placebo-controlled study. Br J Dermatol 2001, 145: 546-53.

14. Lucker G, Verfaille CJ, Heremans A, et al. Topical liarozole in ichthyosis: a double-blind, left-right comparative study followed by a long-term open maintenance study. Br J Dermatol 2005; 152: 566-9.

15. Nemes Z, Steinert PM. Bricks and mortar of the epidermal barrier. Exp Mol Med 1999; 31: 5-19.

16. Hitomi K. Transglutaminases in the skin epidermis. Eur J Dermatol 2005; 15: 313-9.

17. Steinert PM, Marecov LN. Initiation of assembly of the cell envelope barrier structure of stratified squamous epithelia. Mol Biol Cell 1999; 10: 4247-61.

18. Candi E, Schmidt R, Melino G. The cornified envelope: a model of cell death in the skin. Nat Rev Mol Cell Biol 2005; 6: 328-40.

19. Rosenthal DS, Griffiths EM, Yuspa SH, et al. Acute or chronic topical retinoic acid treatment of human skin in vivo alters the expression of epidermal transglutaminase, loricrin, involucrin, filaggrin, and keratins 6 and 13 but not keratins 1, 10, and 14. J Invest Dermatol 1992; 98: 343-50.

20. Michel S, Courseaux A, Miquel C, et al. Determination of retinoid activity by an enzyme-linked immunosorbent assay. Anal Biochem 1991, 192: 232-6.

21. Svendsen ML, Daneels G, Geysen J, et al. Proliferation and differentiation of cultured human keratinocytes is modulated by $1,25(\mathrm{OH})_{2} \mathrm{D} 3$ and synthetic vitamin D3 analogues in a cell density-, calcium-, and serum-dependent manner. Pharmacol Toxicol 1997; 80: 49-56.. 


\section{Effects of R115866 on Reconstituted Human Epidermis}

Based on:

Verfaille $C J^{1,2}$, Stoppie $P^{2}$, Ramaekers $F C S^{1}$ and Borgers $M^{1,2}$

Effects of R115866 on skin permeability using in vitro Reconstituted Human Epidermis.

Submitted for publication

\footnotetext{
${ }^{1}$ Departments of Dermatology and Molecular Cell Biology, GROW, Maastricht University, The Netherlands.

${ }^{2}$ Barrier Therapeutics, Geel, Belgium.
} 


\begin{abstract}
R115866, a substituted benzyl-1, 2, 4,- triazole derivative, is a new generation of Retinoic Acid Metabolism Blocking Agent (RAMBA). R115866 was found to generate retinoid-mimetic biological activities in various retinoid sensitive animal models of keratinisation and is currently under clinical investigation for both oral and topical treatment of psoriasis and acne. In the light of its potential for topical treatment, the effect of R115866 on viability the human skin and modulation of the skin barrier permeability was investigated in vitro using Reconstituted Human Epidermis (RHE). Cell viability was assessed using the MTT assay and morphological evaluation. The modulation of the skin barrier permeability was assessed by measuring the passage of tritiated water through the RHE at different incubation times. The results show that R115866 $\left(10^{-5}\right.$ to $\left.10^{-7} \mathrm{M}\right)$ is devoid of significant enhancing effects on the permeation of tritiated water through RHE and exhibits no cytotoxic effects on the tissues. Further work will be necessary to evaluate the effects of these molecules on other barrier characteristics like proteins and lipids.
\end{abstract}




\section{Introduction}

R115866 (Rambazole ${ }^{\mathrm{TM}}$ ) a substituted benzyl-1,2,4,- triazole derivative is a new generation of Retinoic Acid Metabolism Blocking Agent (RAMBA). The investigational drug is a stable, enantiomerically pure base which has been identified both in vitro and in vivo as a compound with highly specific and selective CYP inhibiting properties against hydroxylases involved in the catabolism of all-trans retinoic acid. ${ }^{1-3}$ Its potency lies in the nanomolar range $\left(\mathrm{IC}_{50}=4 \mathrm{nM}\right)$ which is about three orders of magnitude more powerful than liarozole $\left(\mathrm{IC}_{50}=3 \mu \mathrm{M}\right)$, a previous generation RAMBA. In comparison to its retinoid catabolism inhibiting activity, R115866 shows only trivial inhibitory effects on the CYP-dependent biosynthesis of steroids. R115866 was found to generate retinoidmimetic biological activities in various retinoid sensitive animal models of keratinisation and is currently under clinical investigation for both oral and topical treatment of psoriasis and acne. ${ }^{3-5}$

In the light of its potential for topical treatment, the effect of R115866 on viability and modulation of the human skin barrier permeability was investigated using Reconstituted Human Epidermis (RHE) from SkinEthics as an in vitro model. Together with R115866, two chemically related azole derivatives R115865 (S-enantiomer of R115866) and R116010 were tested. ${ }^{6}$

Culturing of normal human keratinocytes on inert filters has led to the production of functional human skin equivalents. These cultures raised at the air-liquid interface exhibit a well stratified and cornified epidermis with normal barrier function and metabolic activity mimicking the in vivo situation. ${ }^{7}$ So far, they have been used for the assessment of cutaneous immunotoxicological responses, for studies of epidermal responses to irritants and sensitizers, for metabolic studies of pharmaceuticals and for the determination of absorption properties and are suggested a valid alternative for in vivo animal testing., 8

Modulation of the human skin barrier permeability by R115866 is assessed by measuring the passage of tritiated water through the RHE. ${ }^{10}$ The principle of the assay is the following. The molecules to be tested are applied on the cornified side of RHE in association with tritiated water whilst culture medium is added to the basal chamber inserts. At different incubation times, the tritiated water permeated through the RHE is quantified by liquid scintillation counting (LSC). Consequently, if the tested products alter the stratum corneum permeability, the tritium permeation rate will be modified. At the end of the study period, a Methyl Thiazolyl Tetrazolium (MTT) assay is carried out to assess the possible effects of the compounds on viability of the cultured layers. In parallel, tissues are fixed with glutaraldehyde for histological examinations. 
The aim of this study was two-fold: first to estimate the modulation of the human skin barrier permeability by R115866 and second, to investigate if any cytotoxic effects were induced.

\section{Materials and methods}

\section{Compounds and Reagents}

Barrier Therapeutics' compounds R115866, R115865 (S-enantiomer of R115866) and R116010 were supplied as $10^{-2} \mathrm{M}$ stock solutions dissolved in 100\% DMSO (Figure 3.1). They were diluted aseptically in serum free culture medium and mixed with tritiated water (Amersham Biosciences, $500 \mu \mathrm{Ci}$ ) in order to obtain final working solutions of $10^{-5}, 10^{-6}$ and $10^{-7} \mathrm{M}$. The final specific activity of tritium was $45 \mathrm{kBq} / 50 \mu \mathrm{l}$ working solution.

\section{RHE model}

For histological and in vitro percutaneous absorption studies RHE were purchased from SkinEthic Laboratories (Nice, France). RHE consist of a multilayered epidermis that exhibits similar morphological and growth characteristics as human epidermis in vivo. ${ }^{7}$ Briefly, they are obtained by culturing normal human keratinocytes in a biochemically defined medium on polycarbonate culture inserts lifted to the air-liquid interface for 16 days. The keratinocytes form several layers following the stratification pattern of epidermis. The epidermal tissues $\left(0.50 \mathrm{~cm}^{2}\right)$ were shipped to the laboratory in 24 well plates on medium containing agarose gels. At their arrival, the inserts were removed and replaced onto $0.5 \mathrm{ml}$ of SkinEthic maintenance medium (SkinEthic Laboratories), as recommended, and incubated overnight $\left(37^{\circ} \mathrm{C}, 5 \% \mathrm{CO}_{2}\right)$ before testing. Under these conditions the RHE can be maintained viable for several days.

\section{In vitro percutaneous absorption assay}

For testing the percutaneous absorption, $0.5 \mathrm{ml}$ of fresh medium was placed under each RHE insert and $50 \mu \mathrm{l}$ of each solution containing $10^{-5} \mathrm{M}, 10^{-6} \mathrm{M}$ or $10^{-7} \mathrm{M}$ of compound/tritiated water $(45 \mathrm{kBq})$ was applied directly on the cornified side of the corresponding tissue. Each concentration was applied on 3 different tissues for LSC. One tissue was treated with only the compound -no tritiated water- for histology. The tissues were incubated at $37^{\circ} \mathrm{C}\left(5 \% \mathrm{CO}_{2}\right)$ for maximum 2 days. After 15', 30', 45', 1h, 2h, 4h, $6 \mathrm{~h}, 8 \mathrm{~h}, 24 \mathrm{~h}$ and $48 \mathrm{~h}$ of incubation, the culture medium $(0.5 \mathrm{ml})$ was withdrawn from the 
receiver chamber for analysis by LSC and replaced by fresh culture medium. The $0.5 \mathrm{ml}$ aliquots were weighed out in scintillation vials. After adding $10 \mathrm{ml}$ Ultima Gold, the vials were capped, hand-shaken for a few seconds and left for at least 2 hours prior to counting (10 minutes) on a Beta counter (Packard Tri Carb 2900 TR).

As controls, 3 tissues were treated with $50 \mu \mathrm{l}$ of culture medium containing $0.1 \%$ DMSO and $45 \mathrm{kBq}$ of tritiated water and one tissue with only culture medium containing $0.1 \%$ DMSO for histology. Finally, 4 tissues were left untreated.

\section{Histology}

At the end of the experiment, punch biopsies ( $8 \mathrm{~mm}$ in diameter) were taken from the fourth tissue (non-radioactive) for histological examination. Biopsies were immediately fixed in $3 \%$ glutaraldehyde in $0.1 \mathrm{M} \mathrm{KH}_{2} \mathrm{PO}_{4}$, buffered to a $\mathrm{pH}$ of 7.4 at room temperature for 30-60 minutes and stored at $4{ }^{\circ} \mathrm{C}$ until histological preparation. After fixation the samples were washed using the same buffer to which $7.5 \%$ sucrose was added for osmolality reasons and post-fixed for 1 hour in $1 \%$ osmium tetroxide buffered to $\mathrm{pH} 7.4$ with veronal acetate $50 \mathrm{mM}$. After a brief wash in the buffer, the samples were dehydrated in a graded series of ethanol and routinely embedded in epoxy resin (Epon). Light microscopic evaluation of morphological changes was performed on semi-thick Epon-embedded sections $(2 \mu \mathrm{m})$ stained with toluidine blue for 30 seconds. For electron microscopy, ultra-thin Epon-embedded sections (50nm) were counterstained with uranium acetate and lead citrate and examined in a Philips CM100 electron microscope.

\section{Cell viability measurement by MTT reduction}

The viability of the RHE was determined by a colorimetric 3-[4,5-dimethyl-thiazol-2yl]-2,5diphenyl tetrazolium bromide (MTT) assay. The test evaluates the transformation of MTT, yellow, by mitochondrial dehydrogenases into blue/purple formazan crystals, which are insoluble in culture medium. When the tissue is healthy, an intense purple color is observed while the culture remains white when necrosis occurred.

Briefly, $0.5 \mathrm{ml}$ of MTT solution (Sigma) at $0.5 \mathrm{mg} / \mathrm{ml}$ in culture medium is added to all test wells containing tissue. The plate is incubated for 60 minutes at $37{ }^{\circ} \mathrm{C}, 5 \% \mathrm{CO}_{2}$. At the end of the incubation period, the MTT solution is discarded and replaced by isopropanol (Sigma). The extraction process in isopropanol is performed during 30 minutes at room temperature on a shaking platform. From each well, $200 \mu 1$ aliquots of blue MTT extraction solution is transferred to a corresponding well of a 96-well plate and the optical density (O.D.) is measured using a microplate reader (SpectraMax 340) at 540 $\mathrm{nm}$. The amount of formazan generated is proportional to the number of viable cells 
after exposure to the test agent and is expressed as the percentage (\%) to the untreated control using the following formula:

$$
\% \text { of surviving cells }=\frac{\text { O.D. }{ }_{540 \mathrm{~nm}} \text { of test dilution }}{\text { O.D. }{ }_{540 \mathrm{~nm}} \text { of untreated control }} \times 100
$$

The measurement of the viability of the RHE was taken in triplicate.

\section{Data handling}

All calculations were carried out using Microsoft ${ }^{\circledR}$ Excel 2000 and Graphpad Prism ${ }^{\circledR}$ for Windows version 3.02 (GraphPad software, San Diego, CA, USA). The conversion of individual cpm data into mean $\mathrm{Bq} / \mathrm{ml}$ values and the acceptance of each result according to the coefficient of variation obtained were computed automatically using an Excel spreadsheet.

Steady-state fluxes (Jss) were determined from graphs in which the cumulative amount of penetrated ${ }^{3} \mathrm{H}$ was plotted against time. Fluxes were calculated from the slope of the steady-state portion of the curves. The permeability coefficient was calculated using the equation:

$$
\mathrm{Kp}=\left(\frac{\mathrm{V}}{\mathrm{AxCd}}\right) \times \frac{d C r}{d t}
$$

$\mathrm{Kp}$ is the permeability coefficient (cm/s), A is the surface area of the RHE, Cd and $\mathrm{Cr}$ are the concentrations in the donor and the receiver compartments, $\mathrm{V}$ is the volume of the receiver compartment $(\mathrm{ml})$, and $\mathrm{dCr} / \mathrm{dt}$ is the steady state slope of the concentration versus the time profile in the receiver compartment.

Significance of differences between treatments was analysed using GraphPad Prism ${ }^{\mathrm{TM}}$ 3.02 software. The results were analysed by comparison of slopes (cumulated ${ }^{3} \mathrm{H}$ permeated versus square root of time). The comparisons were always performed versus control. A second data analysis was realized by using a test based on confidence interval procedure related to Wilcoxon Rank Sum/Mann-Whitney rank test. The values being out of range (75-133\% of the control) and exhibiting a $\mathrm{P}$ value $<0.05$ (slope comparison) were considered as significantly different. 


\section{R115865}

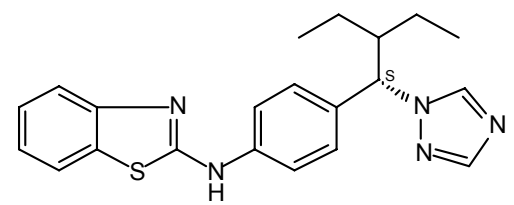

R115866

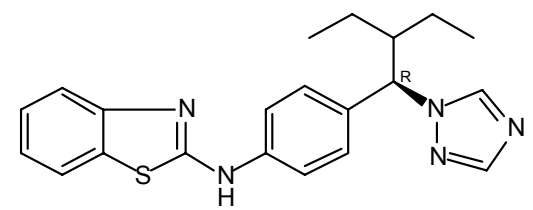

R116010

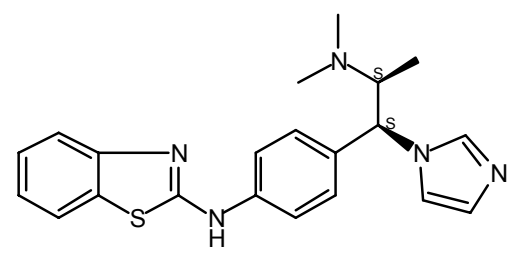

Figure 3.1 Chemical structures of the different molecules: R115865, R115866 and R116010. 


\section{Results and discussion}

\section{Permeation study}

The overall precision expressed as the overall mean of triplicates coefficient of variation (CV\%) is $13 \pm 2 \%$ for the samples collected during the 0 - $8 \mathrm{~h}$ time interval and $21 \pm 2 \%$ for the samples at $24-48 \mathrm{~h}$. Considering a target acceptance limit of $15 \%$, the variability is satisfactory and can be considered as low compared to the data obtained with human skin samples (CV\% in the range 30-45\%).

Time dependent variations of permeated amounts of ${ }^{3} \mathrm{H}$-water for the different compounds are shown in Figure 3.2. Independently of compounds/concentrations applied, the permeation profiles exhibit 2 peaks at 0.75 and 4 hours respectively. Those results are in accordance with previous observations (data not shown). The RHE permeability in this experimental set-up is affected by two factors. In a first step, the presence of water affects the barrier function in the tissue by modulating the hydration rate in the stratum corneum and the epidermis. Water is a small molecule (diameter: $0.28 \mathrm{~nm}$ ) which can penetrate through microscopic pores between lipid molecules. The oxygen atoms of phosphate and carbonyl groups of gangliosidic sialic acid residue are most likely the targets for water bonding. The phospholipid morphology of the membrane is affected by the presence of water in this particular residue. Therefore, a marked increase in tritiated water permeability is transiently observed in the first hour(s) of the experiment. In a second step, the RHE permeability is probably affected by the presence of the tested molecules inducing conformational changes in the tissue (i.e. disruption of the ordered lipid bilayers) and/or improving the partitioning coefficient in the stratum corneum. These two parameters explain the profiles observed.

Time-dependent cumulated amounts of ${ }^{3} \mathrm{H}$ permeated across RHE in the presence or absence of the molecules are shown in Figure 3.3. The results show that it increases rapidly to reach a plateau after 4 hours.

The total amount of radioactivity that passed into the receptor medium in 48 hours was $33.4 \pm 1.3 \mathrm{MBq}$, which is on average $74.2 \%$ of the dose applied. Steady-state flux conditions were reached after approximately 2 hours, independently of the dose/molecule applied. A mean steady-state flux value of $8850 \mathrm{~Bq} / \mathrm{cm}^{2} / \mathrm{h}$ was found for the control, $9906 \mathrm{~Bq} / \mathrm{cm}^{2} / \mathrm{h}$ for R115865, $8996 \mathrm{~Bq} / \mathrm{cm}^{2} / \mathrm{h}$ for $\mathrm{R} 116010$ and $9132 \mathrm{~Bq} / \mathrm{cm}^{2} / \mathrm{h}$ for R115866. As is shown in Table 3.1, the steady flux rates of the compounds are not statistically different from the control.

For the control tissues, we can consider that the Kp of the model is $1.64 \times 10^{-4} \mathrm{~cm} / \mathrm{min}$ (Table 3.2). This is in accordance with previous results obtained by others with the same 
model $\left(1.38 \times 10^{-4} \mathrm{~cm} / \mathrm{min}\right)$ as well as ex vivo in Swiss mouse epidermis $\left(1.95 \times 10^{-4}\right.$

$\mathrm{cm} / \mathrm{min}) .{ }^{11-12}$ However, this is 4 to 5 -fold higher what has been found ex vivo through human skin $\left(0.416 \times 10^{-4} \mathrm{~cm} / \mathrm{min}\right)$ and hairless mouse skin $\left(0.533 \times 10^{-4} \mathrm{~cm} / \mathrm{min}\right)$, by using a traditional diffusion protocol at $37^{\circ} \mathrm{C} .{ }^{13-15}$ The biggest limitation of any commercially available epidermal model is the weak barrier function compared to human skin. On the other hand the culture model appears to be more consistent in its permeability and responsiveness than the highly variable human skin.

\section{Morphology}

Light Microscopy Punch biopsies were taken from the non-radioactive tissues at the end of the experiment for histological examination. Light microscopical images revealed no obvious morphological changes as is demonstrated in Figure 3.4. Total thickness and topography of the different layers were unchanged.

Electron Microscopy

At the ultrastructural level, treatment resulted in the structural preservation of subcellular organelles in all epidermal layers, as shown in Figure 3.5.

\section{Cell viability (MTT assay)}

The results of the MTT assay performed at the end of the assay period (48 hours) to evaluate the potential cytotoxic effects of the different products are reported in Table 3.3. After 48 hours of contact, the mean \% of surviving cells was close to $100 \%$ for all the treatments. This indicates that, in the conditions of the assay, the tested products as well as the presence of DMSO are devoid of cytotoxic effects on the tissues. Moreover, those results demonstrate the tissues integrity during the assay period.

\section{Conclusions}

The preliminary results show that the molecules R115865, R115866 and R116010 are devoid of significant penetrating enhancing effects of tritiated water through RHE at all doses tested. On the contrary, from 2 hours of incubation onwards, the cumulated amount of tritiated water seemed to decrease with $10^{-5} \mathrm{M}$ R116010 and R115865 compared to the control (Figure 3.3.A). The permeation is probably affected by conformational changes caused by the presence of the molecules. All compounds were devoid of cytotoxic effects. Further work is necessary to evaluate the effects on other barrier characteristics of these molecules like proteins and lipids. 
A

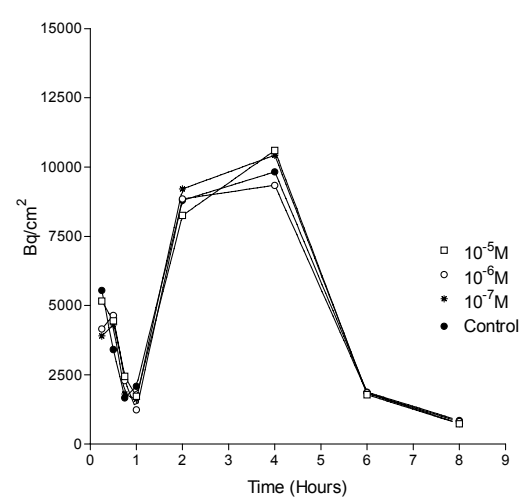

B

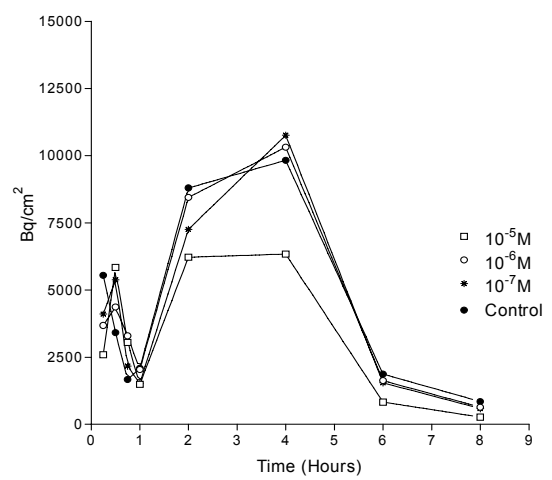

C

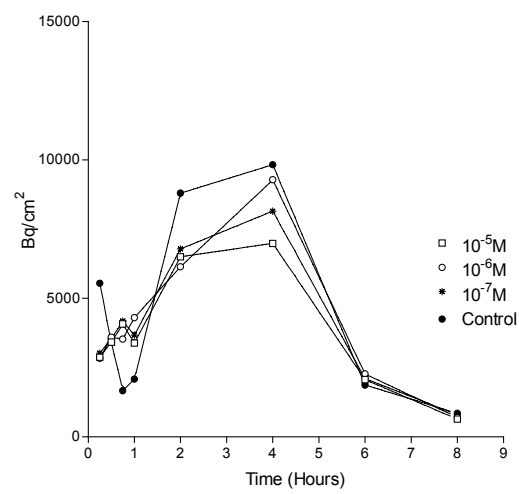

Figure 3.2 Cumulative amount of tritiated water diffused through RHE in the presence of R115866 (A), R116010 (B) and R115865 (C): $10^{-5}, 10^{-6}$ and $10^{-7} \mathrm{M}$. Each value represents the mean of 1 experiment performed in triplicate. 
A

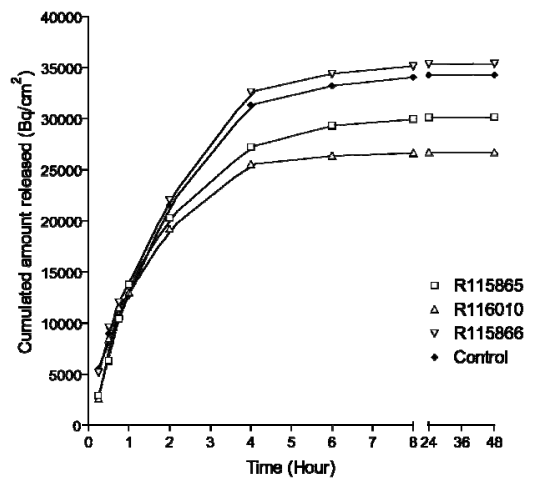

B

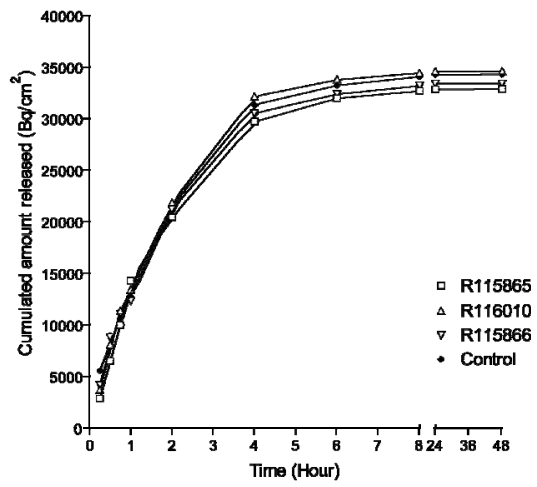

C

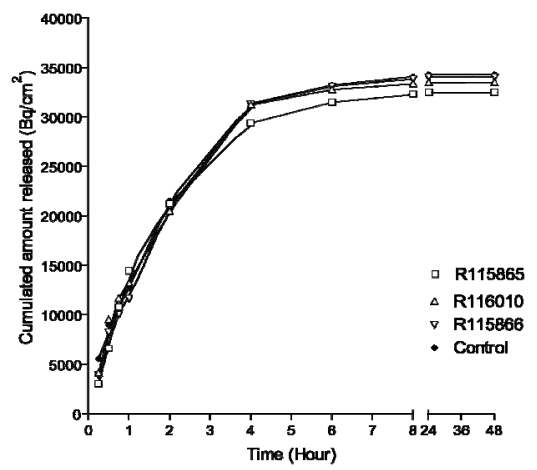

Figure 3.3 Cumulated amount of tritiated water permeated through RHE after topical application of $10^{-5}$ (A), $10^{-6}(\mathrm{~B})$ and $10^{-7} \mathrm{M}(\mathrm{C})$ of the different products: R115865, R116010 and R115866. Each data point represents the mean of 1 experiment performed in triplicate. 
Table 3.1 In vitro tritiated water flux rate at steady state after application of $10^{-5}, 10^{-6}$ and $10^{-7} \mathrm{M}$ of the different molecules. Each value represents the mean of 1 experiment performed in triplicate.

\begin{tabular}{|c|c|c|c|}
\hline \multirow[b]{2}{*}{ Concentration } & \multicolumn{3}{|c|}{ Flux rate $(\mathrm{Bq} / \mathrm{cm} 2 / \mathrm{h})$} \\
\hline & $10^{-5} \mathrm{M}$ & $10^{-6} \mathrm{M}$ & $10^{-7} \mathrm{M}$ \\
\hline R115865 & 9708 & 9841 & $10170 *$ \\
\hline$P$-value** & 0.0140 & 0.0240 & 0.0120 \\
\hline R116010 & 8563 & 9880 & 8545 \\
\hline$P$-value** & 0.0690 & 0.0100 & 0.2090 \\
\hline R115866 & 9099 & 9115 & 9183 \\
\hline$P$-value** & 0.1249 & 0.3516 & 0.5476 \\
\hline Control (0.1\% DMSO) & 8850 & 8850 & 8850 \\
\hline
\end{tabular}

Table 3.2 In vitro Tritiated water coefficient of permeation obtained after application of R115865, R115866 and $\mathrm{R} 116010$ at $10^{-5}, 10^{-6}$ and $10^{-7} \mathrm{M}$.

\begin{tabular}{|l|c|c|c|}
\hline & \multicolumn{3}{|c|}{ Kp $(\mathbf{c m} / \mathbf{m i n}) \mathbf{x 1 0}$} \\
\hline Concentration & $\mathbf{1 0}^{-\mathbf{- 5}} \mathbf{M}$ & $\mathbf{1 0}^{-\mathbf{6}} \mathbf{M}$ & $\mathbf{1 0}^{-\mathbf{7}} \mathbf{M}$ \\
\hline R115865 & 1.798 & 1.822 & 1.883 \\
\hline R116010 & 1.586 & 1.830 & 1.582 \\
\hline R115866 & 1.685 & 1.688 & 1.701 \\
\hline Control (0.1\% DMSO) & 1.639 & 1.639 & 1.639 \\
\hline
\end{tabular}

Table 3.3 Percentage of surviving cells obtained after treatment of RHE in vitro with the molecules to be tested. Each value represents the mean of 1 experiment performed in triplicate.

\begin{tabular}{|c|c|c|c|c|c|c|c|}
\hline \multirow[b]{2}{*}{ Control-Untreated } & \multicolumn{3}{|c|}{ O.D. } & \multicolumn{3}{|c|}{$\begin{array}{c}\text { Individual } \% \text { of surviving } \\
\text { cells }\end{array}$} & \multirow[t]{2}{*}{$\begin{array}{l}\text { Mean \% } \\
\text { of } \\
\text { surviving } \\
\text { cells }\end{array}$} \\
\hline & 1.372 & 1.261 & 1.441 & & & & \\
\hline Mean & 1.358 & & & & & & \\
\hline R115865 $-10^{-5}$ & 1.360 & 1.266 & 1.323 & 100 & 93.2 & 97.4 & 96.9 \\
\hline $\mathrm{R} 115865-10^{-6}$ & 1.361 & 1.194 & 1.437 & 100 & 87.9 & 106 & 98.0 \\
\hline $\mathrm{R} 115865-10^{-7}$ & 1.484 & 1.297 & 1.273 & 109 & 95.5 & 93.7 & 99.5 \\
\hline $\mathrm{R} 116010-10^{-5}$ & 1.344 & 1.409 & 1.246 & 99.0 & 104 & 91.8 & 98.2 \\
\hline $\mathrm{R} 116010-10^{-6}$ & 1.424 & 1.322 & 1.334 & 105 & 97.3 & 98.2 & 100 \\
\hline R116010-10 $0^{-7}$ & 1.496 & 1.403 & 1.392 & 110 & 103 & 103 & 105 \\
\hline $\mathrm{R} 115866-10^{-5}$ & 1.389 & 1.144 & 1.273 & 102 & 84.2 & 93.7 & 93.4 \\
\hline $\mathrm{R} 115866-10^{-6}$ & 1.362 & 1.260 & 1.318 & 100 & 92.8 & 97.1 & 96.7 \\
\hline $\mathrm{R} 115866-10^{-7}$ & 1.317 & 1.103 & 1.257 & 97.0 & 81.2 & 92.6 & 90.3 \\
\hline Control - $0.1 \%$ DMSO & 1.195 & 1.252 & 1.107 & 88.0 & 92.2 & 81.5 & 87.2 \\
\hline
\end{tabular}



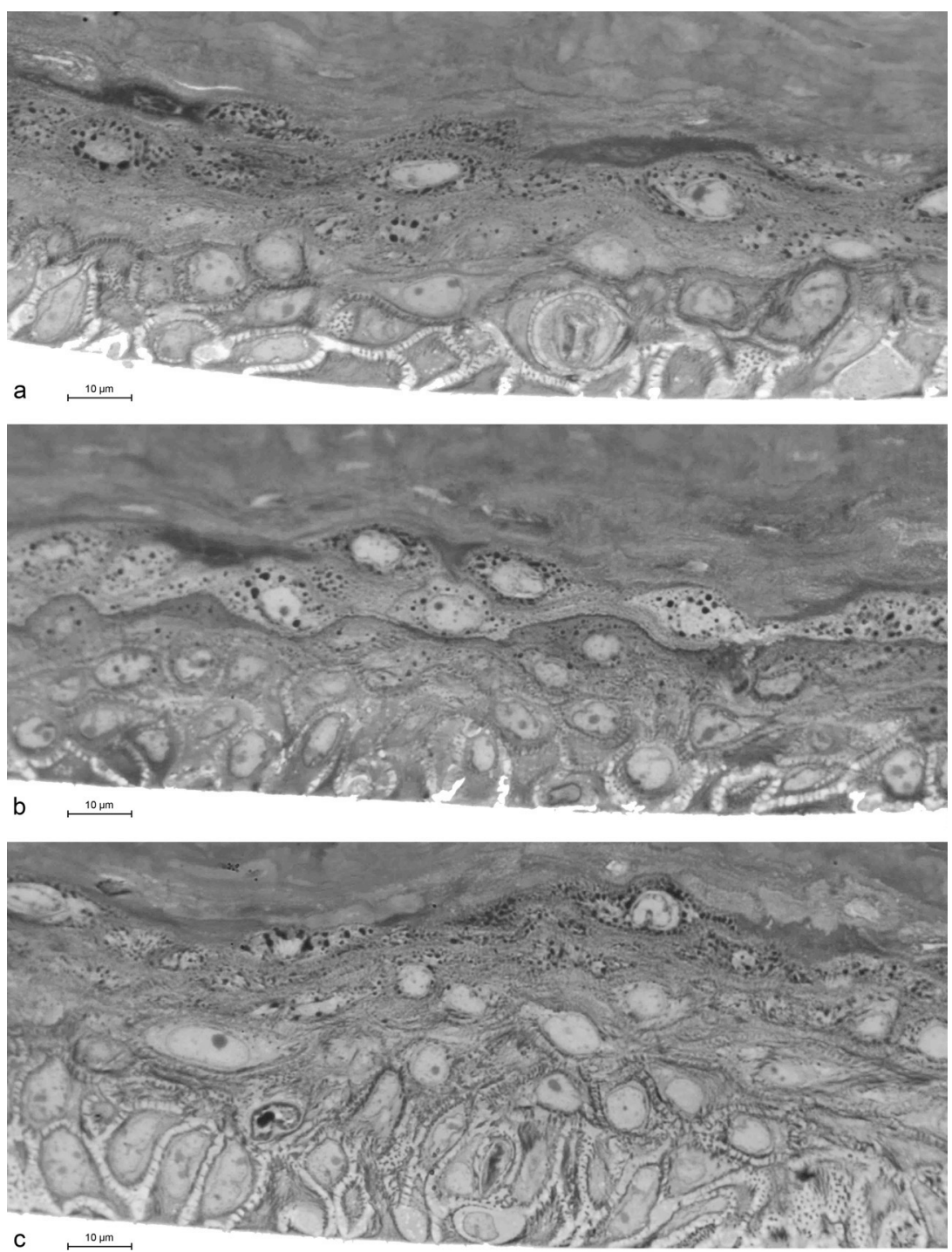

Figure 3.4 Light microscopical images of RHE treated with (a) Control (b) R115866, $10^{-5} \mathrm{M}$ and (c) R116010, $10^{-5} \mathrm{M}$. See page 229 for colour figure. 


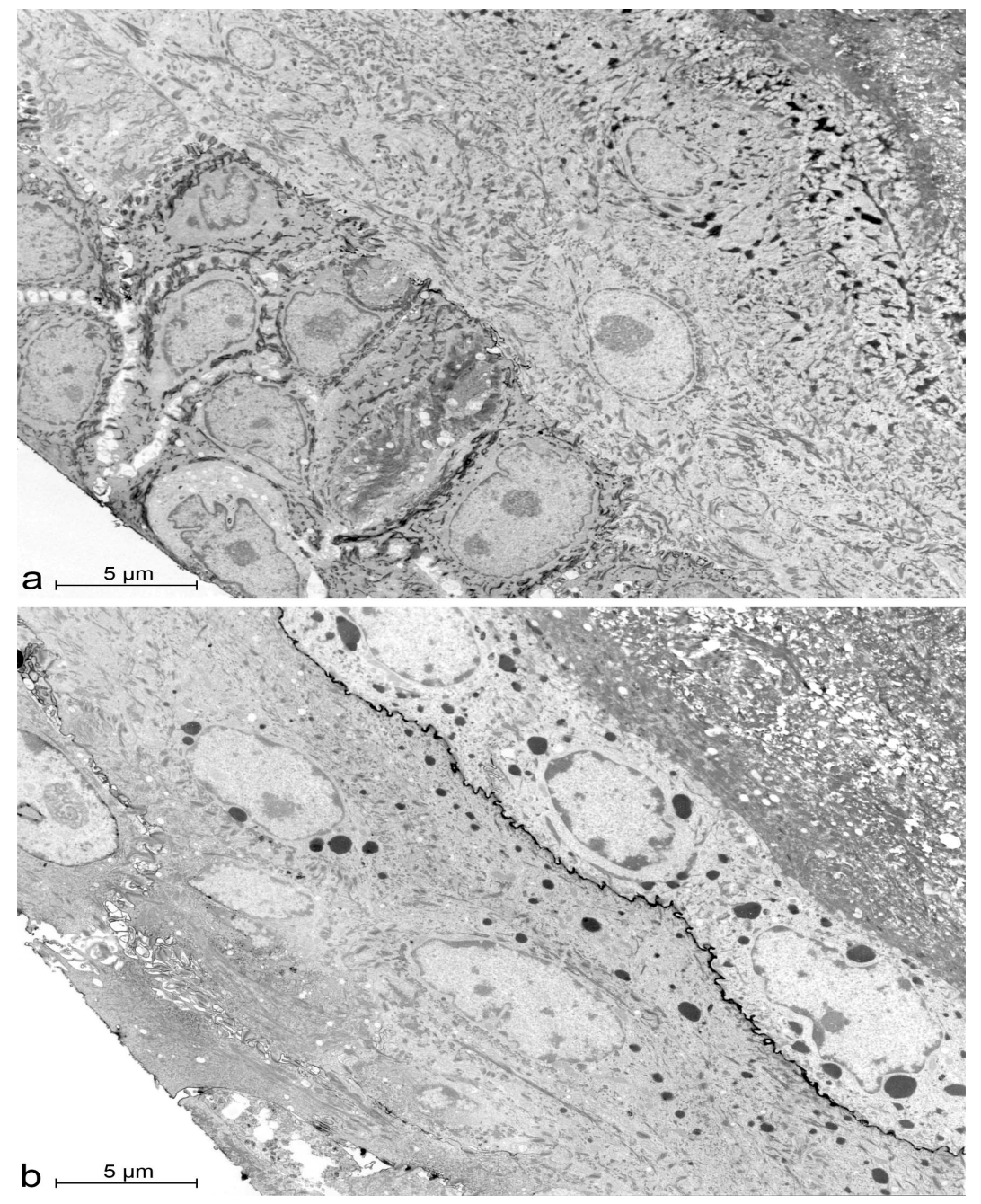

Figure 3.5 Electron microscopical images of RHE treated with (a) Control (b) R115866, 10 $0^{-5} \mathrm{M}$. 


\section{References}

1. Stoppie P, Borgers M, Borghgraef P, et al. R115866 Inhibits all-trans-retinoic acid metabolism and exerts retinoidal effects in rodents. J Pharmacol Exp Ther 2000; 293: 304-12.

2. Stoppie P, Van Wauwe J, Wouters L, et al. Rambazole ${ }^{\mathrm{TM}}$, a potent inhibitor of all-trans-retinoic acid metabolism, applied topically to mouse tail skin exerts retinoid mimetic activity. J Invest Dermatol 2004; 122: $\mathrm{A} 70(\# 420)$

3. Rambazole ${ }^{\mathrm{TM}}$ (R115866) Investigational Drug Brochure, version 3.0., Oct. 2005. Data on file at Barrier Therapeutics.

4. Verfaille CJ, Thissen CACB, Bovenschen JH, et al. Oral R115866 in the treatment of moderate to severe plaque type psoriasis. JEADV 2007; in press.

5. Hachem JP, Verfaille CJ, Coel M, et al. Oral R115866 in the treatment of facial acne vulgaris: a phase 2a trial. EADV, Rhodos, abstract \# PO01.65.

6. Van Heusden J, Van Ginckel R, Bruwiere H, et al. Inhibition of all-TRANS-retinoic acid metabolism by R116010 induces antitumour activity. Br J Cancer 2002; 86: 605-11.

7. Rosdy M, Bertino B, Butet V, et al. Retinoic Acid inhibits epidermal differentiation when applied topically on the stratum corneum of epidermis formed in vitro by human keratinocytes grown on defined medium. In vitro Toxicol 1997; 10: 39-47.

8. Netzlaf F, Lehr C-M, Wertz PW, et al. The human epidermis models EpiSkin ${ }^{\circledR}$, SkinEthic $^{\circledR}$ and Epiderm $^{\circledR}$ : An evaluation of morphology and their suitability for testing phototoxicity, irritancy, corrosivity, and substance transport. Eur J Pharm Biopharm 2005; 60: 167-78.

9. Tornier C, Rosdy M, Maibach HI. In vitro skin irritation testing on reconstituted human epidermis: Reproducibility for 50 chemicals tested with two protocols. Toxicology in Vitro 2006; 20: 401-16.

10. Rosdy M, Fartasch M, Darmon M. Normal permeability barrier to tritiated water in reconstituted human epidermis. Perspectives in Percutaneous Penetration Proceedings 1997; 5B: 144-5.

11. Flynn GL. Physiochemical determinants of skin absorption. In: Principles of route-to-route extrapolation for risk assessment (Gerity TR, Henry CJ, eds). Amsterdam: Elsevier Science Publishing Co Inc.; 1990: 93-127.

12. Rohr UD, Altenburger R, Kissel T. Kinetics of the transdermalreservoir membrane system delivering $\beta$-Estradiol: In vitro/in vivo correlation. Pharm Res 1998; 15: 875-84.

13. Liu P, Higuchi WI, Ghanem AH, et al. Transport of beta-estradiol in freshly excised human skin in vitro: diffusion and metabolism in each skin layer. Pharm Res 1994; 11:1777-84.

14. Liu P, Higuchi WI, Song WQ, et al. Quantitative evaluation of ethanol effects on diffusion and metabolism of $\beta$-estradiol in hairless mouse skin. Pharm Res 1991; 8: 865-72.

15. Liu P, Higuchi WI, Song WQ, et al. Quantitation of simultaneous diffusion and metabolism of $\beta$ estradiol in hairless mouse skin: Enzyme distribution and intrinsic diffusion/metabolism parameters. Int $J$ Pharm 1990; 64: 7-25. 



\section{In vivo pharmacology of liarozole}

Based on:

Verfaille $C J^{1,3}$, Stoppie $P^{2}$ and Borgers $M^{2,3}$. In vivo pharmacology of liarozole.

Submitted for publication

${ }^{1}$ Departments of Dermatology and Molecular Cell Biology, GROW, Maastricht University,

The Netherlands.

${ }^{2}$ Department of Molecular Cell Biology, GROW, Maastricht University, The Netherlands.

${ }^{3}$ Barrier Therapeutics nv, Geel, Belgium. 


\begin{abstract}
Liarozole, an imidazole derivative developed in the late eighties by the Janssen Research Foundation in Belgium, represents a class of compounds coined Retinoic Acid Metabolism Blocking Agents. Other members of that class are ketoconazole and R115866 (Rambazole ${ }^{\mathrm{TM}}$ ).

Extensive in vitro and in vivo pharmacological testing identified liarozole as an inhibitor of several mammalian cytochrome P450 isozymes among which the ones involved in the oxidative metabolism of all-trans retinoic acid. In vivo, this pharmacological activity results in increased plasma and tissue levels of endogenous retinoic acid and consequently offers a potential therapeutic benefit in skin disorders of keratinization like ichthyosis, psoriasis and acne. The objective of this paper is to provide an overview of the non-clinical and clinical in vivo pharmacology of liarozole related to dermatology.
\end{abstract}




\section{Introduction}

All-trans retinoic acid (RA), a metabolic derivative of vitamin A, is one of the principal endogenous compounds that control growth and differentiation of epithelial tissues. ${ }^{1,2}$ Retinoic acid (RA) exerts its activity through binding to specific nuclear retinoic acid receptors (RARs and RXRs), which act as ligand-inducible transcriptional factors. On interaction with RA, these RARs bind to specific DNA sequences and either repress or activate the transcription of adjacent target genes. ${ }^{3,4}$ Plasma and tissue levels of RA are kept under tight homeostatic control. One of the mechanisms contributing to this homeostatic control is the metabolic inactivation of RA through oxidative metabolism, which is initiated by the 4-hydroxylation of RA to form 4-hydroxy-RA and 4-keto-RA (=4-oxo-RA). ${ }^{5}$ Both the 4-hydroxylation of RA and the further oxidation of 4-keto-RA to more polar metabolites are mediated by microsomal cytochrome P450 (CYP) isozymes.

Ketoconazole, at first identified as an imidazole anti-fungal, was found to inhibit in vitro the catabolism of RA by established cell lines ${ }^{6,7}$ and microsomal preparations. ${ }^{8,9,10}$ Accordingly, oral ketoconazole was shown in vivo to delay the metabolism of exogenously administered $\mathrm{RA}^{11}$, to enhance plasma levels of endogenous $\mathrm{RA}^{11}$ and to prevent keratinization in the animal model of oestrogen-induced vaginal keratinization in ovariectomized rats (non published observations). These observations lead to the initiation of an extended project on the synthesis and screening of Retinoic Acid Metabolism Blocking Agents (RAMBAs). As a result liarozole, a novel imidazole derivative, was identified as a valuable candidate.

Liarozole, which refers chemically to $( \pm)$-5-[(3-chlorophenyl)( $1 H$-imidazol-1yl)methyl $1 H$-benzimidazole, is chemically related to the anti-fungal imidazole, ketoconazole. Originally developed as an inhibitor of testosterone biosynthesis, subsequent testing showed it to inhibit both androgen-dependent and -independent experimental tumors. Clinical studies also revealed anti-tumor activity and a surprising retinoid-like cutaneous secondary effect associated with elevated levels of plasma RA. The objective of this paper is to provide an overview of the non-clinical and clinical in vivo pharmacology of liarozole related to dermatology. 


\section{RA-related pharmacodynamic effects}

\section{Non Clinical Pharmacology}

Liarozole was found to inhibit in vitro the metabolism of RA by established cell lines or by microsomal preparations. To assess the effects of liarozole on the in vivo RA metabolism, the following approaches were taken.

\section{Effects of liarozole on plasma and tissue RA concentrations in rats}

In rats ${ }^{11}$, the effect of orally administered liarozole was examined on plasma elimination of exogenously administered RA and on plasma levels of this endogenous retinoid. It was shown that pretreatment $(-1 \mathrm{~h})$ with $40 \mathrm{mg} / \mathrm{kg}$ liarozole decreased the plasma clearance of i.v. injected RA $(0.1 \mathrm{mg} / \mathrm{kg})$ from $35 \mathrm{ml} / \mathrm{min} / \mathrm{kg}$ in vehicle-pretreated rats to 13 $\mathrm{ml} / \mathrm{min} / \mathrm{kg}$ in liarozole-pretreated rats whilst there was no effect on the distribution volume of the retinoid. Residual plasma concentrations of RA, measured 2 hours after its i.v. injection, were increased from undetectable levels $(<1 \mathrm{ng} / \mathrm{ml})$ in vehiclepretreated animals to $5.2,10.1,17.6$ and $22.7 \mathrm{ng} / \mathrm{ml}$ after pre-treatment with $5,10,20$ and $40 \mathrm{mg} / \mathrm{kg}$ liarozole, respectively.

Moreover, it was shown that liarozole $(40 \mathrm{mg} / \mathrm{kg},-1 \mathrm{~h})$ was also able to increase the biological half-life of exogenously injected 4-keto-RA $(0.1 \mathrm{mg} / \mathrm{kg})$ in rats. ${ }^{13}$ The drug nearly doubled the plasma half-life from 7 to $12 \mathrm{~min}$ while having no effect on its distribution volume.

Oral administration of liarozole to rats, not only delayed the plasma elimination rate of intrajugulary injected RA or 4-keto-RA, but also enhanced plasma levels of endogenous RA confirming the in vivo suppressive activity of liarozole on the biodegradation of endogenous RA. After a single oral administration of liarozole $(40 \mathrm{mg} / \mathrm{kg},-2 \mathrm{~h})$ to rats, it was shown that the plasma concentrations of endogenous RA were enhanced. To determine the duration of action of this RA enhancement, liarozole $(40 \mathrm{mg} / \mathrm{kg})$ was administered to rats 1 to 6 hours prior to plasma recovery. ${ }^{11}$ The peak level of endogenous RA in plasma occurred at 3 hours after drug treatment. To assess the potency with which liarozole affects the in vivo biodegradation of the retinoid, rats were treated orally with various doses of liarozole $(0.3-1.25-5-20 \mathrm{mg} / \mathrm{kg})$ or vehicle. ${ }^{12}$ The RA plasma concentration measured 3 hours after drug intake amounted to mean RA levels of $1.9 \pm 0.1$ and $1.4 \pm 0.1 \mathrm{ng} / \mathrm{ml}$ plasma for liarozole doses of $20 \mathrm{mg} / \mathrm{kg}$ and $5 \mathrm{mg} / \mathrm{kg}$, respectively. The lower doses tested ( 1.25 and $0.3 \mathrm{mg} / \mathrm{kg}$ ) were inactive. 
In addition, single and repeated oral dosing of liarozole to rats enhanced also endogenous RA levels in various tissues (unpublished data). In a first study rats were treated with a single oral dose of liarozole (40 or $10 \mathrm{mg} / \mathrm{kg}$ ) or vehicle. At various time intervals after treatment $(2,4,6$ and $8 \mathrm{~h})$, the RA content was assessed in plasma, skin, fat (epididymal and perinephric), kidney, lung, liver and testis. Liarozole (40 or $10 \mathrm{mg} / \mathrm{kg}$ ) was shown to induce tissue- and dose-dependent transient increases of endogenous RA which were mostly pronounced and long-lasting in skin and testis. Eight hours after treatment, significantly elevated levels of endogenous RA compared to the respective vehicle value could still be detected in extracts from skin and testis. Of note, these two tissues also contain higher concentrations of cellular RA binding proteins (CRABPs). ${ }^{14}$ Strikingly, no effect was seen on endogenous RA concentrations in the liver at any of the time intervals tested.

The findings of a second study in rats bearing androgen independent PIF-1 Dunning R3327 prostate carcinomas and treated with a single oral dose of vehicle or liarozole (20 $\mathrm{mg} / \mathrm{kg}$ ) corroborated previous observations. Two, 4, 8 and 12 hours after treatment, RA concentrations were determined in plasma, skin, testis and tumor. Liarozole elicited a sustained increase of RA levels in skin and testis. Mean levels of RA were significantly enhanced in plasma at 2 and 4 hours and in skin and tumor at 2, 4 and 8 hours after drug administration. In testis, administration of liarozole resulted in statistically significant higher RA levels compared to the vehicle until 12 hours following drug administration (Table 4.1).

Finally, subchronic oral administration of liarozole $(40 \mathrm{mg} / \mathrm{kg})$ or vehicle to rats once daily for 5 consecutive days also resulted into a protracted activity in skin and testis as seen in the single dose studies. RA concentrations were determined in plasma, skin, perinephric fat and testis at 2, 4, 6 and 8 hours after the last drug administration. At the 2 and the 4 hour time-point, significantly enhanced RA values were measured in every organ tested in the liarozole group when compared to the vehicle group. Significantly elevated levels of RA compared to vehicle still persisted in skin and testis at 6 and 8 hours following the last drug administration. These data indicate that repeated liarozole treatment of rats does not jeopardize the drug's ability to augment endogenous plasma and tissue levels of RA. 
Table 4.1 Effect of single oral administration of vehicle or liarozole $(20 \mathrm{mg} / \mathrm{kg})$ on endogenous RA levels in plasma, skin, testis and tumor.

\begin{tabular}{|c|c|c|c|}
\hline \multirow[t]{2}{*}{ Tissue } & \multirow{2}{*}{$\begin{array}{l}\text { Time after last } \\
\text { treatment } \\
\text { (hours) }\end{array}$} & \multicolumn{2}{|c|}{$\begin{array}{c}\text { RA concentration }{ }^{\mathrm{a}} \\
\text { [ng (S.E.) per ml plasma or g of tissue] }\end{array}$} \\
\hline & & $\begin{array}{c}\text { Vehicle } \\
(20 \% \text { PEG } 200 \text { in water })\end{array}$ & $\begin{array}{l}\text { Liarozole } \\
(20 \mathrm{mg} / \mathrm{kg})\end{array}$ \\
\hline \multirow[t]{4}{*}{ Plasma } & 2 & $0.6(0.1)$ & $1.9(0.1)$ \\
\hline & 4 & $0.6(0.0)$ & $2.0(0.1)$ \\
\hline & 8 & $0.7(0.1)$ & $0.6(0.1)$ \\
\hline & 12 & $0.8(0.1)$ & $0.4(0.0)$ \\
\hline \multirow[t]{4}{*}{ Skin } & 2 & $1.7(0.2)$ & $6.2(0.6)$ \\
\hline & 4 & $0.9(0.2)$ & $5.5(0.4)$ \\
\hline & 8 & $2.0(0.3)$ & $4.3(0.5)$ \\
\hline & 12 & $1.7(0.2)$ & $1.9(0.2)$ \\
\hline \multirow[t]{4}{*}{ Testis } & 2 & $3.0(0.1)$ & $5.5(0.2)$ \\
\hline & 4 & $3.0(0.5)$ & $6.8(0.3)$ \\
\hline & 8 & $3.8(0.1)$ & $5.5(0.1)$ \\
\hline & 12 & $3.3(0.1)$ & $5.1(0.2)$ \\
\hline \multirow[t]{4}{*}{ Tumor } & 2 & $7.1(0.9)$ & $23.2(2.9)$ \\
\hline & 4 & $9.1(0.8)$ & $21.6(2.5)$ \\
\hline & 8 & $8.3(1.0)$ & $18.0(1.6)$ \\
\hline & 12 & $7.3(0.6)$ & $9.0(0.7)$ \\
\hline
\end{tabular}

Suppression of estrogen-induced vaginal keratinization in ovariectomized rats by liarozole

RA was shown to suppress the keratinization process in the stratified squamous epithelium of the rat vagina. The rat vaginal epithelium assay has been recommended as an in vivo screening test for evaluating the potential biological activity of natural and synthetic retinoids. ${ }^{15}$ As aforementioned liarozole treatment in vivo resulted in higher and more sustained plasma and tissue levels of endogenous RA compared to placebo treatment. Accordingly such compound should be capable of generating RA-mimetic biological effects. Liarozole and RA, therefore, were compared for their effects on vaginal keratinization. ${ }^{12}$ Like RA, liarozole dose-dependently reversed the vaginal keratinization induced by estrogenic stimulation in ovariectomized rats. Both compounds administered orally, once daily for 3 consecutive days, expressed equipotent antikeratinizing activity; they significantly reversed vaginal keratinization at a same dose of $5 \mathrm{mg} / \mathrm{kg}$ (Table 4.2). 
Table 4.2 Inhibitory activity of liarozole and RA on vaginal keratinization induced in ovariectomized rats by estrogen treatment. Each drug was administered p.o. for 3 days to oestradiol undecylate-treated ovariectomized rats. Animals were sacrificed 1 day after the last drug administration. ${ }^{*}$ The degree of vaginal keratinization was scored by light microscopy according to the following arbitrary scale: $++=$ presence of keratinized squamae covering the entire vaginal epithelium; $+=$ presence of keratinized squamae along part of the vaginal epithelium; $0=$ absence of keratinized squamae above the vaginal epithelium. $* *=p<0.05$ vs. solvent.

\begin{tabular}{|l|c|c|c|c|c|}
\hline Treatment & $\begin{array}{c}\text { Dose } \mathbf{( m g} / \mathbf{k g}) \\
\text { \# of Animals } \\
\text { Tested }\end{array}$ & \multicolumn{3}{|c|}{ \# of Animals with Keratinization Score } \\
\hline & & & 0 & + & ++ \\
\hline Vehicle & - & 15 & 0 & 0 & 15 \\
\hline Liarozole & 20 & 6 & 6 & 0 & $0^{* *}$ \\
\hline & 5 & 8 & 4 & 2 & $2^{* *}$ \\
\hline RA & 1.25 & 6 & 0 & 1 & 5 \\
\hline & 0.3 & 6 & 0 & 0 & 6 \\
\hline & 20 & 6 & 6 & 0 & $0^{* *}$ \\
\hline & 5 & 8 & 4 & 3 & $1^{*}$ \\
\hline
\end{tabular}

Since cytokeratin expression is a prominent marker of epithelial differentiation, the effects of liarozole and RA treatment on the production of keratin proteins by the vaginal epithelium were also examined. ${ }^{12}$ Liarozole and RA similarly affected the production of cytokeratins: both compounds turned off the expression of high molecular weight (57-60 kDa) keratin proteins and turned on the expression of the 45 to $47 \mathrm{kDa}$ keratin proteins.

Furthermore, antikeratinizing doses of liarozole were shown to coincide with a doubling of the endogenous RA concentration in the vaginal epithelium, leaving open the possibility of a causal relationship between the drug-induced morphologic changes and local enhancement of retinoid levels.

\section{Induction of pinnal epidermal hyperplasia in hairless mice by liarozole}

Induction of epidermal hyperplasia is one of the few characteristic cutaneous activities induced by retinoids in vivo. ${ }^{16}$ Liarozole, in comparison to RA, was tested for its ability to induce epidermal hyperplasia in hairless mice (unpublished results).

Repeated oral dosing (once daily for 14 consecutive days) of liarozole (20 mg/ $\mathrm{kg}$ ) or RA $(10 \mathrm{mg} / \mathrm{kg})$ to hairless mice similarly affected growth and differentiation of ear epidermis. Liarozole shared with RA the ability to induce epidermal hyperplasia and to affect the expression of cytokeratins in pinnal epidermis (Figure 4.1). 


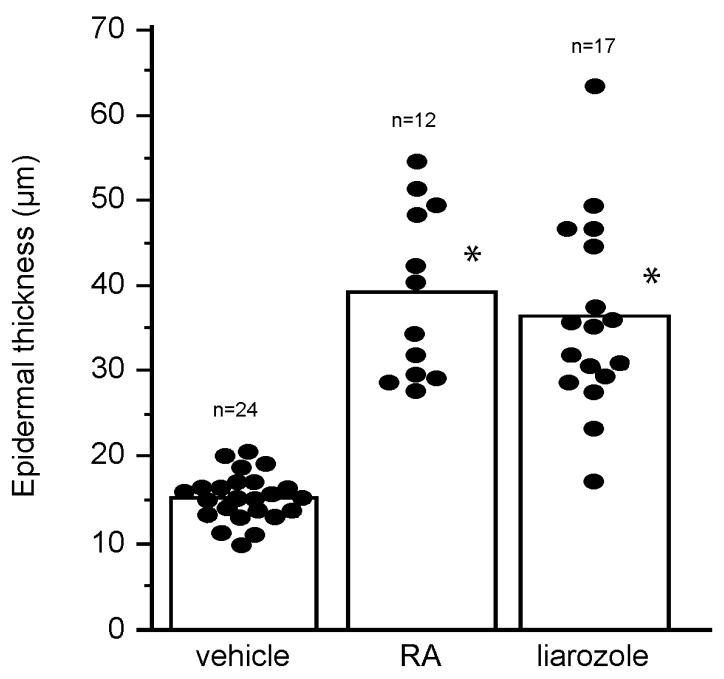

Figure 4.1 Thickness of the pinnal epidermis from hairless mice chronically treated with vehicle (PEG 200), RA (10 mg/kg), or liarozole $(20 \mathrm{mg} / \mathrm{kg})$ as measured by computerized image analysis. Individual values are shown as closed circles, mean values as open columns. $\mathrm{N}=$ number of treated animals, ${ }^{*} \mathrm{p} \leq 0.0001$ versus vehicle.

In a follow-up dose-ranging study $(5,10,20$ and $40 \mathrm{mg} / \mathrm{kg}$ ), liarozole elicited only a statistically significant hyperplastic response at $20 \mathrm{mg} / \mathrm{kg}$, whilst a species specific lethality was observed at $40 \mathrm{mg} / \mathrm{kg} .{ }^{17}$

\section{Conversion of aberrant keratinization in tail epidermis of hairless mice by liarozole}

Another striking cutaneous feature of retinoids in vivo is the formation of a granular layer and the transformation of the parakeratotic type of keratinization to the orthokeratotic type in the scale regions of murine/rat tail epidermis. ${ }^{17}$ Results of a dose-ranging study $(5,10,20$ and $40 \mathrm{mg} / \mathrm{kg})$ in hairless mice, however, were non-conclusive. At 5, 10 and $20 \mathrm{mg} / \mathrm{kg}$ no effects were observed, whilst at $40 \mathrm{mg} / \mathrm{kg}$ the limited number of surviving animals ( 3 out of 8 animals) hampered the interpretation of the results (unpublished results).

\section{Liarozole and irradiated skin}

Potential interactions between ionizing irradiation and liarozole treatment were evaluated in non-tumor bearing hairless mice (unpublished results). Oral liarozole (20 and 40 
$\mathrm{mg} / \mathrm{kg}$ ) protected the skin from the toxic effects (moist desquamation, edema, paw swelling) induced by ionizing irradiation (fractionated regimen; 33x3Gy).

Inhibition of phorbol ester-induced ornithine decarboxylase and tumor promotion in mouse skin by liarozole

The chemoprotective effects of RA in cancer have been extensively investigated in the two-stage, initiation-promotion model of carcinogenesis in mouse skin. ${ }^{18,19}$ Retinoids act to suppress the formation of skin papillomas in this model by interfering with the promotion phase of mouse skin carcinogenesis. The acute induction of the enzyme ornithine decarboxylase (ODC) in mouse skin by various phorbol esters is highly correlated with their tumor-promoting activity.

When administered orally to mice, liarozole $(10-80 \mathrm{mg} / \mathrm{kg})$ produced a dose-related inhibition of ODC induction in dorsal skin by the tumor promoting phorbol ester 12-Otetradecanoyl-phorbol-13-acetate (TPA). The observed potency of oral liarozole compared favorably to oral RA, which was active at 1 to $10 \mathrm{mg} / \mathrm{kg}$.

Similarly, oral pre-treatment of mice with 20 to $80 \mathrm{mg} / \mathrm{kg}$ liarozole produced a doserelated reduction in tumor incidence and tumor burden (i.e. the number of papillomas per mouse.) as was seen after topical pre-treatment of mice with $5 \mu \mathrm{g}$ RA during 17 weeks of tumor promotion. ${ }^{20}$

\section{Conclusion}

The in vivo models reveal that liarozole and RA elicit similar morphologic and biochemical effects on the proliferation/ differentiation processes of diverse types of epithelial tissues. These data support the hypothesis that liarozole, an inhibitor of the CYP-dependent metabolism of RA, mimics the action of RA.

\section{Clinical Pharmacology}

\section{Volunteers-Single Dose Studies}

During single dosing studies with oral liarozole in male volunteers, it was shown that the plasma RA curve after placebo intake shows daily fluctuations, suggesting the presence of a certain biological variation in the human plasma RA level. However, this pattern of daily fluctuation was not discerned in all subjects. Each individual curve was characterized by a plasma RA peak level 1 to 4 hours after placebo intake.

In one study, it was shown that, after intake of escalating single doses of liarozole (37.575-150-300 mg) or placebo, there was a dose-dependent increase in plasma RA levels, 
indicating that liarozole slows down the catabolism of RA. All liarozole doses increased plasma RA concentrations for up to 8 hours after administration, with peak increases at 4 to 6 hours after drug intake. The mean area under the curve (AUC) $0-8 \mathrm{~h}$ statistically significantly increased from $15.7 \mathrm{ng} .8 \mathrm{~h} / \mathrm{ml}$ for placebo to $22.5 \mathrm{ng} . \mathrm{h} / \mathrm{ml}$ for liarozole 150 $\mathrm{mg}(\mathrm{p}=0.03, \mathrm{n}=6)$ and $23.0 \mathrm{ng} . \mathrm{h} / \mathrm{ml}$ for liarozole $300 \mathrm{mg}(\mathrm{p}=0.04, \mathrm{n}=6)$. The data show that while there was a naturally occurring increase in the mean level of RA of $39 \%$ in placebo-treated subjects after 4 hours, RA levels increased more than $100 \%$ for both liarozole $150 \mathrm{mg}$ and $300 \mathrm{mg}$.

In another study with liarozole, where the dose-proportionality of the pharmacokinetics of single oral doses of liarozole (75-150-300 mg) was evaluated together with the effects on RA, it was found that the systemic exposure to liarozole increased more than direct proportionality would predict. The median $\mathrm{T}_{\max }$ was 1.0 hour for all treatments and the $\mathrm{C}_{\max }$ was $0.83,1.93$ and $4.28 \mu \mathrm{g} / \mathrm{ml}$ for respectively 75,150 and $300 \mathrm{mg}$ of liarozole. The increase in RA plasma levels reached its maximum at four hours after administration with all liarozole doses, with mean peak increases of $71 \%, 66 \%$ and $105 \%$ for the 75, 150 and $300 \mathrm{mg}$ dose respectively. Liarozole increased the $\mathrm{AUC}_{0-12 \mathrm{~h}}$ of plasma RA by $23-33 \%$ at all doses in comparison to placebo, but a clear dose-dependent effect was not detected.

A graphical display of the relationship between plasma concentrations of liarozole and changes in RA levels (=RA level after liarozole minus RA level after placebo) reveals a hysteresis loop when the time points are joined in time sequence (Figure 4.2). This indicates that the time to reach the maximal plasma concentration of liarozole is not equal to the time to reach the maximal RA level meaning that a time-delayed relationship exists between plasma concentrations of liarozole and RA.

\section{Volunteers-Multiple Dose Studies}

In a multiple dose study with 12 healthy male volunteers treated orally with $150 \mathrm{mg}$ liarozole b.i.d. for 10 days, a similar increase in mean RA levels versus baseline could be observed 3 hours after drug intake on day 10 as on day 1 . No changes in RA were seen in the placebo treated group. This provides evidence of the sustained effect of liarozole on the RA levels. Importantly, no changes were observed for retinol; thus no effect on vision should be expected. 


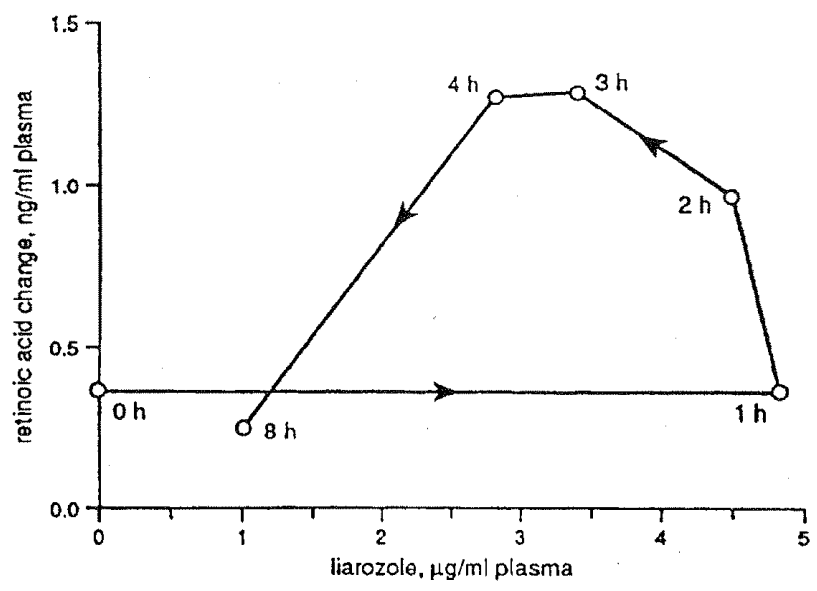

Figure 4.2 Hysteresis loop for the mean change in retinoic acid level (=RA level after liarozole minus RA level after placebo) against the plasma concentrations of liarozole

\section{Volunteers-Effect of topical liarozole}

Kang et al. investigated the effects of topical liarozole (3\%) on the RA 4-hydroxylase activity of human epidermis of normal healthy adults and its ability to modify in vivo human skin responses to RA $(0.001 \%)$ and all-trans-retinol (ROL, $0.025 \%){ }^{21}$ In this study, evidence was provided that liarozole inhibits human skin RA 4-hydroxylase activity and that this inhibition is associated with increased epidermal RA levels in vivo. Moreover it was shown that although liarozole, RA and ROL, when applied separately on human skin at the above mentioned low doses, were not associated with significant erythema or epidermal hyperplasia, concomitant application of liarozole and RA or ROL amplified human skin responses to the retinoid (erythema and hyperplasia with RA; no erythema but hyperplasia with ROL) in a manner characteristic of the retinoid at a higher dose. 


\section{Non RA-related Pharmacodynamic Effects on Cytochrome P450- dependent Steroid Metabolism}

\section{Non clinical Pharmacology}

In mammals, CYP dependent enzymes catalyze numerous hydroxylations involving endogenous compounds, particularly in steroid biosynthesis. Therefore, the selectivity profile of liarozole for the CYP dependent enzymes involved in ovarian, testicular and adrenal functions, as well as those involved in vitamin $\mathrm{D}_{3}$ metabolism, was extensively evaluated in vitro as well as in vivo.

Aromatase (CYP19), 17-hydroxylase/17, 20-lyase (CYP17A) and 11-hydroxylase (CYP11B) were found in vitro to be main target enzymes for liarozole. Animal studies in rats and dogs corroborated that liarozole inhibits both estrogen and testicular androgen biosynthesis in vivo. Daily oral administration of liarozole ( 5 to $80 \mathrm{mg} / \mathrm{kg} / \mathrm{day}$ ) for 3 months to female rats decreased serum estradiol levels, whereas serum progesterone, androstenedione and luteinizing hormone (LH) concentrations increased. Similar findings were observed in female dogs orally dosed for 3 months with liarozole ( 2.5 to $5 \mathrm{mg} / \mathrm{kg}$, b.i.d.). All levels returned to normal after a 2 month recovery period. Comparing rats and dogs, the dog seems to be the most sensitive species to inhibition of androgen biosynthesis (17-hydroxylase/17, 20-lyase complex) by liarozole, since sustained castration levels of plasma/serum testosterone were observed after single $(2.5 \mathrm{mg} / \mathrm{kg})$ and chronic $(2.5 \mathrm{mg} / \mathrm{kg}$, b.i.d., up to 6 months) administration of liarozole. In contrast, peripheral androgen levels in male rats were much less affected after a single oral administration of liarozole ( 1 to $20 \mathrm{mg} / \mathrm{kg}$ ) and were not modified by chronic treatment (10 to $160 \mathrm{mg} / \mathrm{kg} / \mathrm{day}$, up to 6 months). The lack of change in gonadal steroids in chronically treated rats probably results from a pituitary compensation mechanism as evidenced by the rise in gonadotropin levels (follicle-stimulating hormone (FSH) and LH). Similar findings were observed in 3-month oral treatment studies of both rat and dog. Furthermore, hormone levels returned to normal after a 2-month recovery period. The partial inhibition by liarozole of the 11ß-hydroxylase (CYP11B) was responsible for the blunting of corticosterone, cortisol and aldosterone response to adrenocorticotropic hormone (ACTH) challenge in rats and dogs and for the reduction of the serum levels of these steroids observed in the 6-month chronic oral toxicity studies of both species. $^{22}$

Liarozole affects in vitro the final step in the activation of vitamin $\mathrm{D}_{3}$ as well as the catabolism of vitamin $\mathrm{D}_{3}$ (unpublished data). However, the outcome and the physiological significance of the in vitro interactions of liarozole on vitamin D metabolism are still 
not well clarified. No symptoms of hypervitaminosis D have been observed thus far in toxicological and clinical studies.

\section{Clinical Pharmacology}

\section{Effect on Androgens}

In a single dose study with male volunteers treated orally with 75, 150 and $300 \mathrm{mg}$ liarozole, plasma testosterone concentrations were reduced compared to placebo in a dose-dependent manner for up to 12 hours after drug intake. Lowest testosterone levels were reached 4 to 6 hours after drug intake with mean peak reductions of $41 \%, 61 \%$ and $82 \%$ for the 75,150 and $300 \mathrm{mg}$ doses, respectively.

In a dose-escalating study, male volunteers took a single oral dose of $40,80,160$, or 320 $\mathrm{mg}$ of liarozole. Again, a dose-dependent decrease in testosterone levels was observed: 4 and 8 hours after intake, the testosterone levels were reduced by 35-30, 58-55, 71-69 and $81-85 \%$ respectively. Concomitantly an expected rise of the precursors $17 \alpha-$ hydroxyprogesterone and progesterone and also of LH was observed.

When administering $300 \mathrm{mg}$ liarozole b.i.d. for 3 days to healthy male volunteers, testosterone levels dropped significantly within 4-8 hours after each liarozole intake. The trough testosterone concentrations, \pm 12 hours after liarozole treatment, showed a progressive escape, demonstrated by rising testosterone levels. This escape was linked to a marked increase in LH levels. On the fourth day, 24 hours after the last intake, the plasma testosterone levels normalized and LH concentrations decreased. A similar pattern was observed during a 10 days administration of liarozole $150 \mathrm{mg}$ b.i.d. to 12 healthy male volunteers.

Adrenal androgens (DHEA and androstenedione) were assayed in healthy male volunteers after single or multiple dose liarozole. No detectable changes in the adrenal androgens were observed.

\section{Effect on Progesterone, Estrogens and Gonadotropins (LH and FSH)}

Due to the inhibition of the testicular 17-hydroxylase; 17,20-lyase complex, a rise of the precursors $17 \alpha-\mathrm{OH}$-progesterone (up to $140 \%$ ) and progesterone (up to $540 \%$ ) was observed after single dose administration of liarozole $(300 \mathrm{mg})$ in healthy male volunteers. In an escalating single dose study $(40,80,160$ and $320 \mathrm{mg})$, progesterone production was significantly increased in a dose-dependent way by liarozole: its concentration reaches a peak 4 hours after liarozole intake and decreased progressively to return to its 
normal level within 32 hours. 17 $\alpha-\mathrm{OH}$-progesterone production was less affected and maintained its normal rhythm after ACTH administration.

In healthy volunteers, liarozole was shown to be a potent aromatase inhibitor, leading to significantly decreased serum estradiol. The reduction of estradiol levels reached its maximum at 8 hours after a single oral dose of 75, 150 and $300 \mathrm{mg}$ liarozole, with mean peak reductions of 71,82 and $79 \%$, respectively. Concentrations of estradiol were decreased for up to 32 hours after drug administration. Similar observations were seen in a 10-day treatment with oral liarozole $150 \mathrm{mg}$ b.i.d. in healthy male volunteers. Serum estradiol levels remained lowered by 40 to $50 \%$ from day 1 to day 10 . Twentyfour hours after the last drug administration, serum estradiol levels rebounded to levels above those measured in the placebo session of day 1.

LH and FSH follow the naturally occurring positive pituitary feedback mechanism upon the decrease of testosterone and estradiol induced by liarozole as was shown in a 10-day treatment with oral liarozole $150 \mathrm{mg}$ b.i.d. in healthy male volunteers.

\section{Effect on Adrenal Steroids and Mineralocorticoids}

No consistent changes in the basal serum levels of both cortisol and aldosterone were observed during therapy with liarozole, whilst the levels of 11-deoxycorticosterone (DOC) increased 5- to 15-fold. A partial non-significant blunting of cortisol response to exogenous ACTH stimulation was observed both in volunteers and in relapsed prostate cancer patients after single (300 mg) and long-term (300 mg b.i.d. for 2 weeks) liarozole treatment respectively, but none of these patients had clinical signs of hypocortisolism. Neither were any symptoms of hypocortisolism observed in prostate cancer patients treated with liarozole for up to 2 years. On the other hand, the aldosterone response to exogenous ACTH stimulation was clearly blunted with a concomitant rise in DOC. Because of minor changes in basal aldosterone and mineralocorticoid activity of the accumulated precursor DOC, these changes were not clinically significant, as evidenced by the absence of any clinically significant changes in blood pressure or electrolytes in volunteers or in cancer patients.

\section{Effects on Vitamin D and Thyroid Stimulating Hormone (TSH)}

Given the known interaction of vitamin D and RA receptors, vitamin D was assayed in 12 volunteers. During a 10-day treatment with $150 \mathrm{mg}$ liarozole b.i.d., no alterations of the serum levels of 1,25-dihydroxyvitamin $\mathrm{D}_{3}$ and of 25-hydroxyvitamin $\mathrm{D}_{3}$ were detected.

The lack of obvious effect on plasma TSH levels after 3 days of dosing liarozole 300 mg b.i.d. in six male volunteers suggests that the thyroid alterations observed in rats 
after long-term administration of high doses of liarozole are not relevant to the human situation. Moreover, no clinical signs of thyroid dysfunction were observed in the clinical trials in prostate cancer.

\section{Non RA-related Pharmacodynamic Effects on non-Cytochrome P450- dependent Steroid Metabolism and steroid receptor-binding profile}

The effects of liarozole on androgen metabolism were evaluated in primary cultures of collagenase dispersed rat prostate cells incubated with $5.10^{-9} \mathrm{M}$ of $\left[{ }^{14} \mathrm{C}\right]$ testosterone. Up to a concentration of $10^{-5} \mathrm{M}$, liarozole did not affect prostatic $5 \alpha$-reductase, the enzyme which converts testosterone into its biologically more potent metabolite dihydrotestosterone, nor $17 \beta$-hydroxysteroid dehydrogenase, which converts estrone to estradiol. The conversion of estrone and DHEA sulphate, mediated by the sulphatase enzyme, was also unaffected by liarozole.

Liarozole did not alter in vitro radioligand binding to estrogen-, progestin-, androgenand glucocorticoid-receptors.

\section{General Pharmacology}

\section{Interaction with Specific Neurotransmitters and Neuromodulators}

Apart from weak binding affinity for the transporter sites for dopamine $\left(\mathrm{K}_{\mathrm{i}}: 2300 \mathrm{nM}\right)$ and norepinephrine $\left(\mathrm{K}_{\mathrm{i}}: 4300 \mathrm{nM}\right)$, liarozole was devoid of any activity in a variety of in vitro receptor binding assays when tested up to a concentration of $10 \mu \mathrm{M}$. Moreover, liarozole did not inhibit the uptake of $\left[{ }^{3} \mathrm{H}\right] \mathrm{GABA}$ ( $\gamma$-aminobutyric acid) in crude rat synaptosomes. Based on the results of in vivo interaction studies liarozole was devoid of interaction with a variety of neurotransmitters and neuromodulators and their specific receptors (acetylcholine, dopamine, histamine, norepinephrine, serotonin, and opiate) up to $40 \mathrm{mg} / \mathrm{kg}$, s.c. and $160 \mathrm{mg} / \mathrm{kg}$, p.o. in rodents and $40 \mathrm{mg} / \mathrm{kg}$, s.c. and p.o. in dogs.

\section{Interaction with the Central Nervous System}

Up to $40 \mathrm{mg} / \mathrm{kg}$, s.c. and $160 \mathrm{mg} / \mathrm{kg}$, p.o. in rodents and $2.5 \mathrm{mg} / \mathrm{kg}$ i.v., $40 \mathrm{mg} / \mathrm{kg}$, s.c. and p.o. in dogs, liarozole failed to show any consistent effects on general behavior, body functions (muscle tone, body temperature, respiration, pupil diameter, palpebral opening), or reflexes in general observation tests.

At high oral doses in rats, liarozole showed a tendency to decrease motor activity $\left(\mathrm{ED}_{50}\right.$ : $113 \mathrm{mg} / \mathrm{kg}$, p.o.), conditioned food-intake ( $\mathrm{ED}_{50}: 149 \mathrm{mg} / \mathrm{kg}$, p.o.) and, possibly as a 
direct consequence, faecal excretion $\left(\mathrm{ED}_{50}: 149 \mathrm{mg} / \mathrm{kg}\right.$, p.o.) without affecting urinary excretion $\left(\mathrm{ED}_{50}:>160 \mathrm{mg} / \mathrm{kg}\right.$, p.o.). In dogs, liarozole did not inhibit conditioned twoway avoidance behavior.

Liarozole did not affect the behavioral effects induced by Ro-4-1284 in mice or by tryptamine, apomorphine, amphetamine, xylazine, reserpine, pentylenetetrazole, ouabain, barium (II) chloride, nitrogen, potassium cyanide, anoxia or acetic acid in rats.

\section{Interaction with Cardiovascular and Pulmonary Systems}

Cardiovascular safety was evaluated in several in vitro and in vivo experimental set-ups. In vitro studies on isolated cardiac tissue suggest that the compound and its metabolites lack the intrinsic capacity to prolong the action potential or induce early afterdepolarizations or triggered activity in different conditions (normal rhythm, bradycardia, hypokalaemia, etc.) in cardiac cells up to a concentration of $10 \mu \mathrm{M}$ exceeding the peak concentration of unbound liarozole in plasma at twice the expected therapeutic doses in man (150 mg b.i.d) by a factor 20. Liarozole at a concentration of $50 \mu \mathrm{M}$ slightly shortened the duration of the action potential in canine papillary muscles and moderately prolonged the duration of the action potential in guinea pig papillary muscles.

In vivo, after cumulative i.v. doses from 0.01 to $2.5 \mathrm{mg} / \mathrm{kg}$ in closed-chest anaesthetized mongrel dogs, liarozole displayed no relevant effects on the bronchial system or the ECG. In this in vivo preparation, liarozole did not induce relevant changes in heart rate, aortic blood pressure, cardiac contraction and relaxation, total systemic and pulmonary resistance as compared to solvent.

In a 6-month chronic toxicity study in Beagle dogs, liarozole hydrochloride was administered orally at daily doses of $5,7.5$ and $10 \mathrm{mg} / \mathrm{kg}$. No drug or dose related adverse effects on heart rate and ECG were noted.

\section{Interaction with Gastrointestinal and Urinary Systems}

Liarozole when tested up to $1 \mu \mathrm{M}$ had no effect on spontaneous movements and contractions of isolated guinea pig ileum induced by acetylcholine, histamine and barium chloride. At $10 \mu \mathrm{M}$, transiently reduced spontaneous movement, a decrease in basal tone and a slight depression in acetylcholine-induced contraction were observed. At 100 $\mu \mathrm{M}$ reduced spontaneous movement, a decrease in basal tone, and a depression in acetylcholine-, histamine- and barium-induced contractions were observed. On the contrary, liarozole administered up to $80 \mathrm{mg} / \mathrm{kg}$ p.o. or $2.5 \mathrm{mg} / \mathrm{kg}$ i.v. to guinea pigs had no effect on the spontaneous movement of small intestine in situ. 
In rats, high oral doses of liarozole had anti-diarrheal activity $\left(\mathrm{ED}_{50}: 32 \mathrm{mg} / \mathrm{kg}\right)$, inhibited gastric emptying $\left(\mathrm{ED}_{50}: 80 \mathrm{mg} / \mathrm{kg}\right.$, p.o.), reduced gastrointestinal propulsion $\left(\mathrm{ED}_{50}\right.$ : $80 \mathrm{mg} / \mathrm{kg}$, p.o.), and seemed to reduce (ED $\mathrm{ED}_{50}: 149 \mathrm{mg} / \mathrm{kg}$, p.o.) fecal excretion. In dogs, liarozole did not accelerate $\mathrm{MgSO}_{4}$-induced diarrhea $\left(\mathrm{ED}_{50}:>40 \mathrm{mg} / \mathrm{kg}\right.$, p.o.) or block apomorphine-induced emesis ( $\mathrm{ED}_{50}:>40 \mathrm{mg} / \mathrm{kg}$, p.o. or s.c.).

In rats, liarozole showed cytoprotective activity against stress-induced gastric ulcers $\left(\mathrm{ED}_{50}: 11 \mathrm{mg} / \mathrm{kg}\right.$, s.c.; $22 \mathrm{mg} / \mathrm{kg}$, p.o.). After oral administration, liarozole also increased gastric $\mathrm{pH}\left(\mathrm{ED}_{50}: 49 \mathrm{mg} / \mathrm{kg}\right)$.

In two general observation studies liarozole did not affect urinary excretion in rats $\left(\mathrm{ED}_{50}\right.$ : $>40 \mathrm{mg} / \mathrm{kg}$, s.c.; $>160 \mathrm{mg} / \mathrm{kg}$, p.o.). In a $3^{\text {rd }}$ study in which liarozole was administered orally at 5 to $80 \mathrm{mg} / \mathrm{kg}$ to rats, only the highest dose caused an increase in urine volume, in the concentration of potassium, and in total excretion of potassium and chloride.

\section{Allergy, Pain and Inflammation}

Liarozole (administered as medicated diet in an approximate daily dose of $40 \mathrm{mg} / \mathrm{kg}$ over a period of 40 days) did not produce anti-inflammatory activity against Mycobacterium butyricum arthritis in rats. Liarozole (40 mg/kg, s.c.) did not consistently affect skin reactions induced by passive cutaneous anaphylaxis or intradermal injections of histamine, serotonin or compound 48/80. Liarozole (160 mg/kg, p.o.) failed to protect from platelet-activating factor (PAF)-induced lethality in rats, to inhibit substance Pinduced salivation and plasma extravasation in rats and to block lipopolysaccharide(LPS)-induced lethality or hypothermia in rats, suggesting absence of glucocorticoid-like or aspirin-like anti-inflammatory activity (cyclo-oxygenase inhibition). In rats and mice, liarozole (160 mg/kg p.o. and 40mg/kg s.c.) did not inhibit acetic acidinduced writhing in rats or mice, confirming the absence of aspirin-like analgesic or anti-inflammatory activity. 


\section{References}

1. Favennec L, Cals M-J. The biological effects of retinoids on cell differentiation and proliferation. J Clin Chem Clin Biochem 1988; 26: 479-89.

2. Lotan R. Mechanisms of Action of Retinoids. Cancer Bulletin 1986; 38: 113-6.

3. Giguère V. Retinoic acid receptors and cellular retinoid binding proteins complex interplay in retinoid signaling. Endocr Rev 1994; 15: 61-79.

4. Chambon P. A decade of molecular biology of retinoic acid receptors. FASEB J 1996; 10: 940-54.

5. Roos T, Jugert F, Merk H, et al. Retinoid metabolism in the skin. Pharmacol Rev 1988; 50: 315-33.

6. Napoli J. Retinol metabolism in LLC-PK1 Cells. Characterization of retinoic acid synthesis by an established mammalian cell line. J Biol Chem 1986; 261: 13592-7.

7. Williams J, Napoli J. Inhibition of retinoic acid metabolism by imidazole antimycotics in F9 embryonal carcinoma cells. Biochem Pharmacol 1987; 36: 1386-8.

8. Van Wauwe J, Coene MC, Goossens J, et al. Ketoconazole inhibits the in vitro and in vivo metabolism of all-trans-retinoic acid. Pharmacol Exp Ther 1988; 245: 718-22.

9. Ahmad M, Nicholls PJ, Smith HJ, et al. Effect of P450 isozyme-selective inhibitors on in-vitro metabolism of retinoic acid by rat hepatic microsomes. J Pharm Pharmacol 2000; 52: 311-4.

10. Vanden Bossche H, Willemsens G, Janssen PAJ. Cytochrome P450-dependent metabolism of retinoic acid in rat skin microsomes: inhibition by ketoconazole. Skin Pharmacol 1988; 1: 176-85.

11. Van Wauwe J, Coene MC, Goossens J, et al. Effects of cytochrome P-450 inhibition on the in vivo metabolism of all-trans-retinoic acid in rats. J Pharmacol Exp Ther 1990; 252: 365-9.

12. Van Wauwe J, Van Nyen G, Coene MC, et al. Liarozole, an inhibitor of retinoic acid metabolism, exerts retinoid-mimetic effects in vivo. J Pharmacol Exp Ther 1992; 261: 773-8.

13. Van Wauwe J, Coene MC, Cools W, et al. Liarozole fumarate inhibits the metabolism of 4-keto-alltrans-retinoic acid. Biochem Pharmacol 1994; 47: 737-41.

14. Kato M, Blauer WS, Mertz JR, et al. Goodman. Influence of retinoid nutritional status on cellular retinoland cellular retinoic acid binding protein concentrations in various rat tissues. $J$ Biol Chem 1985; 206: 4832-8.

15. Geiger J-M, Weiser H. Rat vaginal epithelium assay for screening retinoids. In: Pharmacology of Retinoids in the Skin (Reichert U, Schroot B, eds.). Basel: Karger, 1989: 141-3.

16. Connor MJ. Evaluation of retinoids (Vitamin A derivatives) by their effects on epidermal histology. In: Models in Dermatology (Maibach HI, Lowe NJ, eds.), Vol. 3. Basel: Karger, 1987; 23-8.

17. Wrench R. Assessing drugs for psoriasiform diseases and their antiparakeratotic mechanisms using the mouse tail test. In: Models in Dermatology (Maibach HI, Lowe NJ, eds), Vol. 2. Basel: Karger, 1985; 79-91.

18. Dawson M, Chao W-R. Comparison of the inhibitory effects of retinoids on 12-O-tetradecanoylphorbol13-acetate-promoted tumor formation in CD-1 and Sencar mice. Cancer Lett 1988; 40: 7-12.

19. Diamond L, O'Brien T, Baird W. Tumor promoters and the mechanisms of tumor promotion. Adv Cancer Res 1980; 32: 1-74.

20. De Coster R, Wouters W, Van Ginckel R, et al. Experimental studies with liarozole (R75251): an antitumoral agent which inhibits retinoic acid breakdown. J Steroid Biochem Molec Biol 1992; 43: 197-201.

21. Kang S, Duell EA, Kim KJ, et al. Liarozole inhibits human epidermal retinoic acid 4-hydroxylase activity and differentially augments human skin responses to retinoic acid and retinol in vivo. $J$ Invest Dermatol 1996; 107: 183-7.

22. Bruynseels J, De Coster R, Van Rooy P, et al. R 75251, a new inhibitor of steroid biosynthesis. Prostate 1990; 16: 345-57. 


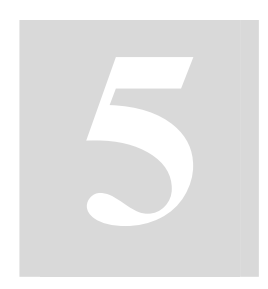

\section{Topical liarozole in ichthyosis}

Based on:

Lucker GPH ${ }^{* 1}$, Verfaille $C J^{* 2,3}$, Heremans AMC ${ }^{4}$, Vanhoutte $\mathrm{FP}^{4}$, Boegheim JPF ${ }^{5}$ and Steijlen PM ${ }^{l}$. Topical liarozole in hereditary ichthyosis: a double-blind, leftright comparative clinical study followed by a long-term maintenance treatment. Published in Br J Dermatol, 152, 566-9, 2005.

* Both authors contributed equally to this paper.

${ }^{1}$ Department of Dermatology, University Hospital Nijmegen, present address: University Hospital Maastricht, The Netherlands.

${ }^{2}$ Departments of Dermatology and Molecular Cell Biology, GROW, Maastricht University, The Netherlands.

${ }^{3}$ Barrier Therapeutics, Geel, Belgium.

${ }^{4}$ Department of Clinical Research and Development, Janssen Research Foundation, Beerse, Belgium.

${ }^{5}$ Department of Clinical Research, Janssen-Cilag B.V., Tilburg, The Netherlands. 


\begin{abstract}
Background: Liarozole, a retinoic acid metabolism blocking agent (RAMBA), inhibits the cytochrome P450 (CYP)-dependent 4-hydroxylation of all-trans-retinoic acid (RA). This results in increased plasma and predominantly tissue RA levels and consequently offers a potential therapeutic benefit in skin disorders of keratinization, like ichthyosis.
\end{abstract}

Objective: The purpose of this study was to assess the short (12 weeks) and long-term (72 weeks) efficacy, safety and tolerability of a 5\% liarozole cream in patients diagnosed with one of the following subtypes of ichthyosis: X-linked recessive ichthyosis, lamellar ichthyosis and congenital bullous ichthyosiform erythroderma.

Methods: Twelve patients were selected for the initial short-term study. After a washout period, patients were treated for 6 weeks with liarozole $5 \%$ cream or placebo using a bilaterally paired double-blind approach. This was followed by an open phase of 4 weeks during which both sides of the body were treated with liarozole $5 \%$ cream. Subsequently, 8 out of 10 patients whom completed the short-term study were motivated to participate immediately in the open maintenance study for 72 weeks. Efficacy, safety and tolerability were monitored over the course of the studies. Efficacy variables were: evaluation of the overall response to treatment and severity and extent of the skin lesions on arms, trunk and legs.

Results: At the end of the double-blind treatment phase, a significant unilateral improvement in extent and severity of skin lesions was observed in favour of the liarozoletreated side which further improved during the open phase. This was supported by the overall assessment of the treatment and patient's self-assessment of efficacy which was scored 'good/excellent' for 7/8 patients at the end of the open maintenance study. Clinical side effects were only minimal and the treatment was well tolerated. No clinically relevant changes were found in the haematological, biochemical, and urinary parameters. Plasma levels of liarozole could be detected throughout the study, the highest levels being observed in those patients with more inflammatory types of ichthyosis.

Conclusion: Data from this study indicate that topical treatment of different forms of hereditary ichthyosis with $5 \%$ liarozole cream is effective and well-tolerated, and may present an alternative to the existing therapies. 


\section{Introduction}

Interest in retinoic acid metabolism blocking agents (RAMBA), in particular liarozole, has received a boost because of its received orphan drug status for congenital ichthyosis by the European Commission and the U.S. Food and Drug Administration.

Ichthyosis is a general term used for a clinically and genetically heterogeneous group of disorders with a generalized scaling affecting the entire skin. Classification, according to Traupe is primarily based on the onset of scaling and the presence or absence of associated symptoms. ${ }^{1}$ Four major groups can be categorized: isolated vulgar, associated vulgar, isolated congenital and associated congenital ichthyoses. Within those groups, a further classification is possible based on genetic, clinical, histological and biochemical features. Autosomal dominant ichthyosis vulgaris (ADIV) and X-linked recessive ichthyosis (XRI) are isolated vulgar ichthyoses. The group of isolated congenital ichthyoses can be subdivided in the harlequin ichthyosis, the lamellar ichthyoses (LI) including non-erythrodermic lamellar ichthyosis (NELI), erythrodermic lamellar ichthyosis (ELI) and autosomal dominant lamellar ichthyosis and the epidermolytic ichthyoses including congenital bullous ichthyotic erythroderma (CBIE) and ichthyosis bullosa of Siemens (IBS). These genetically determined dermatoses are rarely lifethreatening but usually severely debilitating and require life-long treatment. All types of ichthyosis, except for the autosomal dominant ichthyosis vulgaris (ADIV), are rare diseases and can be considered for an orphan drug designation. The incidence of ADIV is $1 / 250$, XRI occurs in 1/6000 males whereas LI, CBIE and IBS are even rarer (1/100.00-300.000). Therefore, the latter diseases are considered for an orphan drug designation.

Except for ADIV, all these forms of ichthyosis exhibit severe scaling not sufficiently improving with moisturizing or keratolytic creams. Topical therapeutic modalities available in ichthyosis mainly consist of urea and lactic acid, aiming at rehydration (moist retention) and keratolysis of the cornified cell layer. However, these ointments are of limited value as they are only effective in ADIV, whereas the more severe ichthyosis subtypes do not markedly improve. A good clinical improvement of lamellar and epidermolytic ichthyosis with topical calcipotriol has been demonstrated. ${ }^{2}$ However, to prevent derangements in calcium metabolism, the maximum weekly amount has been limited to $100 \mathrm{~g}$. This limitation constitutes a restriction for its use, as in these severe ichthyosis patients, a substantial part of the total body surface is affected.

Retinoids are powerful substances available for modulating or controlling keratinocyte proliferation and differentiation. ${ }^{3,4}$ Today the systemic retinoid, acitretin, is considered the only effective treatment option for severe ichthyoses. ${ }^{5}$ However a number of sub- 
stantial side effects like teratogenicity, hepatotoxicity, etc. are limiting its chronic use. ${ }^{6}$ Topical retinoids on the other hand may represent good alternatives to avoid the systemic side-effects. Nevertheless, to date they have not been shown to be a successful alternative because of their propensity for skin irritation with the exception of 13-cisretinoic acid. ${ }^{7}$ Short-term topical application of tazarotene, a novel receptor-selective retinoid, has proven to be effective but, as with other retinoids, irritancy is a significant side-effect. ${ }^{8}$ Long-term treatment and treatment of more than $10 \%$ of the body surface were not investigated.

Liarozole, an imidazole derivative developed in the late eighties by the Janssen Research Foundation in Belgium, represents a new class of compounds coined RAMBA's. Extensive in vitro ${ }^{9-11}$ and in vivo ${ }^{12-14}$ pharmacological testing identified liarozole as an inhibitor of several mammalian cytochrome P450 (CYP) isozymes among which the one involved in the oxidative metabolism of all-trans retinoic acid (RA), the RA-4hydroxylase. Oral liarozole has shown to be an effective treatment for psoriasis and is at least as effective as acitretin in the treatment of severe ichthyoses. ${ }^{15-18}$ To broaden the margin between efficacy and side effects, a topical liarozole formulation was developed. The aim of the present study is to assess the short- and long-term efficacy, safety and tolerability of topical liarozole in the treatment of different forms of severe ichthyosis.

\section{Patients and methods}

\section{Patients}

Male or post-menopausal ( $>2 \mathrm{yrs}$ ) females, aged 18 or more and diagnosed with one of the following subtypes of ichthyosis: XRI, LI and CBIE were eligible. At least one of the lesion severity parameters (see clinical efficacy parameters) at baseline had to have a score of at least 2 on a 4-point scale in which 0 =absent, 1=mild, 2=moderate, $3=$ severe. The lesions had to be symmetrical on both sides of the body. Main exclusion criteria were concurrent inflammatory skin disease, topical or UV treatment within 2 weeks and systemic treatment within 4 weeks prior to the start of the treatment phase, use of vitamin A supplements $(>1000 \mu \mathrm{g} /$ day) and clinically relevant abnormal laboratory test values. The study was approved by the Institutional Medical Ethical Review Board of the University of Nijmegen. Written informed consent was obtained after the nature of the procedures had been fully explained. All clinical investigations were conducted according to the Declaration of Helsinki principles. 


\section{Treatment}

In a randomized, double-blind, placebo-controlled, left-right comparative study, 12 patients with severe ichthyosis were treated with topical liarozole, 5\% cream and placebo only. Minimum wash-out periods, in which only placebo treatment was allowed, were 1 month for systemic agents and 2 weeks for topical treatment or phototherapy. After the wash-out patients treated the lesions for 6 weeks on a double-blind basis: one half of their body with liarozole cream 5\% and the contra-lateral side with placebo only. Thereafter, both sides of the body were treated with liarozole $5 \%$ cream for 4 weeks (open phase). The creams were applied thinly and evenly, twice daily. XRIpatients had a documented steroid-sulphatase deficiency; sun exposure had to be avoided. Patients were examined before treatment, at week 0, 2, 4, 6 of the double-blind treatment phase and at week 10 , the end of the open treatment phase.

Upon completion of the short-term study (10 weeks), patients were motivated to participate in an open maintenance study with 5\% liarozole for 72 weeks to gather long-term efficacy, tolerability and safety data. Visits took place with 4-week intervals.

\section{Clinical efficacy evaluations}

Since no standardized efficacy-scoring methods are available for ichthyosis, we had to develop our own. Efficacy variables evaluated over the course of the studies included severity and extent of the skin lesions on trunk, arms and legs and the overall response to treatment.

At each visit, the investigator made an evaluation of the severity of the skin lesions by rating scaling, roughness, erythema, bullae and hyperpigmentation on trunk, arms and legs separately using a 4 -point scale in which $0=$ absent, $1=$ mild, $2=$ moderate, $3=$ severe. Scaling and roughness were recorded in all subgroups, hyperpigmentation only in XRI, erythema and bullae in CBIE.

The extent of the lesions on the arms and legs was recorded for the left and right side separately and expressed in \% of the surfaces of these body parts, ranging from 0 to $100 \%$.

During treatment, both the investigator and the patient made an overall evaluation of the response to treatment (=compared to baseline) on arms and legs and rated it on a 5-point scale in which $0=$ deteriorated, $1=$ unchanged, $2=$ moderately improved, $3=$ markedly improved, 4= cleared.

Photographs were taken under standardized conditions during the short-term study at baseline, at the end of the double-blind treatment phase (week 6) and at the end of the open treatment phase (week 10). 


\section{Safety and Tolerability}

Throughout the study patients were monitored for adverse events (AEs). Haematological, biochemical, urinary examinations were performed at most visits. Endocrinological parameters (cortisol, testosterone, oestradiol and luteinizing hormone, aldosterone and progesterone) were assessed at regular intervals. Plasma samples for drug level analysis were taken at week 6 and 10 of the short-term study and at week 0, 24, 48 and 72 of the maintenance study.

Tolerance to treatment was assessed by the patients at the beginning of each visit prior to the investigator's clinical assessment by rating subjective symptoms i.e. burning sensation (redness), skin tension and dry skin on both arms and legs separately, on a 4point scale in which $0=$ absent, $1=$ mild, $2=$ moderate, $3=$ severe.

\section{Statistics}

For the short-term study, a total of 12 patients were judged to be sufficient. Analysis of efficacy was based on the intent-to-treat population which includes all randomized patients who used at least one study medication and had post-baseline efficacy data. The difference of the extent and severity of skin lesions between left and right arm or leg and it changes from baseline were evaluated using a two-sided Wilcoxon-signed rank test. Since the maintenance study was an open follow-up study, the statistical analysis was performed in a descriptive manner. All statistical tests were two-tailed and were interpreted at the 5\% level and performed on all patients. Analysis of safety for both studies was based on the all-patient population which includes all patients who received at least one dose of drug.

\section{Results}

\section{Patients}

Twelve patients, 11 males and 1 female were recruited for the short-term study: 6 were diagnosed with XRI, 4 with NELI and 2 with CBIE. All were Caucasian with a mean age of 39 years, a mean weight of $72 \mathrm{~kg}$, and a mean height of $177 \mathrm{~cm}$. Two patients stopped treatment prematurely because of an AE: one at the end of the double-blind phase (itchy papules) and another during the open phase (contact eczema) but still provided data at the last visit, week 10 .

Eight patients ( 7 males, 1 female) whom had completed the short-term study participated in the open maintenance treatment. The mean age was 33.8 years and the subtypes 
were XRI $(n=3)$, NELI $(n=4)$ and CBIE $(n=1)$. All patients completed the study; One patient discontinued therapy for 10 days due to a serious adverse event (myocardial infarction; not drug-related).

\section{Clinical efficacy evaluations}

\section{Extent and severity of skin involvement: Short-term study}

Extent and severity of skin involvement on arms and legs throughout the short-term study is summarized in Table 5.1 and Figures 5.1 and 5.2.

Table 5.1 Overview of the extent and severity of the skin lesions on arms and legs durint the short-term study. Statistical testing on the difference in the change between treatment sides, compared to baseline values: * $\mathrm{p} \leq 0.05, * * \mathrm{p} \leq 0.01, * * * \mathrm{p} \leq 0.001$.

\begin{tabular}{|c|c|c|}
\hline & Liarozole side & Placebo side \\
\hline $\begin{array}{l}\text { Extent of lesions on arms (\%) } \\
\text { week } 0 \\
\text { week } 6 \\
\text { week } 10\end{array}$ & $\begin{array}{l}86 \\
44 * * \\
33\end{array}$ & $\begin{array}{l}86 \\
69 \\
45^{* *}\end{array}$ \\
\hline $\begin{array}{l}\text { Extent of lesions on legs }(\%) \\
\text { week } 0 \\
\text { week } 6 \\
\text { week } 10\end{array}$ & $\begin{array}{l}87 \\
57 \\
48\end{array}$ & $\begin{array}{l}87 \\
74 \\
58 * *\end{array}$ \\
\hline $\begin{array}{l}\text { Severity of scaling on arms } \\
\text { week } 0 \\
\text { week } 6 \\
\text { week } 10\end{array}$ & $\begin{array}{l}2.50 \\
1.08 * * * \\
1.00\end{array}$ & $\begin{array}{l}2.50 \\
2.33 \\
1.36^{* *}\end{array}$ \\
\hline $\begin{array}{l}\text { Severity of scaling on legs } \\
\text { week } 0 \\
\text { week } 6 \\
\text { week } 10\end{array}$ & $\begin{array}{l}2.67 \\
1.50 * * \\
1.45\end{array}$ & $\begin{array}{l}2.67 \\
2.33 \\
1.82\end{array}$ \\
\hline
\end{tabular}

At the start of the double blind treatment phase, the extent of the skin lesions on the arms was $86 \%$. At the end of this phase, the extent was $44 \%$ at the liarozole-treated side $(p=0.001)$ and $69 \%$ at the placebo-treated side $(p<0.005)$. The difference in reduction between both sides was statistically significant in favour of the liarozole-treated side $(p<0.005)$. Also the severity of scaling and roughness was statistically significant reduced at the liarozole-treated side $(\mathrm{p}=0.005)$ but not at the placebo-treated side. Analysis of the difference between both sides revealed that liarozole was superior to placebo for both scaling and roughness $(p=0.0005)$. After 4 weeks of bilateral treatment with liarozole, a considerable reduction of the extent of skin lesions $(-24 \%)$ was found 


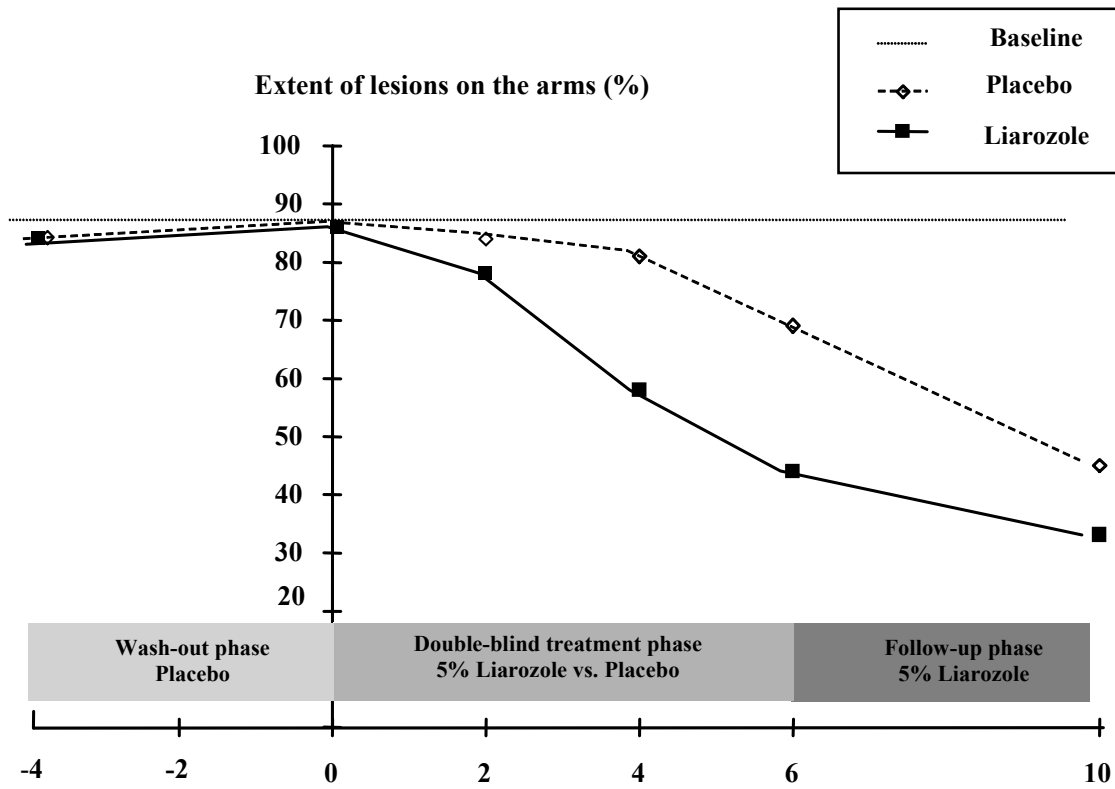

Figure 5.1 Evaluation of the extent of the lesions as a function of time during the short-term study. In the double-blind treatment phase, reduction of skin lesions on the arms is considerable (86 to $44 \%$ ) at the liarozole-treated side, whereas improvement is only modest at the placebo-treated side ( 86 to $69 \%$ ). There is clear a catching-up effect on the previously placebo-treated side during the open treatment phase with liarozole.

at the previously placebo-treated arms $(\mathrm{p}<0.01)$, whereas only a moderate continued reduction $(-11 \%)$ was found at the contra-lateral side $(\mathrm{p}<0.1)$. Analysis of the difference in shifts between both sides, displayed an improvement in favour of the side previously treated with placebo $(\mathrm{p}<0.05)$.

With regard to severity, the previously placebo-treated arms showed a reduction of scaling $(\mathrm{p}<0.005)$ and roughness $(\mathrm{p}<0.005)$ which was absent at the contra-lateral side. Comparing both sides, again revealed improvement in favour of the previously placebotreated side (scaling and roughness: $\mathrm{p}<0.005$ ). As shown in Table 5.1, the development of extent and severity of lesions on the legs in both double-blind treatment and open follow-up phase, parallels the shifts described for the arms. 


\section{Severity of scaling on the arms}

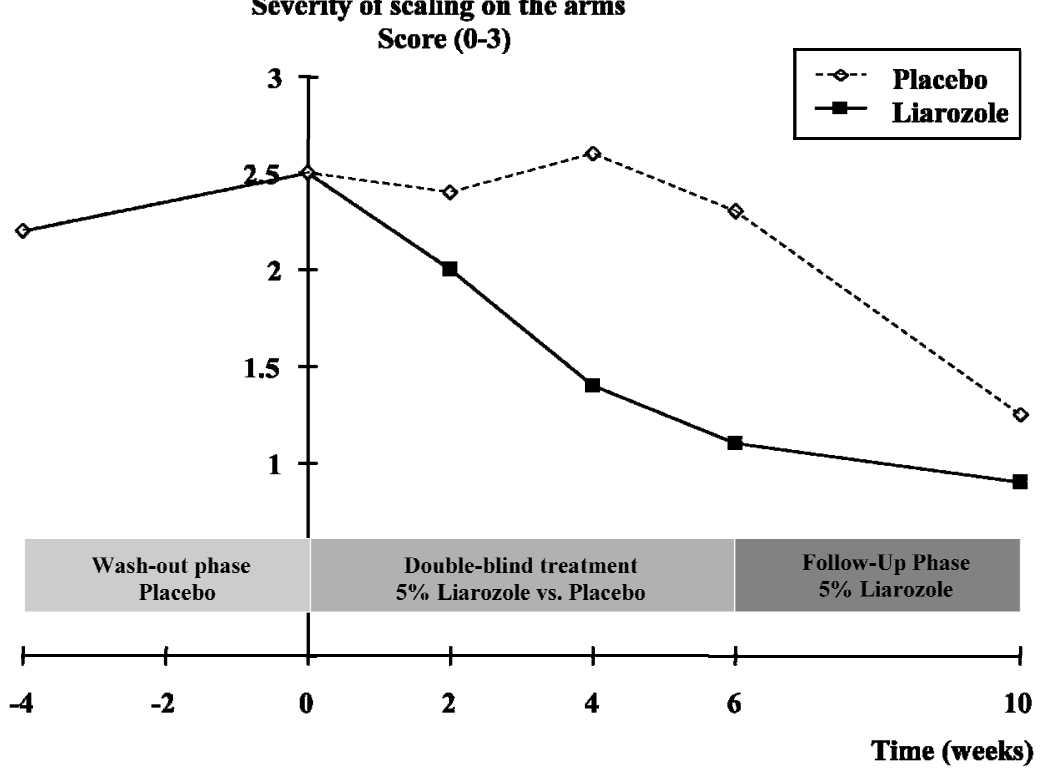

Figure 5.2 Evaluation of the severity of scaling on the arm as a function of time during the short-term study. The severity was scored on a 4-point scale in which $0=$ absent and $3=$ severe. The severity of the scaling on the arms shows a definite improvement in favour of the liarozole-treated side during the doubleblind treatment phase. A catching-up effect is observed on the previously placebo-treated side during the open treatment phase with liarozole.

\section{Overall response to treatment: Short-term study}

The overall response to treatment, assessed by the investigator, was significantly superior to placebo from week 4 onwards. After 6 weeks of treatment the liarozole-treated arm was markedly improved in 11 cases (92\%) and the placebo-treated arm in only one case $(8 \%)$. The liarozole-treated leg was markedly improved in 7 cases $(58 \%)$ and the placebo-treated leg in only one case ( $8 \%)$. None of the patients had completely cleared arms and legs. An overview of the overall assessment by the patient at the end of the open phase is presented in Table 5.2. Figure 5.3 shows a patient at baseline, at the end of the double-blind (week 6) and at the end of the open phase (week 10). 
Table 5.2 Survey of overall assessment (arm and legs) scored by the patient at week 10 (the end of the open phase of the short-term study) compared to baseline.

\begin{tabular}{|l|c|c|c|c|c|c|c|c|}
\hline & \multicolumn{3}{|c|}{ Assessment on arm } & \multicolumn{3}{c|}{ Assessment on leg } \\
\hline & \multicolumn{2}{|c|}{ Liarozole } & \multicolumn{2}{c|}{ Placebo } & \multicolumn{2}{c|}{ Liarozole } & \multicolumn{2}{c|}{ Placebo } \\
\hline & N & \% & N & \% & N & $\%$ & N & $\%$ \\
\hline No change & 0 & 0 & 0 & 0.0 & 1 & 8.3 & 1 & 8.3 \\
\hline Slightly improved & 3 & 25.0 & 6 & 50.0 & 6 & 50.0 & 9 & 75.0 \\
\hline Markedly improved & 8 & 66.7 & 5 & 41.7 & 5 & 41.7 & 2 & 16.7 \\
\hline Cleared & 1 & 8.3 & 1 & 8.3 & 0 & 0.0 & 0 & 0.0 \\
\hline
\end{tabular}
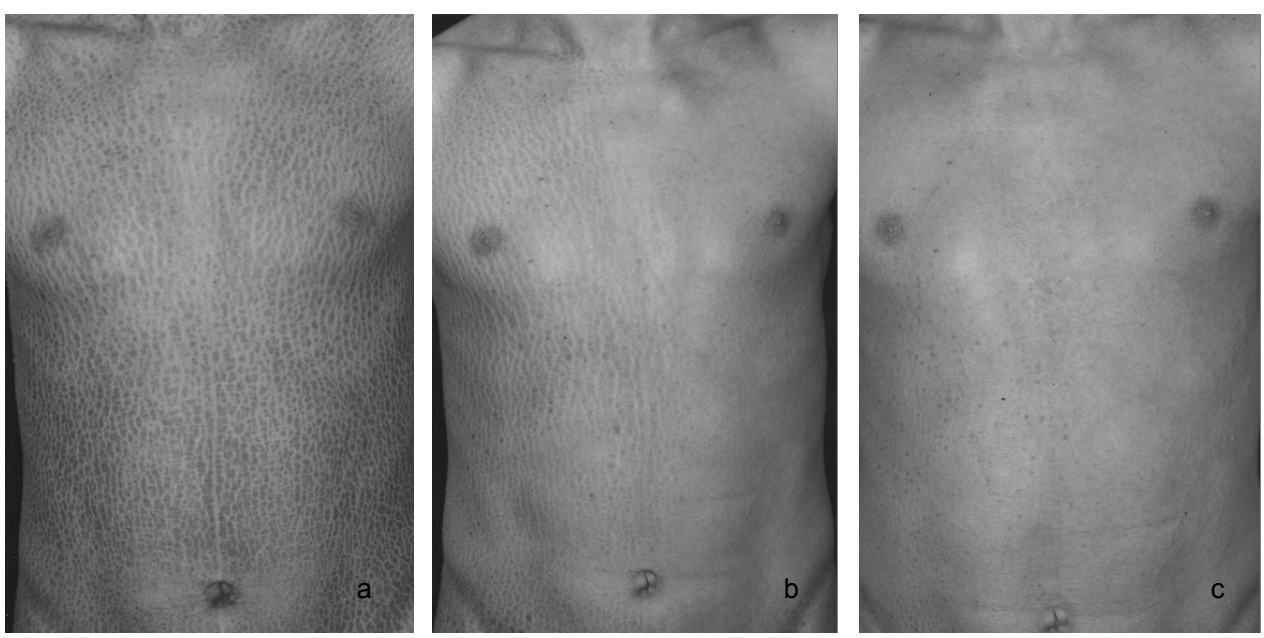

Figure 5.3 NELI patient: a) before treatment, exhibiting large brown scales covering a substantial part of the skin surface; b) at the end of the double-blind treatment, showing marked improvement at the liarozole treated side (left side of the person), whereas improvement at the cream-base treated side (right side of the person) is only small; c) after 6 weeks double-blind and 4 weeks open liarozole treatment, improvement is marked on both sides. At the previously cream-base treated right side, minimal scaling is still visible. See page 230 for colour figure.

\section{Long-term study}

During the 72 weeks open maintenance treatment, the extent and severity of the lesions were further reduced compared to the results obtained at the end of the previous shortterm study. This was supported by the overall assessment of the result of treatment (rated by both the investigator and patients), which was considered to be 
'good/excellent' for seven patients at the end of the study. One patient became eventually completely cleared.

\section{Safety and Tolerability}

Six out of 12 patients reported AEs during the short-term study (Table 5.3). In 5 out of 6 , the AEs were probably drug related since they were present only on the liarozole treated side. Two patients discontinued treatment due to AEs: one patient because of itch and papules, probably drug related (after 42 days), and another because of contact eczema (after 54 days), which he had already developed during the wash-out phase when he was treated with placebo cream only. No serious adverse events were reported. In the maintenance study, side-effects were minimal and temporary: 7 out of 8 patients reported 11 AEs, the most frequently reported was 'sticky feeling on the skin", reported by 4 patients. One serious adverse event, myocardial infarction, was reported to be not drug-related. No clinically relevant changes of hematological, biochemical and urinary parameters were found. Endocrinological examinations revealed a reduction in the plasma oestradiol concentration, whereas no relevant changes were found in all other hormones tested.

Table 5.3 Survey of adverse events of the short-term study: (A) dose reduction, (B) temporary stop, treatment continuation, permanent stop, (C) temporary stop, (D) dose reduction, (E) permanent stop. Per study phase, the side of the body (liarozole-treated or placebo-treated) of the adverse events is mentioned.

\begin{tabular}{|c|l|l|l|l|}
\hline Patient & \multicolumn{1}{|c|}{ Adverse events } & $\begin{array}{c}\text { Wash- out } \\
\text { phase }\end{array}$ & $\begin{array}{c}\text { Double-blind } \\
\text { phase }\end{array}$ & $\begin{array}{c}\text { Open } \\
\text { phase }\end{array}$ \\
\hline 1 & Itch on trunk & & liarozole (A) & liarozole \\
\hline 2 & Dry lips & & liarozole (B) & \\
\hline 3 & $\begin{array}{l}\text { - itch } \\
\text { - erythematous papules on arms } \\
\text { - itching erythematous papules on legs }\end{array}$ & & \\
\hline 4 & $\begin{array}{l}\text { Bilateral contact eczema on nates, upper legs and } \\
\text { abdomen }\end{array}$ & $\begin{array}{l}\text { placebo } \\
\text { (C) }\end{array}$ & liacebo + \\
\hline 5 & Itch on trunk & liarozole (D) & liarozole \\
\hline 9 & Paresthesia after application of cream & liarozole & \\
\hline
\end{tabular}

Liarozole cream was well tolerated. In the short-term study, the tolerance ratings were not statistically significantly different between the liarozole-treated and placebo-treated side at the end of the double-blind treatment phase. The dryness of the arms and legs was reduced significantly on both treatment sides. Also at the end of the open phase, 
tolerance ratings were the same for both sides. In the long-term maintenance study, burning sensation (redness), skin tension and dryness of the arms and legs were only reported the first 4 weeks and at week 48. Mild to moderate burning sensation of the trunk occurred more often and was reported until week 48. Mild skin tension and dryness on trunk were only reported during the first four weeks.

\section{Pharmacokinetics}

The plasma concentration of liarozole varied strongly between the different subtypes: XRI: $<2.5-24 \mathrm{ng} / \mathrm{ml}$; CBIE: $15-217 \mathrm{ng} / \mathrm{ml}$ and NELI: $25-428 \mathrm{ng} / \mathrm{ml}$ (Figure 5.4). The plasma concentration seemed to be related to the type of ichthyosis: the highest concentrations were found in patients with NELI and the lowest in patients with XRI.

The female NELI patient was an exception to that as she had very low liarozole plasma levels varying between $25-60.5 \mathrm{ng} / \mathrm{ml}$ which is not even close to the amounts reached by the male NELI patients: $153-402 \mathrm{ng} / \mathrm{ml}$. The amount of liarozole used in these groups was not different.

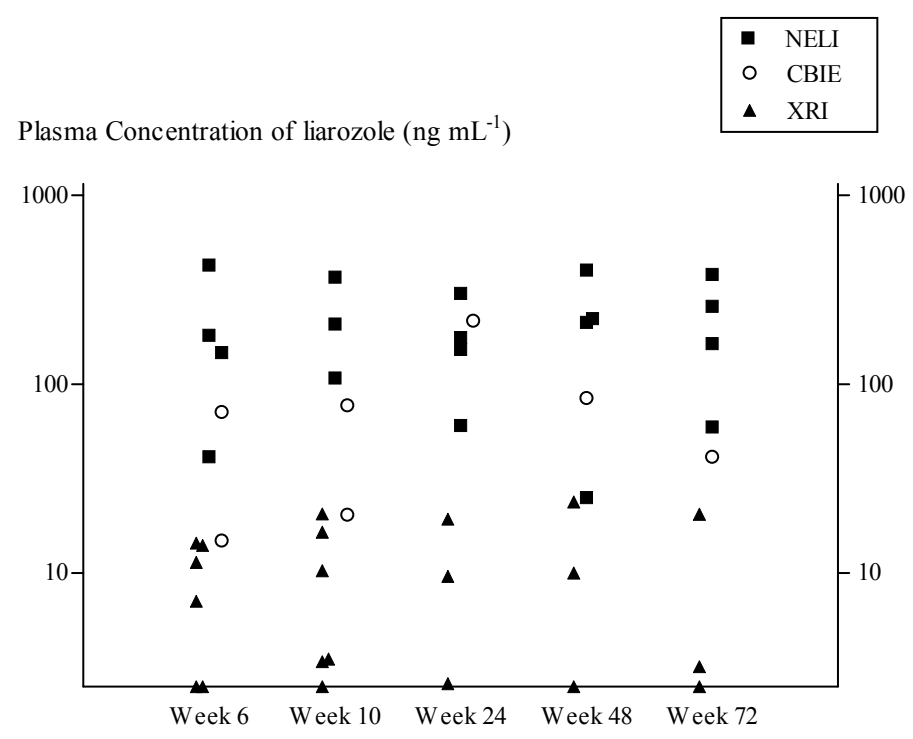

Figure 5.4 Scatter diagram of the plasma concentrations of liarozole in the various forms of ichthyosis after 6, 10 weeks of the short-term treatment (NELI, $n=4$; CBIE, $n=2 ;$ XRI, n=6) and after 24, 48 and 72 weeks of the maintenance treatment (NELI, $n=4$; CBIE, $n=1 ;$ XRI, $n=3$ ) with topical liarozole $5 \%$, in a graph with a logarithmical vertical axis. The horizontal axis indicates the detection limit of the method used $(2.5 \mathrm{ng} / \mathrm{ml})$. The liarozole plasma concentrations appear rather high in NELI, moderate in CBIE and low in XRI 


\section{Discussion}

Data from the reported study indicate that topical liarozole $5 \%$ cream is effective in various forms of ichthyosis (XRI, NELI, and CBIE). After 4 and 6 weeks of doubleblind treatment, the extent of the lesions and the severity of scaling were significantly more reduced at the liarozole-treated side than at the placebo-treated side. The effectiveness of liarozole was also evident in the open phase, where the largest improvement was found at the previously placebo-treated side. The reduction of the extent and severity of the lesions further improved during the 72 weeks maintenance study. This was supported by the overall assessment of the result of treatment.

Overall, long-term treatment with topical liarozole was well tolerated. Side effects were minimal and temporary. The most frequently reported AE was 'sticky feeling on the skin" which was reported by 4 patients during the whole treatment period. The spectrum of side effects of topical liarozole is similar or milder to that of calcipotriol or topical retinoids.

The studies indicate that administration of topical liarozole $5 \%$ cream can result in somewhat elevated liarozole plasma concentrations in patients with NELI or CBIE, but less in patient with XRI suggesting systemic absorption. As no significant differences were found between these groups in the amount of liarozole used, differences in plasma concentrations might be related to differences in the skin barrier function, resulting in differences in absorption. This will need further investigation in a larger population. However, except for one NELI patient, plasma levels were not elevated enough to contribute to the therapeutic effect of the drug, as only the side treated with liarozole cream, responded well to the treatment during the double-blind phase. This NELI patient had levels comparable to the peak plasma levels found in healthy volunteers after a single oral dose administration of $37.5 \mathrm{mg}$ (unpublished data), considered a subtherapeutic dose in the oral dose-finding studies in psoriasis ${ }^{16}$. Clinical improvement is probably achieved by a local inhibition of the endogenous breakdown of retinoic acid, resulting in elevated retinoic acid levels specifically in the target epidermal cells, thereby minimizing the risk of systemic effects as illustrated by the good tolerance in this study.

Plasma liarozole levels might exert hormonal effects, as the oestradiol levels were decreased in some patients. Since oestradiol levels tend to show quite some fluctuation during the day and over the course of a month in women, the absence of a correlation between liarozole and oestradiol levels makes conclusions particularly difficult.

In conclusion, the end result of this topical RAMBA pharmacological approach is that the patient has the benefit of a retinoid activity without being exposed to the high levels 
of RA or synthetic retinoids usually responsible for the safety issues with those latter drugs. These benefits, rationally derived from the pharmacological profile of a RAMBA, are supported by the clinical findings with topical liarozole in the treatment of severe ichthyosis and justify consideration of liarozole cream as front-line treatment for this rare and difficult to manage dermatological disease.

\section{Acknowledgements}

We would like to thank Ir. R. Wapenaar and M.Sc. J.P.J.M. Pfeil for the statistical analysis. 


\section{References}

1. Traupe H, ed. The Ichthyoses. A guide to clinical diagnosis, genetic counselling and therapy. Berlin: Springer-Verlag, 1989.

2. Lucker GPH, Kerkhof PCM van de, Dijk MR van, et al. Effect of topical calcipotriol on congenital ichthyoses. Br J Dermatol 1994; 131: 546-50.

3. Orfanos CE, Ehlert R, Gollnick H. The retinoids, a review of their clinical pharmacology. Drugs 1987; 34: 459-503.

4. Chytil F. Retinoic acid: Biochemistry, pharmacology, toxicology and therapeutic use. Pharmacol Rev 1984; 36: 93-100.

5. Blanchet-Bardon C, Nazzaro V, Rognin C, et al. Acitretin in the treatment of severe disorders of keratinization. Results of an open study. JAAD 1991; 24: 982-6.

6. Pilkington T, Brogden RN. Acitretin. A review of its pharmacology and therapeutic use. Drugs 1992; 43: 597-627.

7. Lucker GPH, Kerkhof PCM van de, Castelijns FACM, et al. Topical treatment of ichthyosis with 13-cisretinoic acid. A clinical and immunohistochemical study. Eur J Dermatol 1995; 5: 566-71.

8. Hofmann B, Stege H, Ruzicka T, et al. Effect of topical tazarotene in the treatment of congenital ichthyoses. Br J Dermatol 1999; 141: 642-6.

9. Wouters W, van Dun J, Dillen A, et al. Effects of liarozole, a new antitumoral compound, on retinoic acid induced inhibition of cell growth and on retinoic acid metabolism in MCF-7 human breast cancer cells. Cancer Res 1992; 52: 2841-6.

10. Williams JB, Napoli JL. Metabolism of retinoic acid and retinol during differentiation of F9 embryonal carcinoma cells. Proc Natl Acad Sci USA 1985; 82: 4658-62.

11. De Coster R, Wouters W, van Ginckel R, et al. Experimental studies with liarozole (R75251): an antitumoral agent which inhibits retinoic acid breakdown. J Steroid Biochem Molec Biol 1992; 43: $197-$ 201.

12. van Wauwe J, Coene MC, Goossens J, et al. Effects of cytochrome P-450 inhibition on the in vivo metabolism of all-trans-retinoic acid in rats. J Pharmac Exp Ther 1990; 252: 365-9.

13. van Wauwe J, Van Nyen G, Coene M-C, et al. Liarozole, an inhibitor of retinoic acid metabolism, exerts retinoid-mimetic effects in vivo. J Pharmacol Exp Ther 1992; 261: 773-8.

14. Kang S, Duell EA, Kim KJ, et al. Liarozole inhibits human epidermal retinoic acid 4-hydroxylase activity and differentially augments human skin responses to retinoic acid and retinol in vivo. $J$ Invest Dermatol 1996; 107: 183-7.

15. Dockx P, Decree J, Degreef H. Inhibition of the metabolism of endogenous retinoic acid as treatment for severe psoriasis: an open study with oral liarozole. Br J Dermatol 1995; 133: 426-32.

16. Berth-Jones J, Todd G, Hutchinson PE, et al. Treatment of psoriasis with oral liarozole: a dose-ranging study. Br J Dermatol 2000; 143: 1170-6.

17. Lucker GPH, Heremans AMC, Boegheim PJ, et al. Oral treatment of ichthyosis by the cytochrome P-450 inhibitor liarozole. Br J Dermatol 1997; 136: 71-5.

18. Verfaille CJ, Steijlen PM, Blanchet-Bardon C, et al. Phase II and III studies to evaluate the efficacy and safety of oral liarozole and acitretin in the treatment of severe ichthyosis. $J$ Eur Acad Dermatol Venereol 2004; 18 (Suppl. 2): 145. 



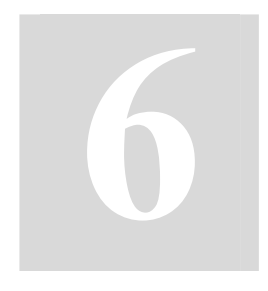

\section{Oral liarozole in ichthyosis}

Based on:

Verfaille $\mathrm{CJ}^{1,2}$, Vanhoutte $\mathrm{FP}^{3}$, Blanchet-Bardon $C^{4}$, van Steensel MAM${ }^{6}$, Steijlen $P M^{5,6}$ Oral liarozole versus acitretin in the treatment of ichthyosis: a phase II/III multicentre, double-blind, randomized, active-controlled study.

Br J Dermatol, 2007, DOI 10.1111/j.1365-2133.2006.07745.x.

\footnotetext{
${ }^{1}$ Departments of Dermatology and Molecular Cell Biology, GROW, Maastricht University, The Netherlands.

${ }^{2}$ Barrier Therapeutics, Geel, Belgium.

${ }^{3}$ Department of Clinical Research and Development, Janssen Research Foundation, Beerse, Belgium.

${ }^{4}$ Department of Dermatology, Hôpital St.Louis, Paris, France.

${ }^{5}$ Department of Dermatology, Radboud University Medical Center Nijmegen, The Netherlands.

${ }^{6}$ Department of Dermatology, University Hospital Maastricht, The Netherlands.
} 


\begin{abstract}
Background: Liarozole, a retinoic acid metabolism blocking agent, has been granted orphan drug status for congenital ichthyosis by the European Commission and the U.S. Food and Drug Administration.

Objective: The purpose of this trial was to investigate the efficacy, tolerability and safety of oral liarozole vs. acitretin in patients with ichthyosis.

Methods: In this double-blind comparative trial of liarozole vs. acitretin, 32 patients with ichthyosis were randomized to be treated with either oral liarozole $75 \mathrm{mg}$ in the morning and $75 \mathrm{mg}$ in the evening or with acitretin $10 \mathrm{mg}$ in the morning and $25 \mathrm{mg}$ in the evening for 12 weeks. Clinical efficacy, tolerability and safety were monitored.

Results: Between-group comparisons for efficacy and tolerability revealed no statistically significant differences except for scaling on the trunk at baseline which was significantly worse in the liarozole group $(\mathrm{p}=0.024)$ and showed a more pronounced improvement in this group than in the acitretin-treated patients $(p=0.047)$. Based on the overall evaluation of the response to treatment at endpoint, 10 out of 15 patients in the liarozole group and 13 out of 16 patients in the acitretin group were considered by the investigator to be at least markedly improved. The expected retinoic acid-related adverse events were mostly mild to moderate and tended to occur less frequently in the liarozole group. No serious adverse events related to the drugs occurred.
\end{abstract}

Conclusion: The present study indicates that liarozole at a daily dose of $150 \mathrm{mg}$ is equally effective as a treatment for ichthyosis as acitretin but shows a trend towards a more favourable tolerability profile. The results of this trial warrant further clinical trials to confirm efficacy and safety of liarozole as an orphan drug in ichthyosis. 


\section{Introduction}

Ichthyosis is a general term used to describe a large and heterogeneous group of cornification disorders that are genetic in nature and are characterized clinically by the formation of visible scales all over the body surface and an excessively dry skin. ${ }^{1}$ Most types of ichthyosis, except for autosomal dominant ichthyosis vulgaris (ADIV, prevalence: 1/250), are rare diseases, e.g. X-linked recessive ichthyosis (XRI, 1/6000 males), lamellar ichthyosis (LI, 1/200,000), bullous congenital ichthyosiform erythroderma (CBIE, 1/300,000) exhibiting severe scaling not sufficiently improving with moisturizing or keratolytic creams. The quality of life of these patients may be severely affected. ${ }^{2}$ Treatment of these debilitating diseases is by definition lifelong, but the options for treatment are limited.

As disorders of keratinization, several forms of ichthyosis can be treated with all-transretinoic acid (all-trans-RA), a physiological derivative of vitamin A and one of the principal endogenous compounds that controls growth and differentiation of epithelial tissue. ${ }^{3}$ However, the pharmacological activity of all-trans-RA is restricted by its rapid rate of metabolism via cytochrome P-450 (CYP) enzymes and the use of systemic retinoids is limited by side effects and long-lasting teratogenicity. ${ }^{4,5}$ Alternatives are urgently needed.

Liarozole is an imidazole derivative developed in the late eighties by the Janssen Research Foundation in Belgium. It inhibits the CYP-dependent hydroxylation of alltrans-RA and represents a new class of drugs called retinoic acid metabolism blocking agents (RAMBAs). Liarozole has been granted orphan drug status for congenital ichthyosis by the European Commission and the U.S. Food and Drug Administration. Liarozole was identified through extensive in vitro ${ }^{6-8}$ and in vivo ${ }^{9-11}$ testing as an inhibitor of several mammalian CYP isoenzymes among which the one involved in the oxidative catabolism of all-trans-RA, the retinoic acid 4-hydroxylase. By inhibiting the intracellular breakdown of endogenous all-trans-RA, its levels in plasma and predominantly in the skin increase to slightly above normal. Unlike synthetic retinoids, which add massive amounts of exogenous retinoid-like substances to the body, liarozole uses the body's own production of retinoic acid to achieve therapeutic effects. Besides inhibiting the 4-hydroxylation of all-trans-RA, liarozole also inhibits cytochrome P450dependent steps in the biosynthetic pathways of testicular, ovarian and adrenal steroids, mainly the conversion of androgens to estrogens (aromatase), progestin to androgens (17-hydroxylase; 17,20-lyase) and of 11-deoxycorticosterone to corticosterone (11hydroxylase). ${ }^{12}$ However, the effect on testicular and adrenal steroid biosynthesis may not be clinical relevant, as upon chronic administration of oral liarozole in human 
volunteers, recovery of plasma testosterone and cortisol levels was achieved by pituitary compensation (unpublished data). In accordance, psoriasis patients receiving oral liarozole treatment for 3 months did not develop abnormalities in cortisol and testosterone levels. $^{13}$

Based on its mechanism of action and its pharmacokinetic profile, liarozole may offer an effective treatment in keratinisation disorders such as ichthyosis with a possibly more favourable tolerability profile compared to the current treatments. Liarozole has been extensively tested in prostate cancer and psoriasis. ${ }^{13-15}$ As far as ichthyosis is concerned, oral treatment with liarozole has been evaluated in an open exploratory trial where it was shown to cause substantial clinical improvement in all patients at a daily dose of up to $300 \mathrm{mg} .{ }^{16}$ Side effects were limited to mucocutaneous symptoms. Topical liarozole, as a $5 \%$ cream, has also been proven to be very effective in ichthyosis. ${ }^{17}$

The current article describes the results of a double-blind, multi-centre, comparative trial assessing the efficacy and safety of oral liarozole vs. the standard treatment of acitretin in patients diagnosed with different types of ichthyosis.

\section{Patients and methods}

\section{Patients}

To participate in this trial, men and women, aged 16 or more, had to be diagnosed with one of the following subtypes of ichthyosis: XRI, LI or CBIE. At least one of the severity parameters according to the investigator's assessment at baseline had to have a score of at least 2 on a 4 -point scale $(0=$ absent, $1=$ mild, $2=$ moderate, $3=$ severe). In addition, women had to be at least 2 years postmenopausal or to have had a hysterectomy. Patients had to be, except for their ichthyosis, in good health according to their history and physical examination.

Main exclusion criteria were concurrent inflammatory skin disease, topical or ultraviolet treatment within 2 weeks and systemic treatment within 4 weeks prior to the start of the treatment phase, use of vitamin A supplements ( $>1000 \mu \mathrm{g}$ daily) and clinically relevant abnormal laboratory test values. Patients were enrolled at 2 study centres: the Department of Dermatology of the University Medical Centre Nijmegen (The Netherlands) and the Department of Dermatology, Hôpital St.Louis in Paris (France). The trial protocol was reviewed and approved by each study centre's independent ethics committee and all patients provided written informed consent prior to enrollment. All clinical investigations were conducted according to the Declaration of Helsinki principles. 


\section{Treatment}

The trial was a phase II/III, multicentre, double-blind, randomized comparative study to investigate the efficacy, tolerability and safety of oral liarozole $150 \mathrm{mg}$ daily, vs. the standard treatment of acitretin $35 \mathrm{mg}$ daily in patients with ichthyosis. Duration of the treatment was 12 weeks. Minimum wash-out periods prior to starting medication were 1 month for systemic agents and two weeks for topical treatment or phototherapy. During the wash-out period, patients were only allowed to use bland emollients given by the investigator.

Both liarozole and acitretin were supplied as capsules identical in appearance, taste and smell and packaged in morning and evening boxes. Patients were instructed to take one capsule orally in the morning with food (liarozole $75 \mathrm{mg}$, acitretin $10 \mathrm{mg}$ ) and one capsule in the evening with a meal (liarozole $75 \mathrm{mg}$, acitretin $25 \mathrm{mg}$ ) with 12 hours between the two intakes. At the end of week 4 or week 8 of the treatment phase, the daily dosage could be increased as a function of tolerance and efficacy to liarozole 225 $\mathrm{mg}$ or acitretin $45 \mathrm{mg}$. If the patient did not tolerate the increased dosage, it could be lowered again.

\section{Randomization and blinding procedures}

Patients admitted to the trial were randomly allocated to one of the two treatment groups according to a randomization code generated by the Janssen Research Foundation. Balancing ensured that equal numbers of subjects were entered in each treatment group as required. In each center, subject numbers were assigned consecutively, starting with the lowest number available. The investigator was provided with a sealed envelope for each subject, containing coded details of the treatment in de double-blind phase. This code was to be broken only in case of emergency where the further treatment of the subject was dependent on the trial medication he or she had been receiving. If the code was broken the subject had to be withdrawn from the trial and followed up if appropriate. All sealed envelopes were collected at the end of the trial.

\section{Clinical evaluations}

At the pretrial visit, the investigator assessed whether the patient met the inclusion criteria, a complete and current medical history was recorded and a physical examination including vital signs and body weight was carried out. Fasting blood samples were taken for haematology and blood biochemistry. A urine sample was collected for urinalysis. 


\section{Clinical efficacy measures}

Clinical evaluation of the skin took place at weeks 0 (baseline), 4, 8 and 12 of the treatment phase. As no standardized efficacy-scoring methods are available for ichthyosis, we had to develop our own methods. Clinical efficacy was evaluated in terms of an overall evaluation of response to treatment (compared to baseline) rated by both the investigator and the patient using a 5-point scale: $0=$ deteriorated, $1=$ unchanged, $2=$ moderately improved, $3=$ markedly improved, $4=$ cleared. Other variables over the course of the study were severity of skin lesions assessed as individual symptoms (scales, erythema and bullae) scored for each location (trunk, upper limbs, and lower limbs) on a 4-point scale: $0=$ absent, $1=$ mild, $2=$ moderate, $3=$ severe. For each symptom, the sums of the scores over the different body sites were calculated and referred to as overall score for the specific symptom. In addition, for each location the sum was made for all symptoms and referred to as total symptom score for the specific location. An overall symptom score was calculated by summation over all symptoms and locations. Furthermore, photographs were taken under standardized conditions at baseline and, if possible, at all other visits.

\section{Tolerability and safety measures}

The tolerance to treatment was assessed by the subject by rating subjective symptoms of itching, redness, dry skin, dry lips and conjunctivitis on a 4-point scale: $0=$ absent, $1=$ mild, $2=$ moderate, $3=$ severe. Blood and urine samples were collected for haematology, biochemistry and urinalysis. Throughout the trial the patients were monitored for adverse events that were rated according to their severity (mild, moderate or severe) and relationship to the study medication (not, possibly or definitely related).

\section{Statistical analysis}

Sample size was determined empirically. As only a small number of patients with ichthyosis are available, a recruitment of 40 patients was considered realistic in the available time period. Results of hypothesis testing are reported as two-sided p-values. Two-sided p-values less than or equal to 0.05 were considered to indicate statistical significance.

In the analysis of the trial, two patient populations were defined: i) the all-patient population which includes patients who received at least one dose of drug and ii) the intent-to-treat population, which includes all randomized patients, who used at least one trial medication, and had post-baseline efficacy data. 
Analysis of efficacy was based on the intent-to-treat population. The primary efficacy variable was 'overall response to treatment at endpoint', defined as both the investigator's and patient's overall evaluation of response to treatment as at least markedly improved. Endpoint is defined as the last available observation of each patient. The number of responders for the primary efficacy variable was compared between the treatment groups using a two-sided Fisher exact probability test. In addition, 95\% confidence intervals were constructed around the difference in response rate between the two treatment groups. Possible investigator effects were examined by summarizing the response rates within each centre by descriptive statistics and confidence intervals. For each visit, descriptive statistics were calculated for the additional efficacy variables. Absolute values of the investigator's and patient's evaluation of response-to-treatment and of the individual severity symptom scores were analyzed for differences between treatment groups at each timepoint by means of the Cochran-Mantel-Haenszel row mean-scores test. Severity of skin lesions and its changes from baseline were evaluated for within-group difference using the Wilcoxon signed-rank test and for between group differences using the Wilcoxon-Mann-Whitney rank-sum test.

Tolerability was assessed in the intent-to-treat population both as individual symptoms and their sum as composite score for total tolerability. Absolute values of the individual tolerability symptoms were analyzed for differences between treatment groups at each time point by means of the Cochran-Mantel-Haenszel row mean-scores test. Changes from baseline of the individual tolerability symptoms and total tolerability score were evaluated for within-group difference using the Wilcoxon signed-rank test and for between group differences using the Wilcoxon-Mann-Whitney rank-sum test.

Analysis of safety was based on the all-patient population. Type and incidence of all adverse events were tabulated per treatment group and phase. For the clinical laboratory data, descriptive statistics and pre- vs. post-treatment cross tabulations (with classes for below, within and above normal ranges) were generated for all tests done. Important abnormalities, as determined by the occurrence of pathological values, were tabulated per treatment group and phase.

\section{Results}

\section{Patients}

Overall, 41 patients with ichthyosis were screened and 32 randomized, (all male, 30 of 32 white skinned) 15 to liarozole and 17 to acitretin. Baseline demographics were comparable between the two treatment groups and are summarized in Table 6.1. 
Table 6.1 Patient demographics at baseline. * expressed as median value. XRI=X-linked Recessive Ichthyosis; LI=Lamellar Ichthyosis; CBIE= Bullous Congenital Ichthyosiform Erythroderma

\begin{tabular}{|c|c|c|}
\hline Variable & Liarozole $(n=15)$ & Acitretin $(n=17)$ \\
\hline \multicolumn{3}{|l|}{ Ichthyosis subtypes: } \\
\hline XRI & 11 & 10 \\
\hline LI & 3 & 5 \\
\hline CBIE & 1 & 2 \\
\hline Age (years, range)* & $41(17-74)$ & $34(16-52)$ \\
\hline Height $(\mathrm{cm} \text {, range })^{*}$ & $179(165-197)$ & $176(161-193)$ \\
\hline Weight $(\mathrm{kg} \text {, range })^{*}$ & $69(59-91)$ & $68(52-112)$ \\
\hline Heart rate (beats/min, range)* & $68(52-112)$ & $64(52-88)$ \\
\hline
\end{tabular}

In the liarozole group, 6 patients had their daily dose increased up to $225 \mathrm{mg}$. One patient (CBIE) had to decrease the dose after 22 days because of an adverse event (bullous eruption) and switched to $75 \mathrm{mg}$ daily on alternating days. In the acitretin group 3 patients had their daily dose increased to $45 \mathrm{mg}$ and one to $60 \mathrm{mg}$. One patient (XRI) had to decrease the daily dose to $25 \mathrm{mg}$ after 57 days because of an adverse event (skin disorder).

Before trial completion, 3 patients in the liarozole group discontinued treatment due to adverse events and 2 discontinued in the acitretin group: one because of non-compliance and one due to adverse events (Figure 6.1). Two patients in the liarozole group had a second skin condition other than ichthyosis: one had a lipoma on the back, and another had multiple seborrhoeic keratoses.

For analysis on an intention-to-treat basis, 15 patients were suitable in the liarozole group and 16 in the acitretin group.

At baseline, there was no significant between-group difference for any of the individual symptom scores (scaling, erythema, bullae), on any of the body parts (trunk, upper and lower limbs) apart from the scaling on the trunk. The severity of scaling on the trunk at baseline was rated as severe in 10 of 15 patients of the liarozole group and only in 4 of 16 patients of the acitretin group $(\mathrm{p}=0.024)$. There was also a significant between-group difference for the total symptom score on the trunk $(\mathrm{p}=0.031)$ at baseline, with the liarozole patients having more severe symptoms than the acitretin patients. The tolerance scores between groups at baseline were not significantly different. For haematology, one patient in the liarozole group presented at baseline with a leucocytosis which normalized towards the end of the treatment. 


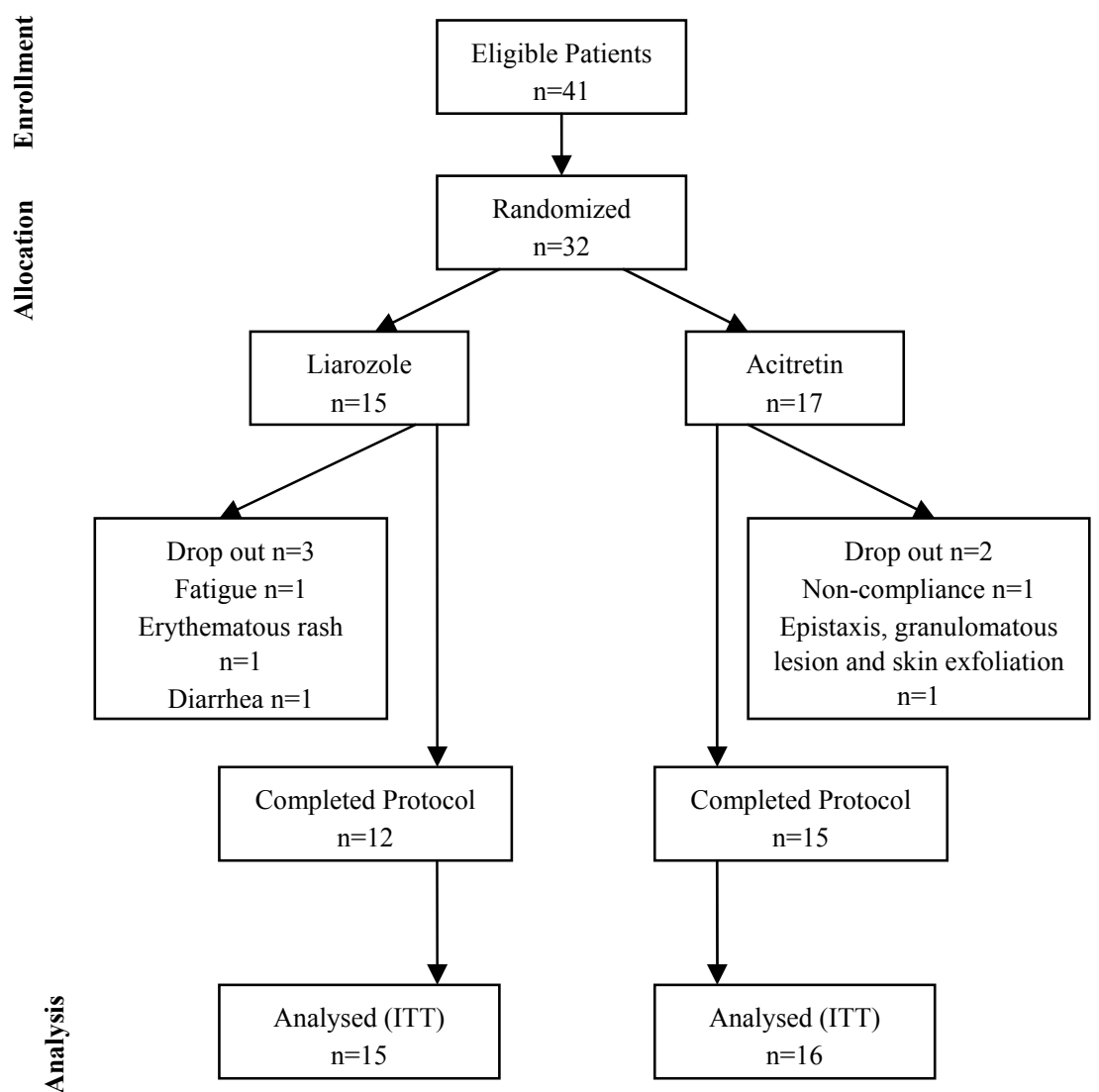

Figure 6.1 Participant Flow. ITT, intent-to-treat.

\section{Clinical efficacy evaluation}

Except for one patient in the acitretin group, the intention-to-treat population was identical to the all-patient population.

In the liarozole group, the investigators considered the overall response to treatment at endpoint as at least markedly improved in 10 of 15 patients, whereas 9 of 15 patients rated themselves as at least markedly improved. In the acitretin group, the investigators scored 13 of 16 patients as at least markedly improved at endpoint and 12 of 16 patients scored themselves as markedly improved. For both the investigator's and patient's overall evaluation of response to treatment, no statistically significant between-group difference was observed at any time point. Response to treatment at endpoint yielded 
9/15 responders in the liarozole group, while there were $12 / 16$ responders in the acitretin group. No statistically significant difference between treatment groups was observed $(\mathrm{p}=0.458)$. The $95 \%$ confidence interval of the difference in response rates (acitretin-liarozole) was $-18 \%$ to $48 \%$.

The parameters assessed for the severity of the skin lesions were scaling, erythema and formation of bullae on trunk, upper and lower limbs. An overview on the individual overall scores (for scaling, erythema and bullae) and the overall total symptom scores per treatment group at baseline vs. endpoint is presented in Table 6.2.

Apart from the scaling on the trunk at baseline $(\mathrm{p}=0.024)$, between-group comparisons showed no significant difference for any of the individual symptom scores (scaling, erythema, bullae) at any time point, on any of the body parts (trunk, upper and lower limbs). No statistically significant between-group differences were observed for the change in severity from baseline, at any time point, except for the scaling on the trunk at week $12(\mathrm{p}=0.024)$ and at endpoint $(\mathrm{p}=0.047)$.

Overall scaling (sum of scaling at all locations) at each time point had improved significantly from baseline $(\mathrm{p} \leq 0.001)$ within both treatment groups. Figure 6.2 shows the evaluation of the overall scaling, changes from baseline as a function of time. For overall erythema and overall bullae no significant changes from baseline were observed in any of the treatment groups.

The overall total symptom score, in both treatment groups, had significantly improved from baseline, reaching $\mathrm{p}<0.001$ for liarozole and $\mathrm{p}=0.008$ for acitretin at endpoint. No statistically significant between-group difference at any time point could be observed for the overall total symptom score and for the change from baseline. Figure 6.3 represents the overall total symptom score (= sum of all symptoms at all sites), changes from baseline for both treatment groups as a function of time. Examples of clinical photographs are presented in figures 6.4 and 6.5 . 
Table 6.2 Overview of the individual overall scores (scales, erythema, bullae) and the overall symptom score at baseline (B) versus endpoint (E) for both treatment groups. Maximum possible overall score for scaling, erythema and bullae is 9 each; maximum possible overall total symptom score is $27 . \mathrm{XRI}=\mathrm{X}$-linked recessive ichthyosis; LI=lamellar ichthyosis; $\mathrm{CBIE}=$ bullous congenital ichthyosiform erythroderma; ITT=intent-totreat.

Overall score:
scales $(\mathbf{B} / \mathbf{E})$

Overall score:
erythema $(B / E)$

Overall score:
bullae (B/E)

Overall total
symptom score: $(\mathrm{B} / \mathrm{E})$

\section{Liarozole (ITT, $\mathbf{n = 1 5 )}$}

\begin{tabular}{|c|c|c|c|c|c|}
\hline 1 & XRI & $9 / 2$ & $0 / 0$ & $0 / 0$ & $9 / 2$ \\
\hline 2 & XRI & $9 / 1$ & $0 / 2$ & $0 / 0$ & $9 / 3$ \\
\hline 3 & XRI & $4 / 0$ & $0 / 0$ & $0 / 0$ & $4 / 0$ \\
\hline 4 & XRI & $9 / 2$ & $0 / 0$ & $0 / 0$ & $9 / 2$ \\
\hline 5 & XRI & $9 / 6$ & $0 / 0$ & $0 / 0$ & $9 / 6$ \\
\hline 6 & XRI & $9 / 1$ & $0 / 3$ & $0 / 0$ & $9 / 4$ \\
\hline 7 & XRI & $9 / 1$ & $0 / 0$ & $0 / 0$ & $9 / 1$ \\
\hline 8 & XRI & $9 / 2$ & $9 / 3$ & $0 / 0$ & $18 / 5$ \\
\hline 9 & XRI & $7 / 3$ & $0 / 0$ & $0 / 0$ & $7 / 3$ \\
\hline 10 & XRI & $3 / 4$ & $1 / 1$ & $0 / 0$ & $4 / 5$ \\
\hline 11 & XRI & $6 / 2$ & $3 / 0$ & $0 / 0$ & $9 / 2$ \\
\hline 12 & LI & $9 / 0$ & $4 / 6$ & $0 / 0$ & $13 / 6$ \\
\hline 13 & LI & $6 / 1$ & $3 / 9$ & $0 / 0$ & $9 / 10$ \\
\hline 14 & LI & $9 / 3$ & $3 / 0$ & $0 / 0$ & $12 / 3$ \\
\hline 15 & CBIE & $9 / 6$ & $6 / 6$ & $2 / 1$ & $17 / 13$ \\
\hline \multicolumn{6}{|c|}{ Acitretin (ITT, n=16) } \\
\hline 1 & XRI & $9 / 9$ & $0 / 0$ & $0 / 0$ & $9 / 9$ \\
\hline 2 & XRI & $9 / 1$ & $0 / 2$ & $0 / 0$ & $9 / 3$ \\
\hline 3 & XRI & $6 / 0$ & $0 / 3$ & $0 / 0$ & $6 / 3$ \\
\hline 4 & XRI & $7 / 0$ & $0 / 0$ & $0 / 0$ & $7 / 0$ \\
\hline 5 & XRI & $5 / 0$ & $0 / 0$ & $0 / 0$ & $5 / 0$ \\
\hline 6 & XRI & $8 / 2$ & $0 / 0$ & $0 / 0$ & $8 / 2$ \\
\hline 7 & XRI & $5 / 6$ & $0 / 3$ & $0 / 0$ & $5 / 9$ \\
\hline 8 & XRI & $6 / 1$ & $0 / 0$ & $0 / 0$ & $6 / 1$ \\
\hline 9 & XRI & $7 / 1$ & $0 / 0$ & $0 / 0$ & $7 / 1$ \\
\hline 10 & XRI & $5 / 0$ & $3 / 0$ & $0 / 0$ & $8 / 0$ \\
\hline 11 & LI & $9 / 3$ & $6 / 3$ & $0 / 0$ & $15 / 6$ \\
\hline 12 & LI & $6 / 3$ & $0 / 0$ & $0 / 0$ & $6 / 3$ \\
\hline 13 & LI & $7 / 3$ & $0 / 3$ & $0 / 0$ & $7 / 6$ \\
\hline 14 & LI & $6 / 3$ & $6 / 3$ & $0 / 0$ & $12 / 6$ \\
\hline 15 & CBIE & $9 / 6$ & $0 / 6$ & $0 / 4$ & $9 / 16$ \\
\hline 16 & CBIE & $8 / 3$ & $6 / 3$ & $0 / 0$ & $14 / 6$ \\
\hline
\end{tabular}




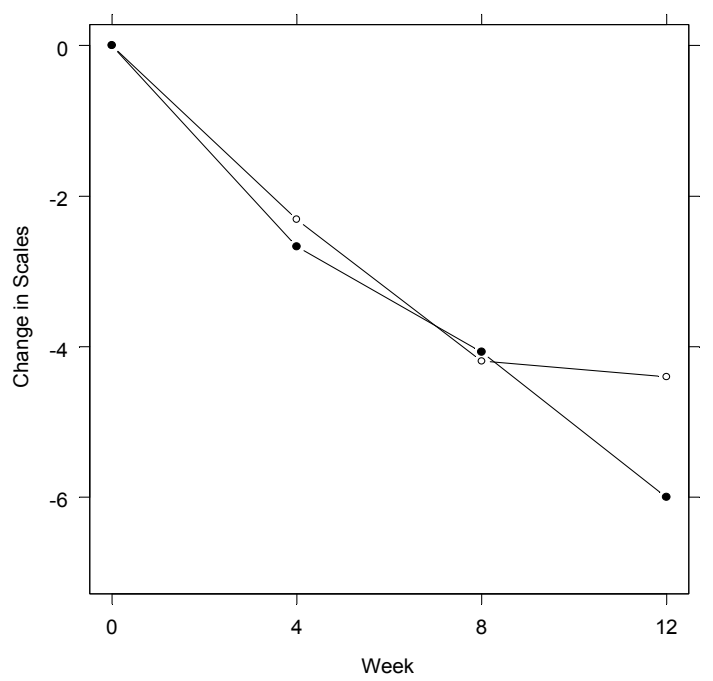

Figure 6.2 Evaluation of the overall symptom score: changes in scaling from baseline as a function of time. Filled circles $(\bullet)$ represent liarozole and empty circles $(\bigcirc)$ represent acitretin median values.

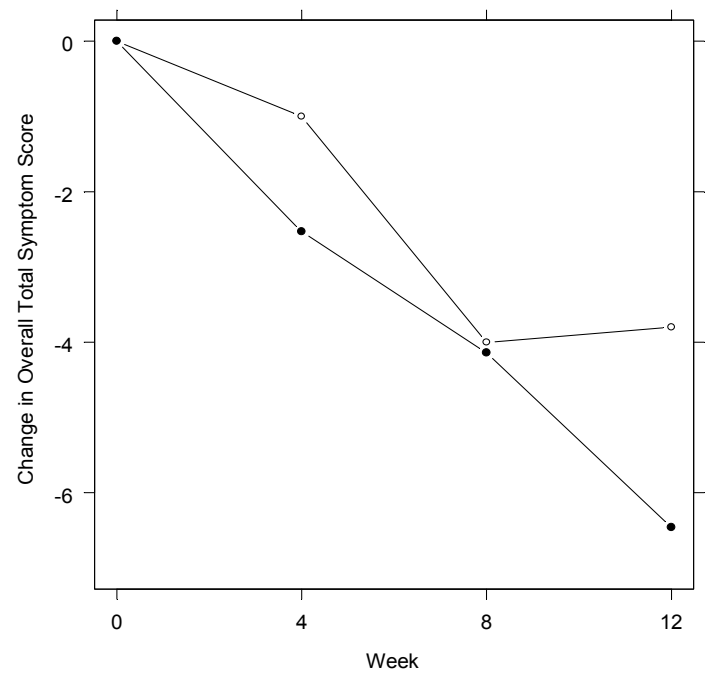

Figure 6.3 Evaluation of the overall total symptom score changes from baseline as a function of time. Filled circles $(\bullet)$ represent liarozole and empty circles $(\bigcirc)$ represent acitretin median values 

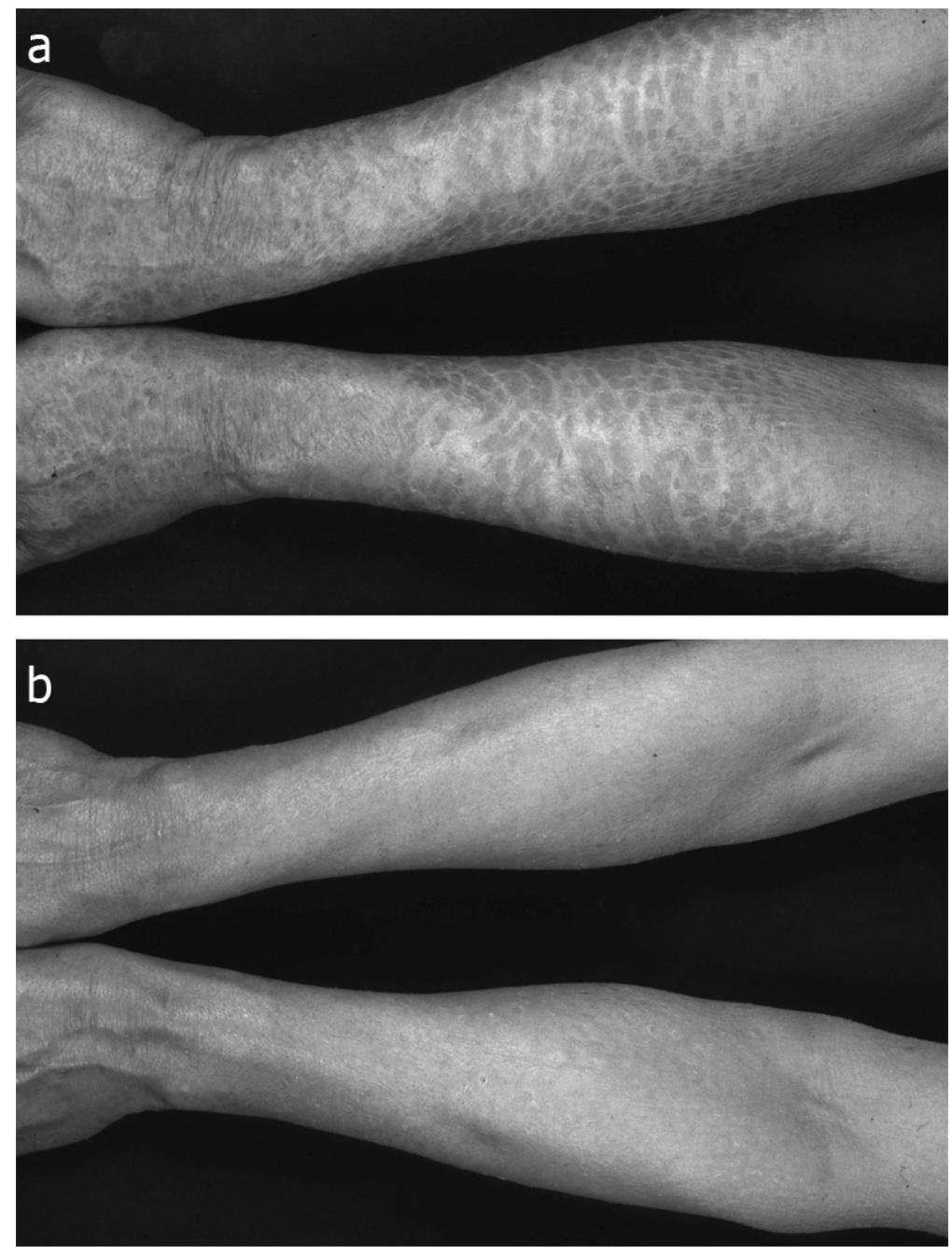

Figure 6.4 A patient with lamellar ichthyosis with the typical phenotype consisting of large brown scales covering the arm: (a) before treatment and (b) after 2 weeks of treatment with $75 \mathrm{mg}$ liarozole twice daily. See page 231 for colour figure. 

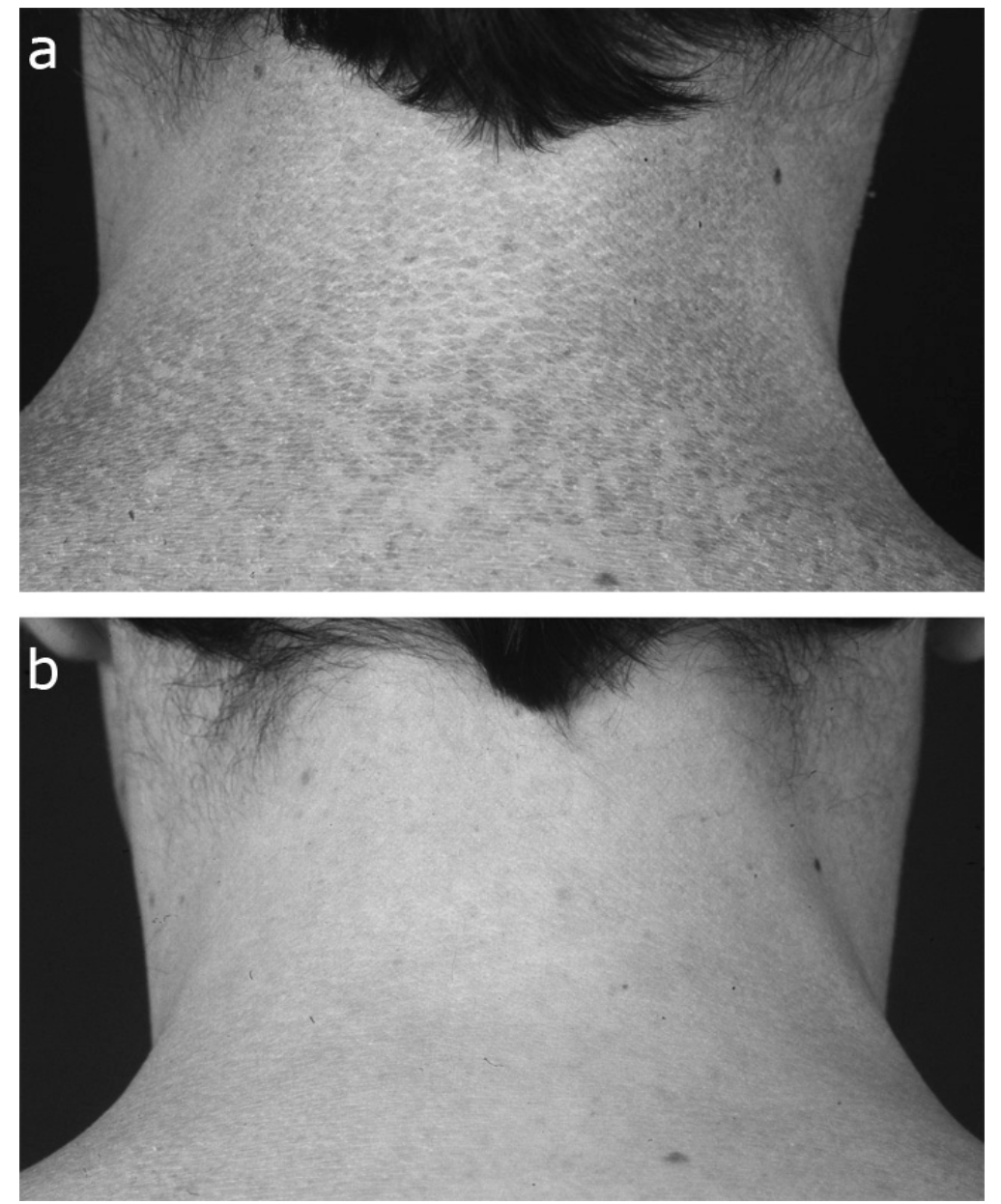

Figure 6.5 Typical hyperkeratosis in the neck of a patient with X-linked recessive ichthyosis which is giving the so-called 'dirty look' present before treatment with liarozole (a). Scaling is almost completely absent after treatment with liarozole (b). See page 232 for colour figure. 


\section{Tolerability and safety evaluation}

The evaluation of the tolerance to treatment (itching, redness, dry skin, dry lips, and conjunctivitis) by the patients showed no statistically significant between-group differences at any time point. An overview of the tolerance score per treatment group is given in Table 6.3. Within both groups, significant changes from baseline were observed at endpoint for dry skin which had improved (liarozole $\mathrm{p}=0.020$, acitretin $\mathrm{p}<0.001$ ) and dry lips which had worsened (liarozole $\mathrm{p}=0.003$, acitretin $\mathrm{p}<0.001$ ). Itching, being absent to mild at baseline in the majority of patients, improved in both treatment groups during treatment except for week 4 where it had worsened in the acitretin group. At endpoint, itching was absent in 11 of 15 and mild in 4 of 15 patients in the liarozole group versus 10 of 17 and 6 of 17 in the acitretin group. One patient in the acitretin group still had severe itching.

Table 6.3 Overview of tolerance scores of both treatment groups. No statistically significant between-group differences were observed. Significant changes from baseline were observed in both groups for dry skin (improvement) and dry lips (worsening).

\begin{tabular}{|c|c|c|c|c|}
\hline \multirow[b]{3}{*}{ Symptoms: } & \multicolumn{4}{|c|}{ Scores: Absent/mild/moderate/severe, $n$} \\
\hline & \multicolumn{2}{|c|}{ Liarozole $(n=15)$} & \multicolumn{2}{|c|}{ Acitretin $(n=17)$} \\
\hline & Baseline & Endpoint & Baseline & Endpoint \\
\hline Itching & $6 / 8 / 0 / 1$ & $11 / 4 / 0 / 0$ & $6 / 9 / 1 / 1$ & $10 / 6 / 0 / 1$ \\
\hline Redness & $8 / 3 / 3 / 1$ & $7 / 5 / 2 / 1$ & $12 / 1 / 4 / 0$ & $8 / 7 / 2 / 0$ \\
\hline Dry skin & $4 / 0 / 3 / 8$ & $5 / 5 / 4 / 1$ & $1 / 0 / 10 / 6$ & $5 / 8 / 1 / 3$ \\
\hline Dry lips & $12 / 2 / 1 / 0$ & $1 / 10 / 3 / 1$ & $13 / 4 / 0 / 0$ & $1 / 10 / 4 / 2$ \\
\hline Conjunctivitis & $15 / 0 / 0 / 0$ & $14 / 1 / 0 / 0$ & $17 / 0 / 0 / 0$ & $16 / 1 / 0 / 0$ \\
\hline
\end{tabular}

As shown in Table 6.4, the investigators reported 10 adverse events in $46 \%(\mathrm{n}=7)$ of the patients in the liarozole group and 25 adverse events in $71 \%(\mathrm{n}=12)$ of the patients in the acitretin group. Most reported adverse events were mild to moderate. The most frequently reported adverse events occurring in $\geq 10 \%$ of the patients in the liarozole group were dry mouth and skin disorder (sticky skin) and in the acitretin group dry mouth, skin exfoliation, skin disorder (sticky skin and irritated skin), eczema and epistaxis.

Before trial completion, 3 patients dropped out in the liarozole group due to adverse events: diarrhoea (moderate, not drug-related), fatigue (mild, possibly drug-related) and erythematous rash on face and hands (moderate, definitely drug-related). In the acitretin group, one drop-out was due to adverse events of epistaxis (severe), periungual granu- 
lomatous tissue (moderate) and skin exfoliation (moderate), all considered definitely drug-related. Apart from epistaxis, no other adverse events were reported as severe. No deaths or serious adverse events were reported throughout the study.

Table 6.4 Overview of adverse events profile of both treatment groups.

\begin{tabular}{|c|c|c|}
\hline & $\begin{array}{l}\text { Liarozole } \\
(n=15)\end{array}$ & $\begin{array}{c}\text { Acitretin } \\
(\mathbf{n}=17)\end{array}$ \\
\hline Number of patients with 1 or more adverse events during treatment & 7 & 12 \\
\hline \multicolumn{3}{|l|}{ Adverse events reported in $\geq 10 \%$ of patients in any treatment group, $n$} \\
\hline Dry mouth & 2 & 3 \\
\hline Skin exfoliation & 0 & 4 \\
\hline Skin disorder & 1 & 3 \\
\hline Eczema & 0 & 2 \\
\hline Epistaxis & 0 & 2 \\
\hline Serious adverse events & 0 & 0 \\
\hline Discontinuations & $3^{\mathrm{a}}$ & $2^{\mathrm{b}}$ \\
\hline Deaths & 0 & 0 \\
\hline $\begin{array}{l}\text { a due to adverse events } \\
{ }^{b} \text { one due to adverse events and one due to non-compliance }\end{array}$ & & \\
\hline
\end{tabular}

Blood biochemistry in the liarozole group showed three abnormal values. One patient had a slight increase in chlorine (113 mmol/l, upper limit 111) at week 4 and also a slight increase in alanine aminotransferase (78 U/1, upper limit 60). Another patient had an increase in triglycerides at week $12(3.22 \mathrm{mmol} / \mathrm{l}$, upper limit 2.5$)$. In the acitretin group, 5 abnormal values were seen in the blood biochemistry: one patient had a limited increase of urea on week $8(9.7 \mathrm{mmol} / \mathrm{l}$, upper limit 8.3$)$, which almost normalized to $8.9 \mathrm{mmol} / \mathrm{l}$ at week 12 and 4 patients had elevated triglycerides (Table 6.5). Most biochemical factors tested did not show significant changes. None of the changes mentioned was considered of major clinical relevance.

Table 6.5 Overview of values from patients with elevated triglycerides (mmol/l) during the treatment period. Upper limit for triglycerides is $2.5 \mathrm{mmol} / \mathrm{l}$. ND, not determined.

\begin{tabular}{|l|c|c|c|c|}
\hline Treatment group & Baseline & Week 4 & Week 8 & Week 12 \\
\hline Liarozole & 1.21 & 2.26 & 1.54 & 3.22 \\
\hline Acitretin & 2.24 & 2.72 & 4.52 & 2.75 \\
\hline Acitretin & 2.27 & 2.50 & 2.54 & 3.19 \\
\hline Acitretin & 2.02 & 1.65 & ND & 2.93 \\
\hline Acitretin & 1.65 & 3.06 & 2.50 & 2.81 \\
\hline
\end{tabular}




\section{Discussion}

Retinoids have been shown to normalize deregulated proliferative activity and exert some anti-inflammatory action. ${ }^{18}$ Although the underlying genetic defect within the ichthyosis population is heterogeneous, retinoids have been employed with good or excellent results in many types of ichthyosis except in ADIV. ${ }^{1}$ However, systemic administration of retinoids is frequently associated with mucocutaneous side-effects, liver toxicity and abnormalities of serum lipid profiles. ${ }^{19,20}$ Today, although not approved in certain countries, e.g. the USA, acitretin is the most effective systemic treatment for most types of severe ichthyosis. The major issues with acitretin, from a clinical point of view, are hyperlipidaemia and its long-term teratogenicity. Pre-menopausal women are advised not to become pregnant for at least 2 (Europe) to 3 (USA) years following treatment. During acitretin treatment in psoriasis at a daily dose of $30-60 \mathrm{mg}$, a $35 \%$ increase in serum triglycerides was observed. ${ }^{21}$ Topical retinoids may represent good alternatives to avoid the systemic side-effects, although to date they have not been shown to be successful because of their propensity for skin irritation with the possible exception of 13-cis-retinoic acid. ${ }^{22}$ Short-term topical application of tazarotene, a novel receptor selective retinoid, has proven to be effective but, as with other retinoids, irritancy is a significant side-effect. ${ }^{23}$ So far, no specific treatment modalities are available for the heterogeneous group of ichthyosis. Considering the toxicity associated with existing oral therapies, there is need for safer and more effective agents. Compounds enhancing intracellular all-trans-RA levels, RAMBAs, represent a new therapeutic concept.

RAMBAs are distinctively different from synthetic retinoids. RAMBAs are "nonretinoid' drugs that block the intracellular breakdown of the body's own retinoic acid. In doing so, the intracellular all-trans-RA concentration increases to therapeutic levels but only in those tissues where all-trans-RA is metabolized by the 4-hydroxylase, including the skin. Animal and human studies have shown that the pharmacological effects of liarozole are mediated by enhanced levels of endogenous retinoic acid in the body. Oral administration of liarozole to rats delayed the plasma elimination rate of intrajugularly injected all-trans-RA and enhanced the plasma levels of endogenous all-trans-RA confirming the in vivo suppressive activity of liarozole on the biodegradation of endogenous RA. ${ }^{9-10}$ In addition, endogenous all-trans-RA levels in various tissues were enhanced (unpublished data) and kinetic studies both in humans and animals revealed a rapid clearance of liarozole from the plasma and a normalization of all-trans-RA levels (within $24 \mathrm{hrs}$ ) once treatment was stopped. ${ }^{24}$ Following a twice-daily dose of $150 \mathrm{mg}$ liarozole in healthy male volunteers, steady-state was attained within 2 days of dosing 
with mean liarozole plasma concentrations fluctuating between 0.36 and $2.57 \mu \mathrm{g} / \mathrm{ml}$. Plasma concentrations of liarozole hardly accumulated, the mean accumulation ratio was about 1.3 and the terminal half-life after the last $150-\mathrm{mg}$ dose averaged 8.7 hours. In contrast to synthetic retinoids which are delivered to the body in large amounts and tend to stay in tissues and fat for months or even years, RAMBAs do not expose tissues to these high all-trans-RA concentrations responsible for retinoid-related chronic toxicity and teratogenicity for months to years after discontinuation of therapy.

Liarozole is effective in different types of ichthyosis at a daily dosage of $150 \mathrm{mg}$. This finding is in agreement with the results from a previous trial in which liarozole was administered up to $300 \mathrm{mg}$ daily to ichthyosis patients for 12 weeks. ${ }^{16}$ Compared with acitretin, no significant differences were observed for any of the efficacy parameters except for the improvement of the scaling on the trunk at week $12(p=0.024)$ and at endpoint ( $\mathrm{p}=0.047$ ). This observation might be explained by assuming that liarozole is more effective at clearing severe scaling than is acitretin. Alternatively, as scaling on the trunk at baseline was more severe in the liarozole group, improvement of scaling may have been more obvious to the observers, resulting in relatively higher scores in symptom improvement. However, we consider it unlikely that all observers had the same bias. Hence we favour the former explanation. Most patients from both treatment groups had XRI and only a few presented with LI or CBIE. The main reason for this is probably the lower incidence $(1 / 200,000-1 / 300,000)$ of the latter subtypes compared to XRI (1/6,000 males). Also the fact that women were excluded unless they were at least 2 years postmenopausal or had had a hysterectomy made inclusion of patients with LI and CBIE even harder.

The expected retinoic acid related adverse events were mostly mild to moderate in both groups but tended to occur less frequently in the liarozole group. The incidence of hypertriglyceridaemia in this trial was also lower in the liarozole group $(n=1)$ than in the acitretin group $(n=4)$. Importantly, the main advantage of liarozole over acitretin lies in the inherent property that liarozole has towards long-term teratogenicity, a major drawback for the use of oral retinoids in women. Its efficacy and its particular pharmacokinetics make the use of liarozole an attractive candidate for the treatment of ichthyosis. In conclusion, the efficacy and safety results obtained in this study warrant further development of liarozole as an orphan drug in ichthyosis. Considering the diversity of the ichthyosis types and the small number of patients within this study, a larger study will be needed to confirm these results. An international multicentre phase II/III study in patients with LI is ongoing. 


\section{Acknowledgements}

The authors thank Luc Meuleners and Luc Wouters for their help with the statistical analysis.

\section{References}

1. Traupe $\mathrm{H}$, ed. The Ichthyoses. A guide to clinical diagnosis, genetic counselling and therapy. Berlin: Springer-Verlag, 1989.

2. Ganemo A, Lindholm C, Lindberg M, et al. Quality of life in adults with congenital ichthyosis. $J A d v$ Nurs 2003; 44: 412-9.

3. Chytil F. Retinoic acid: Biochemistry, pharmacology, toxicology and therapeutic use. Pharmacol Rev 1984; 36: 93-100.

4. Orfanos C, Ehlert R, Gollnick H. The retinoids, a review of their clinical pharmacology. Drugs 1987; 34: 459-503.

5. Pilkington T, Brogden R. Acitretin. A review of its pharmacology and therapeutic use. Drugs 1992; 43: 597-627.

6. Wouters W, van Dun J, Dillen A, et al. Effects of liarozole, a new antitumoral compound, on retinoic acid induced inhibition of cell growth and on retinoic acid metabolism in MCF-7 human breast cancer cells. Cancer Res 1992; 52: 2841-6.

7. Williams J, Napoli J. Metabolism of retinoic acid and retinol during differentiation of F9 embryonal carcinoma cells. Proc Natl Acad Sci USA 1985; 82: 4658-62.

8. De Coster R, Wouters W, van Ginckel R, et al. Experimental studies with liarozole (R75251): an antitumoral agent which inhibits retinoic acid breakdown. J Steroid Biochem Mol Biol 1992; 43: 197-201.

9. Van Wauwe J, Coene MC, Goossens J, et al. Effects of cytochrome P-450 inhibition on the in vivo metabolism of all-trans-retinoic acid in rats. J Pharmacol Exp Ther 1990; 252: 365-9.

10. Van Wauwe J, Van Nyen G, Coene MC, et al. Liarozole, an inhibitor of retinoic acid metabolism, exerts retinoid-mimetic effects in vivo. J Pharmacol Exp Ther 1992; 261: 773-8.

11. Kang S, Duell E, Kim K, et al. Liarozole inhibits human epidermal retinoic acid 4-hydroxylase activity and differentially augments human skin responses to retinoic acid and retinol in vivo. J Invest Dermatol 1996; 107: 183-7.

12. Bruynseels J, De Coster R, van Rooy P, et al. R 75251, a new inhibitor of steroid biosynthesis. Prostate 1990; 16: 345-57.

13. Berth-Jones J, Todd G, Hutchinson P, et al. Treatment of psoriasis with oral liarozole: a dose-ranging study. Br J Dermatol 2000; 143: 1170-6.

14. Dockx P, Decree J, Degreef H. Inhibition of the metabolism of endogenous retinoic acid as treatment for severe psoriasis: an open study with oral liarozole. Br J Dermatol 1995; 133: 426-32.

15. Bhushan M, Burden AD, McElhone K, et al. Oral liarozole in the treatment of palmoplantar pustular psoriasis: a randomized, double-blind, placebo-controlled study. Br J Dermatol 2001; 145: 546-53.

16. Lucker G, Heremans A, Boegheim P, et al. Oral treatment of ichthyosis by the cytochrome P-450 inhibitor liarozole. Br J Dermatol 1997; 136: 71-5.

17. Lucker G, Verfaille C, Heremans A, et al. Topical liarozole in ichthyosis: a double-blind, left-right comparative study followed by a long-term open maintenance study. Br J Dermatol 2005; 152: 566-9. 
18. Orfanos C, Zouboulis C, Almond-Roesler B, et al. Current use and future potential role of retinoids in dermatology. Drugs 1997; 53: 358-88.

19. David M, Hodak E, Lowe N. Adverse effects of retinoids. Medical Toxicology 1988; 3: 273-88.

20. Peck G, DiGiovanna J. Synthetic retinoids in dermatology. In: The retinoids: Biology, Chemistry and Medicine (Sporn M, Roberts A, Goodman D, eds), $2^{\text {nd }}$ edn. New York: Raven Press, 1994; 631-58.

21. Valquist C, Selinus I, Vessby B. Serum lipids changes during acitretin (etretin) treatment of psoriasis and palmo-plantar pustulosis. Acta Derm Venereol Stockh 1988; 68: 300-5.

22. Lucker G, van de Kerkhof P, Castelijns F, et al. Topical treatment of ichthyosis with 13-cis-retinoic acid. A clinical and immunohistochemical study. Eur J Dermatol 1995; 5: 566-71.

23. Hofmann B, Stege H, Ruzicka T, et al. Effect of topical tazarotene in the treatment of congenital ichthyoses. Br J Dermatol 1999; 141: 642-6.

24. Barrett $\mathrm{D}$, Bryla $\mathrm{P}$, van de Velde, et al. Liarozole investigators' brochure, $2^{\text {nd }}$ edn, version $5.0,22$ February 2005. Data on file at Barrier Therapeutics. 


\section{Retinoids and RAMBAs in psoriasis}

Based on:

van de Kerkhof $P C M^{1}$ and Verfaille $C J^{2,3}$. Retinoids and RAMBAs in psoriasis. In: Retinoids and Carotenoids in Dermatology. Valquist A\& Duvic M, eds. New York: Taylor and Francis Group, LLC; 2007.

In press.

${ }^{1}$ Department of Dermatology, Radboud University Nijmegen Medical Centre, The Netherlands.

${ }^{2}$ Departments of Dermatology \& Molecular Cell Biology, GROW, Maastricht University,

The Netherlands.

${ }^{3}$ Barrier Therapeutics nv, Geel, Belgium. 


\section{Introduction}

It is well known that psoriasis is a retinoid-sensitive disease. For decades, topical as well as oral retinoids have been widely used as anti-psoriatic treatments. In general, topical treatment remains the most frequently used therapy for patients with mild to moderate psoriasis, whereas systemic retinoids contribute to the therapeutic management of patients with more severe and recalcitrant types of psoriasis.

The aim of this chapter is to give a brief overview of the history of retinoids in psoriasis and to focus on the clinically relevant data of topical tazarotene and oral acitretin, two retinoids that are largely contributing to the therapeutic management of patients with psoriasis. Oral tazarotene will be discussed briefly. Finally, the characteristics and future perspectives of the rexinoids (bexarotene) and the retinoic acid metabolism blocking agents (RAMBAs) in psoriasis will be highlighted.

\section{History and disease characteristics}

Psoriasis is a chronic, multi-factorial and complex skin disorder affecting 1 to $3 \%$ of the world's population. It is characterized by well-defined red patches covered by silvery, flaky scales ranging from a few spots on the extensor surfaces and the scalp to large areas all over the body. The disease can evolve with periodic flare-ups. There are several variations of psoriasis but the most common type is chronic plaque psoriasis. The cause of psoriasis is unknown and although psoriasis manifests itself as a skin disorder, it is not excluded that the disease is caused by impaired or defective cell mediated immunity (T-cell driven). It has been known for quite a long time that psoriasis runs in some families. Analysis of concordance rates amongst monozygotic and dizygotic twins is another source of evidence that genetic factors are importance for psoriasis. Psoriasis is associated with HLA-B13, HLA-B17, HLA-B37 and HLA-Cw6. Further studies revealed that these latter associations were secondary to an association with HLA-Cw6.

Based upon analyses of family pedigrees, a polygenic inheritance provides the best model for the complex genetics of psoriasis. Genome-wide linkage scans have demonstrated several genetic loci for psoriasis; these studies have recently been reviewed by Rahman and Elder ${ }^{1}$.

Table 7.1 summarizes gene loci linked to psoriasis. PSORS1 has been mapped to chromosome $6 \mathrm{p} 21.3$ by independent groups and is considered to be a major gene involved in psoriasis. It was found that about $50 \%$ of psoriatic patients had involvement of PSORS1. In fact, the critical region appears to be a $300 \mathrm{~kb}$ interval around the centromere end of 
class I MHC. Although HLA-Cw6 is clearly associated with psoriasis, it is unlikely that HLA-C itself is the susceptibility gene.

Table 7.1 Overview of gene loci involved in the pathogenesis of psoriasis

\begin{tabular}{|c|c|}
\hline Gene Locus & Position on chromosome \\
\hline PSORS1 & $6 \mathrm{p} 21.3$ \\
\hline PSORS2 & $17 \mathrm{q} 25$ \\
\hline PSORS3 & $4 \mathrm{q} 32-35$ \\
\hline PSORS4 & $1 \mathrm{q} 21$ \\
\hline PSORS5 & $3 \mathrm{q} 21$ \\
\hline PSORS6 & $19 \mathrm{p} 13-\mathrm{q} 13$ \\
\hline PSORS7 & $1 \mathrm{p} 35-34$ \\
\hline PSORS8 & $16 \mathrm{q} 12-13$ \\
\hline PSORS9 & $4 \mathrm{q} 31-34$ \\
\hline PSORASI & $16 \mathrm{q} 12$ \\
\hline
\end{tabular}

Histological examination of the psoriatic lesions reveals the following abnormalities: epidermal hyperproliferation, premature keratinisation and immune cell infiltration ${ }^{2}$. Up to now no preventive therapy exists for psoriasis, symptomatic therapy is the only therapy available.

The history of the development of retinoids in dermatology goes back decades and comprises several generations which have been extensively described in the first chapter of this book. ${ }^{3,4}$ Briefly, already in the beginning of the last century, it was known that Vitamin A (retinol) plays a major role in the proliferation and differentiation of epithelial structures. Vitamin A deficiency in man results in dry skin with follicular hyperkeratosis. At that time, an essential role of vitamin A was also attributed in diseases like Darier's disease and ichthyosis.

Vitamin A was investigated at non-physiological doses in acne and psoriasis. Megadoses of vitamin A (2-4 million IU) resulted only in a slight improvement of psoriasis, but the symptoms of a vitamin A intoxication such as intracranial hypertension with nervous disturbances, dryness of the mucous membranes and skin, peeling of the skin were unacceptable. ${ }^{5}$ Hundreds of derivatives of vitamin A were investigated and tretinoin (all-trans-retinoic acid) as well as isotretinoin (13-cis-retinoic acid) proved to be therapeutic substances in the topical treatment of acne. ${ }^{6}$ However tretinoin and isotretinoin had no anti-psoriatic potential following topical application. We had to wait 
until 1997 before tazarotene, the first topical retinoid to be active in psoriasis, became available.

Because the efficacy of orally administrated vitamin A and all-trans-retinoic acid (alltrans-RA) was insufficient, the search for synthetic analogues with a better efficacy and safety profile resulted in the synthesis of the mono-aromatic retinoids like etretinate and later of its free active carboxylic acid metabolite acitretin. Etretinate and acitretin are highly and equally effective systemic treatments for psoriasis and adverse events appear to be similar in severity and incidence. Today acitretin is the preferred systemic retinoid for the treatment of psoriasis because of its better pharmacokinetic profile. A major problem with systemic retinoids is their teratogenicity and a separation of this phenomenon from their therapeutic effects has still not been achieved. The search for new ligands offering at least the same efficacy and a better risk/benefit ratio than the existing retinoids has resulted in the development of specific RXR ligands or rexinoids like bexarotene which are effective but still not devoid of serious side effects.

Another new approach is to increase the endogenous retinoic acid levels in the skin by blocking the catabolism of intracellular all-trans-RA with a RAMBA. RAMBAs such as liarozole and its successor R115866 have been proven efficacious in the treatment of keratinisation disorders like psoriasis, ichthyosis and acne. Currently R115866 is intensively investigated for the treatment of psoriasis (Phase 2b). 


\section{Topical retinoids: Tazarotene}

Tazarotene is the first topical retinoid being approved for the treatment of psoriasis, despite the fact that several topical retinoids have been available for decades for retinoid sensitive diseases.

\section{Mechanism of action}

Tazarotene is a synthetic acetylenic retinoid. It is in fact an ethyl ester prodrug that is rapidly hydrolyzed to tazarotenic acid, its active and more water-soluble form. Having a more selective affinity for the retinoic acid receptors (RAR) than tretinoin, tazarotenic acid shows transactivation through RAR- $\gamma$ and RAR- $\beta$ and less through RAR- $\alpha .{ }^{7,8}$ It does not bind RXR. The mechanism of action of tazarotene in psoriasis is not defined but the drug has been shown to have both antiproliferative and anti-inflammatory activities. $^{9-11}$

\section{Pharmacokinetics}

Percutaneous penetration of topical tazarotene is limited. ${ }^{12}$ The systemic absorption after a single application in psoriatic patients is less than $1 \%$ of the applied dose and $2.6 \%$ and $5.3 \%$ after once daily applications during 2 weeks of tazarotene $0.05 \%$ and $0.1 \%$ gel respectively. After 12 weeks treatment with $0.05 \%$ and $0.1 \%$ tazarotene the systemic absorption was $1.8 \%$ and $3.9 \%$, respectively. ${ }^{13}$ In phase III trials with either the gel or the cream, low tazarotene plasma concentrations $(\leq 0.15 \mathrm{ng} / \mathrm{ml})$ were observed in $1-3 \%$ of the psoriatics after 12 weeks of treatment. ${ }^{12-15}$ Low but detectable $(>0.05 \mathrm{ng} / \mathrm{ml})$ plasma levels of tazarotenic acid were observed in $47-69 \%$ of these patients.

The mean half-life $\left(t^{1} / 2\right)$ of topical tazarotenic acid is similar in normal and psoriatic patients and is approximately 18 hours. Tazarotenic acid has a high affinity for plasma proteins $(>99 \%)$ and has a relatively small volume of distribution $(1.97 \mathrm{l} / \mathrm{kg})$. Tazarotene is mainly eliminated via urinary and faecal routes as sulfoxides and sulfones. CYP2C8 and flavine-containing mono oxygenases mediate oxidation of tazarotenic acid to its sulfoxide, which is the primary metabolite in urine. ${ }^{13}$

\section{Indications and contra-indications}

Topical tazarotene has been approved for the treatment of chronic plaque psoriasis in several countries and is available as a $0.05 \%$ and $0.1 \%$ cream or gel formulation. ${ }^{16-19} \mathrm{In}$ the US, tazarotene cream is indicated for plaque psoriasis and the gel for stable plaque 
psoriasis with up to $20 \%$ body surface involvement. In Europe, tazarotene gel is indicated for mild-to-moderate plaque psoriasis involving up to $10 \%$ body surface area.

Tazarotene is applied once daily in the evening and it is recommended to start with the $0.05 \%$ formulations and to increase the concentration if necessary and tolerated.

In view of its teratogenic potential, tazarotene is contra-indicated in pregnant women and in women who are not taking adequate birth control. Tazarotene is also contraindicated in patients being exposed to substantial sunlight and not using adequate sun protection and in patients using photosensitizers or having photodermatitis.

\section{Efficacy}

\section{Tazarotene as monotherapy}

Tazarotene gel $(0.05 \%$ and $0.1 \%)$ applied once daily for 12 weeks has been shown to be efficacious as monotherapy for mild to moderate plaque psoriasis in two large vehiclecontrolled clinical trials. ${ }^{14}$ With $0.1 \%$ tazarotene, already at week 1 , a statistically significant improvement compared to the vehicle could be observed whereas for the $0.05 \%$ formulation 4 weeks of treatment were needed.

Also the cream formulation proved beneficial in the treatment of psoriasis in two vehicle-controlled studies. ${ }^{15}$ Both the 0.05 and $0.1 \%$ cream formulations applied once daily for 12 weeks followed by a 12 weeks treatment free follow-up were significantly more effective than the vehicle cream. The $0.1 \%$ tazarotene cream was generally more effective than the $0.05 \%$ cream, although slightly less well tolerated. During the 12 weeks post treatment phase, both concentrations of tazarotene cream were significantly better than vehicle in maintaining therapeutic effect.

In one study $0.1 \%$ and $0.05 \%$ tazarotene gel formulations applied once daily for 12 weeks followed by a 12 week treatment free follow-up were compared to a potent corticosteroid, fluocinonide $0.05 \%$ cream twice daily. ${ }^{20}$ At the end of the 12 weeks treatment course both tazarotene gel formulations had a similar efficacy as the potent corticosteroid fluocinonide $0.05 \%$ cream but the corticosteroid showed an earlier onset of efficacy. Compared to tazarotene $0.05 \%$, fluocinonide cream was significantly better from week 2-8 and compared to tazarotene $0.1 \%$ at week 4 . Fluocinonide $0.05 \%$ cream should be the preferred treatment when a fast clearing is mandatory. On the other hand, tazarotene treatment has a slower relapse as compared to fluocinonide.

Comparative studies between tazarotene $0.1 \%$ gel once daily and calcipotriol $0.005 \%$ ointment twice daily revealed a superior efficacy of calcipotriol during the first 8 weeks 
but an equal efficacy after 12 weeks of treatment. ${ }^{21}$ Local irritation was noted only in the tazarotene treated lesions.

\section{Combination therapy with corticosteroids}

Whilst tazarotene is effective on its own, it is frequently used in the clinic in combination with corticosteroids or phototherapy in order to avoid retinoid dermatitis, which develops in a significant proportion of patients treated with tazarotene as a monotherapy.

The combination of tazarotene with various topical corticosteroids has been compared to tazarotene monotherapy, ${ }^{22-24}$ corticosteroid monotherapy ${ }^{25}$ and calcipotriol. ${ }^{26}$ In all trials, topical corticosteroid and tazarotene $0.1 \%$ gel were applied once daily, except in one study, where they were applied on alternate days. ${ }^{24}$

Table 7.2 summarizes the response rates obtained in two large scale studies comparing a 12 week treatment of plaque type psoriasis with tazarotene $0.1 \%$ gel monotherapy versus the combination with a corticosteroid. ${ }^{22,23}$ The combinations of $0.1 \%$ tazarotene gel with mid-to high potency corticosteroids show a higher efficacy than tazarotene monotherapy after 12 weeks treatment. ${ }^{23}$ The results from the low potency corticosteroid group did not statistically differ from the vehicle group.

It has also been shown that the median time to initial treatment success was substantially improved by combining tazarotene $0.1 \%$ gel with a corticosteroid. ${ }^{23}$ It took at least 4 weeks for tazarotene monotherapy + placebo to reach $50 \%$ improvement of PASI versus 3 weeks for the combination of tazarotene with fluocinolone acetonide $0.01 \%$ cream (high potency) and only 2 weeks for the combination with mometasone furoate $0.1 \%$ cream (mid-potency). The best performing steroid was betamethasone dipropionate $0.05 \%$ cream but the best strategy based on efficacy and tolerability in both studies was the concomitant use of tazarotene $0.1 \%$ gel with mometasone furoate $0.1 \%$ cream. Mometasone furoate $0.1 \%$ cream causes less local and systemic side effects than betamethasone dipropionate $0.05 \%$ cream.

The efficacy of the combination of tazarotene $0.1 \%$ gel once daily + calcipotriol $0.005 \%$ ointment twice daily compared to a clobetasol ointment treatment twice daily, in a 2week open label, left-right comparison study was not statistically significant different. ${ }^{27}$ There seems to be no chemical incompatibility between calcipotriol ointment and tazarotene gel. 
Table 7.2 Response rates to tazarotene $0.1 \%$ gel in combination with topical corticosteroids. Responses evaluated after 12 weeks of treatment.

\begin{tabular}{|c|c|c|c|}
\hline Reference & Treatment & $\begin{array}{c}\text { Potency } \\
\text { of } \\
\text { corticosteroid }\end{array}$ & $\begin{array}{c}\% \text { of patients } \\
\text { reaching at least } \\
50 \% \text { overall } \\
\text { improvement } v s . \\
\text { baseline }\end{array}$ \\
\hline 21 & Tazarotene & N.A. & 35 \\
\hline 21 & $\begin{array}{l}\text { Tazarotene } \\
+ \text { fluocinonide } 0.05 \% \text { ointment. }\end{array}$ & High & 48 \\
\hline 21 & $\begin{array}{l}\text { Tazarotene } \\
+ \text { mometasone furoate } 0.1 \% \text { ointment }\end{array}$ & High & 66 \\
\hline 21 & $\begin{array}{l}\text { Tazarotene } \\
+ \text { diflorasone diacetate } 0.05 \% \text { ointment }\end{array}$ & High & 55 \\
\hline 21 & $\begin{array}{l}\text { Tazarotene } \\
+ \text { diflorasone diacetate } 0.05 \% \text { cream }\end{array}$ & Mid-high & 44 \\
\hline 21 & $\begin{array}{l}\text { Tazarotene } \\
+ \text { betamethasone dipropionate } 0.05 \% \text { cream }\end{array}$ & Mid-high & 78 \\
\hline 21 & $\begin{array}{l}\text { Tazarotene } \\
+ \text { fluticasone propionate } 0.005 \% \text { ointment }\end{array}$ & Mid-high & 57 \\
\hline 22 & $\begin{array}{l}\text { Tazarotene } \\
+ \text { placebo cream }\end{array}$ & N.A. & 80 \\
\hline 22 & $\begin{array}{l}\text { Tazarotene } \\
+ \text { fluocinolone acetonide } 0.01 \% \text { cream }\end{array}$ & Low & 79 \\
\hline 22 & $\begin{array}{l}\text { Tazarotene } \\
+ \text { mometasone furoate } 0.1 \% \text { cream }\end{array}$ & Mid & 91 \\
\hline 22 & $\begin{array}{l}\text { Tazarotene } \\
+ \text { fluocinonide } 0.05 \% \text { cream }\end{array}$ & High & 95 \\
\hline
\end{tabular}

\section{Combination with phototherapy}

Combination therapy of tazarotene and ultraviolet B therapy (UVB) proved to be rather effective although we have to be aware of the enhancement of phototoxicity of tazarotene by simultaneous treatment.

Several studies have indicated that tazarotene in combination with phototherapy is well tolerated and superior to monotherapy in terms of anti-psoriatic efficacy as well as in onset of action. ${ }^{28-31}$ In a clinical broad band UVB study, the combination of tazarotene gel $0.1 \%$ with UVB clearly shortened the time to reach $50 \%$ improvement (25 days versus 53) and lowered the median cumulative UVB dose needed from $1394.5 \mathrm{~mJ} / \mathrm{cm}^{2}$ to $390 \mathrm{~mJ} / \mathrm{cm}^{2}$ compared to UVB monotherapy. ${ }^{31}$ 
In another study topical tazarotene plus narrow-band UVB $(311 \mathrm{~nm})$ resulted in a $64 \%$ reduction of PASI assessed after 4 weeks as compared to a $48 \%$ reduction by UVB monotherapy. ${ }^{30}$

One study comparing the effect of narrow-band UVB irradiation in combination with topical tazarotene versus the combination with calcipotriol and a second study comparing PUVA in combination with tazarotene or tacalcitol ointment both failed to reveal significant differences between the respective regimens. ${ }^{32,33}$

\section{Side effects}

Local irritation is the most common side effect of topical retinoids. The most common side effects associated with topical tazarotene as a monotherapy are desquamation, burning/stinging, dry skin, erythema and pruritus. ${ }^{14,15,20}$ The incidence of side effects was higher in patients using the $0.1 \%$ formulations as compared to the $0.05 \%$ formulations. When compared to calcipotriol monotherapy, the frequency of the above mentioned adverse events was higher using the tazarotene gel whilst the efficacy is the same. No significant phototoxicity was associated with the combination of topical tazarotene and UVB. ${ }^{30,31}$

\section{Treatment strategies}

In general, topical treatment remains to be the most frequently used approach in treating patients with mild to moderate psoriasis. Topical tazarotene and topical vitamin D3 analogues have become a first line treatment the last decade. Dithranol and tar treatment are prescribed for patients not responding to other topicals and UVB treatment and for those patients who are not or not yet eligible for a systemic treatment. High potency topical corticosteroids as a monotherapy are used in those patients having strong irritation to vitamin D3 analogues or tazarotene. Combining topical tazarotene with a topical corticosteroid reduces both the irritancy to tazarotene monotherapy as well as the wellknown side effects of corticosteroids such as tachyphylaxis, striae, skin atrophy and adrenal gland suppression. The combination also increases the rate of improvement and the ultimate treatment efficacy as compared to tazarotene monotherapy. As compared to corticosteroid monotherapy the combination lengthens the remission.

Reduction of the application time to a few minutes by washing-off a topical treatment has been shown to enhance efficacy and reduce irritancy. Short contact application has become a popular approach in dithranol treatment. It also has been shown for topical tazarotene that reduction of the application to a few minutes reduces irritancy substantially without compromising efficacy too much. ${ }^{34}$ 


\section{Systemic retinoids: Acitretin}

Today, acitretin, a second-generation systemic retinoid, is the preferred systemic retinoid in the treatment of psoriasis for more than 10 years. ${ }^{35,36}$ Acitretin can be used as a monotherapy but is frequently used in combination with other anti-psoriatic drugs.

\section{Mechanism of action}

Acitretin, which is the pharmacologically active metabolite of etretinate, has been shown to activate all three RARs, without evidence that it actually binds to these receptors. ${ }^{37}$ Acitretin has been shown to reduce scaling and to interfere with various aspects of cutaneous inflammation, without evidence for immune suppression.

\section{Pharmacokinetics}

The absorption of acitretin is very variable amongst individuals and is optimal when ingested with food. The mean elimination half-life of acitretin is about two days ${ }^{38,39}$, whereas the mean elimination half-life of etretinate, the ethyl ester of acitretin, is 120 days but can still be detected in the subcutis as long as 18 months after treatment. ${ }^{40}$ Acitretin was developed because it was thought to be cleared from the body more rapidly than etretinate. However, re-esterification of acitretin to etretinate in the human body has found to be possible, especially if the patient has a substantial alcohol intake. $^{41,42}$ Therefore, in view of the teratogenic effect, women of childbearing potential who have been treated with acitretin have to continue contraception for 2 years in Europe and for 3 years in the US after stopping the therapy.

Drug interactions with acitretin may be relevant, in particular with drugs interfering with cytochrome P450 metabolism such as cyclosporine and with drugs competing for plasma protein binding such as phenytoin.

\section{Indications and contra-indications}

Table 7.3 summarizes the indications and contra-indications of the use of acitretin in psoriasis. The recommended initial and ongoing evaluations are outlined in Tables 7.4 and 7.5 , respectively. 
Table 7.3 Indications and contraindications for acitretin in the treatment of psoriasis

\section{Indications:}

Severe psoriasis, which cannot be managed by topical treatments or phototherapy, including day-care and in-patient dithranol treatment

Erythrodermic or pustular psoriasis

\section{Contraindications for acitretin in the treatment of psoriasis:}

Moderate to severe liver dysfunction

Severe kidney dysfunction

Pregnancy and lactation

Women of childbearing potential who cannot guarantee adequate contraception during and up to 3 years following discontinuation of acitretin

Hyperlipidaemia, especially hypertriglyceridaemia, which can not be controlled

Concomitant medications which interfere with retinoids

Concomitant hepatotoxic drugs

Diabetes mellitus which cannot be controlled

Alcohol abuse

Table 7.4 Pre-acitretin treatment screening parameters.

\section{Pre-Acitretin Screening}

History to exclude contraindications

Liver function tests (AST, ALT, $\gamma \mathrm{GT}$, alkaline phosphatase, bilirubin)

Serum triglycerides and cholesterol

Glucose

Serum creatinine

Pregnancy test

Spinal X-ray (initially performed during the first 3 months of therapy if long-term treatment is anticipated)

Table 7.5 List of clinical evaluations during acitretin treatment.

\section{Evaluation during acitretin treatment}

Monitor mucocutaneous side effects

Serum cholesterol/triglycerides and liver enzymes (every 2 weeks for the first 6 weeks, then every 6-12 weeks)

Serum creatinine (elderly patients or patients with mild to moderate renal dysfunction)

Monitor for development of hyperostoses by history and by X-ray of spine (once every two years)

Pregnancy test (before treatment commences) 


\section{Efficacy}

\section{Acitretin as monotherapy}

For palmo-plantar and generalized pustular psoriasis (von Zumbusch) and for erythrodermic psoriasis retinoids can be considered to be first-line therapies. Lesions respond more rapidly in monotherapy than with most other therapies. Initial dosages of $1 \mathrm{mg} / \mathrm{kg}$ /day for pustular psoriasis, $0.5 \mathrm{mg} / \mathrm{kg} /$ day for chronic plaque psoriasis, and 0.25 $\mathrm{mg} / \mathrm{kg}$ /day for erythrodermic psoriasis are recommended. Since correct dosing is the determinant for optimal efficacy of acitretin, the dosage sometimes needs to be adjusted. In general, mild cheilitis is indicative for a sufficient bioavailability of acitretin.

In generalised pustular psoriasis acitretin has been shown to be effective in $84 \%$ of the patients (Figure 7.1). ${ }^{43}$ The lack of immune suppression of acitretin makes this therapy also suitable for psoriasis associated with human immunodeficiency virus infection. ${ }^{44}$
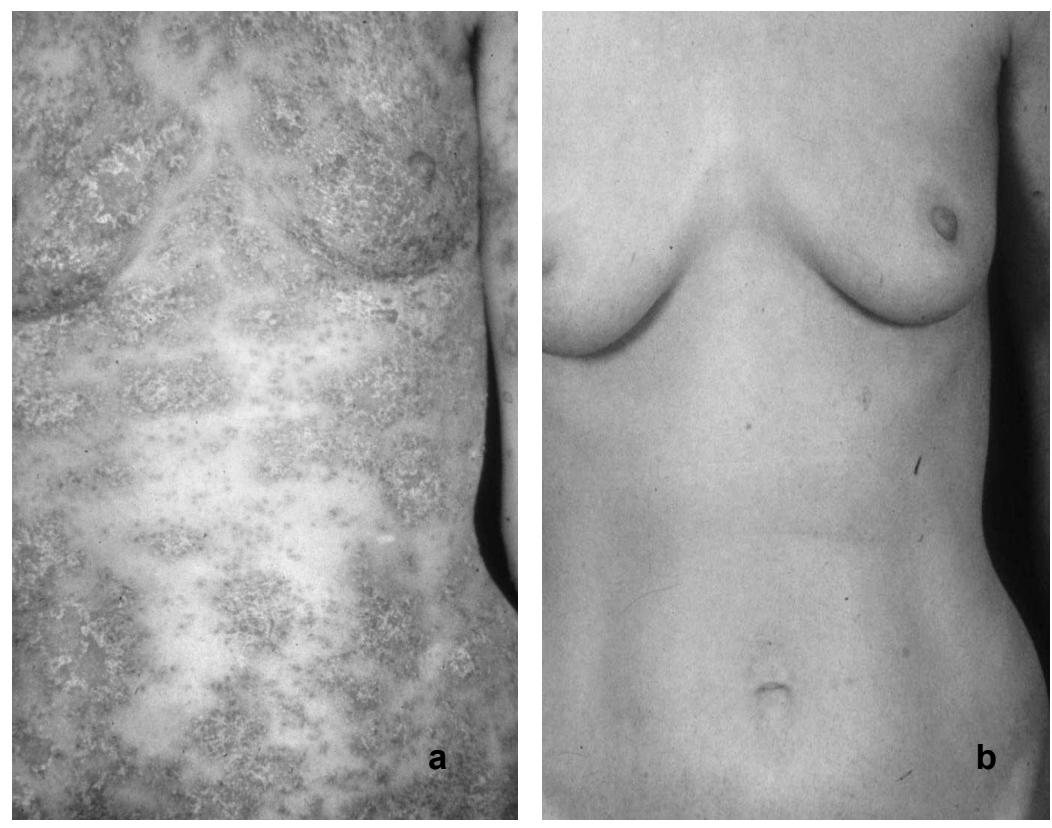

Figure 7.1 Clinical response to acitretin $(1 \mathrm{mg} / \mathrm{kg} /$ day $)$ in a patient with generalised pustular psoriasis (a) before and (b) after 4 weeks of treatment. See page 233 for colour figure.

The plaque-type psoriasis responds variably and the use of acitretin as a monotherapy should be limited to severe forms not manageable by topical treatments or phototherapy, including day care and in-patient dithranol treatment. The clinical response is dose- 
dependent; different dosages of 10 to $75 \mathrm{mg}$ /day have been evaluated. ${ }^{45-52}$ Starting with high doses of acitretin $(0.5-1 \mathrm{mg} / \mathrm{kg} /$ day $)$ may result in an initial worsening and the sudden appearance of side-effects on the skin (cheilitis, dry skin, pruritus) jeopardizing the compliance of the patient. Starting with a low dosage $(10 \mathrm{mg} /$ day $)$ and a progressive increase of the dosage seems to be more acceptable for the patient and can avoid the worsening of the existing lesions.

In a comparative study versus etretinate, at least $75 \%$ improvement in the PASI was observed in $23.1 \%$ of the patients treated with $50 \mathrm{mg}$ acitretin after 8 weeks of treatment and at least $50 \%$ improvement of PASI was reached by $54 \%$ of the patients. ${ }^{53}$ In a second study, the mean PASI improvement after 12 weeks was between 70-75\%. ${ }^{54}$

Acitretin has been shown to be an effective maintenance therapy in patients with chronic plaque psoriasis. Of all patients $75 \%$ and $88 \%$ reached PASI-50 after 6 months and 12 months treatment respectively. ${ }^{45,55,56}$

Treatment with acitretin during several months might improve nail psoriasis considerably. ${ }^{57}$ Although present in $80-90 \%$ of all psoriasis patients ${ }^{58}$ and negatively affecting their quality of life ${ }^{59}$, no specific placebo-controlled studies are currently available in nail psoriasis.

It is generally agreed that acitretin is not effective in psoriatic arthritis.

Studies with acitretin between 25 to $60 \mathrm{mg}$ daily have been shown to considerably reduce the risk of developing new cutaneous malignancies in patients who have received high dose PUVA treatment in the past or have been treated with cyclosporine. ${ }^{60-63}$

\section{Combination with phototherapy}

A consensus conference on the treatment of acitretin in combination with UVB or PUVA revealed that the combination enhances efficacy and limits the treatment frequency, duration and the cumulative doses compared to the UVB or PUVA monotherapy. The combination also permits lower acitretin doses which imply an increased safety and compliance. ${ }^{64,65}$

Broadband UVB in combination with acitretin has been shown to be highly effective as compared to monotherapies. ${ }^{66-69}$ A study comparing UVB treatment combined with placebo to UVB treatment combined with acitretin $(50 \mathrm{mg} /$ day) resulted in a $74 \%$ improvement in PASI in patients treated with UVB plus acitretin $50 \mathrm{mg} /$ day versus $35 \%$ with UVB and placebo and $42 \%$ with acitretin monotherapy. ${ }^{67}$

The preferred schedule when using the combination is pre-treatment during 2 weeks with low-dose acitretin followed by the combination. In case of insufficient response to 
UVB monotherapy, acitretin $25 \mathrm{mg}$ may be added which requires a $50 \%$ reduction of UVB dose.

The combination of $25 \mathrm{mg}$ acitretin daily with narrowband UVB three times a week has been shown to be highly effective in patients with difficult-to-treat psoriasis ${ }^{70}$. An improvement of at least $75 \%$ of the severity score was reached in $72.5 \%$ of the patients, only $12.5 \%$ had less than $50 \%$ improvement.

Also the combination of acitretin and $\mathrm{PUVA}^{71-73}$ or Bath $\mathrm{PUVA}^{74}$ has been shown to be more effective than the monotherapies. In general, 14 days prior to PUVA treatment patients have to take acitretin $25 \mathrm{mg}$ /day. As with UVB, adding acitretin to PUVA monotherapy requires a reduction of the initial UVA dose by $50 \%$.

\section{Combination therapy with topical vitamin D analogues}

Compared to each of the monotherapies, an improved efficacy has been observed for the combination of acitretin with topical calcipotriol $(50 \mu \mathrm{g} / \mathrm{g}) .^{75}$

\section{Combination therapy with biologicals}

Today no studies have been performed comparing the efficacy of the combination of acitretin and a biological with both monotherapies. The combination of acitretin 25 $\mathrm{mg}$ /day with etanercept $25 \mathrm{mg}$ twice weekly has been shown to be safe and effective in difficult-to-treat psoriasis. ${ }^{76}$ Also, several case studies have been reported showing that the combination of acitretin with a biological may be rather effective. ${ }^{77-79}$ A case of Acrodermatitis Continua Hallopeau responding successfully to the combination of etanercept and acitretin has been reported as well as a beneficial long-term improvement in a patient who had unsuccessfully treated with acitretin for 43 months but who improved substantially by a 12 week combination course of alefacept and acitretin. ${ }^{80,81}$

\section{Contraindicated combinations and combinations for restrictive use}

Cyclosporine inactivation by the cytochrome P-450 system can be inhibited by acitretin meaning that the combination of acitretin and cyclosporine carries the risk of accumulation of cyclosporine. The effect of etretinate on the cytochrome P-450-mediated metabolism of cyclosporine has been studied in vitro and indicates that there is no metabolic interaction; it is likely that the two drugs are metabolized by different P-450 isoenzymes. ${ }^{82}$ The combination of methotrexate and acitretin has been used in those patients in whom all treatments have failed. ${ }^{83}$ Although this combination can be very effective, due to severe hepatotoxicity this combination is not longer advisable. ${ }^{84}$ 


\section{Strategies of combination treatment}

Psoriasis patients deserve long-term control of their disease with optimal benefit/risk ratio. The existing therapies, although providing excellent short-term control, may produce acute or chronic toxicities limiting their long-term use. Combination therapy can offer a solution. Cather and Menter ${ }^{85}$ defined three objectives for a combination therapy: the first objective would be to achieve a similar efficacy and a lower toxicity with a lower dose; the combinations calcipotriol plus acitretin and UVB/PUVA plus acitretin are well established approaches to reach this goal. A second objective is to achieve fast clearing and subsequently maintain the improvement by sequential therapy. Powerful clearing therapies such as cyclosporine, methotrexate, photo(chemo)therapy, infliximab or the traditional topical treatment with dithranol may be followed by acitretin maintenance resulting in a long-term safe control of the disease. In particular in patients with previous exposure to potentially carcinogenic treatments this approach is useful. The third objective is to avoid cumulative toxicity by rotational treatment. Patients with difficult-to-treat psoriasis whom require a continuous treatment should use rotate treatments in order to reduce toxicity and still maintaining improvement of their psoriasis.

\section{Side effects}

Mucocutaneous side effects of acitretin comprise cheilitis, dryness of the eyes, nasal and oral mucosa, epistaxis, xerosis, brittle nails, hair loss and burning or sticky skin. In fact, some degree of cheilitis is an indication for sufficient bioavailability and, therefore is, to some extent, a parameter to individualize the optimal dosage. Another side effect frequently seen during the first 4 weeks of treatment is the initial aggravation of psoriasis with an increase of the body surface area involved. A more seldom mucocutaneous side effect is "retinoid dermatitis", which may mimic "unstable psoriasis". Periungual pyogenic granulomas may occur during long-term use of acitretin. ${ }^{45,86}$

In $25-50 \%$ of patients treated with acitretin hyperlipidaemia has been reported and it is, in most patients, reversible when reducing the dosage or when treatment is stopped. ${ }^{87}$ Highly increased levels of triglycerides imply increased risk for pancreatitis and chronic increases may increase the risk for cardiovascular comorbidities. In patients treated with acitretin, one should be aware that diabetes mellitus, obesity, increased alcohol intake are risk factors for development of hyperlipidaemia. In patients with moderate to severe psoriasis increases in serum lipids and dislipidemias have been reported without retinoid treatment. ${ }^{88-91}$ Therefore, figures on occurrence of hyperlipidaemia in psoriasis should be corrected for the overall predisposition under psoriatics to develop hyperlipidaemia. 
Lifestyles changes to prevent hyperlipidaemia should be stimulated in psoriatics and in particular those who are treated with retinoids. Elevation of transaminases are seen in $13-16 \%$ of acitretin treated patients. ${ }^{86}$ A liver biopsy study did not reveal a significant risk for liver toxicity. ${ }^{92}$ Severe increases of liver test functions are rare, but may indicate toxic hepatitis induced by acitretin. ${ }^{93}$

Strict contraception in women of childbearing potential is required during and 2 to 3 years following acitretin treatment. Teratogenic complications following acitretin treatment is discussed elsewhere in this book. ${ }^{94-96}$

Less frequently, patients receiving acitretin may experience arthralgia, myalgia or paraesthesia as well as possible worsening of pre-existing bone disorders during long term therapy. ${ }^{97-99}$ Pseudotumor-like symptoms and signs have been recorded sporadically. The combination of retinoids with tetracyclins may increase the risk of this side effect. Symptoms and signs of intracranial hypertension are severe headache, nausea and vomiting, visual disturbances and papilloedema. ${ }^{95}$ Although the relationship to acitretin has not been convincingly shown, depression and suicide have been suggested to occur during acitretin treatment. ${ }^{95}$ Decreased colour vision and impaired night vision might occur during acitretin treatment. 


\section{Systemic retinoids: Tazarotene}

Oral tazarotene $(4.5 \mathrm{mg} / \mathrm{day})$ has been shown to be efficacious in moderate to severe psoriasis in two double-blind placebo-controlled trials and in a long-term open label trial. $^{100}$

Results of the phase III trials, reported at the Winter American Academy of Dermatology in 2003, demonstrated effectiveness of oral tazarotene versus placebo.

Additional data of the open label study, reported at the $62^{\text {nd }}$ annual meeting of the American Academy of Dermatology 2004, also showed efficacy of oral tazarotene in long-term treatment of psoriasis ( 52 weeks, once daily). A moderate to complete clearing (at least 50\% global improvement) was achieved by 56\% of the patients by week 16 and $68 \%$ by week 24 . A marked improvement (at least $75 \%$ global improvement) was achieved by $44 \%$ of patients by week 36 . During long-term treatment, oral tazarotene was associated with adverse events such as alopecia, hypertriglyceridaemia, hepatotoxicity, ocular dryness, desquamation and pruritus.

Pharmacokinetic data of oral tazarotene indicate that the drug poses little risk for deep tissue storage and accumulation in humans suggesting a shorter post-treatment waiting period for women who wish to conceive after discontinuation of oral tazarotene treatment.

However, although efficacious in psoriasis, oral tazarotene has not yet been approved by the U.S. Food and Drug Administration (FDA) due to lack of safety data. ${ }^{100}$ 


\section{Systemic Rexinoids: Bexarotene}

Innovations in retinoid treatment in psoriasis are to be expected from RXR-selective ligands or rexinoids. Bexarotene (Targretin ${ }^{\circledR}$, LGD1069) a novel synthetic specific RXR-ligand has been developed for the treatment of cutaneous T-cell lymphoma (CTCL) where it was shown to inhibit T-cell accumulation which is also an important feature of psoriasis. ${ }^{101,102,111}$ Thus, as it might provide a new approach in the treatment of psoriasis, bexarotene is currently under investigation for this indication.

\section{Mechanism of action}

Bexarotene selectively binds and activates RXR receptors: $\operatorname{RXR} \alpha, \operatorname{RXR} \beta$ and $\operatorname{RXR} \gamma \cdot{ }^{103}$ and not to RARs. RXR receptors function as heterodimers with other nuclear receptors (e.g. retinoic acid receptor (RAR), vitamin D receptor (VDR), thyroid receptor (TR) and peroxisome proliferator activator receptor (PPAR)) who play an important role in cell function and physiology, meaning that the biological activities of bexarotene could be broader than that of compounds that activate RARs.

Bexarotene has been shown to inhibit the growth of tumour cell lines of haematopoietic and squamous cell origin and to induce apoptosis. ${ }^{104-109}$ In vivo bexarotene induces tumor regression in some animals ${ }^{104}$, while in other models tumor induction is prevented. ${ }^{106}$ As such, bexarotene has been developed for the treatment of CTCL. ${ }^{101}$

In clinical studies bexarotene $\left(300 \mathrm{mg} / \mathrm{m}^{2} /\right.$ day) proved to have an activity in patients with CTCL, even in patients in a late stage of the disease and who were not responsive to other systemic therapy, resulting in a regression or even temporary complete clinical response. The exact mechanism of action of bexarotene in the treatment of CTCL is unknown.

\section{Pharmacokinetics}

Oral bexarotene is absorbed with a $T_{\max }$ of about two hours and its $T_{1 / 2}$ is about seven hours. Studies in patients with advanced malignancies show approximate single dose linearity within the therapeutic range and low accumulation with multiple doses.

Bexarotene is highly bound ( $>99 \%$ ) to plasma proteins. In vitro studies suggest that cytochrome P450 3A4 is the major cytochrome P450 responsible for formation of the oxidative metabolites which may be glucuronidated. The oxidative metabolites are active in in vitro assays of retinoid receptor activation. Neither bexarotene nor its metabolites are excreted in urine in appreciable amounts. Bexarotene is thought to be eliminated primarily through the hepatobiliary system. ${ }^{10,111}$ 


\section{Efficacy}

Benign hyperproliferative and retinoid sensitive disorders, such as psoriasis are good candidates for studies with bexarotene. In a first study by Smit et al. (2004) it was shown that systemic treatment with bexarotene up to $3.0 \mathrm{mg} / \mathrm{kg} /$ day, decreases epidermal proliferative and inflammation parameters. ${ }^{112}$ In a phase II dose finding study $(0.5$, 1,2 and $3 \mathrm{mg} / \mathrm{kg} /$ day for 12 weeks), no significant dose-dependent difference between the 4 doses groups for mPASI (modified PASI), PEL (plaque elevation) and physician's global assessment (PGA) was demonstrated. ${ }^{113}$ There was a statistical improvement of psoriasis $(\geq 50 \%)$ with mean response rates of $22 \%$ for in $\mathrm{mPASI}, 52 \%$ for PEL and $36 \%$ for PGA. Based on these data, doses higher than $3.0 \mathrm{mg} / \mathrm{kg} /$ day and lower than 0.5 $\mathrm{mg} / \mathrm{kg}$ /day should be investigated in a placebo-controlled design. If higher doses are needed, side effects known from the treatment of patients with CTCL may be a limiting factor for bexarotene in the treatment of psoriasis or the drug could also be evaluated in combination with other anti-psoriatic therapy.

\section{Side effects}

The U.S. FDA approved oral bexarotene for the treatment of cutaneous manifestations of CTCL in patients refractory to at least one prior systemic therapy. In the high doses used to treat CTCL nearly all patients suffer adverse effects, which can include hyperlipidaemia (risk of pancreatitis), hypothyroidism, and haematological reactions (leukopenia, anemia). ${ }^{114}$ Many side effects limit the use of bexarotene as a monotherapy for CTCL.

Adverse events in the psoriasis trial were comparable to the CTCL trial with a lower frequency and severity. ${ }^{112}$ No serious adverse events related to the drug occurred. However, hyperlipidaemia (56\%) and a decrease in free T4 serum levels (54\%) were most frequently reported adverse events related to the drug. Typical retinoid-related adverse events were pruritus, in only $14 \%$ of the patients and cheilitis in $10 \%$.

Although the clinical data suggest an anti-psoriatic effect of bexarotene, the side effects, especially hypertriglyceridaemia and hypothyroidism, may require intervention and may restrict the use of higher doses in psoriasis patients. Further studies are needed to ascertain the relevance of bexarotene to the treatment of psoriasis. ${ }^{114}$ 


\section{Retinoic Acid Metabolism Blocking Agents: RAMBAs}

A new class of molecules named Retinoic Acid Metabolism Blocking Agents (RAMBAs) sometimes referred to as retinoic acid 4-hydroxylase inhibitors have proven to be of therapeutic benefit in keratinisation disorders like psoriasis, ichthyosis and acne. In this section the mechanism of action of RAMBAs and their history will be presented followed by an illustration of the proof of principle in psoriasis with liarozole, the first RAMBA ever been in clinical development for indications like psoriasis and ichthyosis. Today, R115866 (Rambazole ${ }^{\mathrm{TM}}$ ), representing a new generation of highly potent and selective RAMBAs, is in clinical development for the treatment of psoriasis. Specific information on its pharmacology and pharmacokinetics will be provided. Furthermore results of a phase 2a study in psoriasis will be highlighted, suggesting that R115866 has a promising profile for treating psoriasis.

\section{Mechanism of action}

All-trans-RA, a minor metabolite of retinol and $\beta$-carotene, is believed to be the most active naturally occurring retinoid. It's significantly more active (100-1000 fold) than retinol in experimental systems. One of the pathways of all-trans-RA inactivation occurs by hydroxylation at the $\mathrm{C} 4$ position of the cyclohexenyl ring to form 4-hydroxyall-trans-RA which is converted by a reductase into 4-keto-all-trans-RA that is in turn further transformed into more polar metabolites. Both the 4-hydroxylation process of all-trans-RA and the further oxidation of 4-keto-all-trans-RA to more polar metabolites involve microsomal cytochrome P-450 (CYP) dependent enzymes. ${ }^{115,116}$ RAMBAs are non-retinoid drugs that block the CYP dependent 4-hydroxylation which results in an increase of the intracellular all-trans-RA concentration. ${ }^{117,118}$ (see Figure 7.2)

Unlike existing therapies where massive amounts of exogenous retinoids, natural or synthetic, are administered to the body, a RAMBA modulates the body's own production of all-trans-RA to achieve the same therapeutic effects. By inhibiting its intracellular catabolism, endogenous all-trans-RA accumulates in the skin to therapeutic levels. Once treatment is stopped, a RAMBA is quickly eliminated from the body returning the metabolism of retinoic acid back to normal and declining the elevated all-trans-RA levels back to physiological levels. The rapid clearance of the RAMBAs is important as it decreases the potential for side effects in contrast to the available synthetic retinoids, which may stay in some organs for a long time, and which can cause retinoid related chronic toxicity and birth defects for months after discontinuation of therapy. 


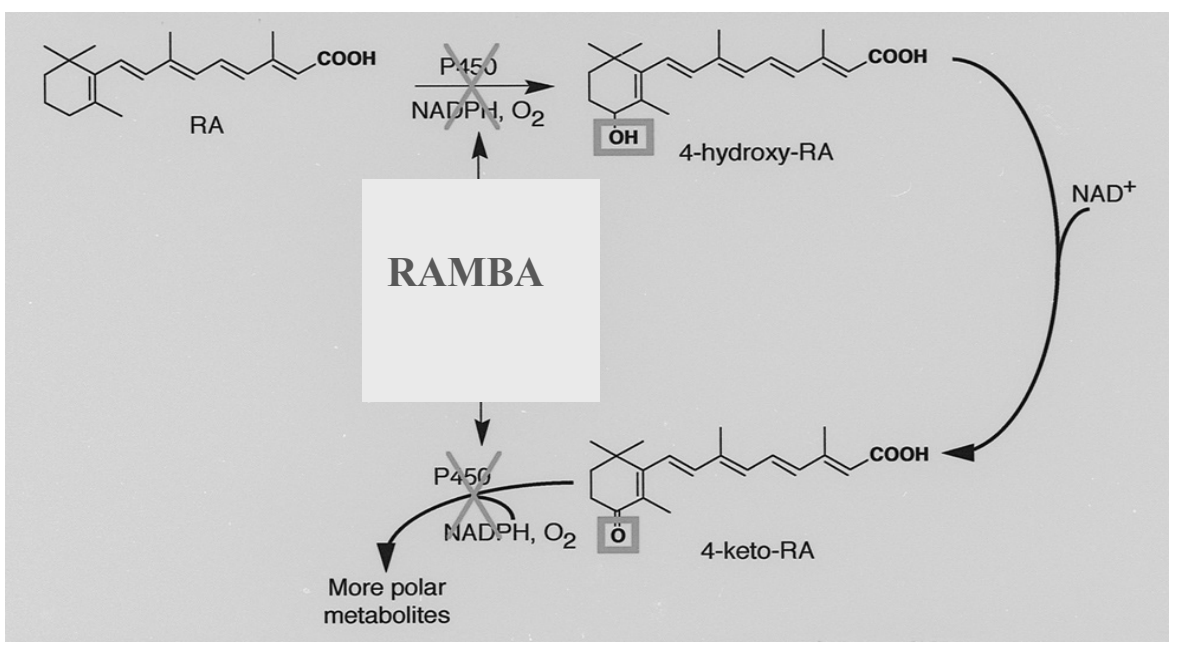

Figure 7.2 Mechanism of action of RAMBAs

\section{History of RAMBAs}

The first azole shown to display RAMBA properties was the antifungal ketoconazole. Besides its antifungal activity, ketoconazole was shown to inhibit in an apparently competitive manner the CYP mediated metabolism of all-trans-RA by hamster liver microsomes. ${ }^{119}$ The search for more selective CYP inhibitors of all-trans-RA metabolism led to the identification of liarozole. Liarozole is an imidazole derivative that is lacking anti-fungal activity but shares with ketoconazole its inhibitory effects on epidermal all-trans-RA metabolism $\left(\mathrm{IC}_{50}=2 \mu \mathrm{M}\right)$ and on the CYP mediated 17-hydroxylase17,20-lyase in testes microsomes. Like ketoconazole, administration of liarozole to rats enhances endogenous plasma concentrations of endogenous RA and reduces the elimination rate of intravenously injected RA from plasma. ${ }^{120,121}$ Liarozole also inhibits several other cytochrome P450-dependent steroid biosynthesis reactions - mainly the conversion of androgens to estrogens (aromatase) and of 11-deoxycorticosterone to corticosterone (11-hydroxylase). ${ }^{122,123}$

Developed in the 90's as a non-hormonal agent in the treatment of prostate cancer and various other cancers, liarozole was considered to be of potential benefit in the treatment of skin disorders like psoriasis and ichthyosis. This was based on the fact that the reported adverse events in the cancer trials were mainly cutaneous reactions showing a striking similarity with vitamin A related symptoms. Currently, liarozole is in develop- 
ment as an orphan drug for ichthyosis (excluding autosomal dominant ichthyosis vulgaris). ${ }^{124-126}$ In this chapter, only its effects in psoriasis will be reviewed. Whereas the first RAMBAs where non-selective CYP inhibitors, a thorough screening of hundreds of molecules against different CYP-isozymes yielded a very selective and highly active retinoic acid 4-hydroxylase inhibitor namely R115866.

\section{Liarozole: proof of principle in psoriasis}

A total of 6 clinical trials assessing the efficacy and safety of oral liarozole in psoriasis have been conducted. ${ }^{127-131}$ All trials were double-blind, placebo-controlled, randomized, parallel group trials, except for one open pilot trial and one active-controlled trial with acitretin at daily doses of $25 \mathrm{mg}$. All trials initially consisted of a treatment period of 12 weeks and a follow-up of 8 to 12 weeks, except for the open study in which no follow-up period was foreseen. Liarozole was administered in daily doses ranging from 50 to $300 \mathrm{mg}$

A pooled analysis of the efficacy data of the 6 trials included in total 828 subjects of which 501 had been randomized to liarozole treatment. ${ }^{127}$. Significant mean decreases in PASI score compared to baseline and improvement in disease conditions were observed for all groups receiving liarozole. Nevertheless, large differences in response and improvement percentages between the groups receiving a liarozole dose lower than 150 $\mathrm{mg}$ and higher than $150 \mathrm{mg}$ were observed. Both PASI score evaluations and global clinical evaluations pointed out that relative increases in response were largest when increasing the liarozole dose from 75 to $150 \mathrm{mg}$. Upon further increasing the liarozole dose, no further significant changes in percentage of responders were noticed. All doses of liarozole were found to be well tolerated, although the occurrence of the most recurrent adverse events (e.g. skin disorders, pruritus, dry mouth) was notably higher in subjects receiving a liarozole dose higher than $150 \mathrm{mg}$. However, the incidence of such adverse events in the $150 \mathrm{mg}$ liarozole group did not surpass that of the acitretin group. A liarozole dose of $150 \mathrm{mg}$ was therefore found to be optimal for the treatment of psoriasis.

\section{R115866: a new generation ramba}

R115866 (Rambazole ${ }^{\mathrm{TM}}$ ), a substituted benzyl-1, 2, 4,- triazole derivative, has been identified as a third generation of RAMBAs with improved potency and selectivity. ${ }^{132}$ The investigational drug is a stable, enantiomerically pure base which has been identified both in vitro and in vivo as a compound with highly specific and selective CYP inhibiting properties against hydroxylases involved in the catabolism of all-trans-RA. 
Regarding its potency, R115866 is an inhibitor of all-trans-RA catabolism in the nanomolar range $\left(\mathrm{IC}_{50}=4 \mathrm{nM}\right.$, human CYP26 transfected yeast microsomes $)$ and is about three orders of magnitude more powerful than liarozole $\left(\mathrm{IC}_{50}=3 \mu \mathrm{M}\right)$. As for its selectivity R115866 shows, in comparison to its retinoid catabolism inhibiting activity, only trivial inhibitory effects $\left(\mathrm{IC}_{50}=1.2-2.6 \mu \mathrm{M}\right)$ on the CYP-dependent biosynthesis of steroids (testosterone and oestradiol). Furthermore, consistent with its ability to enhance endogenous RA content in tissues and plasma, R115866 was found to generate retinoidmimetic biological activities in various retinoid sensitive animal models of keratinisation. ${ }^{132}$ In these studies no major effects other than its primary pharmacodynamic effect were evidenced. By virtue of this property and the modulating effects of RA on epithelial growth and differentiation, R115866 is currently in clinical investigation for both oral and topical treatment of psoriasis and acne.

\section{Pharmacokinetics}

In vitro studies using isolated hepatocytes and subcellular liver fractions from mouse, rat, dog and human indicated that R115866 was metabolized by all of the species. The potential of R115866 to interact with specific cytochrome CYP substrates was studied in human liver microsomes. The lowest $\mathrm{IC}_{50}$ values were observed for two substrates metabolized via CYP3A4; being $1.3 \mu \mathrm{M}$ and $2.6 \mu \mathrm{M}$. These concentrations, however, are considerably higher than those observed following administration of R115866 to humans. $^{133}$

The pharmacokinetics of R115866 after single and repeated oral dosing was studied in healthy male subjects. The oral absorption after a single dose (0.6-20 mg) was fast with peak plasma concentrations reached within $1 \mathrm{~h}$ after dosing. R115866 was eliminated with a mean dominant half-life of $1-2 \mathrm{~h}$ and a mean terminal half-life of 6-7 $\mathrm{h}$. The single-dose pharmacokinetics of R115866 appeared to be dose-proportional. After repeated b.i.d. dosing for 8 days (0.5-2-4 mg), steady-state was attained after one day. At the end of treatment on day 8 , mean dominant and terminal half-lives were in the order of $2 \mathrm{~h}$ and $15 \mathrm{~h}$, respectively. Steady-state plasma concentrations increased proportionally with the dose between $0.5 \mathrm{mg}$ and $2 \mathrm{mg}$ b.i.d., and more than doseproportionally between $2 \mathrm{mg}$ and $4 \mathrm{mg}$ b.i.d. A dose-related increase in plasma RA was observed. On day 8 of the b.i.d. dosing of R115866, the exposure of RA in terms of $\mathrm{C}_{\max }$ was lower than on day 1 , whereas in terms of $\mathrm{AUC}_{0-12 \mathrm{~h}}$ the exposure remained fairly similar. $^{133}$

Tissue distribution data are not available from humans but were collected following single oral administration of R115866 at $2.5 \mathrm{mg} / \mathrm{kg}$ to male rats. R115866 was extensively distributed throughout the body with a volume of distribution at steady-state of 
$5.21 / \mathrm{kg}$. As in plasma, maximum concentrations of R115866 were observed at 1 hour (the first sampling time) post-dose in all tissues investigated except for the skin ( 3 hours post-dose). Maximum tissue concentrations of R115866 in the skin (43.1ng/g) were similar to those in plasma $(40.1 \mathrm{ng} / \mathrm{ml})$. Concentrations of R115866 in tissues declined at a rate similar to those in plasma, except in adrenals where the rate of decline was slightly slower. ${ }^{133}$

\section{Indications and contra-indications}

Today, no clinical data are available on drug-interactions and contra-indications with R115866. Even though R115866 belongs to the class of azole derivatives, the drug's main mode of action in skin is based on the inhibition of the CYP-mediated metabolic inactivation of the body's own retinoic acid. Hence drug interactions and other forms of interactions as well as contra-indications and precautions related with retinoids should be taken into consideration (e.g. prevention of pregnancy, monitoring of lipid levels, avoiding co- medication inhibiting or inducing CYP 3 A4). ${ }^{133}$

\section{Efficacy}

The efficacy and safety of oral R115866 in moderate to severe plaque-type psoriasis was assessed in an open label, phase 2 a trial where 19 subjects were treated once daily with $1 \mathrm{mg}$ R115866 for 8 weeks. ${ }^{134}$ Efficacy analysis performed at the end of the treatment phase and after a 2-week treatment free follow-up period showed a timedependent improvement of PASI. At end of treatment, 5/19 patients $(26 \%)$ showed an improvement in PASI of at least 50\% compared to 8/17 (47\%) at follow-up meaning that the optimal clinical efficacy has not yet been reached with an 8 week treatment schedule. In all treated patients, throughout the whole treatment period, plasma levels of RA increased $0.5-1.5 \mathrm{ng} / \mathrm{ml}, 2$ to 4.5 hours after intake of $1 \mathrm{mg}$ R115866 and returned to approximately baseline levels within 24 hours. Figure 7.3 shows the elbow of a patient (a) at baseline and (b) at the end of the 2-week follow-up.

\section{Side effects}

Adverse experiences reported in association with the use of R115866 are expected to be fewer and less severe than those reported for retinoids. The most common observed symptoms in the clinical studies performed until now are those associated with increased levels of RA, i.e. pruritis, xerosis and cheilitis. Additionally, epistaxis and cases of increased blood triglycerides have been reported. ${ }^{133,134}$ 

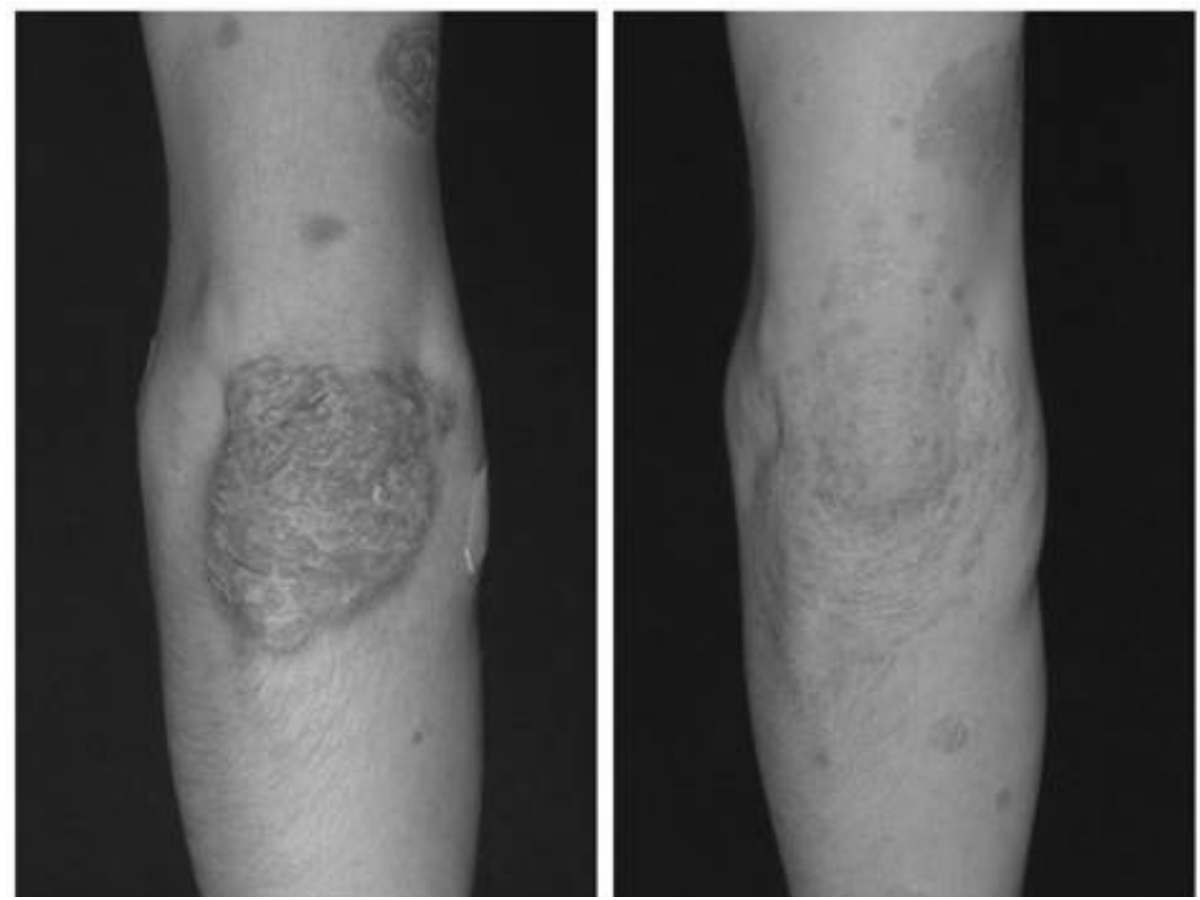

Figure 7.3 Clinical response to R115866 (1mg/ day) in a patient with moderate to severe plaque type psoriasis (a) before treatment and (b) after 10 weeks i.e. 8 week treatment +2 weeks treatment free follow-up. See page 234 for colour figure.

\section{Conclusions}

Several retinoids have been developed and used successfully over the years for the treatment of psoriasis. However, today, acitretin $\left(\right.$ Neotigason $^{\circledR}$, Soriatane ${ }^{\circledR}$ ) is the only oral, and tazarotene $\left(\right.$ Zorac $^{\circledR}$, Tazorac ${ }^{\circledR}$ ) the only topical retinoid, approved for psoriasis in most European countries and in the U.S. Oral tazarotene has completed Phase III studies but at the time of writing its manufacturer has received a non-approvable letter from the FDA. Despite the fact that many new therapies, like the biologicals, have been developed, retinoids as monotherapy or in combination with other treatment modalities remain a useful therapy for the treatment of psoriasis. The search goes on and synthetic retinoids continue to evolve and improve in terms of specificity and decreased toxicity. Rexinoids and new approaches like RAMBAs are currently intensively investigated with promising results. 


\section{References}

1. Rahman P, Elder JT. Genetic epidemiology of psoriasis and psoriatic arthritis. Ann Rheum Dis 2005, 64: $1137-9$

2. Bonnekoh B, Gollnick HPM. Topical and systemic retinoids. In: Textbook of Psoriasis (van de Kerkhof PCM, ed), $2^{\text {nd }}$ edition. London: Blackwell Science Ltd, 2003; 247-74.

3. Stuttgen G. Zur Lokal behandlung von keratosen mit Vitamin A-Säure. Dermatologica 1962; 124: 65-80.

4. Peck G, DiGiovanna J. Synthetic retinoids in dermatology. In: The retinoids: Biology, Chemistry and Medicine (Sporn M, Roberts A, Goodman D, eds), $2^{\text {nd }}$ edition. New York: Raven Press, Ltd, 1994; 639-58.

5. Frey JR, Schoch MA. Therapeutische Versuche bei Psoriasis mit Vitamin A, zugleich ein Beitrag zur AHypervitaminose. Dermatologica 1952; 104: 80.

6. Kligman AM, Fulton JE Jr, Plewig G. Topical vitamin A acid in acne vulgaris. Arch Dermatol 1969; 99: 469-76.

7. Chandraratna RAS. Rational design of receptor-selective retinoids. $J$ Am Acad Dermatol 1998; 39: S124-8.

8. Esgleyes-Ribot T, Chandraratna RA, Lew-Kaya DA, et al. Response of psoriasis to a new topical retinoid, AGN 190168. J Am Acad Dermatol 1994; 30: 581-90.

9. Nagpal S, Thacker SM, Patel S, et al. Negative regulation of two hyperproliferative keratinocyte differentiation markers by a retinoic acid receptor-specific retinoid: insight into the mechanism of retinoid action in psoriasis. Cell Growth Differ 1996; 7: 1783-91.

10. Duvic M, Nagpal S, Ascano AT, et al. Molecular mechanisms of tazarotene action in psoriasis. $J$ Am Acad Dermatol 1997; 37: S18-24.

11. Thacher SM, Vasudevan J, Tsang KY, et al. New dermatological agents for the treatment of psoriasis. $J$ Med Chem 2001; 44: 281-97.

12. Marks R. Pharmacokinetics and safety review of tazarotene. J Am Acad Dermatol 1998; 39: S134-8.

13. Tang-Liu DD-S, Matsumoto RM, Usansky JJ. Clinical pharmacokinetics and drug metabolism of tazarotene: a novel topical treatment for acne and psoriasis. Clin Pharmacokinet 1999; 37: 273-87.

14. Weinstein GD, Krueger GG, Lowe NJ, et al. Tazarotene gel, a new retinoid, for topical therapy of psoriasis: vehicle-controlled study of safety, efficacy and duration of therapeutic effect. $J$ Am Acad Dermatol 1997; 37: 85-92.

15. Weinstein GD, Koo JY, Krueger GG, et al. Tazarotene cream in the treatment of psoriasis: Two multicenter, double-blind, randomized, vehicle-controlled studies of the safety and efficacy of tazarotene creams $0.05 \%$ and $0.1 \%$ applied once daily for 12 weeks. J Am Acad Dermatol 2003; 48: 760-7.

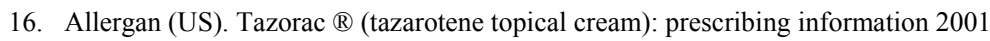

17. Allergan (US). Tazorac ${ }^{\circledR}$ (tazarotene topical gel): prescribing information $2003 \mathrm{Dec}$.

18. Allergan Ltd (UK). Zorac $0.05 \%$ gel (online) Available from URL: http://emc.medicines.org.uk (Accessed 2006 Feb 15)

19. Allergan Ltd (UK). Zorac $0.1 \%$ gel (online) Available from URL: http://emc.medicines.org.uk (Accessed 2006 Feb 15)

20. Lebwohl M, Ast E, Callen JP, et al. Once-daily tazarotene gel versus twice-daily fluocinonide cream in the treatment of plaque psoriasis. J Am Acad Dermatol 1998; 38: 705-11.

21. Tzung TY, Wu JC, Hsu NJ, et al. Comparison of tazarotene $0.1 \%$ gel plus petrolatum once daily versus calcipotriol $0.005 \%$ ointment twice daily in the treatment of plaque psoriasis. Acta Derm Venereol 2005 ; 85: 236-9. 
22. Green L, Sadoff W, Lebwohl MG, et al. A clinical evaluation of tazarotene $0.1 \%$ gel with and without a high-or mid-high-potency corticosteroid, in patients with stable plaque psoriasis. J Cutan Med Surg 2002; 30: 95-102.

23. Lebwohl MG, Breneman DL, Goffe BS, et al. Tazarotene $0.1 \%$ gel plus corticosteroid cream in the treatment of plaques psoriasis. J Am Acad Dermatol 1998; 39: 590-6.

24. Gollnick H, Menter A. A combination therapy with tazarotene plus a topical corticosteroid for the treatment of plaque psoriasis. Br J Dermatol 1999; 40: 18-23.

25. Koo JY, Martin D. Investigator-masked comparison of tazarotene gel q.d. plus mometasone furoate cream q.d. vs. mometasone furoate cream b.i.d. in the treatment of plaque psoriasis. Int J Dermatol 2001; 40: $210-2$.

26. Guenther LC, Poulin YP, Pariser DM. A comparison of tazarotene $0.1 \%$ gel once daily plus mometasone furoate $0.1 \%$ cream once daily versus calcipotriene $0.005 \%$ ointment twice daily in the treatment of plaque psoriasis. Clin Ther 2000; 22: 1225-38.

27. Bowman PH, Maloney JE, Koo JY. Combination of calcipotriene (Dovonex) ointment and tazarotene (Tazorac) gel versus clobetasol ointment in the treatment of plaque psoriasis: a pilot study. J Am Acad Dermatol 2002; 46: 907-13.

28. Koo JY. Tazarotene in combination with phototherapy. J Am Acad Dermatol 1998; 3: S144-8.

29. Behrens S, Grundmann-Kollmann M, Peter RU, et al. Combination treatment of psoriasis with photochemotherapy and tazarotene gel, a receptor-selective topical retinoid. Br J Dermatol 1999; 141: 177.

30. Behrens S, Grundmann-Kollman M, Schiener R, et al. Combination phototherapy of psoriasis with narrow-band UVB irradiation and topical tazarotene gel. J Am Acad Dermatol 2000; 42: 493-5.

31. Koo JY, Lowe NJ, Lew-Kaya, DA, et al. Tazarotene plus UVB phototherapy in the treatment of psoriasis. J Am Acad Dermatol 2000; 43: 821-8.

32. Schiener R, Behrens-Williams SC, Pillekamp H, et al. Calcipotriol vs. tazarotene as combination therapy with narrowband ultraviolet B $(311 \mathrm{~nm})$ : efficacy in patients with severe psoriasis. Br J Dermatol 2000; 143: $1275-8$.

33. Tzaneva S, Honigsmann H, Tanew A, et al. A comparison of psoralen plus ultraviolet A (PUVA) monotherapy, tacalcitol plus PUVA and tazarotene plus PUVA in patients with chronic plaque-type psoriasis. Br J Dermatol 2002; 147: 748-53.

34. Veraldi S, Schianchi R. Short-contact therapy with tazarotene in psoriasis vulgaris. Dermatology 2003; 206: $347-8$.

35. Lee CS, Koo J. A review of acitretin, a systemic retinoid for the treatment of psoriasis. Expert Opin Pharmacother 2005; 6: 1725-34.

36. Yamauchi PS, Rizk D, Lowe NJ. Retinoid therapy for psoriasis. Dermatol Clin 2004; 22: 467-76.

37. Apfel C, Crettaz M, Siegentaler G, et al. Synthetic retinoids: binding to retinoic acid receptors. In: Retinoids 10 years on (Saurat JH, ed). Basel: Korgen, 1991.

38. McClure SL, Valentine J, Gordon KB. Comparative tolerability of systemic treatments for plaque type psoriasis. Drug Safety 2002; 25: 913-27.

39. Wiegand UW, Chou RC. Pharmacokinetics of acitretin and etretinate. J Am Acad Dermatol 1998; 39: S25-33.

40. Rollmann O, Vahlquist A. Retinoid concentrations in skin, serum and adipose tissue of patients treated with etretinate. Br J Dermatol 1983; 109: 439-47.

41. Almond-Roesler B, Orfanos CE. Trans-acitretin wird in etretinat rückmetabolisiert. Hautarzt 1996; 47: 173-7.

42. Larsen FG, Jakobsen P, Knudsen J, et al. Conversion of acitretin to etretinate in psoriatic patients is influenced by ethanol. J Invest Dermatol 1993; 100: 623-7. 
43. Ozawa A, Ohkido M, Haruki Y, et al. Treatment of generalized pustular psoriasis: a multicenter study in Japan. J Dermatol 1999; 26: 141-9.

44. Buccheri L, Katchen BR, Karter AJ, et al. Acitretin therapy is effective for psoriasis associated with human immunodeficiency virus infection. Arch Dermatol 1997; 133: 711-5.

45. Murray HE, Anhalt AW, Lessard R, et al. A 12-month treatment of severe psoriasis with acitretin: Results of a Canadian open multicenter trial. J Am Acad Dermatol 1991; 24: 598-602.

46. Ling MR. Acitretin: optimal dosing strategies. $J$ Am Acad Dermatol 1999; 41: 2-6.

47. Lowe NJ, Lazarus V, Matt L. Systemic retinoid therapy for psoriasis. J Am Acad Dermatol 1988; 19: 186-91.

48. Goldfarb MT, Ellis CN, Gupta AK, et al. Acitretin improved psoriasis in a dose-dependent fashion. J Am Acad Dermatol 1988; 18: 655-62.

49. Olsen EA, Weed WW, Meyer CJ, et al. A double-blind, placebo-controlled trial of acitretin for the treatment of psoriasis. J Am Acad Dermatol 1989; 21: 681-6.

50. Torol L, Kadar L, Geiger JM. Acitretin treatment of severe psoriasis. Acta Dermatol Venereol Supl (Stockh) 1989; 146: 104-6.

51. Geiger JM, Czarnetski BM. Acitretin (Ro 10-1670, etretin). Overall evaluation of clinical studies. Dermatologica 1988; 176: 182-90.

52. Lassus A, Geiger JM, Nyblom M, et al. Treatment of severe psoriasis with etretin (R0-10-1670). Br J Dermatol 1987; 117: 333-41.

53. Gollnick H, Bauer R, Brindley C, et al. Acitretin versus etretinate in psoriasis. Clinical and pharmacokinetic results of a German Multicenter study. J Am Acad Dermatol 1988; 19: 458-69.

54. Kragballe K, Jansen CT, Geiger JM, et al. A double-blind comparison of acitretin and etretinate in the treatment of severe psoriasis. Results of a Nordic multicentre study. Acta Derm Venereol 1989; 6: 35-40.

55. Gollnick H, Zaun H, Ruzicka T. Relapse rate of severe generalised psoriasis after treatment with acitretin or etretinate. Results of the first randomised double blind multicenter half-year follow-up study. Eur $J$ Dermatol 1993; 3: 442-6.

56. Geiger JM. Efficacy of acitretin in severe psoriasis. Skin Therapy Lett 2003; 8: 1-3.

57. Brazalli V, Martinali S, Prestinari F, et al. An impressive therapeutic result in nail psoriasis to acitretin. $J$ Eur Acad Dermatol Venereol 2004; 229, 30.

58. De Berker, D. Management of nail psoriasis. Clin Exp Dermatol 2000; 25, 357-62.

59. De Jong EM, Seegers BA, Gulinck MK, et al. Psoriasis of the nails associated with disability in a large number of patients: results of a recent interview with 1728 patients. Dermatology 1996; 193: 300-3.

60. Agnewk L, Bunker CB. Multiple cutaneous squamous carcinoma in psoriatic associated with ciclosporin, alcohol abuse and ultraviolet radiation exposure which were suppressed by acitretin. J Eur Acad Dermatol Venereol 2003; 17: 113-4.

61. DiGiovanna JJ. Posttransplantation skin cancer: scope of the problem, management, and role for systemic retinoid chemoprevention. Transplant Proc 1998; 30: 2771-5.

62. van de Kerkhof PCM, de Rooij MJM. Multiple squamous cell carcinomas in a psoriatic patient following high dose photochemotherapy and cyclosporin treatment. Response to longterm acitretin maintenance. $\mathrm{Br}$ J Dermatol 1997; 136: 276-8.

63. Lebwohl M, Tannis C, Cazasco D. Acitretin suppression of squamous cell carcinoma: a case report and literature review. J Dermatol Treat 2003; 14: 3-6.

64. Lebwohl M, Menter A, Koo J, et al. Combination therapy to treat moderate to severe psoriasis. $J$ Am Acad Dermatol 2004; 50: 416-30.

65. Lebwohl M, Drake L, Menter A, et al. Acitretin in combination with UVB or PUVA in the treatment of psoriasis. J Am Acad Dermatol 2001; 45: 544-53. 
66. Ruzicka T, Sommerburg C, Braun-Falco O, et al. Efficiency of acitretin in combination with UV-B in the treatment of severe psoriasis. Arch Dermatol 1990; 126: 482-6.

67. Lowe N, Prystowski JH, Bourget T, et al. Acitretin plus UVB therapy for psoriasis: comparisons with placebo plus UVB and acitretin alone. J Am Acad Dermatol 1991; 24: 591-4.

68. Iest J, Boer J. Combined treatment of psoriasis with acitretin and UVB phototherapy compared with acitretin alone and UVB alone. Br J Dermatol 1989; 120: 665-70.

69. Lebwohl M. Acitretin in combination with UVB or PUVA. J Am Acad Dermatol 1999; 41: 22-4.

70. Spuls PI, Rozenblit M, Lebwohl M. Retrospective study of the efficacy of narrowband UVB and acitretin. J Dermatology Treat 2003; 14: 17-20.

71. Tanew A, Guggenbichler A, Honigsmann $\mathrm{H}$, et al. Photochemotherapy for severe psoriasis without or in combination with acitretin: a randomized, double-blind comparison study. J Am Acad Dermatol 1991; 26: $682-4$.

72. Saurat JH, Geiger JM, Amblard P, et al. Randomized double-blind multicenter study comparing acitretin-PUVA, etretinate-PUVA, and placebo-PUVA in the treatment of severe psoriasis. Dermatologica 1988; 177: 218-4.

73. Laurahanta J, Geiger JM. A double-blind comparison of acitretin and etretinate in combination with bath PUVA in the treatment of extensive psoriasis. Br J Dermatol 1989; 121: 107-12.

74. Muchenberger S, Schof E, Simon JC. The combination of oral acitretin and bath PUVA for the treatment of severe psoriasis. Br J Dermatol 1997; 137: 587-9.

75. van de Kerkhof PCM, Cambazard F, Hutchinson F, et al. The effect of the addition of calcipotriol ointment $(50 \mu \mathrm{g} / \mathrm{g})$ to acitretin therapy in psoriasis. Br J Dermatol 1998; 138: 84-9.

76. Iyer S, Yamauchi P, Lowe NJ. Etanercept for severe psoriasis and psoriatic arthritis: observations on combination therapy. Br J Dermatol 2002; 146: 118-21.

77. Strober BE, Clarke S. Etanercept for the treatment of psoriasis: combination therapy with other modalities. J Drugs Dermatol 2004; 3: 270-2.

78. Spuls PI, Hadi S, Rivera L, et al. Retrospective analysis in the treatment of psoriasis of the palms and soles. J Dermatol Treat 2003; 14: 21-5.

79. Sobell JM, Hallas SJ. Systemic therapies for psoriasis: understanding current and newly emerging therapes. Semin Cutan Med Surg 2003; 22: 187-95.

80. Kazinski K, Joyce KM, Hodson D. The successful use of etanercept in combination therapy for treatment of acrodermatitis Continua Hallopeau. J Drugs Dermatol 2005; 4: 3604.

81. Van Duijnhoven MWF, De Jong EMGJ, Gerritsen WJ, et al. Alefacept modifies long-term disease severity and improves the response to other treatments. Eur J Dermatol 2005; 15: 1-8.

82. Webber IR, Back DJ. Effect of etretinate on cyclosporin metabolism in vitro. Br J Dermatol 1993; 128: 42-4.

83. van der Veen EF, Ellis CN, Campbell JP, et al. Methotrexate and etretinate as concurrent therapies in severe psoriasis. Arch Dermatol 1982; 118: 660.

84. Beck HI, Foged EK. Toxic hepatitis due to combination therapy with methotrexate and etretinate in psoriasis. Dermatologica 1983; 167: 94-6.

85. Cather JC, Menter A. Combining traditional agents and biologics for the treatment of psoriasis. Seminars in Cutaneous Medicine and Surgery 2005, 24: 37-45.

86. Koo J, Nguyen Q, Gamba C. Advances in psoriasis therapy. Adv Dermatol 1997; 12: 47-72.

87. Yamauchi PS, Rizk D, Kormili T, et al. Systemic retinoids. In: Therapy of moderate to severe psoriasis. (Weinstein GD, Gottlieb AB, eds). New York: Marcel Dekker, Inc., 2003, 137-150.

88. Piskin S, Gurkok F, Ekuklu G, et al. Serum lipid levels in psoriasis. Yonsei Med J 2003; 44: 24- 6. 
89. Rocha-Pereira P, Santos Silva A, Rebelo I, et al. Dislipidemia and oxidative stress in mild and severe psoriasis as a risk for cardiovascular disease. Clin Chim Acta 2001; 303: 33-9.

90. Vahlquist C, Michaelson G, Vessby B. Serum lipoproteins in middle-aged men with psoriasis. Acta Derm Venereol 1987; 67: 12-5.

91. Valquist C, Selinus I, Vessby B. Serum lipids changes during acitretin (etretin) treatment of psoriasis and palmo-plantar pustulosis. Acta Derm Venereol 1988; 6: 300-5.

92. Roenigk HH Jr, Callen JP, Guzzo CA, et al. Effects of acitretin on the liver. J Am Acad Dermatol 1999; 41: $584-8$.

93. Van Ditzhuijsen TJ, van Haelst UJ, van Dooren-Greebe RJ, et al. Severe hepatotoxic reaction with progression to cirrhosis after use of a novel retinoid (acitretin). J. Hepatol 1990; 11: 185-8.

94. Mills CM, Marks R. Adverse reactions to oral retinoids. An update. Drug Saf 1993; 9: 280-90.

95. David M, Hodak E, Lowe NJ. Adverse effects of retinoids. Med Toxicol 1988; 3: 273-88.

96. Geiger JM, Baudin M, Saurat JH. Teratogenic risk with etretinate and acitretin treatment. Dermatology 1994; 189: 109-16.

97. Di Giovanna JJ, Sollito RB, Abangan DL. Osteoporosis is a toxic effect in a long-term etretinate therapy. Arch Dermatol 1995; 131: 1321-2.

98. van Dooren-Greebe RJ, Lemmens JA, de Boo T, et al. Prolonged treatment with oral retinoids in adults: no influence on the prevalence, incidence and severity of spinal abnormalities. Br J Dermatol 1996; 134: 71-6.

99. Naldi L, Griffiths CME. Traditional therapies in the management of moderate to severe chronic plaque psoriasis: an assessment of the benefits and risks. Br J Dermatol 2005; 152: 597-615.

100. http://www.fda.gov/ohrms/dockets/ac/04/slides/2004-4062S1_02_Allergan-Presentation_files/frame.htm (Accessed 15 Feb. 2006)

101. Duvic M, Hymes K, Heald P, et al. Bexarotene is effective and safe for treatment of refractory advanced-stage cutaneous T-cell lymphoma: multinational phase II-III trial results. J Clin Oncol 2001; 19: 2456-71.

102. Prince HM, McCormack C, Ryan G, et al. Bexarotene capsules and gel for previously treated patients with cutaneous T-cell lymphoma: results of the Australian patients treated on phase II trials. Australas $J$ Dermatol 2001; 42: 91-7.

103. Zhang C, Duvic M. Retinoids: therapeutic applications and mechanisms of action in cutaneous T-cell lymphoma. Dermatol Ther 2003; 16: 322-30.

104. Bischoff ED, Heyman RA, Lamph WW. Effect of the retinoid X receptor-selective ligand, LGD1069, on mammary carcinoma after tamoxifen failure. J Natl Cancer Inst 1999; 91: 2118-24.

105. Bischoff ED, Gottardis MM, Moon TE, et al. Beyond tamoxifen: the retinoid X receptor-selective ligand LGD1069 (TARGRETIN) causes complete regression of mammary carcinoma. Cancer Res 1998; 58: 479-84.

106. Gottardis MM, Bischoff ED, Shirley MA, et al. Chemoprevention of mammary carcinoma by LGD1069 (Targretin): an RXR-selective ligand. Cancer Res 1996; 56: 5566-70.

107. Gamage SD, Bischoff ED, Burroughs KD, et al. Efficacy of LGD1069 (Targretin), a retinoid X receptorselective ligand, for treatment of uterine leiomyoma. J Pharmacol Exp Ther 2000; 295: 677-81.

108. Boehm MF, Zhang L, Zhi L, et al. Design and synthesis of potent retinoid X receptor selective ligands that induce apoptosis in leukemia cells. $J$ Med Chem 1995; 38: 3146-55.

109. Zhang C, Hazarika P, Ni X, et al. Induction of apoptosis by bexarotene in cutaneous T-cell lymphoma cells: relevance to mechanism of therapeutic action. Clin Cancer Res 2002; 8: 1234-40.

110. Lowe MN, Plosker GL. Bexarotene. Am J Clin Dermatol 2000; 1: 245-50.

111. Ligand pharmaceuticals Inc. (US) Targretin ${ }^{\circledR}$ (bexarotene) capsules, $75 \mathrm{mg}$ : package insert. Available at http://www.fda.gov/cder/foi/label/1999/21055lbl.pdf (accessed Jan. 2006). 
112. Smit JV, de Jong EM, van Hooijdonk CA, et al. Systemic treatment of psoriatic patients with bexarotene decreases epidermal proliferation and parameters for inflammation, and improves differentiation in lesional skin. J Am Acad Dermatol 2004; 51: 257-64.

113. Smit JV, Franssen ME, de Jong EM, et al. A phase II multicenter clinical trial of systemic bexarotene in psoriasis. J Am Acad Dermatol 2004; 51: 249-56.

114. Farol LT, Hymes KB. Bexarotene: a clinical review. Expert Rev Anticancer Ther 2004; 4: 180-8.

115. Napoli JL. Retinoic acid: its biosynthesis and metabolism. Prog Nucleic Acid Res Mol Biol 1999; 63: 39-88.

116. Petkovich PM. Retinoic acid metabolism. J Am Acad Dermatol 2001; 45: S136-42.

117. Vanden Bossche H, Willemsens S. Retinoic acid and cytochrome P-450. Retinoids 1991; 10: 79-88.

118. Kang S, Duell E, Kim K, et al. Liarozole inhibits human epidermal retinoic acid 4-hydroxylase activity and differentially augments human skin responses to retinoic acid and retinol in vivo. $J$ Invest Dermatol 1996; 107: 183-7.

119. Van Wauwe JP, Coene M-C, Goossens J, et al. Ketoconazole inhibits the in vitro and in vivo metabolism of all-trans- retinoic acid. $J$ Pharmacol Exp Ther 1988; 245: 718-22.

120. Van Wauwe J, Coene M-C, Goossens J, et al. Effects of cytochrome P-450 inhibition on the in vivo metabolism of all-trans-retinoic acid in rats. J Pharmacol Exp Ther 1990; 252: 365-9.

121. Van Wauwe J, Van Nyen G, Coene M-C, et al. Liarozole, an inhibitor of retinoic acid metabolism, exerts retinoid-mimetic effects in vivo. J Pharmacol Exp Ther 1992; 261: 773-8.

122. De Coster R, Wouters W, van Ginckel R, et al. Experimental studies with liarozole (R75251): an antitumoral agent which inhibits retinoic acid breakdown. J Steroid Biochem Mol Biol 1992; 43: 197-201.

123. Bryson HM, Wagstaff AJ. Liarozole. Drugs Aging 1996; 9: 478-84.

124. Lucker G, Heremans A, Boegheim P, et al. Oral treatment of ichthyosis by the cytochrome P-450 inhibitor liarozole. Br J Dermatol 1997; 136: 71-5.

125. Lucker G, Verfaille CJ, Heremans A, et al. Topical liarozole in ichthyosis: a double-blind, left-right comparative study followed by a long-term open maintenance study. Br J Dermatol 2005; 152: 566-9.

126. Verfaille CJ, Steijlen PM, Blanchet-Bardon C, et al. Phase II and III studies to evaluate the efficacy and safety of oral liarozole and acitretin in the treatment of severe ichthyosis. J Eur Acad Dermatol Venereol 2004; 18 (Suppl. 2): 145.

127. Vandeplassche G, Verfaille CJ, Beger B, et al. Safety of oral liarozole in subjects with ichthyosis or psoriasis. J Eur Acad Dermatol Venereol 2004; 18 (Suppl. 2): 395-6.

128. Dockx P, Decree J, Degreef H. Inhibition of the metabolism of endogenous retinoic acid as treatment for severe psoriasis: an open study with oral liarozole. Br J Dermatol 1995; 133: 426-32.

129. Berth-Jones J, Todd G, Hutchinson P, et al. Treatment of psoriasis with oral liarozole: a dose-ranging study. Br J Dermatol 2000; 143: 1170-6.

130. Bhushan M, Burden $\mathrm{AD}$, McElhone $\mathrm{K}$, et al. Oral liarozole in the treatment of palmoplantar pustular psoriasis: a randomized, double-blind, placebo-controlled study. Br J Dermatol 2001; 145: 546-53.

131. Vandeplassche G, Beger B, Staszak J, et al. Long-term safety of oral liarozole, a new retinoic acid metabolism blocking agent. J Eur Acad Dermatol Venereol 2005; 19 (Suppl. 2): FC13.14.

132. Stoppie P, Borgers M, Borghgraef P, et al. R115866 inhibits all-trans-retinoic acid metabolism and exerts retinoidal effects in rodents. J Pharmacol Exp Ther 2000; 293: 304-12.

133. Rambazole ${ }^{\mathrm{TM}}$ (R115866) Investigational Drug Brochure; version 3.0.; Oct. 2005. Data on file at Barrier Therapeutics.

134. Steijlen PM, Thissen CA, Bovenschen JH, et al. Oral Rambazole ${ }^{\mathrm{TM}}$ in patients with moderate to severe plaque type psoriasis- a pilot trial. J Eur Acad Dermatol Venereol 2005; 19 (Suppl. 2): P06.84 



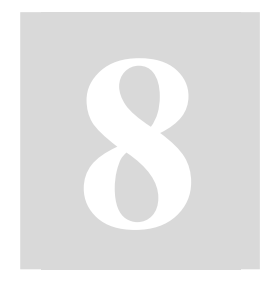

\section{Oral R115866 in psoriasis}

Based on:

Verfaille $C J^{1,4}$, Thissen $C A C B^{2}$, Bovenschen $J^{3}{ }^{3}$, Mertens $J^{4}$, Steijlen $P M^{1,2}$, van de Kerkhof PCM ${ }^{3}$. Oral R115866 in the treatment of moderate to severe plaque type psoriasis.

$J E A D V$, in press.

${ }^{1}$ Departments of Dermatology \& Molecular Cell Biology, GROW, Maastricht University, The Netherlands.

${ }^{2}$ Departments of Dermatology, AZM, University Hospital Maastricht, The Netherlands.

${ }^{3}$ Department of Dermatology, Radboud University Nijmegen Medical Centre, The Netherlands.

${ }^{4}$ Barrier Therapeutics $n v$, Geel, Belgium. 


\begin{abstract}
Background: R115866 (Rambazole ${ }^{\mathrm{TM}}$ ) is a new generation all-trans Retinoic Acid Metabolism Blocking Agent (RAMBA), highly specific against the retinoic acid 4hydroxylase. The drug alleviates hyperproliferation and normalizes differentiation of the epidermis in animal models of psoriasis.
\end{abstract}

Objective: To explore the efficacy, safety and tolerability of systemic R115866 in patients with moderate to severe plaque type psoriasis.

Patients and methods: In this open label, single-arm trial, patients were treated with $\mathrm{R} 115866,1 \mathrm{mg} /$ day for 8 weeks, followed by a 2-week treatment free follow-up period. Patients were monitored for efficacy and safety.

Results: Nineteen patients (ITT-population) were treated and 14 completed the entire study. Two patients discontinued due to lack of efficacy and 3 due to adverse events. At the end of the treatment, $26 \%$ of the patients showed at least $50 \%$ reduction in Psoriasis Area Severity Index (PASI) compared to baseline. Further improvement was observed at the end of the 2-week follow-up period where $47 \%$ of the patients showed a $50 \%$ or greater reduction in PASI. Kinetic data showed no evidence of accumulation of either R115866 or retinoic acid in plasma. The most common adverse events were pruritus, xerosis, cheilitis and an increase in blood triglycerides. The majority of adverse events were mild to moderate. No deaths or serious adverse events were reported.

Conclusion: Eight week daily treatment with $1 \mathrm{mg}$ R115866 resulted in a significant reduction in PASI from baseline to end of therapy. Additional improvement was seen after the 2-week follow-up period. The drug was well tolerated. R115866 merits further evaluation to optimize its clinical efficacy and safety profile in moderate to severe plaque type psoriasis. 


\section{Introduction}

R115866 (Rambazole ${ }^{\mathrm{TM}}$ ) is identified as a new generation all-trans Retinoic Acid Metabolism Blocking Agent (RAMBA). The investigational drug is a novel tri-azole derivative with highly potent and selective cytochrome P-450 (CYP) inhibiting properties against hydroxylases involved in the metabolic inactivation pathway of all-transretinoic acid (all-trans-RA). R115866 affects the catabolism of all-trans-RA at nanomolar concentrations, whereas micromolar concentrations are needed to inhibit other CYPs.

The rationale behind the use of a RAMBA is blocking the breakdown of the body's own all-trans-RA by using a non-retinoid drug thereby augmenting endogenous intracellular all-trans-RA. Several animal experiments have documented the in vivo suppressive effects of R115866 on the all-trans-RA metabolism in rats. ${ }^{1}$ A single oral R115866 treatment transiently increases endogenous all-trans-RA in the rat skin. In other animal models, like all-trans-RA, both oral and topical R115866 induce epidermal hyperplasia in mouse ear skin, exhibit the formation of a granular layer and transform the parakeratotic type of keratinization to the orthokeratotic type in the scale regions of murine tail epidermis. ${ }^{2}$ R115866 inhibits both orally and topically the vaginal keratinization in estrogen-stimulated rats. By virtue of this property and the well-known modulating effects of all-trans-RA on epithelial growth and differentiation ${ }^{3-6}$, R115866 is potentially useful for disorders associated with or due to an aberrant keratinization, such as plaque psoriasis.

Phase I single (0.6 to $20 \mathrm{mg}$ ) and multiple [0.5, 2 and $4 \mathrm{mg}$ twice daily (b.i.d), for one week] dose escalation trials with oral R115866 in healthy volunteers reveal a fast absorption of R115866 with peak plasma concentrations obtained at approximately one hour (h) after drug intake. ${ }^{7,8}$ Elimination of R1 15866 occurs with a dominant half-life of 1.1 to $2.1 \mathrm{~h}$. Steady-state plasma concentrations of R115866 are reached within one day of multiple dosing and terminal half-lives after the last dose are in the order of $15 \mathrm{~h}$. In the multiple dose study, mean through and peak plasma concentrations of R115866 on the last day fluctuated between 0.036 and $0.32 \mathrm{ng} / \mathrm{ml}$ for the $0.5 \mathrm{mg}$ b.i.d. dose and between 0.13 and $1.6 \mathrm{ng} / \mathrm{ml}$ for the $2 \mathrm{mg}$ b.i.d. dose. The peak plasma RA concentration averaged $2.06 \mathrm{ng} / \mathrm{ml}$ for placebo versus 2.86 and $3.52 \mathrm{ng} / \mathrm{ml}$ for 0.5 and $2 \mathrm{mg} \mathrm{R} 115866$ b.i.d respectively and remained within or slightly above the normal biological range (1 to $4 \mathrm{ng} / \mathrm{ml}$ ) of all-trans-RA levels in human plasma as published in literature. ${ }^{9-12}$ Compared to liarozole, a previous generation RAMBA, $\mathrm{R} 115866$ is a more potent $\left(\mathrm{IC}_{50}\right.$ in $\mathrm{nM}$ range) and selective CYP26 inhibitor hence expected to result in clinical efficacy at lower dosages and consequently in less adverse events. The increase in all-trans-RA 
as observed in clinical trials with liarozole has been used to predict an active dose level of R115866 in terms of efficacy. ${ }^{13-15}$

The main purpose of this study was to explore the efficacy, tolerability and safety of oral R115866 at a daily dose of $1 \mathrm{mg}$ in patients with moderate to severe plaque-type psoriasis. The rationale for the short treatment period of 8 weeks was based on the available animal toxicity data with R115866 and the clinical efficacy data obtained with acitretin, the only oral retinoid approved for treating psoriasis in Europe and the U.S. ${ }^{16}$ After 8 weeks of treatment a more than 50\% improvement in PSI score [corrected Psoriasis Area Severity Index (PASI) score] was achieved in 50\% of severe psoriasis patients treated with $10 \mathrm{mg}, 40.5 \%$ with $25 \mathrm{mg}$ and $53.8 \%$ with $50 \mathrm{mg}$ acitretin. Based on these results and based on the mechanism of action of R115866, an 8 week treatment course with $1 \mathrm{mg}$ daily was considered sufficient to reveal clinical efficacy.

\section{Patients and Methods}

\section{Study design}

The study was a phase $2 \mathrm{a}$, multicentre, open-label study to assess the efficacy, tolerability and safety of oral R115866 in subjects with moderate to severe plaque-type psoriasis; PASI $\geq 5$. Patients were enrolled in two study centers: the Department of Dermatology of the University Hospital Maastricht and the Department of Dermatology of the Radboud University Nijmegen Medical Center, both in the Netherlands. The protocol has been reviewed and approved by each study center's independent ethics committee and all patients provided written informed consent prior to study enrollment. All clinical investigations were conducted according to the Declaration of Helsinki principles.

\section{Treatment}

In this open-label study, patients were instructed to take two capsules of $0.5 \mathrm{mg}$ R115866, total daily dose of $1 \mathrm{mg}$, in the morning with breakfast for a period of 8 weeks. The 8 -week treatment period was followed by a 2 -week treatment-free follow-up period. The investigator could decide to decrease the dose to $0.5 \mathrm{mg}$ once daily if necessary. At the visit days, patients were advised to be fasted for at least $8 \mathrm{~h}$ before blood sampling. Their medication had to be taken in the clinic with breakfast after collection of the pre-dose blood samples and ECG recordings. 


\section{Patient population}

Male patients and female patients (at least 2 years post-menopausal or undergone successful surgical sterilization at least 1 year before inclusion), 18 years or older and diagnosed with moderate to severe plaque type psoriasis (PASI score $>5.0$ ) were allowed to participate in this trial. Patients had to be, except for psoriasis, in good health according to their history and physical examination. No clinically relevant abnormalities in the laboratory test results (hematology, biochemistry, endocrinology and urine analysis) at visit 1 and a signed written informed consent were required from all patients. The following medication wash-out periods before entering the study were requested: 2 weeks for topical or ultraviolet treatment, 4 weeks for systemic treatment for psoriasis or vitamin A supplements ( $>1000 \mu \mathrm{g} /$ day).

Main exclusion criteria included non-plaque type forms of psoriasis, concurrent inflammatory skin disease, co-existing serious disease, heart disorders, ECG abnormalities, hyperlipidaemia, use of drugs that could interfere with either psoriasis or the study drug, previous use of any psoriasis biological agent, known intolerance to retinoids and the suspicion of alcohol abuse.

\section{Clinical evaluations}

Clinical evaluations were made at week 0 (baseline), week 1, 2, 4, and 8 of the treatment phase and at week 10 ( 2 weeks post-treatment). The following efficacy measures were evaluated by the same investigator per site over the course of the study:

\section{Psoriasis area and severity index}

The PASI was used to evaluate the extent and severity of psoriasis. The PASI is a composite score ranging from 0 to 72 and varying in steps of 0.1 that includes assessments of the extent of skin involvement, erythema, plaque elevation/induration, and desquamation. ${ }^{17}$

\section{Overall evaluation of efficacy by investigator}

At each post-baseline visit, the investigator compared the patient's overall disease severity to the overall disease severity at baseline. The overall evaluation of efficacy was graded on a 6 -point scale ranging from $0=$ worse, $1=$ unchanged $(<10 \%$ improvement), $2=$ slight improvement $( \pm 25 \%), 3=$ moderate improvement $( \pm 50 \%), 4=$ marked improvement $( \pm 75 \%)$ to $5=$ almost to complete clearance $(90-100 \%)$. 


\section{Lesion severity assessment by investigator}

An assessment of the overall lesion severity was performed by the investigator after scoring the PASI based on the psoriasis signs of erythema, plaque induration/elevation and desquamation. The severity was graded on a 6-point scale ranging from 0 to 5 (Table 8.1).

Table 8.1 Overall lesion severity assessment scales

\begin{tabular}{|c|c|}
\hline Scale & Description \\
\hline 0 & $\begin{array}{l}\text { No plaque elevation above normal skin level, may have residual non-erythematous discoloration, } \\
\text { no psoriatic scale }\end{array}$ \\
\hline 1 & $\begin{array}{l}\text { Essentially flat with possible trace elevation, may have up to mild erythema, may have limited } \\
\text { amount of very fine scales }\end{array}$ \\
\hline 2 & $\begin{array}{l}\text { Slight but definite elevation of plaque above normal skin level, may have up to moderate } \\
\text { erythema, fine scales with some lesions partially covered }\end{array}$ \\
\hline 3 & $\begin{array}{l}\text { Moderate elevation with rounded or sloped edges to plaque, moderate erythema; somewhat } \\
\text { coarser scales with most lesions partially covered }\end{array}$ \\
\hline 4 & $\begin{array}{l}\text { Marked elevation with hard, sharp edges to plaque; severe erythema; coarse, thick scales with } \\
\text { virtually all lesions covered and a rough surface }\end{array}$ \\
\hline 5 & $\begin{array}{l}\text { Very marked elevation with very hard, sharp edges to plaque; very severe erythema; very coarse, } \\
\text { thick scales with all lesions covered and a very rough surface }\end{array}$ \\
\hline
\end{tabular}

\section{Patient's self-assessment of treatment}

A subjective overall evaluation of treatment was made by the patient relative to baseline using the following scale: $0=$ worse, $1=$ unchanged, $2=$ slight improvement, $3=$ moderate improvement, $4=$ marked improvement, $5=$ almost to complete clearance.

\section{Photographs}

In order to document efficacy, photographs of the whole body and of 3-4 designated areas, e.g. elbow, legs, trunk were taken at each center under standardized conditions.

\section{Pharmacokinetics/pharmacodynamics}

Plasma levels of R115866 and all-trans-RA were measured throughout the trial. After collection of the pre-dose blood samples (only for all-trans-RA), a second blood sample was collected between 2-4.5 hours after drug intake for both all-trans-RA and R115866 at each subsequent visit. At the follow-up visit, only all-trans-RA monitoring was performed. All plasma samples were analyzed using a validated liquid chromatographytandem mass spectrometry method with a lower limit of quantitation at $0.010 \mathrm{ng} / \mathrm{ml}$ for $\mathrm{R} 115866$ and $0.5 \mathrm{ng} / \mathrm{ml}$ for all-trans-RA. 


\section{Safety and tolerability evaluation}

Adverse events (AEs) were recorded throughout the study period. In addition, at every visit blood samples for hematology, endocrinology (luteinizing hormone, oestradiol, cortisol, aldosterone and testosterone) and biochemistry were taken. Urinalysis was only performed at screening. Cardiovascular safety was monitored at each visit by pre- and post-dose measurements of electrocardiograms (ECG), blood pressure and heart rate. Possible clinical signs of retinoic acid related cutaneous side effects i.e. xerosis, pruritus, cheilitis, epistaxis, periungual granulomatous reaction, hair loss and fragile skin were evaluated and graded for severity (absent, mild, moderate or severe) at all visits.

\section{Statistics}

The intent-to-treat (ITT) population consisted of all patients who were assigned to treatment. The safety population was identical to the ITT population. Statistical analysis was carried out for both the ITT population and the complete cases (i.e. all patients whom completed treatment and had efficacy data at end of treatment) using the SAS Version 8.2 system for statistical analysis. ${ }^{18}$ Continuous data are summarized as median change from baseline and distribution-free $95 \%$ confidence intervals for the median. Statistical significance versus baseline values was assessed with the Wilcoxon signed rank test. Two-sided p-values less than or equal to 0.05 is considered to indicate statistical significance.

\section{Results}

\section{Patients}

Of 28 patients that were screened, 19 were enrolled and treated with R115866 (ITT population). All patients were Caucasian of which 15 were males and 4 females. The mean (range) age was 49.6 years (25-76), mean body weight $91.1 \mathrm{~kg}$ (71-160), mean body mass index $29.4 \mathrm{~kg} / \mathrm{m}^{2}$ (21.0-49.4) and mean PASI 13 (5.8-41.8). Five patients discontinued during the study. Reasons for discontinuation included lack of efficacy $(\mathrm{n}=2)$ and AEs $(\mathrm{n}=3)$. Fourteen patients completed the 8-week treatment and the 2-week follow-up. However, there are only 13 complete cases, since one patient is lacking efficacy data at the end of treatment (week 8). The flowchart is presented in Figure 8.1. 


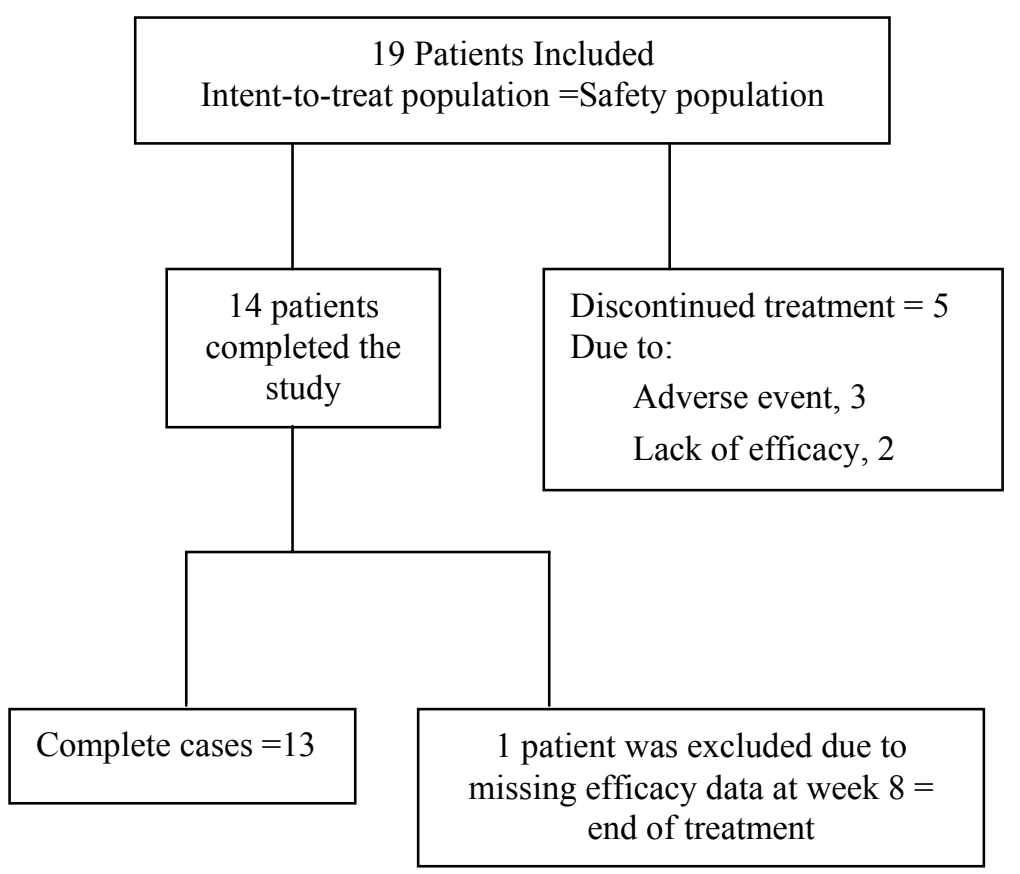

Figure 8.1 Patient disposition

\section{Clinical evaluations}

\section{Psoriasis area and severity index}

Compared to baseline, a statistically significant reduction in PASI score was found at all time points evaluated except for week 4. An initial statistically significant reduction versus baseline was observed after one week of treatment with a median PASI reduction of $7.8 \%(P=0.001)$. The median reduction in PASI increased with treatment duration and amounted from $8.2 \%(P=0.038)$ after 2 weeks of treatment to $21 \%$ at the end of treatment (week $8 ; P=0.048)$ and further increased to $49 \%(P<0.001)$ at the end of the 2week follow-up period (week 10; $P<0.001)$. At the end of treatment, $5 / 19(26 \%)$ patients showed a reduction in PASI of at least 50\% (Figures 8.2 and 8.3) compared to $8 / 17(47 \%)$ at the end of the follow-up period. Detailed information on the individual PASI and percentage PASI reduction per visit as compared to baseline is given in Table 8.2 . 
Analysis of the complete cases revealed a statistically significant reduction in PASI score compared to baseline at all time points evaluated with a median PASI reduction of $37 \%(P=0.002)$ at end of therapy further augmenting to $51 \%(P<0.001)$ after 2 weeks follow-up. At the end of treatment, 5/13 (38\%) patients showed a PASI reduction of at least 50\%. At the end of the follow-up period 7/13 (54\%) and 9/13 (69\%) patients had a reduction of at least $50 \%$ and $45 \%$ respectively.
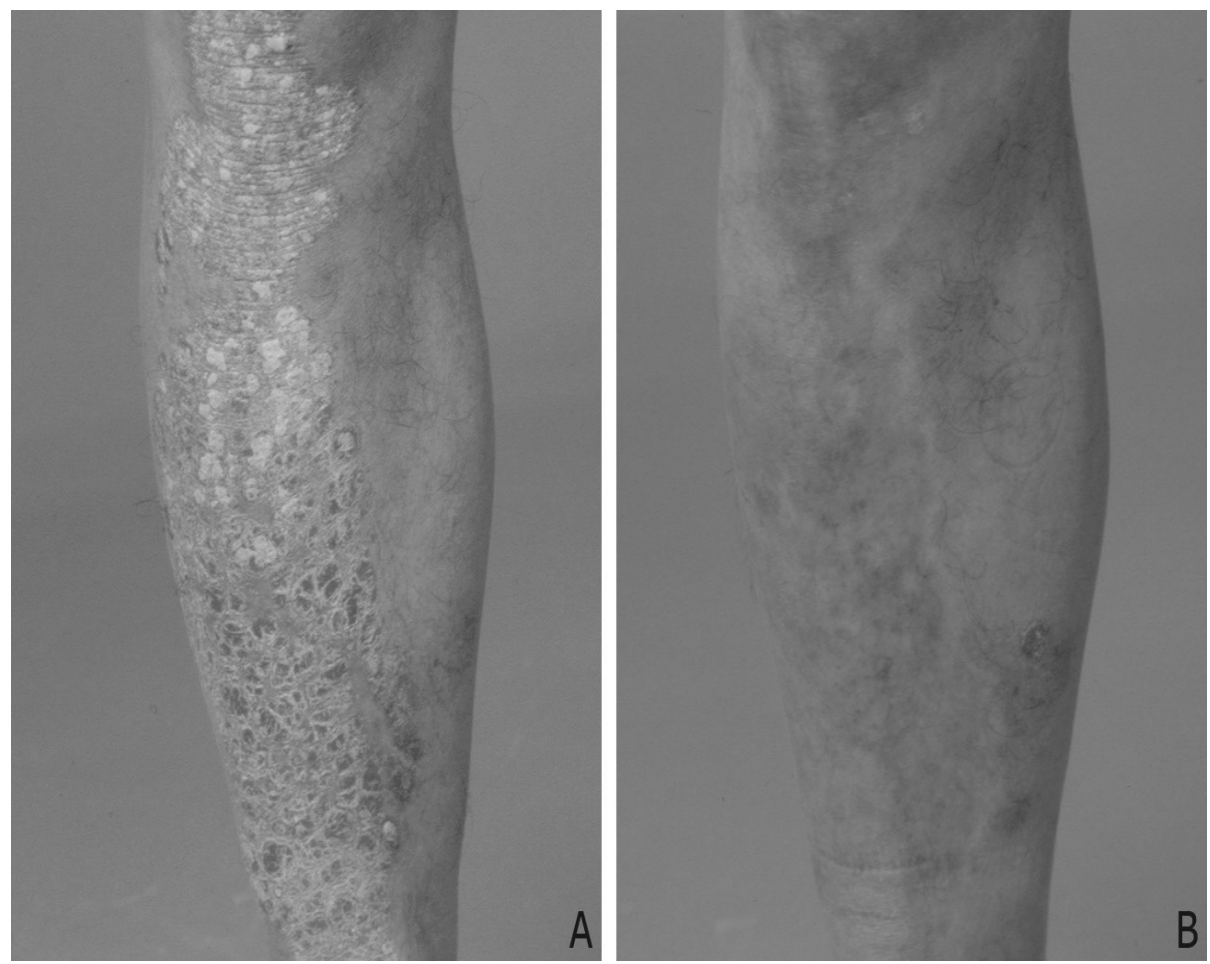

Figure 8.2 Plaque type psoriasis on lower leg of a patient (S206) before treatment (A) and after 8 weeks of treatment with $1 \mathrm{mg}$ R115866 (B). See page 235 for colour figure. 

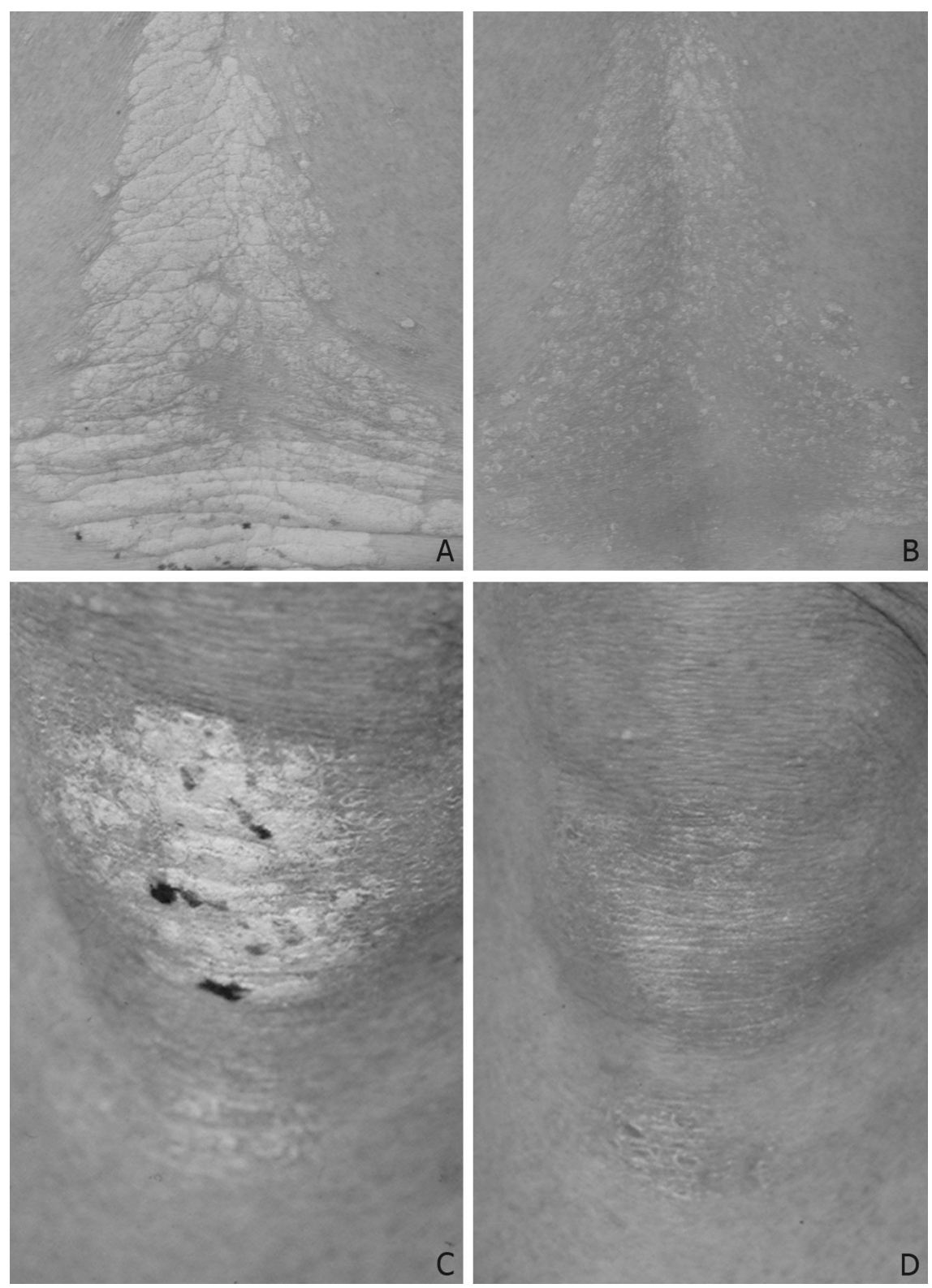

Figure 8.3 Plaque type psoriasis on back and knee of a patient (S226) at baseline (A and C) and after 8 weeks of treatment with $1 \mathrm{mg}$ R115866 (B and D). See page 236 for colour figure. 
Table 8.2 Overview of individual PASI scores ( $\%$ change from baseline) for every patient at every visit.

\begin{tabular}{|c|c|c|c|c|c|c|}
\hline \multirow{2}{*}{$\begin{array}{l}\text { All patients } \\
\qquad \mathbf{N}=19\end{array}$} & \multirow{2}{*}{$\begin{array}{l}\text { Baseline } \\
\text { Week } 0\end{array}$} & \multicolumn{4}{|c|}{ Treatment } & \multirow{2}{*}{$\begin{array}{r}\text { Follow-up } \\
\text { Week } 10\end{array}$} \\
\hline & & Week 1 & Week 2 & Week 4 & Week 8 & \\
\hline S202 & 6.9 & $6.9(0 \%)$ & $6.8(-1 \%)$ & $6.8(-1 \%)$ & $6.6(-4 \%)$ & $5.6(-19 \%)$ \\
\hline S204 & 7.7 & $7.1(-8 \%)$ & $7.1(-8 \%)$ & $7.5(-3 \%)$ & $6.1(-21 \%)$ & $4.9(-36 \%)$ \\
\hline S205 & 16.6 & $14.5(-13 \%)$ & $14.6(-12 \%)$ & $11.6(-30 \%)$ & $7.2(-57 \%)$ & $8.6(-48 \%)$ \\
\hline S206 & 19.2 & $18.6(-3 \%)$ & $17(-12 \%)$ & $13.2(-31 \%)$ & $6.8(-65 \%)$ & $0.8(-96 \%)$ \\
\hline S207 & 9.6 & $9.6(0 \%)$ & $8.3(-14 \%)$ & $7.7(-20 \%)$ & $3.3(-66 \%)$ & $3.3(-66 \%)$ \\
\hline S209 & 7.4 & $6.6(-11 \%)$ & $5.7(-23 \%)$ & $4.5(-39 \%)$ & $3(-58 \%)$ & $2.1(-72 \%)$ \\
\hline S212 & 15.9 & $14.1(-11 \%)$ & $15.6(-2 \%)$ & $17(+7 \%)$ & $13.6(-14 \%)$ & $11.2(-30 \%)$ \\
\hline S217 & 6.3 & $6.8(+8 \%)$ & $7.4(+18 \%)$ & $5.3(-16 \%)$ & $8.1(+29 \%)$ & $5.5(-13 \%)$ \\
\hline S218 & 12 & $11.1(-8 \%)$ & $10.3(-14 \%)$ & $8.2(-32 \%)$ & $6.6(-45 \%)$ & $3.2(-73 \%)$ \\
\hline S220 & 18 & $14.6(-19 \%)$ & $14.3(-21 \%)$ & $10.3(-43 \%)$ & $8.5(-53 \%)$ & $9.2(-49 \%)$ \\
\hline S224 & 41.8 & $33.6(-20 \%)$ & $31.6(-24 \%)$ & $31.6(-24 \%)$ & $27.9(-33 \%)$ & $20.5(-51 \%)$ \\
\hline S226 & 9.8 & $9.0(-8 \%)$ & $9.0(-8 \%)$ & $10.2(+4 \%)$ & $7.2(-26 \%)$ & $4.4(-55 \%)$ \\
\hline S228 & 6.7 & $6.7(0 \%)$ & $6.4(-4 \%)$ & $5.7(-15 \%)$ & $4.2(-37 \%)$ & $2.5(-63 \%)$ \\
\hline$S 221^{a}$ & 15.1 & 13.3 & 16.3 & 12.7 & - & 5.4 \\
\hline$S 213(28 d)^{b}$ & 11.2 & 8.9 & 9.3 & 23.1 & - & 7.2 \\
\hline$S 227(14 d)^{b}$ & 15.9 & 17.9 & 23.7 & - & - & - \\
\hline$S 216(9 d)^{c}$ & 9.5 & 8.1 & - & - & - & 9.6 \\
\hline$S 219(39 d)^{c}$ & 10.8 & 10.8 & 10.2 & 8.8 & 11.8 & 11.4 \\
\hline$S 223(2 d)^{c}$ & 5.8 & - & - & - & - & - \\
\hline Median & 10.8 & 10.2 & 10.2 & 9.5 & 7.0 & 5.5 \\
\hline Mean & 13.0 & 12.1 & 12.3 & 11.5 & 8.6 & 6.8 \\
\hline Min & 5.8 & 6.6 & 5.7 & 4.5 & 3.0 & 0.8 \\
\hline Max & 41.8 & 33.6 & 31.6 & 31.6 & 27.7 & 20.5 \\
\hline \multicolumn{7}{|c|}{$\begin{array}{l}\text { a Excluded from complete cases due to lack of efficacy data at week } 8 \\
\text { b Discontinuations due to insufficient therapeutic effect }\end{array}$} \\
\hline
\end{tabular}




\section{Overall evaluation of efficacy by investigator}

A statistically significant improvement from week 4 of treatment onwards was shown, with increased improvement towards the end of treatment $(P=0.004)$ and follow-up $(P<0.001)$ (Table 8.3). At the end of treatment, 8 patients $(44 \%)$ scored at least moderate improvement, 4 scored slight improvement (23\%) and 6 scored worse or unchanged (34\%). At follow-up 11 patients (64\%) were rated at least moderate improved. Two patients scored slight improvement (12\%) and 4 patients scored unchanged (24\%).

Table 8.3 Overall evaluation of efficacy by the investigator-ITT population

\begin{tabular}{|c|c|c|c|c|c|c|c|c|c|c|}
\hline \multicolumn{9}{|c|}{ Treatment period $(\mathbf{n}=18) * * *$} & \multirow{2}{*}{\multicolumn{2}{|c|}{$\begin{array}{c}\text { Follow-up } \\
(\mathrm{n}=17) * * \\
10\end{array}$}} \\
\hline Weeks (scheduled) & \multicolumn{2}{|c|}{1} & \multicolumn{2}{|c|}{2} & \multicolumn{2}{|c|}{4} & \multicolumn{2}{|c|}{8} & & \\
\hline Investigator assessment & $\mathbf{n}$ & $\%$ & $\mathbf{n}$ & $\%$ & $\mathbf{n}$ & $\%$ & $\mathbf{n}$ & $\%$ & $\mathbf{n}$ & $\%$ \\
\hline Worse & 2 & 11 & 4 & 22 & 3 & 18 & 3 & 17 & 0 & 0 \\
\hline Unchanged & 11 & 61 & 7 & 39 & 4 & 22 & 3 & 17 & 4 & 24 \\
\hline Slight improvement & 5 & 28 & 7 & 39 & 9 & 50 & 4 & 22 & 2 & 12 \\
\hline Moderate improvement & 0 & 0 & 0 & 0 & 2 & 11 & 6 & 33 & 5 & 29 \\
\hline Marked improvement & 0 & 0 & 0 & 0 & 0 & 0 & 2 & 11 & 5 & 29 \\
\hline Almost complete clearance & 0 & 0 & 0 & 0 & 0 & 0 & 0 & 0 & 1 & 6 \\
\hline p-value vs baseline* & \multicolumn{2}{|c|}{0.453} & \multicolumn{2}{|c|}{0.549} & \multicolumn{2}{|c|}{0.037} & \multicolumn{2}{|c|}{0.004} & \multicolumn{2}{|c|}{$<0.001$} \\
\hline
\end{tabular}

\section{Lesion severity assessment by investigator}

(Table 8.4) A statistically significant reduction of the lesion severity score was obtained at the end of the treatment $(P=0.016)$ and at follow-up $(P<0.001)$. At baseline, no patients were rated with a score none or minimal versus $3(16 \%)$ at end of treatment and $8(42 \%)$ at follow-up. Where 6 patients $(32 \%)$ were scored severe at baseline, only 3 $(16 \%)$ had this score at end of treatment and $1(6 \%)$ at follow-up.

\section{Patient self-assessment of treatment}

Patient self-assessment of treatment was statistically significant improved from week 1 of treatment onwards (Table 8.5). During the course of the treatment and follow-up, none of the patients rated their disease as almost completely cleared. A moderate to marked improvement was rated in 3 patients after 4 weeks of treatment, in 8 patients at end of treatment and in 9 patients at follow-up. At the end of treatment, 4 patients $(22 \%)$ 
scored a slight improvement, 2 (11\%) scored unchanged and $4(22 \%)$ worse versus 3 $(18 \%), 3(18 \%)$ and $2(12 \%)$ respectively at follow-up.

Table 8.4 Lesion severity score by the investigator-ITT population

\begin{tabular}{|c|c|c|c|c|c|c|c|c|c|c|c|c|}
\hline \multirow{3}{*}{$\begin{array}{l}\text { Weeks } \\
\text { Severity } \\
\text { assessment }\end{array}$} & \multirow{2}{*}{\multicolumn{2}{|c|}{$\begin{array}{c}\text { Baseline } \\
\text { 0 }\end{array}$}} & \multicolumn{8}{|c|}{ Treatment period $(n=19)$} & \multirow{2}{*}{\multicolumn{2}{|c|}{$\begin{array}{c}\begin{array}{c}\text { Follow-up } \\
(\mathrm{n}=17)^{* * *}\end{array} \\
10\end{array}$}} \\
\hline & & & \multicolumn{2}{|c|}{1} & \multicolumn{2}{|c|}{2} & \multicolumn{2}{|c|}{4} & \multicolumn{2}{|c|}{8} & & \\
\hline & $\mathbf{n}$ & $\%$ & $\mathbf{n}$ & $\%$ & $\mathbf{n}$ & $\%$ & $\mathbf{n}$ & $\%$ & $\mathbf{n}$ & $\%$ & $\mathbf{n}$ & $\%$ \\
\hline None & 0 & 0 & 0 & 0 & 0 & 0 & 0 & 0 & 0 & 0 & 1 & 6 \\
\hline Minimal & 0 & 0 & 0 & 0 & 0 & 0 & 0 & 0 & 3 & 16 & 7 & 41 \\
\hline Mild & 2 & 11 & 3 & 16 & 5 & 26 & 8 & 42 & 7 & 37 & 3 & 18 \\
\hline Moderate & 11 & 58 & 11 & 58 & 7 & 37 & 7 & 37 & 6 & 32 & 5 & 29 \\
\hline Severe & 6 & 32 & 5 & 26 & 7 & 37 & 4 & 21 & 3 & 16 & 1 & 6 \\
\hline Very severe & 0 & 0 & 0 & 0 & 0 & 0 & 0 & 0 & 0 & 0 & 0 & 0 \\
\hline p-value * & \multicolumn{2}{|c|}{ NA } & \multicolumn{2}{|c|}{0.500} & \multicolumn{2}{|c|}{0.750} & \multicolumn{2}{|c|}{0.055} & \multicolumn{2}{|c|}{0.016} & \multicolumn{2}{|c|}{$<0.001$} \\
\hline
\end{tabular}

Table 8.5 Patient's self-assessment-ITT population

\begin{tabular}{|c|c|c|c|c|c|c|c|c|c|c|}
\hline \multirow{3}{*}{$\begin{array}{l}\text { Weeks (scheduled) } \\
\text { Patient self-assessment }\end{array}$} & \multicolumn{8}{|c|}{ Treatment period $(n=18) * * *$} & \multirow{2}{*}{\multicolumn{2}{|c|}{$\begin{array}{c}\text { Follow-up } \\
(\mathrm{n}=17)^{* *} \\
10\end{array}$}} \\
\hline & \multicolumn{2}{|c|}{1} & \multicolumn{2}{|c|}{2} & \multicolumn{2}{|c|}{4} & \multicolumn{2}{|c|}{8} & & \\
\hline & $\mathbf{n}$ & $\%$ & $\mathbf{n}$ & $\%$ & $\mathbf{n}$ & $\%$ & $\mathbf{n}$ & $\%$ & $\mathbf{n}$ & $\%$ \\
\hline Worse & 3 & 17 & 4 & 22 & 4 & 22 & 4 & 22 & 2 & 12 \\
\hline Unchanged & 4 & 22 & 2 & 11 & 2 & 11 & 2 & 11 & 3 & 18 \\
\hline Slight improvement & 9 & 50 & 9 & 50 & 9 & 50 & 4 & 22 & 3 & 18 \\
\hline Moderate improvement & 2 & 11 & 3 & 17 & 3 & 17 & 6 & 33 & 3 & 18 \\
\hline Marked improvement & 0 & 0 & 0 & 0 & 0 & 0 & 2 & 11 & 6 & 35 \\
\hline Almost complete clearance & 0 & 0 & 0 & 0 & 0 & 0 & 0 & 0 & 0 & 0 \\
\hline p-value vs baseline* & \multicolumn{2}{|c|}{0.037} & \multicolumn{2}{|c|}{0.035} & \multicolumn{2}{|c|}{0.035} & \multicolumn{2}{|c|}{0.007} & \multicolumn{2}{|c|}{0.002} \\
\hline $\begin{array}{l}\text { * Wilcoxon signed rank test, tw } \\
\text { ** For patients S223 and S227 } \\
\text { *** For S223 no last observatio }\end{array}$ & alue & whifts & sor & $s$ bas & & & & & & \\
\hline
\end{tabular}




\section{Pharmacokinetics and -dynamics}

Figure 8.4 shows the R115866 plasma concentrations at all treatment visits, 2-4.5 hours (h) after drug intake which are to be considered post-peak levels since the $T_{\max }$ after a single dose is 1-2 h. The maximum observed concentration of R115866 in plasma was $1.390 \mathrm{ng} / \mathrm{ml}$, the minimum was $0.140 \mathrm{ng} / \mathrm{ml}$. The mean/median plasma concentrations of R115866 at 2 to $4.5 \mathrm{~h}$ after trial medication intake were comparable throughout the 8week treatment period and are listed in Table 8.6.

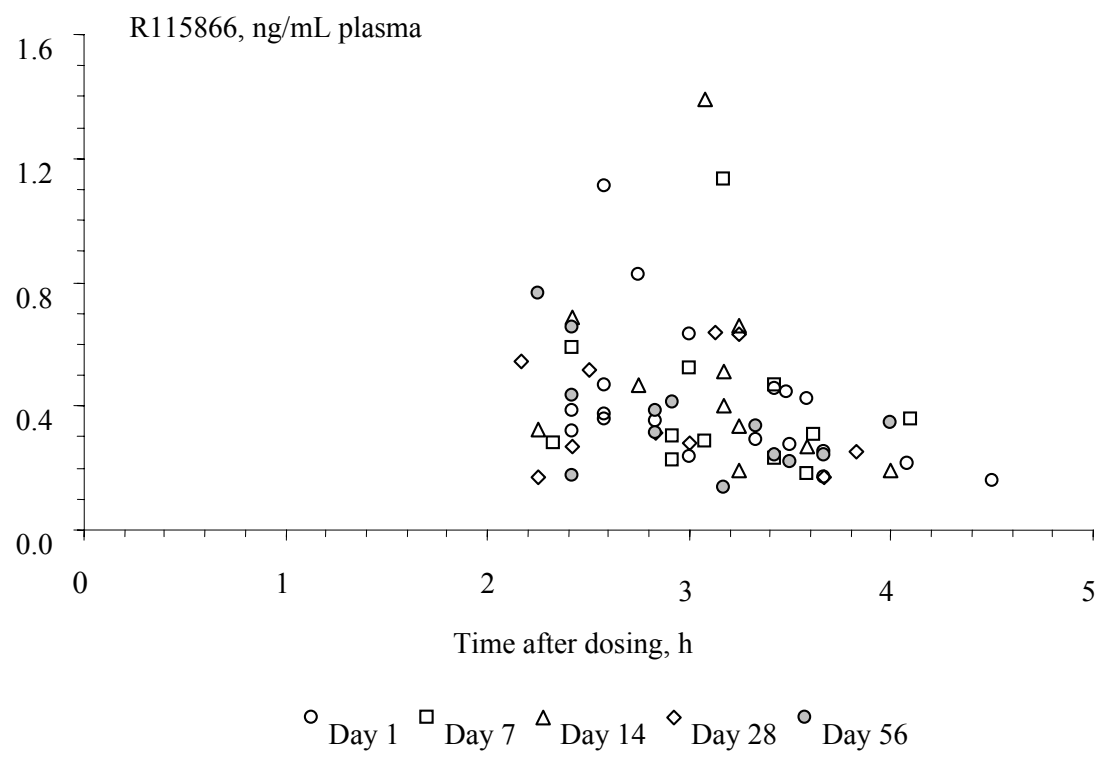

Figure 8.4 Individual plasma concentrations of R115866 after trial medication intake (1 mg o.d.)

Table 8.6 Post-peak plasma concentrations of R115866 after repeated oral dosage of $1 \mathrm{mg}$, once daily for 8 weeks.

\begin{tabular}{|c|c|c|c|c|}
\hline \multicolumn{5}{|c|}{ R115866, ng/ml plasma (mean \pm S.D.) } \\
\hline $\begin{array}{l}\text { Day } 1 \\
(n=19)\end{array}$ & $\begin{array}{l}\text { Day } 7 \\
(n=12)\end{array}$ & $\begin{array}{l}\text { Day } 14 \\
(n=11)\end{array}$ & $\begin{array}{l}\text { Day } 28 \\
(n=10)\end{array}$ & $\begin{array}{c}\text { Day } 56 \\
(n=13)\end{array}$ \\
\hline $0.408 \pm 0.233$ & $0.407 \pm 0.260$ & $0.494 \pm 0.340$ & $0.379 \pm 0.184$ & $0.359 \pm 0.181$ \\
\hline
\end{tabular}




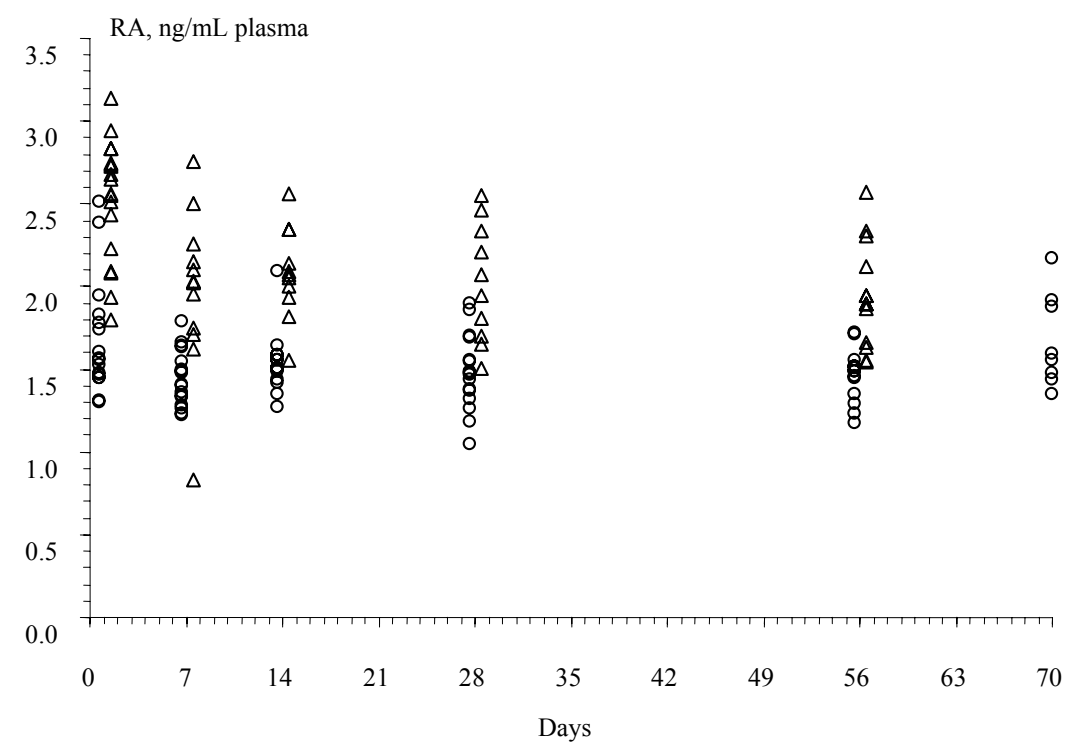

Figure 8.5 Plasma concentrations of RA pre- and post-dose during an 8 week treatment period with R115866 $1 \mathrm{mg}$ o.d. ( $\mathrm{O}$ : pre dose; $\triangle$ : post dose) and two weeks thereafter.

Figure 8.5 shows the individual pre- and post-dose plasma concentrations of all-transRA during the treatment period and at the end of follow-up period. Pre-dose all-transRA concentrations remained constant during the whole study period. At all time points, in all treated patients, all-trans-RA plasma levels consistently increased $(0.5-1.5 \mathrm{ng} / \mathrm{ml})$ between 2 to $4.5 \mathrm{~h}$ after intake of $1 \mathrm{mg} \mathrm{R} 115866$. This increase was somewhat larger after the first dose (median difference $=0.98 \mathrm{ng} / \mathrm{ml}$ ), but was similar after 1, 2, 4 and 8 weeks of treatment (median difference ranging from 0.50 to $0.62 \mathrm{ng} / \mathrm{ml}$ ). All-trans-RA plasma levels measured before, during and after the treatment remained within the normal biological limits.

\section{Safety and tolerability evaluation}

R115866 treatment was overall well tolerated. The safety population includes all patients who were exposed to at least one dose of the trial medication $(n=19)$. All AEs reported by more than 1 patient are listed in Table 8.7. In all patients, a total of 94 adverse events (AEs) were recorded of which 31 (33\%) were mild, 50 (53\%) moderate and $13(14 \%)$ severe. Severe AEs reported in more than 1 patient were pruritus $(n=5)$ and xerosis $(n=2)$, other severe AEs with one instance each were cheilitis, increased blood triglycerides, skin fragility, pain of skin and atrial fibrillation. For the individual 
AEs, cheilitis was most commonly $(n=11)$ recorded and was scored 'very likely' or 'probably related' to the trial medication. Other AEs reported as very likely or probably related to trial medication were pruritus $(n=6)$, xerosis $(n=6)$, increased triglycerides $(n=7)$ and epistaxis $(n=4)$.

Table 8.7 Incidence of AEs reported for 2 or more patients (Per system organ class and regardless of severity and drug relatedness)-ITT population $(\mathrm{n}=19)$

\begin{tabular}{|l|c|c|}
\hline \multicolumn{1}{|c|}{$\begin{array}{c}\text { System organ class } \\
\text { Preferred term }\end{array}$} & $\begin{array}{c}\text { Number of AEs reported } \\
\text { in }>\mathbf{1} \text { patient }\end{array}$ & $\begin{array}{c}\text { Patients } \\
\mathbf{n = 1 9}(\mathbf{\%})\end{array}$ \\
\hline Total & 71 & $19(100)$ \\
\hline Skin and appendages disorders & 37 & $16(84.2)$ \\
\hline Pruritus & 16 & $12(63.1)$ \\
\hline Xerosis & 12 & $10(52.6)$ \\
\hline Skin fragility & 4 & $3(15.8)$ \\
\hline Hair disorder & 3 & $3(15.8)$ \\
\hline Dry skin & 2 & $2(10.5)$ \\
\hline Gastrointestinal disorders & 15 & $13(68.4)$ \\
\hline Cheilitis & 13 & $11(52.6)$ \\
\hline Dry mouth & 2 & $2(10.5)$ \\
\hline Metabolic and nutritional disorders & 11 & $10(52.6)$ \\
\hline Increase in blood triglycerides & 11 & 10 \\
\hline Central and peripheral nervous system disorders & 3 & $2(10.5)$ \\
\hline Headache & 3 & 2 \\
\hline Vascular disorders & 5 & $4(21.1)$ \\
\hline Epistaxis & 5 & 4 \\
\hline
\end{tabular}

Three patients were withdrawn from the study due to adverse events. One patient [S223] discontinued after 2 days of treatment because of non-symptomatic atrial fibrillation at the ECG evaluation. However after further evaluation, it appeared that this condition was probably pre-existing and the relationship to the trial medication was considered very doubtful. Another patient [S216] discontinued treatment after 9 days because of aggravation of T-wave abnormalities on the ECG and suggestive for myocardial ischemia (possibly drug-related) although the patient presented himself in a good condition without any complaints or cardiac symptoms. This patient was included presenting already at baseline with an asymptomatic abnormal morphology of the T-wave which is considered a protocol deviation. A third patient [S219] was discontinued from treatment after 39 days due to 'worsening pruritus' (possibly drug-related) and 'severe xerosis' 
(very likely drug-related). No deaths or serious adverse events were reported during the trial.

No clinically relevant laboratory abnormalities were reported during the trial except for an increase in blood triglycerides. Six patients had above normal values for triglycerides already at baseline, i.e. before the first intake of R115866 and values remained above normal at several time points during treatment/follow-up. In 10 patients abnormal triglyceride levels were reported as adverse event. In one patient [S221] the study medication was reduced to $0.5 \mathrm{mg} /$ day due to significant hypertriglyceridemia noticed after 3 weeks of treatment.

No clinically relevant abnormal values were noted for the endocrinology parameters and no clinically significant changes in vital signs, weight and ECG-intervals were observed.

From the seven cutaneous retinoic acid-related symptoms evaluated at each visit, the most commonly reported symptoms at baseline were pruritus $(n=13)$ and xerosis $(n=9)$. Fragile skin and hair loss were reported in 3 and 2 patients, respectively, while periungual granulomatous reaction, cheilitis and epistaxis were not observed at baseline. During treatment the incidence of patients reporting symptoms increased. The greatest shift from baseline was observed for cheilitis with no patients reporting the symptom at baseline versus 8 at the end of treatment. After 2 weeks follow-up, cheilitis was reported by 3 patients. Periungual granulomatous reaction was not reported at any time point. The majority of patients scored the cutaneous retinoic acid-related symptoms as mild to moderate.

\section{Discussion}

Eight weeks of therapy with R115866 at a $1 \mathrm{mg}$ daily dose in patients with moderate to severe plaque-type psoriasis resulted in a statistically significant improvement versus baseline for all assessed efficacy variables at the end of the treatment phase (week 8), with a p-value less than 0.05 for both the analysis of the complete cases as well as the ITT-population. Importantly, the improvement continued and was even more pronounced 2 weeks after the last drug intake indicating that treatment duration will likely have to go beyond 8 weeks in order to achieve optimal clinical efficacy. From the complete cases, $5 / 13(38 \%)$ had at least $50 \%$ reduction of PASI at end of therapy and $7 / 13(54 \%)$ at follow-up compared to baseline. At least $45 \%$ reduction of PASI was achieved at follow-up in 9/13 patients (69\%). These data are in line with data found in the literature on acitretin, the preferred systemic retinoid in the treatment of psoriasis for more than 10 years. ${ }^{19}$ In one study where treatment with acitretin was initiated at 
$50 \mathrm{mg} /$ day for 4 weeks followed by dose adjustment according to therapeutic response, $44.5 \%$ of the patients reached a $50 \%$ improvement of PASI after 8 weeks. ${ }^{20}$ In a second study, where the initial dose was $40 \mathrm{mg} /$ day, $57 \%$ of the patients reached PASI 50 after 8 weeks. $^{21}$

An oral daily dose of 1mg R115866 for 8 weeks was well tolerated. One patient [S221] had a dose reduction after 3 weeks of treatment due to severe hypertriglyceridemia. In this patient $0.5 \mathrm{mg}$ R115866 daily was still efficacious: a PASI reduction of $64.2 \%$ was achieved after 2 weeks follow-up compared to baseline. Six out of nine screening failures in this study were due to hypertriglyceridemia and six patients that were included in the trial had already triglyceride levels above normal values at baseline, before the first intake of the study medication. Elevated blood triglycerides or the susceptibility to have increases in blood triglycerides may be intrinsic to the psoriasis population since no abnormal triglyceride levels were recorded as an $\mathrm{AE}$ in a recent exploratory trial with R115866, $1 \mathrm{mg}$ daily in 17 patients with moderate to severe facial acne vulgaris. ${ }^{22-25}$ Recent work by Mallbris et al. in 200 patients with psoriasis at the onset of the disease supports the notion that lipid abnormalities in psoriasis are already present and probably genetically determined. ${ }^{26}$ However, this phenomenon needs further investigation and close monitoring. Cheilitis was repetitively seen between week 2 and 8 of the treatment phase in the majority of patients $(70 \%)$ who responded well to treatment. This effect disappeared quickly after treatment.

The body needs and therefore produces very little all-trans-RA. Blocking its breakdown will give only modest all-trans-RA elevations in specific target cells where all-trans-RA is metabolized by the retinoic acid 4-hydroxylase. The advantage of administering a RAMBA is that there is markedly less all-trans-RA accumulation and circulation in the body as compared to retinoids which need to be administered at high doses because the majority of the drug probably never reaches its target. The consequence is that a large amount of the administered retinoid ends up in the plasma and subsequently in other non-targeted tissue where it may be causing some of the undesirable effects (e.g. hepatotoxicity). ${ }^{27,28,29}$

Kinetic data in this trial were in line with the data obtained in the Phase I trials. ${ }^{7}$ The mean/median R115866 plasma concentrations, 2-4.5 hours after drug intake remained fairly constant throughout the trial, indicating that there is no accumulation. A modest and temporary effect of R115866 was seen on all-trans-RA plasma levels which remained within physiological limits. The uptake of all-trans-RA from the circulation by the tissues will be far less when compared to administering oral retinoids. ${ }^{27,28}$ At all time points, increases in all-trans-RA were comparable except after the first dose where the increase was slightly higher. This could be explained by the fact that increases in all- 
trans-RA will lead to an up-regulation of 4-hydroxylase activity resulting in a higher catabolism of all-trans-RA. ${ }^{30}$ It is well-known that this negative feed-back mechanism is responsible for the reduced activity seen with retinoids after long-term treatment. The constant all-trans-RA plasma increases could indicate that this feed-back mechanism seems not to affect much the potential of R115866. Some retinoids like etretinate and acitretin also have the disadvantage of being stored in subcutaneous adipose tissue from which they are slowly released into the plasma. This is, in view of the teratogenic potential, a real burden for women of child-bearing age as they have to continue contraception for 3 years after stopping therapy with the above mentioned drugs. ${ }^{31} \mathrm{R} 115866$ is rapidly cleared from the body once treatment is stopped (within hours) which minimizes the waiting period to become pregnant significantly as compared to acitretin.

As part of this clinical trial, the dynamics of epidermal proliferation, keratinization, lesional T-cell subsets and cells expressing NK-receptors were assessed in 6 patients. The data have been presented elsewhere. ${ }^{32}$ Briefly, it was shown that clinical efficacy of $\mathrm{R} 115866$ is primarily the result of restoring proliferation $(\mathrm{Ki} 67,-63 \% ; P<0.01)$ ) and differentiation (keratin 10 expression: $+29 \%$; $P<0.01$ ) of epidermal keratinocytes as compared to baseline. Secondarily, a tendency toward reductions of relevant T-cell subsets and cells expressing NK-receptors was shown but was not yet significant after 8 weeks of treatment. The positive, although not significant, immunological results obtained in this small subpopulation support again the concept that a longer treatment with R115866 will probably further improve clinical efficacy. Recent data from a biomarker expression study in skin with topical R115866 gel $(0.07 \%$ and $0.35 \%)$ applied for 9 days in healthy volunteers exhibited not only an induction of cellular retinoic acid binding protein-2 and keratin 4 mRNA but also a reduction of IL-1 $\alpha$ mRNA at the skin level. ${ }^{33}$ This observation, together with the above mentioned tendency towards a reduction of T-cell subsets in psoriasis patients, suggests that R115866 might also possess anti-inflammatory activities. However further study is needed to confirm these interesting but preliminary results.

\section{Conclusion}

The promising results from this exploratory study suggest that R115866 may be an effective and well tolerated treatment for patients with moderate to severe plaque-type psoriasis and warrant further investigation. A treatment duration extending 8 weeks may improve the therapeutic effect and may be needed to achieve optimal clinical efficacy. 


\section{References}

1. Stoppie P, Borgers M, Borghgraef P, et al. R115866 Inhibits all-trans-retinoic acid metabolism and exerts retinoidal effects in rodents. J Pharmacol Exp Ther 2000; 293: 304-12.

2. Stoppie P, Van Wauwe J, Wouters L, et al. Rambazole ${ }^{\mathrm{TM}}$, a potent inhibitor of all-trans-retinoic acid metabolism, applied topically to mouse tail skin exerts retinoid mimetic activity. J Invest Dermatol 2004; 122: A70(\#420)

3. Asselineau D, Darmon M. Retinoic acid provokes metaplasia of epithelium formed in vitro by adult human epidermal keratinocytes. Differentiation 1995; 58: 297-306.

4. Kopan R, Traska G, Fuchs E. Retinoids as important regulators of terminal differentiation: examining keratin expression in individual epidermal cells at various stages of keratinization. J Cell Biol 1987; 105: 427-40.

5. Napoli JL. Retinoic acid: its biosynthesis and metabolism. Prog Nucleic Acid Res Mol Biol 1999; 63: $139-88$.

6. Petkovich PM. Retinoic acid metabolism. J Am Acad Dermatol 2001; 45: S136-42.

7. Cools M, Stoppie P, Cauwenbergh G, et al. Tolerability, safety and pharmacokinetics of single and multiple oral dosages of R115866 (Rambazole ${ }^{\mathrm{TM}}$ ) in healthy volunteers. Presented at Eur Acad Dermatol \& Venereol 2006, Rhodos, P035.22.

8. Rambazole ${ }^{\mathrm{TM}}$ (R115866) Investigational Drug Brochure; version 3.0.; Oct. 2005. Data on file at Barrier Therapeutics.

9. Hartman S, Brors O, Bock J, et al. Exposure to retinyl esters, retinol and retinoic acids in non-pregnant women following increasing single and repeated oral doses of vitamin A. Ann Nutr Metab 2005; 49: $155-64$

10. Tang G, Russell RM. 13-cis Retinoic acid is an endogenous compound in human serum. $J$ Lipid Res 1990; 31: 175-82.

11. Wiegand U-W, Chou RC. Pharmacokinetics of oral isotretinoin. J Am Acad Dermatol 1998; 39: S8-S12.

12. Napoli JL, Pramanik BC, Williams JB, et al. Quantification of retinoic acid by gas-liquid chromatography-mass spectrometry: total versus all-trans-retinoic acid in human plasma. $J$ Lipid Res 1985 ; 26 : 387-92.

13. Dockx P, Decree J, Degreef H. Inhibition of the metabolism of endogenous retinoic acid as treatment for severe psoriasis: an open study with oral liarozole. Br J Dermatol 1995; 133: 426-32.

14. Berth-Jones J, Todd G, Hutchinson PE, et al. Treatment of psoriasis with oral liarozole: a dose-ranging study. Br J Dermatol 2000; 143: 1170-6.

15. Bhushan $\mathrm{M}$, Burden $\mathrm{AD}$, McElhone $\mathrm{K}$, et al. Oral liarozole in the treatment of palmoplantar pustular psoriasis: a randomized, double-blind, placebo-controlled study. Br J Dermatol 2001; 145: 546-53.

16. Gollnick H, Bauer R, Brindley C, et al. Acitretin versus etretinate in psoriasis. Clinical and pharmacokinetic results of a German Multicenter study. J Am Acad Dermatol 1988; 19: 458-69.

17. Fredriksson T, Pettersson U. Severe psoriasis-oral therapy with a new retinoid. Dermatologica 1978; 157: 238-44.

18. SAS version 8.2 , SAS Institute, Cary, USA.

19. Geiger JM. Efficacy of acitretin in severe psoriasis. Skin Therapy Lett 2003; 8: 1-3.

20. Murray HE, Anhalt AW, Lessard R, et al. A 12-month treatment of severe psoriasis with acitretin: Results of a Canadian open multicenter trial. J Am Acad Dermatol 1991; 24: 598-602.

21. Kragballe K, Jansén CT, Geiger JM, et al. A double-blind comparison of acitretin and etretinate in the treatment of severe psoriasis. Results of a Nordic multicentre study. Acta Derm Venereol 1989; 69: $35-40$. 
22. Vahlquist C, Michaelson G, Vessby B. Serum lipoproteins in middle-aged men with psoriasis. Acta Derm Venereol 1987; 67: 12-5.

23. Vahlquist C, Selinus I, Vessby B. Serum lipids changes during acitretin (etretin) treatment of psoriasis and palmo-plantar pustulosis. Acta Derm Venereol 1988; 6: 300-5.

24. Piskin S, Gurkok F, Ekuklu G, et al. Serum lipids in psoriasis. Yonsei Med J 2003; 44: 24-6.

25. Hachem JP, Verfaille CJ, Coel M, et al. Oral R115866 (Rambazole ${ }^{\mathrm{TM}}$ ) in the treatment of facial acne vulgaris. Presented at Eur Acad Dermatol \& Venereol 2006, Rhodos, P001.65.

26. Mallbris L, Granath F, Hamsten A, et al. Psoriasis is associated with lipid abnormalities at the onset of skin disease. J Am Acad Dermatol 2006; 54: 614-20.

27. Kurlandsky SB, Gamble MV, Ramakrishnan R, et al. Plasma delivery of retinoic acid to tissues in the rat. J Biol Chem 1995; 270: 17850-7.

28. Allen JG, Bloxham DP. The pharmacology and pharmacokinetics of the retinoids. Pharmacol Ther 1989; 40: $1-27$.

29. David M, Hodak E, Lowe NJ. Adverse effects of retinoids. Medical Toxicology 1988; 3: 273-88.

30. Duell EA, Kang S, Voorhees JJ. Retinoic acid isomers applied to human skin in vivo each induce a 4-hydroxylase that inactivates only trans retinoic acid. J Invest Dermatol 1996; 106: 316-20.

31. Geiger JM, Baudin M, Saurat JH. Teratogenic risk with etretinate and acitretin treatment. Dermatology 1994; 189: 109-16.

32. Bovenschen HJ, Otero ME, Langewouters AM, et al. Oral retinoic acid metabolism blocking agent rambazole for plaque psoriasis: an immunohistochemical study. Br J Dermatol 2007; 156: 263-70.

33. Cools M, Pavez-Lorie E, Borgers M, et al. Effect of topical R115866 (Rambazole ${ }^{\mathrm{TM}}$ ) gel on the expression of biomarkers in the skin of healthy volunteers. J Invest Dermatol 2006; 126: S40 (\#240). 



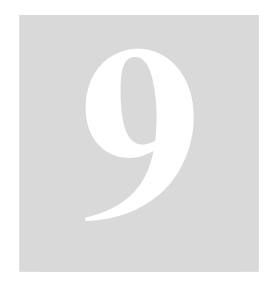

\section{Oral R115866 in acne}

Based on:

Verfaille $\mathrm{CJ}^{1,2}$, Coel $\mathrm{M}^{3}$, Boersma $\mathrm{HI}^{4}$, Mertens $\mathrm{J}^{2}$, Borgers $\mathrm{M}^{1,2}$, Roseeuw $D^{5}$. Oral R115866 in the treatment of moderate to severe facial acne vulgaris: an exploratory study.

Br J Dermatol, in press.

${ }^{1}$ Departments of Dermatology and Molecular Cell Biology, GROW, Maastricht University, The Netherlands.

${ }^{2}$ Barrier Therapeutics $n v, B-2440$ Geel, Belgium.

${ }^{3}$ Private Practice in Dermatology, B-1800 Vilvoorde, Belgium.

${ }^{4}$ Department of Dermatology, Albert Schweitzer Hospital, NL-3331 LZ Zwijndrecht, The Netherlands.

${ }^{5}$ Department of Dermatology, Free University Brussels (AZ-VUB), B-1090 Jette, Belgium. 


\begin{abstract}
Background: R115866 (Rambazole ${ }^{\mathrm{TM}}$ ), a new generation all-trans Retinoic Acid Metabolism Blocking Agent (RAMBA), is a non-retinoid compound enhancing intracellularly the endogenous levels of all-trans-retinoic acid (all-trans-RA) by blocking its catabolism. By virtue of this property and the proven positive effects of retinoids in the treatment of acne, R115866 could potentially be a useful drug for this complex skin disorder.
\end{abstract}

Objective: To explore the therapeutic effect, safety and tolerability of systemic R115866 in male patients with moderate to severe facial acne vulgaris (at least 15 papules and/or pustules and minimum 2 nodular-cystic lesions).

Patients and methods: In this open label, single-arm, exploratory trial, 17 patients were treated once daily with $1 \mathrm{mg}$ of R115866 for 12 weeks, followed by a 4-week treatmentfree follow-up period. Patients were monitored for efficacy, tolerability and safety.

Results: Analysis of efficacy at the end of treatment (week 12; $n=16$ ) showed a mean reduction in inflammatory lesions of $77.4 \%(\mathrm{p}<0.001)$, in non-inflammatory lesions of $58.3 \%(\mathrm{p}<0.001)$, and in total lesion count of $76 \%(\mathrm{p}<0.001)$ as compared to baseline. All lesion counts were significantly reduced from week 4 onwards, except for the closed comedones and papules, which were significantly reduced from week 8 onwards. Only mild side-effects were reported occasionally.

Conclusion: The data from this study indicate that oral daily treatment with $1 \mathrm{mg}$ R115866 during 12 weeks in patients with moderate to severe facial acne vulgaris is efficacious and well tolerated. R115866 merits further investigation to assess the optimal dose and its potential as a new therapy for this indication. 


\section{Introduction}

Limited to the sebaceous follicles of the head and upper trunk, acne vulgaris is a skin disorder with a very complex aetiology involving aberrant keratinization and/or desquamation of follicular epithelial cells, increased sebum production and excretion, and colonization of the follicle by Propionibacterium acnes which induces inflammation. The primary lesion in acne is the "microcomedone" that may evolve over time into a non-inflammatory lesion i.e. open comedone (blackhead) or closed comedone (whitehead) and further to an inflammatory lesion (pustule, papule or nodulocystic lesion). ${ }^{1,2}$ Topical retinoids, as single therapy or in combination with antimicrobial therapy, have been recommended as the primary treatment for mild to moderate forms of acne vulgaris. However irritation and corticosteroid resistance limit their use. ${ }^{3-5}$

Oral isotretinoin (13-cis-retinoic acid), the only drug currently available affecting all before mentioned pathogenic factors of acne, is reserved for patients with moderate to severe inflammatory acne because of its side-effects profile i.e. teratogenicity, elevations in triglycerides, in liver enzymes and to a lesser degree in cholesterol levels. ${ }^{6-9}$ The high incidence of cutaneous retinoic acid (RA)-related side effects can sometimes be troublesome and lead to discontinuation of the treatment. So there is room for effective alternatives with a more favourable safety profile.

R115866 is a triazole derivative identified as a new generation Retinoic Acid Metabolism Blocking Agent (RAMBA). At nanomolar concentrations, R115866 exhibits highly potent and very selective cytochrome P-450 (CYP) inhibiting properties against hydroxylases involved in catabolism of all-trans-retinoic acid (all-trans-RA) like CYP26 whereas micromolar concentrations are needed to inhibit other CYPs. ${ }^{10,11}$ By blocking the breakdown of endogenous all-trans-RA within the cells, RAMBAs transiently increase the cellular all-trans-RA levels.

Several animal experiments have documented the in vivo suppressive effects of R115866 on all-trans-RA metabolism in rats. Single oral R115866 treatment was shown to transiently increase endogenous all-trans-RA in rat skin. Similar to all-trans-RA, both oral and topical R115866 exhibited a modulating effect on epithelial growth and differentiation in various animal models of keratinization. ${ }^{10}$ In addition, topical application of R115866 has revealed a reduction of the utriculus size in rhino mouse back skin and also a dose-dependent reduction of mRNA of pro-inflammatory cytokines in the skin of healthy volunteers suggesting a possible anti-inflammatory activity. ${ }^{12,13}$

By virtue of this pharmacodynamic property and the well-known modulating effects of all-trans-RA on both epidermal and sebocyte growth and differentiation, R115866 is 
potentially of use for disorders where aberrant keratinisation is associated with aberrant sebum production/excretion, such as in acne vulgaris.

The main purpose of this exploratory trial was to assess the efficacy, tolerability and safety of oral R115866 administered for 12 weeks at a daily dose of $1 \mathrm{mg}$ in patients with moderate to severe facial acne vulgaris.

\section{Patients and Methods}

\section{Study design}

This exploratory, multi-center, open-label study assessed the efficacy, tolerability and safety of oral R115866 in patients with moderate to severe facial acne vulgaris. Patients were enrolled in three study centers: a private practice in Dermatology in Vilvoorde, Belgium; the Department of Dermatology, Albert Schweitzer Hospital, Zwijndrecht, The Netherlands and the Department of Dermatology, Academic Hospital Jette, Free University of Brussels, Belgium.

The protocol has been reviewed and approved by each study center's independent ethics committee and all patients provided written informed consent prior to study enrollment. All clinical investigations were conducted according to the Declaration of Helsinki principles.

\section{Treatment}

Patients took two capsules of $0.5 \mathrm{mg}$ R115866, total daily dose of $1 \mathrm{mg}$, in the morning with breakfast for a period of 12 weeks. At the visit days, patients were advised to be fasted for at least $8 \mathrm{~h}$ before blood sampling. Their medication had to be taken in the clinic with breakfast after collection of the pre-dose blood samples and electrocardiogram (ECG) recordings. The 12-week treatment period was followed by a 4-week treatment-free follow-up period. The investigator could decide to decrease the dose to $0.5 \mathrm{mg}$ once daily if necessary. No additional topical treatments were allowed.

\section{Patient population}

Healthy male patients between 16 and 50 years with at least 15 papules and/or pustules and a minimum of 2 nodular-cystic lesions were allowed to participate in this trial. Clinically relevant abnormalities in the laboratory test results (haematology, biochemistry, endocrinology and urine analysis) at screening were not accepted. All patients had to sign a written informed consent. Wash-out periods before entering the study were: 
2 weeks for topical or ultraviolet (UV) treatment or excessive UV exposure and 4 weeks for previous systemic treatment of acne. Main exclusion criteria included other types of acne, concurrent inflammatory disease, co-existing serious disease, hyperlipidaemia, clinically relevant electrocardiogram (ECG) abnormalities, heart disorders, use of drugs that could interfere with either acne or the study drug, use of Vitamin A ( $>1000 \mu \mathrm{g} /$ day) or oral retinoids 6 months prior to screening, known intolerance to retinoids and the suspicion of alcohol or drug abuse.

\section{Clinical evaluations}

Clinical evaluations were performed by the same investigator per site over the course of the study at baseline, at week 4,8 and 12 of the treatment and at the end of the followup (week 16).

\section{Facial acne-related lesion count}

All acne-related lesions (open/closed comedones, papules, pustules and nodules) were counted by the investigator on the front, the left/right cheek, the chin and the nose. This resulted in a separate count per area of every lesion type (open/closed comedones, papules, pustules and nodules), in a total inflammatory (sum of papules, pustules and nodules), a total non-inflammatory (sum of open and closed comedones) and a total acne lesion count. A definition of the lesions is displayed in Table 9.1

Table 9.1 Definition of the acne lesions. Any intermediate lesion was counted according to its major component. Prominent follicles, small milia or trichostasis spinulosa are excluded from the count. Non inflamed lesions are not counted on the nose, at the edge of the nose and at the hairline.

\begin{tabular}{|c|c|}
\hline Lesion & Description \\
\hline Comedones & $\begin{array}{l}\text { Non-inflamed lesions, small, discrete, raised areas of the skin, usually occurring in the } \\
\text { opening of a hair follicle. The lesions are not red, but may be discoloured (blackheads = } \\
\text { open comedones) or not (whiteheads = closed comedones). }\end{array}$ \\
\hline Papules & $\begin{array}{l}\text { Inflammatory superficial lesions, less than } 5 \mathrm{~mm} \text { in diameter, raised circular areas of the } \\
\text { skin, red, containing no visible pus }\end{array}$ \\
\hline Pustules & $\begin{array}{l}\text { Inflammatory superficial lesions, less than } 5 \mathrm{~mm} \text { in diameter, raised circular areas of the } \\
\text { skin, red, containing a visible central core of white or yellow purulent material }\end{array}$ \\
\hline Nodules & $\begin{array}{l}\text { Deep inflammatory lesions with a diameter of } 5 \mathrm{~mm} \text { or larger. They may become } \\
\text { suppurative or hemorrhagic. Nodular lesions are commonly referred to as cysts. Palpation } \\
\text { was used for detection, since some nodules are almost invisible, but easily palpable }\end{array}$ \\
\hline
\end{tabular}




\section{Overall acne severity}

Both the investigator and the patient independently, evaluated the overall facial acne severity on a 5-point scale in which $0=$ none (clear, no inflammatory lesions), 1=Minimal (very few or no inflammatory lesions present), 2=Mild (few to several papules or pustules, no nodules), $3=$ Moderate (several to many papules or pustules, few to several nodules), $4=$ Severe (numerous or extensive papules or pustules, many nodules).

\section{Global assessment of effectiveness}

A subjective global evaluation of the patient's overall disease severity relative to baseline was made by both the investigator and the patient independently. The global assessment of effectiveness was graded on a 6 -point scale with $0=$ worse, $1=$ unchanged $(<$ $10 \%$ improvement), $2=$ slight improvement $( \pm 25 \%), 3=$ moderate improvement $( \pm 50 \%)$, $4=$ marked improvement $( \pm 75 \%)$ and $5=$ Almost to complete clearance $(90-100 \%)$.

\section{Photographs}

In order to document efficacy, photographs of the facial area were taken under standardized conditions at each designated visit.

\section{Safety and tolerability evaluation}

Adverse events were recorded throughout the study period. Blood samples for haematology, biochemistry and endocrinology (luteinising hormone, oestradiol, cortisol, aldosterone and testosterone) were taken at every visit. Urinalysis was only performed at screening. Cardiovascular safety was monitored at each visit. At all visits, possible clinical signs of cutaneous RA-related side effects (xerosis, pruritus, cheilitis, epistaxis, periungual granulomatous reaction, hair loss and fragile skin) were evaluated and graded for their severity (none, mild, moderate or severe).

\section{Statistics}

The intent-to-treat (ITT) population consisted of all patients who were assigned to treatment. The per-protocol (PP) population consisted of all enrolled patients that used trial medication for the specified period, that were evaluable at the end of the treatment period and that did not use other prohibited therapy during the entire trial period. The PP population was the primary population in the analysis of efficacy. The safety population was identical to the ITT population. Statistical significance of changes in lesion counts and overall acne severity as compared to baseline values was assessed with the 
Wilcoxon signed rank test. Global assessment of severity by investigator and patient were compared to "no change" (= score 1) as hypothesized outcome using the Wilcoxon signed rank test. Two-sided p-values less than or equal to 0.05 were considered to indicate statistical significance. All computations were carried out using the SAS Version 8.2 system for statistical analysis. ${ }^{14}$

\section{Results}

\section{Patients}

Twenty patients were screened, 17 (male, Caucasian) enrolled and treated with R115866. There were 3 screening failures due to an insufficient number of lesions. Mean age (range) was 22.3 (13-36) years and mean weight $71.3(55-97) \mathrm{kg}$. One patient discontinued the study due to lost of follow up after 4 weeks of treatment. Sixteen patients completed the entire study.

\section{Clinical evaluations}

The PP-population $(n=16)$ was used to evaluate efficacy and is presented here.

\section{Facial acne-related lesion count}

Detailed information of each patient on the acne lesion counts and percentage reduction as compared to baseline is given in Tables 9.2 and 9.3, respectively.

At baseline the mean (range) for the total acne lesion count was 81.3 (22-199), for total inflammatory lesion count 56.2 (15-170) and for total non-inflammatory lesion count $25.1(0-60)$.

Compared to baseline, a statistically significant reduction was seen in both total noninflammatory $(\mathrm{p}=0.016)$ and total inflammatory lesion count $(\mathrm{p}=0.018)$ from week 4 of the treatment onwards and at all time points for the total acne lesion count $(p \leq 0.001)$. The mean \% reduction in total acne lesion count from baseline increased with treatment duration and amounted from $31.5 \%$ after 4 weeks of treatment to $76 \%$ at the end of treatment (week 12; p $<0.001$ ) to $77.2 \%$ at the end of the follow-up period (week 16; $\mathrm{p}<0.001)$. At the end of treatment, the mean $\%$ reduction in total inflammatory lesion count versus baseline was $77.4 \%(\mathrm{p}<0.001)$ with $6 / 16(37.5 \%)$ patients showing at least $90 \%$ reduction. The mean \% reduction in total non- inflammatory lesion count versus baseline was $58.3 \%(\mathrm{p}<0.001)$ with $5 / 16(31.25 \%)$ patients showing at least $90 \%$ reduction. For all individual lesion types, a similar degree of lesion reduction was seen after 12 weeks of treatment. 
The mean \% reduction of the acne lesions was still improving during the treatment free follow-up period reaching 77.2\% $(\mathrm{p}<0.001)$ for total acne lesion count, $78.4 \%$ $(p<0.001)$ for total inflammatory lesion count and $63.2 \%(p<0.001)$ for noninflammatory lesion count.

Table 9.2 Summary of total non-inflammatory (N-ILC) and total inflammatory lesion count (ILC) per patient $(\mathrm{n}=16)$ at baseline, at week 4, 8 and 12 weeks of treatment with R115866 and at follow-up.

\begin{tabular}{|c|c|c|c|c|c|}
\hline \multirow[b]{2}{*}{ Patient } & \multirow{2}{*}{$\begin{array}{l}\text { Baseline } \\
\text { Week } 0\end{array}$} & \multicolumn{3}{|c|}{ Treatment } & \multirow{2}{*}{$\begin{array}{c}\text { Follow-up } \\
\text { Week } 16\end{array}$} \\
\hline & & Week 4 & Week 8 & Week 12 & \\
\hline & N-ILC/ILC & N-ILC/ILC & N-ILC/ILC & N-ILC/ILC & N-ILC/ILC \\
\hline $\mathrm{S} 402$ & $29 / 170$ & $29 / 11$ & $31 / 28$ & $29 / 5$ & $10 / 11$ \\
\hline S403 & $37 / 84$ & $19 / 29$ & $21 / 34$ & $17 / 23$ & $15 / 56$ \\
\hline $\mathrm{S} 405$ & $60 / 35$ & $39 / 43$ & $22 / 22$ & $14 / 13$ & $19 / 12$ \\
\hline S419 & $40 / 75$ & $45 / 77$ & $52 / 94$ & $28 / 37$ & $24 / 36$ \\
\hline $\mathrm{S} 420$ & $29 / 56$ & $18 / 33$ & $0 / 2$ & $0 / 3$ & $0 / 3$ \\
\hline S421 & $0 / 22$ & $0 / 11$ & $0 / 9$ & $0 / 0$ & $0 / 0$ \\
\hline $\mathrm{S} 422$ & $16 / 30$ & $0 / 3$ & $0 / 1$ & $0 / 1$ & $0 / 4$ \\
\hline $\mathrm{S} 423$ & $23 / 40$ & $0 / 12$ & $0 / 4$ & $0 / 1$ & $0 / 2$ \\
\hline S424 & $10 / 15$ & $0 / 30$ & $0 / 2$ & $0 / 3$ & $0 / 1$ \\
\hline $\mathrm{S} 425$ & $4 / 19$ & $3 / 18$ & $0 / 4$ & $0 / 0$ & $0 / 0$ \\
\hline S561 & $48 / 45$ & $35 / 36$ & $17 / 31$ & $10 / 15$ & $0 / 5$ \\
\hline S562 & $21 / 51$ & $11 / 47$ & $11 / 53$ & $12 / 25$ & $19 / 19$ \\
\hline S563 & $13 / 36$ & $13 / 46$ & $11 / 31$ & $6 / 16$ & $6 / 19$ \\
\hline S564 & $26 / 63$ & $24 / 56$ & $7 / 32$ & $9 / 25$ & $18 / 21$ \\
\hline S565 & $31 / 62$ & $5 / 40$ & $7 / 26$ & $15 / 14$ & $3 / 3$ \\
\hline S567 & $14 / 96$ & $31 / 58$ & $30 / 50$ & $17 / 24$ & $15 / 20$ \\
\hline Mean & $25.1 / 56.2$ & $17.0 / 34.4$ & $13.1 / 26.4$ & $9.8 / 12.8$ & $8.1 / 13.3$ \\
\hline SD & $16.0 / 38.3$ & $15.3 / 20.2$ & $15.0 / 24.7$ & $9.8 / 11.5$ & $8.9 / 15.3$ \\
\hline Median & $24.5 / 48.0$ & $15.5 / 34.5$ & $9.0 / 27.0$ & $9.5 / 13.5$ & $4.5 / 8.0$ \\
\hline Min & $0 / 15$ & $0 / 3$ & $0 / 1$ & $0 / 0$ & $0 / 0$ \\
\hline Max & $60 / 170$ & $45 / 77$ & $52 / 94$ & $29 / 37$ & $24 / 56$ \\
\hline
\end{tabular}


Table 9.3 Summary of lesion counts reduction (\%) versus baseline at week 4, 8 and 12 of treatment and at follow-up. $\mathrm{n}=16$ for each group, exact two-sided $\mathrm{p}$-value from Wilcoxon signed rank test comparison with value at baseline.

\begin{tabular}{|c|c|c|c|c|c|}
\hline & & \multicolumn{4}{|c|}{ Week } \\
\hline & & 4 & 8 & 12 & 16 \\
\hline \multirow[t]{6}{*}{ Total Count of All Acne Lesions } & Mean & 31.5 & 56.0 & 76.0 & 77.2 \\
\hline & SD & 35.3 & 35.3 & 19.2 & 22.4 \\
\hline & Median & 21.6 & 57.6 & 72.3 & 90.4 \\
\hline & Min & -20 & -27 & 43 & 41 \\
\hline & Max & 93 & 98 & 100 & 100 \\
\hline & P-value & 0.001 & $<.001$ & $<.001$ & $<.001$ \\
\hline \multirow[t]{6}{*}{ Total Count of Inflammatory lesions } & Mean & 23.5 & 53.7 & 77.4 & 78.4 \\
\hline & SD & 49.1 & 36.2 & 18.3 & 21.0 \\
\hline & Median & 27.7 & 58.6 & 76.2 & 87.8 \\
\hline & Min & -100 & -25 & 51 & 33 \\
\hline & Max & 94 & 97 & 100 & 100 \\
\hline & P-value & 0.018 & $<.001$ & $<.001$ & $<.001$ \\
\hline \multirow[t]{6}{*}{ Total Count of Non-inflammatory lesions } & Mean & 29.9 & 45.8 & 58.3 & 63.2 \\
\hline & SD & 55.6 & 60.2 & 39.8 & 38.7 \\
\hline & Median & 31.0 & 64.0 & 59.7 & 66.9 \\
\hline & Min & -121 & -114 & -21 & -7 \\
\hline & Max & 100 & 100 & 100 & 100 \\
\hline & $\mathrm{P}$-value & 0.016 & 0.009 & $<.001$ & $<.001$ \\
\hline
\end{tabular}

\section{Overall acne severity}

The mean (range) investigator's overall acne severity score at baseline was 3.3 (3-4) reaching $1.3(0-3)$ at the end of treatment and $1.6(0-3)$ at follow up. The mean (range) patients' baseline score was $3.1(2-4)$ reaching $1.3(0-2)$ at the end of treatment and 1.2 $(0-2)$ at follow up. When compared to baseline, both investigator's and patient's overall acne severity scores improved significantly from week 4 onwards $(p=0.002$ and $p<0.001$ respectively) reaching both $\mathrm{p} \leq 0.001$ for subsequent visits. A summary is given in Table 9.4. 
Table 9.4 Summary of physician's and patient's overall acne severity scores at baseline; end of treatment and at follow-up.

\begin{tabular}{|c|c|c|c|c|c|c|c|c|c|c|}
\hline \multirow[b]{2}{*}{ Scores* } & \multicolumn{5}{|c|}{$\begin{array}{l}\text { Physician's Overall } \\
\text { Acne Severity Score }\end{array}$} & \multicolumn{5}{|c|}{$\begin{array}{c}\text { Patient's Overall } \\
\text { Acne Severity Score }\end{array}$} \\
\hline & $\mathbf{0}$ & 1 & 2 & 3 & 4 & $\mathbf{0}$ & 1 & 2 & 3 & 4 \\
\hline Baseline $(n=16)$ & 0 & 0 & 0 & 11 & 5 & 0 & 0 & 3 & 8 & 5 \\
\hline End of treatment (Week 12, $\mathrm{n}=16)$ & 2 & 8 & 5 & 1 & 0 & 2 & 8 & 6 & 0 & 0 \\
\hline Follow-Up (Week 16, n=16) & 3 & 5 & 4 & 4 & 0 & 5 & 3 & 8 & 0 & 0 \\
\hline
\end{tabular}

\section{Global assessment of effectiveness}

A statistically significant improvement of both the physician's and the patient's global efficacy score was obtained from week 4 onwards till the end of the treatment and follow-up ( $<0.001)$. The mean (range) global efficacy score at the end of treatment was 3.8 (1-5) when scored by the physician and 3.9 (2-5) when scored by the patient. At follow-up the scores were $3.6(0-5)$ and $3.9(0-5)$ when scored by the physician and the patient respectively. A summary is given in Table 9.5.

Table 9.5 Summary of physician's and patient's global assessment of effectiveness $(n=16)$

\begin{tabular}{|c|c|c|c|c|c|c|c|c|c|c|c|c|}
\hline \multirow[b]{2}{*}{ Scores* } & \multicolumn{6}{|c|}{$\begin{array}{c}\text { Physician's } \\
\text { Global assessment of } \\
\text { Effectiveness }\end{array}$} & \multicolumn{6}{|c|}{$\begin{array}{c}\text { Patient's } \\
\text { Global assessment of } \\
\text { Effectiveness }\end{array}$} \\
\hline & $\mathbf{0}$ & 1 & 2 & 3 & 4 & 5 & $\mathbf{0}$ & 1 & 2 & 3 & 4 & 5 \\
\hline Week 4 & 1 & 1 & 5 & 5 & 3 & 1 & 0 & 1 & 5 & 6 & 3 & 1 \\
\hline Week 8 & 1 & 3 & 2 & 4 & 2 & 4 & 1 & 2 & 1 & 6 & 3 & 3 \\
\hline End of treatment (Week 12) & 0 & 1 & 0 & 6 & 4 & 5 & 0 & 0 & 1 & 4 & 6 & 5 \\
\hline Follow-Up (Week 16) & 1 & 1 & 1 & 3 & 4 & 6 & 1 & 0 & 1 & 3 & 3 & 8 \\
\hline
\end{tabular}

\section{Safety and tolerability evaluation}

R115866 treatment was well tolerated, a total of 16 adverse events (AEs) were recorded in 9/17 patients: 10 were mild, 5 moderate and 1 severe (eczema). Six AEs including the case of severe eczema were interpreted as not drug-related, 3 doubtful, 6 possibly drugrelated and 1 (mild stomach discomfort) as very likely related to treatment. AEs re- 
ported in more than one patient were dry skin $(n=3)$, contact dermatitis $(n=2)$, and eczema $(n=2)$. All AEs were resolved at the end of the trial. No deaths or serious adverse events were reported during the trial.

No clinically relevant ECGs or laboratory abnormalities were reported and there was no abnormal evolution of test values in any of the investigated parameters. Elevation above normal values for triglycerides was observed in 3 patients during treatment but none were reported as AE.

At baseline, no cutaneous RA-related side effects were reported. Periungual granulomatous reaction was not observed at any time point. During treatment the RA-related side effects were scored as mild to moderate in the majority of patients. Comparison of severity scores during treatment with baseline revealed a significant aggravation of xerosis ( 4 and 8 weeks: $\mathrm{p} \leq 0.01$; 12 weeks: $\mathrm{p}=0.008$ ), cheilitis $(4,8$ and 12 weeks: $\mathrm{p} \leq 0.01$ ) and pruritus (4 weeks: $\mathrm{p}=0.031$ ). All RA-related side effects had disappeared after 4 weeks treatment-free follow-up, except for xerosis (mild, $n=1$ ) and hair loss (mild, $\mathrm{n}=3$ ).

\section{Discussion}

Oral treatment with R115866 at a daily dose of $1 \mathrm{mg}$ for 12 weeks in patients with moderate to severe facial acne vulgaris resulted in a statistically significant improvement for all assessed efficacy variables at the end of the treatment phase (Figures 9.1 and 9.2). Importantly, the improvement was still pronounced 4 weeks after the last drug intake. This excellent treatment effect was observed for the individual lesion types and confirmed by the acne severity scores and the assessment of overall effectiveness by the investigator and the patients.

In a double-blind randomized placebo-controlled study with oral tazarotene, which is in development for acne, a mean \% reduction of non-inflammatory lesion count of $56 \%$ was achieved after 12 weeks of treatment. ${ }^{15}$ These data are in line with our data showing a $58.3 \%$ mean reduction of non-inflammatory lesion count after 12 weeks further improving to $63.2 \%$ at follow up. With $1 \mathrm{mg} \mathrm{R} 115866$, a $76 \%$ mean reduction of total count of papules and pustules was achieved after 12 weeks versus $50 \%$ and $52 \%$ for $3 \mathrm{mg}$ and $6 \mathrm{mg}$ oral tazarotene, respectively; the mean \% reduction of the nodulocystic lesions was $81.3 \%$ for R115866 versus $65 \%$ and $71 \%$ for $3 \mathrm{mg}$ and $6 \mathrm{mg}$ oral tazarotene. ${ }^{15}$ Our preliminary efficacy results suggest that R115866, compared to oral tazarotene, has an equivalent potency towards improving the non-inflammatory lesions but may exhibit a greater efficacy of improving inflammatory lesions. The effect of 
R115866 on the acne lesions was remarkable in its early onset of action as well as its final result. More studies in a larger population are needed to reproduce these findings. In this small patient group, R115866 was well tolerated with an acceptable safety profile. Elevated triglyceride levels, a side effect often seen after oral isotretinoin treatment, were reported in 3/17 patients but, because they were limited in nature (all less than twice the accepted upper normal limit), none have been reported as adverse event. $^{6-9}$ Oral ingestion of retinoids at effective clinical doses results in a significant increase of the physiological retinoid levels in blood and consequently in tissue where it may be causing some of the undesirable effects (e.g. hepatotoxicity). ${ }^{16-22}$ R115866 does not add an exogenous retinoid load to the whole body; it selectively increases the intracellular levels of retinoic acid (RA) in those cell systems where CYP enzymes are present that specifically metabolize endogenous RA, like CYP $26 .^{23-25}$ This targeted selective increase of all-trans-RA is expected to result in a better safety profile than that observed with oral retinoids.

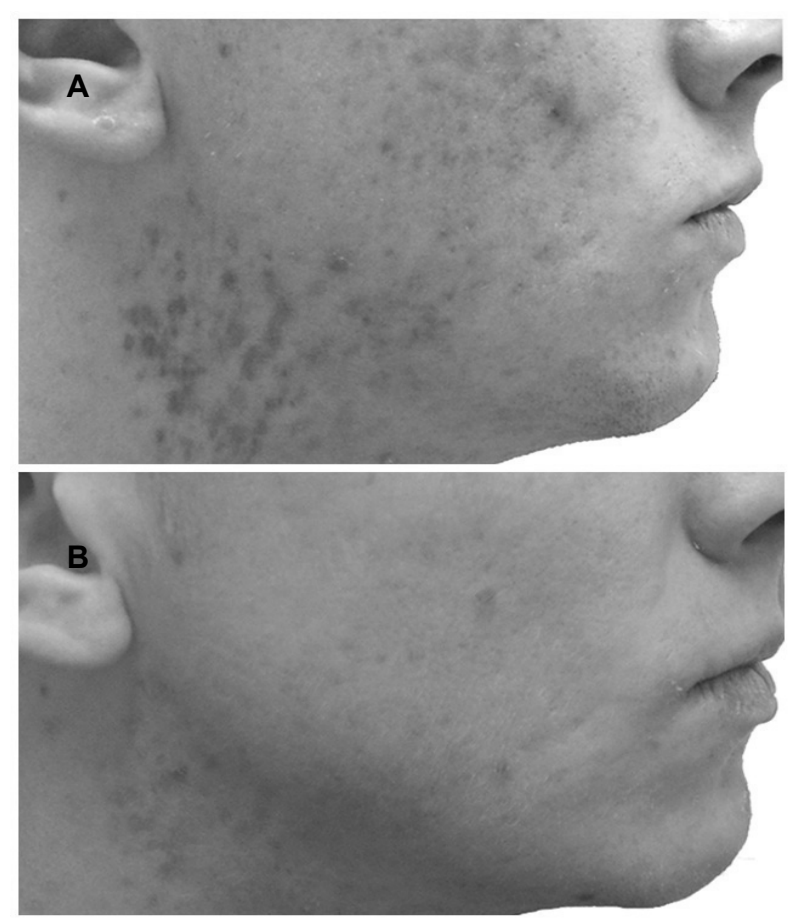

Figure 9.1 Healing of severe papular facial acne with some residual discolouring in the sub-mandibular area (A) before treatment and (B) after 12 weeks of treatment with $1 \mathrm{mg}$ R 115866 daily. See page 237 for colour figure. 

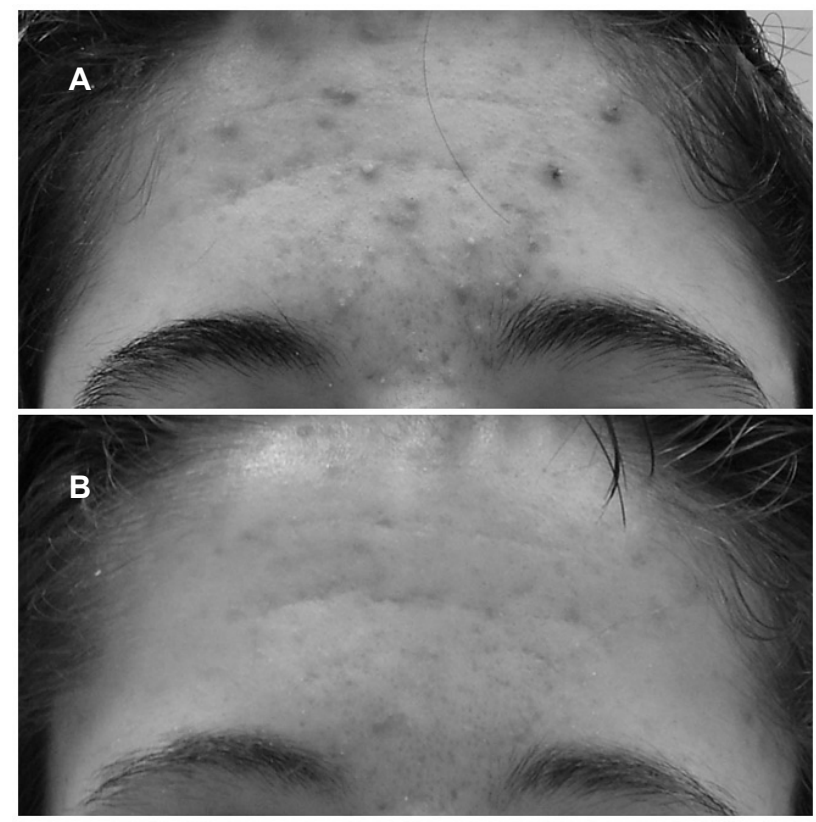

Figure 9.2 Case of moderate papulo-pustular acne almost completely cleared with minimal scarring after 12 weeks of treatment with $1 \mathrm{mg}$ R115866 daily: (A) before treatment, (B) after 12 weeks treatment. See page 238 for colour figure.

\section{Conclusion}

The results in a limited number of patients with moderate to severe facial acne vulgaris indicate that R115866 could not only be an effective but also a well tolerated treatment with equally good effects on inflammatory and non-inflammatory lesions. Although the series of patients is small, it is worth mentioning that the side effects were low in incidence and severity. R115866 deserves further clinical investigation for dose and duration in facial acne vulgaris.

\section{Acknowledgements}

The authors wish to thank Luc Wouters for the statistical analysis. 


\section{References}

1. Zouboulis CC, Eady A, Philpott M, et al. What is the pathogenesis of acne? Exp Dermatol 2005; 14: 143-52.

2. Pawin $\mathrm{H}$, Beylot $\mathrm{C}$, Chivot $\mathrm{M}$, et al. Physiopathology of acne vulgaris: recent data, new understanding of the treatments. Eur J Dermatol 2004; 14: 4-12.

3. Gollnick H, Schramm M. Topical drug treatment in acne. Dermatology 1998; 196: 119-25.

4. Eady EA. Bacterial resistance in acne. Dermatology 1998; 196: 59-66.

5. Gollnick H, Cunliffe W, Berson D, et al. Management of acne: a report from a Global Alliance to Improve Outcomes in Acne. J Am Acad Dermatol 2003; 49: S1-37.

6. Strauss JS, Rapini RP, Shalita AR, et al. Isotretinoin therapy for acne: results of a multicenter doseresponse study. J Am Acad Dermatol 1984; 10: 490-6.

7. Orfanos CE, Zouboulis CC. Oral retinoids in the treatment of seborrhoea and acne. Dermatology 1998; 196: $140-7$.

8. Kunynetz RA. A review of systemic retinoid therapy for acne and related conditions. Skin Therapy Lett 2004; 9: $1-4$.

9. http://www.fda.gov/cder/foi/label/2005/018662s056lbl.pdf: Accutane (Oral isotretinoin capsules) prescribing information: accessed on July $31^{\text {st }} 2006$.

10. Stoppie $\mathrm{P}$, Borgers $\mathrm{M}$, Borghgraef $\mathrm{P}$, et al. R115866 Inhibits all-trans-retinoic acid metabolism and exerts retinoidal effects in rodents. J Pharmacol Exp Ther 2000; 293: 304-12.

11. R115866 Investigational Drug Brochure; version 4.0.; Jun. 2006. Data on file at Barrier Therapeutics.

12. Stoppie P, Van Wauwe J, Wouters L, et al. Rambazole ${ }^{\mathrm{TM}}$, a potent inhibitor of all-trans-retinoic acid metabolism, applied topically to mouse tail skin exerts retinoid mimetic activity. $J$ Invest Dermatol 2004; 122: A70( \#420)

13. Cools M, Pavez-Lorie E, Borgers M, et al. Effect of topical R115866 (Rambazole ${ }^{\mathrm{TM}}$ ) gel on the expression of biomarkers in the skin of healthy volunteers. J Invest Dermatol 2006; 126: S40 (\#240).

14. SAS version 8.2 , SAS Institute, Cary, USA

15. Tan JKL, Lew-Kaya D, Walker PS. Oral tazarotene reduces comedones. JAAD 2004; 50: P20 (\#78)

16. Hartman $\mathrm{S}$, Brors $\mathrm{O}$, Bock $\mathrm{J}$, et al. Exposure to retinyl esters, retinol and retinoic acids in non-pregnant women following increasing single and repeated oral doses of vitamin A. Ann Nutr Metab 2005; 49: 155-64.

17. Tang G, Russell RM. 13-cis Retinoic acid is an endogenous compound in human serum. $J$ Lipid Res 1990; 31: 175-82.

18. Wiegand U-W, Chou RC. Pharmacokinetics of oral isotretinoin. J Am Acad Dermatol 1998; 39: S8-S12.

19. Kurlandsky SB, Gamble MV, Ramakrishnan R, et al. Plasma delivery of retinoic acid to tissues in the rat. J Biol Chem 1995; 270: 17850-7.

20. Allen JG, Bloxham DP. The pharmacology and pharmacokinetics of the retinoids. Pharmacol Ther 1989; 40: $1-27$.

21. David M, Hodak E, Lowe NJ. Adverse effects of retinoids. Medical Toxicology 1988; 3: 273-88.

22. Penniston KL, Tanumihardjo SA. The acute and chronic toxic effects of vitamin A. Am J Clin Nutr 2006; 83: 191-201.

23. Napoli JL. Retinoic acid: its biosynthesis and metabolism. Prog Nucleic Acid Res Mol Biol 1999; 63: 139-88.

24. Napoli JL. Interactions of retinoid binding proteins and enzymes in retinoid metabolism. Biochim Biophys Acta 1999; 1440: 139-62.

25. Petkovich PM. Retinoic acid metabolism. J Am Acad Dermatol 2001; 45: S136-42. 


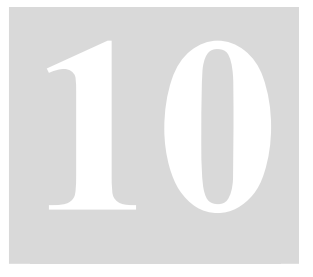

General Discussion 


\section{Hyperkeratotic disorders and RAMBAs}

All-trans-retinoic acid (all-trans-RA), the naturally occurring derivative of vitamin $\mathrm{A}$ is one of the principal endogenous compounds that controls growth and differentiation of epithelial tissue. ${ }^{1,2}$ In order to sustain normal structure and function, the epidermis of the skin, a keratinized epithelium, requires a certain quantity of all-trans-RA. Cells retrieve their all-trans-RA from the plasma, either directly or indirectly as vitamin A (retinol, ROL). Both endogenous compounds are ingested through the diet and are constitutively present in plasma at a concentration of $4-14 \mathrm{nM}$ for all-trans-RA and $2 \mu \mathrm{M}$ for ROL under normal dietary conditions. ${ }^{3-6}$ They are available to the epidermis from the vasculature of the underlying dermis. Once permeated to the epidermis, ROL may serve as a substrate for all-trans-RA synthesis in situ. ${ }^{7}$ Inside the cells, all-trans-RA exerts most of its biological activities through binding to specific receptors (RAR-RXR), belonging to the superfamily of nuclear receptors. ${ }^{8,9}$ Nuclear receptors regulate transcription of genes by acting as ligand-inducible transcription factors. As such they can manage genes involved in processes as cell differentiation, cell proliferation, apoptosis etc. Today, the molecular mechanisms underlying the action of retinoids i.e. both the natural and synthetic compounds that share structural and/or functional similarity with vitamin A, are not yet fully understood. They can be antiproliferative in hyperproliferating systems, induce hyperproliferation in normal proliferating systems and they possess immunomodulating properties. The concentration of all-trans-RA within the cells is tightly regulated in part by specific catabolising microsomal cytochrome P450 enzymes i.e the CYP26 family which oxidizes all-trans-RA into 4-hydroxy-RA and further into 4-oxoRA. CYP2S1, another cytochrome P450 enzyme has also shown to be able to catabolise all-trans-RA in skin. ${ }^{10,11}$

Since the discovery that vitamin A-deficiency leads to keratinizing metaplasia and hyperkeratosis, numerous studies have followed focusing on the metabolism and pharmacological action of 'retinoids' in the skin which has led to the establishment of retinoid treatment for various skin diseases like psoriasis, ichthyosis and acne. ${ }^{12-14}$

Although very effective, the use of oral retinoids is hampered by systemic toxicity i.e. long-lasting teratogenicity, hypertriglyceridaemia, hepatotoxicity, skeletal malformations, etc. Effective clinical doses of oral retinoids significantly increase the physiological retinoid levels in the circulation and consequently, in the whole body where they may cause undesirable effects. ${ }^{15,16}$ Some retinoids are even stored in adipose tissue and cause chronic toxicity and birth defects for months after discontinuation of therapy. ${ }^{17}$ Next to that, prolonged treatment with retinoids has proven to induce Cyp26A1- 
mediated catabolism which leads to reduced responsiveness, higher effective therapeutic doses and consequently more unwanted side-effects. ${ }^{18,19}$

Hypothetically, the above mentioned problems could be circumvented by using a different clinical approach to administering retinoids, i.e. modulating the retinoic acid concentrations at the cellular level by using Retinoic Acid Metabolism Blocking Agents or RAMBAs. RAMBAs are compounds that block the cytochrome P450-dependent enzyme, retinoic acid 4-hydroxylase (CYP26), responsible for the intracellular catabolism of all-trans-RA in specific target cells which leads to an increase of intracellular all-trans-RA concentration. ${ }^{20-23}$ Unlike existing therapies where high amounts of exogenous retinoids, natural or synthetic, are administered to the body, a RAMBA modulates the body's own production of all-trans-RA to achieve the same therapeutic effects. ${ }^{24}$ Once treatment is stopped, a RAMBA is quickly eliminated from the body returning the intracellular metabolism of all-trans-RA back to normal and declining the elevated alltrans-RA tissue levels. ${ }^{25}$ This targeted selective increase of all-trans-RA combined with the rapid clearance of the RAMBAs is expected to result in a better safety profile compared to oral retinoids. ${ }^{15,16}$

Answering the question whether RAMBAs, in particular liarozole and R115866, could represent an effective and safer therapeutic approach for hyperkeratotic disorders like ichthyosis, psoriasis and acne was the main objective of this thesis.

The first aim was to investigate the clinical use of liarozole in ichthyosis. Interest in liarozole, once in clinical development for psoriasis in the nineties, has now received a boost because of its orphan drug status for congenital ichthyosis in Europe and the US. $^{26-28}$ Both topical and oral clinical use of liarozole in several ichthyosis subtypes (XRI, LI and CBIE) has been described in detail in chapters 5 and 6.

The second aim was to explore the clinical efficacy, tolerability and safety of oral R115866, a more potential and selective RAMBA than liarozole, in psoriasis. The results of an 8 weeks study in 19 patients with moderate to severe plaque-type psoriasis have been presented in detail in chapter 8 .

The third aim, which was the most challenging one, was to explore the clinical efficacy, tolerability and safety of oral R115866 in moderate to severe facial acne vulgaris. The results of an open study in 17 patients with moderate to severe facial acne vulgaris have been presented in detail in chapter 9 .

This chapter will summarize and discuss the results of the above mentioned clinical studies as well as some future perspectives. At the end, some general considerations are discussed. 


\section{Liarozole, a new treatment option for severe ichthyosis?}

Today, although not approved in certain countries of the European Union and the US for this condition, acitretin is the most effective and the only systemic treatment available for most of the severe types of ichthyosis. ${ }^{29,30}$ However, while effective, acitretin is not well tolerated by the patients. The major issues are considerable RA-related cutaneous side effects, hypercholesterolaemia, hyperlipidaemia and the long-term teratogenicity. Pre-menopausal women are advised not to become pregnant for at least 2 years following acitretin treatment. ${ }^{17}$ Due to the side-effect profile of acitretin, many patients prefer to go without systemic treatment. Since no other drugs, systemic or topical, have been approved for congenital ichthyosis in EU or the US today; the only options left are the use of emollients, bathing, mechanical removal of the scales and other less effective methods which badly impact the quality of life. There is a clear need for safer and more effective agents for these orphan diseases.

Clinical efficacy, tolerability and safety of oral and topical liarozole in severe ichthyosis

In 1998, Lucker et al. provided the first evidence in an open study that oral liarozole was an effective treatment for severe ichthyosis. The overall response to treatment assessed by the investigator at the end of a 12 week treatment period with $300 \mathrm{mg}$ liarozole daily revealed an at least markedly improvement in all patients. ${ }^{31}$ The treatment was well tolerated, adverse events (AEs) were reported in 11 out of 12 patients. The most frequently reported AEs were mild mucocutaneous RA-related side effects being cheilitis (10/12), pruritus (6/12) and xerosis (3/12).

Over the years, the dose-finding studies with liarozole in the psoriasis population have shown that $75 \mathrm{mg}$ b.i.d. was the optimum dose and that any dose higher than $75 \mathrm{mg}$ b.i.d. didn't give an appreciable better therapeutic effect and was less tolerated. Next to that, studies with synthetic retinoids have shown that the dose needed for therapeutic efficacy is similar for the various types of keratinisation disorders, including psoriasis and ichthyosis. Based on these data, the dose of oral liarozole was lowered to $75 \mathrm{mg}$ b.i.d. for the comparative study versus acitretin in ichthyosis described in chapter 6 .

The results of the double-blind comparative study suggest that oral liarozole at a daily dose of $150 \mathrm{mg}$ is equally effective as a treatment for severe ichthyosis as acitretin (35mg daily) and shows a trend towards a more favourable tolerability profile. Overall scaling (sum of scaling at all locations, i.e. trunk, upper and lower limbs) had improved significantly from baseline $(\mathrm{p}<0.001)$ within both treatment groups. For overall erythema and overall bullae, no significant changes from baseline were observed in any of 
the treatment groups. The overall response to treatment when assessed by the investigator revealed at least marked improvement in 10/15 patients for the liarozole group and in $12 / 16$ patients for the acitretin group. Both the number of adverse events and the incidence of hypertriglyceridaemia in this trial were lower in the liarozole group than in the acitretin group and will be further discussed below, however a larger trial will be needed to show statistical significance.

To broaden the margin between efficacy and side-effects, a topical formulation was developed. In Chapter 5, the short- and long-term clinical efficacy and safety of topical liarozole $5 \%$ cream has been described in 12 patients with several ichthyosis subtypes (XRI, LI and CBIE). After a 4 weeks double-blind treatment versus placebo, a significant unilateral improvement in extent and severity of skin lesions was observed in favour of the liarozole-treated side. The extent and severity of the lesions further improved during the 6 weeks open phase and 72 weeks maintenance phase. At the end of the maintenance study, the overall assessment of the response to treatment rated by the investigator as well as the patient was considered to be "good/excellent" for 7 out of 8 patients and 1 patient was completely cleared. Kinetic data from this study indicate some systemic absorption of topical liarozole in patients with NELI or CBIE and less with XRI. As no significant differences were found between these groups in the amount of liarozole used, the differences in liarozole plasma concentrations might be related to a different absorption caused by differences in skin barrier function amongst the subtypes. This will need further investigation in a larger population. Clinical side effects were only minimal. Topical liarozole was well tolerated, even through the 72 weeks maintenance study with only 11 AEs reported in 7 out of 8 patients, all being mild and temporary. The most reported AE was 'sticky feeling of the skin' reported by 4 patients. Currently, the clinical data demonstrating the efficacy and safety of liarozole in the treatment of ichthyosis is limited. However, the present data gathered and the particular pharmacokinetics of liarozole indicate that the drug is an attractive candidate worthwhile developing for the treatment of severe ichthyosis.

\section{Future studies with liarozole in severe ichthyosis}

Dose-finding studies will be required to optimize both the efficacy and safety of topical and oral liarozole treatment. The major issue one encounters when performing clinical studies in an orphan disease like severe ichthyoses is finding enough patients. The low incidence and the genetic heterogeneity of the ichthyoses make recruitment very hard. Next to that, there is the fact that placebo-controlled studies lasting longer than 3 months are not well accepted by the patients. An ongoing phase II/III study is evaluating the efficacy and safety of 2 doses of oral liarozole (75 mg and $150 \mathrm{mg}$ once daily) 
given during 12 weeks compared to placebo in patients with lamellar ichthyosis. The outcome of the study should clarify whether a once daily treatment regimen of liarozole also provides therapeutic activity while further improving the side effect profile of the drug.

\section{Oral R115866, a promising anti-psoriatic treatment?}

Despite the fact that many new therapies, like the biologicals, have been developed, retinoids as monotherapy or in combination with other treatment modalities remain a useful therapy for the treatment of psoriasis. ${ }^{32,33}$ Today, acitretin (Neotigason $\AA$, Sori$\left.\operatorname{atane}^{\circledR}\right)$ is the only oral, and tazarotene $\left(\operatorname{Zorac}^{\circledR}, \operatorname{Tazorac}^{\circledR}\right)$, the only topical retinoid, approved for psoriasis in most European countries and in the US. ${ }^{29,34-38}$ Oral tazarotene has completed Phase III studies but at the time of writing its manufacturer has received a non-approvable letter from the U.S. Food and Drug Administration. ${ }^{39}$ As mentioned before, the use of acitretin is also restricted in psoriasis due to its toxicity profile and its long-term teratogenicity.

Whereas the first RAMBAs where non-selective CYP inhibitors, a thorough screening yielded a very selective and highly active retinoic acid 4-hydroxylase inhibitor namely R115866 (Rambazole $\left.{ }^{\mathrm{TM}}\right)^{23}$ Similar to all-trans-RA, both oral and topical R115866 exhibit modulating effects on epithelial growth and differentiation in various animal models of keratinisation which suggests a therapeutic potential in hyperkeratotic disorders like psoriasis. ${ }^{23,40,41}$ Compared to liarozole, $\mathrm{R} 115866$ is a more potent $\left(\mathrm{IC}_{50}\right.$ in $\mathrm{nM}$ range) and selective retinoic acid 4-hydroxylase inhibitor, hence expected to result in clinical efficacy at lower dosages and consequently in less adverse events.

Clinical efficacy, tolerability and safety of oral R115866 in moderate to severe plaque type psoriasis

The results of an 8 weeks exploratory study in patients with moderate to severe plaquetype psoriasis, suggest that oral R115866 may be an effective and well tolerated treatment which warrants further investigation, see chapter 8 . Of the complete cases, 38\% had at least PASI50 at end of treatment and 54\% at follow-up. These data are in line with efficacy data found on acitretin, the preferred systemic retinoid in the treatment of psoriasis for more than 10 years. ${ }^{42}$ PASI 50 was reached after 8 weeks treatment with acitretin in $44.5 \%$ and $57 \%$ of the patients respectively treated with an initial dose of $50 \mathrm{mg} /$ day and $40 \mathrm{mg}$ /day for 4 weeks followed by a dose adjustment according to therapeutic response. ${ }^{43,44}$ A treatment duration extending 8 weeks may be needed to achieve optimal clinical efficacy. 
The most common adverse events with R115866 in this trial were pruritus, xerosis, cheilitis and an increase in blood triglycerides which will be discussed below.

Kinetic data were in line with those obtained in healthy volunteers and revealed no accumulation of R115866 throughout the study and a rapid clearance (within hours) from the body once treatment was stopped. ${ }^{24}$ At all time points, increases in plasma alltrans-RA levels remained within physiological limits and were comparable, except after the first dose, where the increase was slightly higher. This might indicate that the feedback mechanism responsible for the reduced activity seen with retinoids after long-term treatment does not seem to affect much the potential of R115866.

Assessment of the dynamics of epidermal proliferation, keratinization, lesional T-cell subsets and cells expressing NK-receptors in only 6 patients (data have been presented elsewhere) revealed that clinical efficacy of R115866 is primarily the result of restoring proliferation and differentiation of epidermal keratinocytes. ${ }^{45}$ Also a tendency toward reduction of relevant $\mathrm{T}$-cell subsets and cells expressing NK-receptors was shown suggesting that R115866 might possess anti-inflammatory activities and supporting the concept that a longer treatment with R115866 will probably further improve clinical efficacy.

In conclusion, R115866 may be an effective and well tolerated treatment for patients with moderate to severe plaque-type psoriasis and warrant further investigation.

\section{Future studies with R115866 in psoriasis}

The preliminary data presented here suggest that R115866 has a potential as a treatment for plaque-type psoriasis. Additional controlled studies and dose-finding studies will be required to confirm the efficacy and establish the optimum treatment dose and safety. The fact that some non-responders in this exploratory study had a very high body mass index (e.g. 49.4) could indicate that a 'dose by weight' (mg/kg) regimen might be necessary. Next to that, the data point out that a longer treatment with R115866 will probably improve clinical efficacy so optimisation of the treatment duration is definitely necessary. Future clinical studies should include a quality of life survey and close monitoring of triglycerides. Also the possible anti-inflammatory activity of R115866 needs further investigation.

As R115866 seems to be a promising drug for the treatment of plaque type psoriasis, it could be worthwhile exploring the clinical efficacy of R115866 in other types of psoriasis like palmo-plantar psoriasis or even psoriatic arthritis. 


\section{Oral R115866, an effective treatment for facial acne?}

Although being the most effective treatment available for severe acne, the use of oral isotretinoin is restricted due to its side effect profile i.e. teratogenicity, elevations in triglycerides and liver enzymes and to a lesser degree cholesterol levels. ${ }^{46-49}$ Also the high incidence of cutaneous RA-related side effects can sometimes be troublesome and lead to discontinuation of the treatment. So there is room for alternatives with a more favourable safety profile.

Next to its effect on epithelial growth and differentiation, oral R115866 also reduces the sebaceous gland size in hamsters. In addition, topical application of R115866 has revealed a reduction of the utriculus size in rhino mouse back skin (predictive for acne) and also a dose-dependent reduction of pro-inflammatory cytokines at the mRNA level like IL-1 $\alpha$ in the skin of healthy volunteers, suggesting a possible anti-inflammatory activity. ${ }^{41,50}$ Based on these properties, R115866 was hypothesized to be effective in skin disorders such as acne vulgaris where an aberrant keratinization is combined with an excessive sebum production/excretion.

Clinical efficacy, tolerability and safety of oral R115866 in moderate to severe facial acne vulgaris

The results of an open exploratory trial in patients with moderate to severe facial acne vulgaris as presented in chapter 9, indicate that R115866 could indeed not only be an effective but also a well tolerated treatment with equally good effects on inflammatory and non-inflammatory lesions. A significant mean reduction in inflammatory lesions of $77.4 \%(\mathrm{p}<0.001)$, in non-inflammatory lesions of $58.3 \%(\mathrm{p}<0.001)$, and in total lesion count of $76 \%(p<0.001)$ was observed at the end of treatment compared to baseline. The improvement was still pronounced 4 weeks after the last drug intake. This excellent treatment effect was confirmed by the acne severity scores and overall effectiveness scores by investigator and patients. In line with our data, a $56 \%$ mean reduction of noninflammatory lesions was achieved after 12 weeks of treatment with oral tazarotene, a synthetic retinoid in development for acne and psoriasis. However, the mean \% reduction of total count of papules and pustules was $76 \%$ for R115866 versus $50 \%$ for $3 \mathrm{mg}$ and $52 \%$ for $6 \mathrm{mg}$ tazarotene; the mean \% reduction of the nodulocystic lesions were $81.3 \%$ for R115866 versus $65 \%$ and $71 \%$ for $3 \mathrm{mg}$ and $6 \mathrm{mg}$ tazarotene. ${ }^{51}$ These preliminary results suggest that R115866 is equipotent to oral tazarotene in improving the non-inflammatory lesions but may exhibit a greater efficacy in improving inflammatory lesions. Although the series of patients is small, it is worth mentioning that the reported side effects were low in incidence and severity. No elevated blood triglyceride levels 
were reported as adverse event although they are often seen after oral isotretinoin treatment. $^{49}$

In conclusion, oral R115866 deserves further clinical investigation to optimize dose and duration of treatment in patients with moderate to severe acne.

\section{Future studies with R115866 in facial acne vulgaris}

In order to further clarify the potential of oral R115866 in the treatment of moderate to severe facial acne vulgaris, larger clinical studies using a placebo- or active-controlled approach as well as dose-finding studies will be necessary. As topical R115866 revealed a reduction of the utriculus size in rhino mouse back skin (predictive for acne) and also a dose-dependent reduction of pro-inflammatory cytokines in the skin of healthy volunteers, another option would be to investigate the potential of topical R115866 in the milder forms of facial acne vulgaris. If such studies prove to be positive, one might think of using the combination of oral R115866 as a short-term first line therapy for the moderate to severe forms of acne followed by a maintenance treatment with topical R115866.

\section{General Considerations}

The major issues with the available oral retinoids today, as described above, are hyperlipidaemia and long-term teratogenicity (acitretin). How about the RAMBAs, liarozole and R115866?

\section{Hypertriglyceridaemia}

During acitretin treatment in psoriasis at a dose of 30 to $60 \mathrm{mg} / \mathrm{day}$, a $35 \%$ increase in serum triglycerides was observed. ${ }^{44}$ A safety analysis of all the data gathered over the years in the psoriasis and ichthyosis clinical trials with liarozole showed a higher incidence $(p=0.298)$ of hypertriglyceridaemia in the $150 \mathrm{mg}$ liarozole group $(10 \%)$ compared to the placebo (5\%) but a significantly lower incidence compared to acitretin group (15\%, $\mathrm{p}=0.036) .{ }^{52}$ Similar observations were found for hypercholesterolemia: $6 \%$ in the $150 \mathrm{mg}$ liarozole group vs. $3 \%$ in the placebo ( $>0.999$, ns) and $9 \%$ in the acitretin group $(p=0.034)$. Also for the $\geq 150 \mathrm{mg}$ liarozole group, the incidence of hypertriglyceridaemia and hypercholesterolemia is significantly lower when compared to the acitretin group ( $\mathrm{p}=0.002$ and 0.005 respectively).

In the open psoriasis study with oral R115866 (chapter 8), elevated triglycerides were reported as an adverse event in 10 out of 19 patients. Interestingly, 6 out of 9 screening failures in this study were due to pre-existent hypertriglyceridaemia and 6 patients that 
were included had already triglyceride levels above normal values at baseline, so before the first intake of the study medication. The fact that no abnormal triglyceride levels were recorded as an $\mathrm{AE}$ in the open exploratory trial with R115866 in moderate to severe facial acne vulgaris adds evidence to the hypothesis that elevated blood triglycerides or the susceptibility to have increases in blood triglycerides may be intrinsic to the psoriasis population. ${ }^{53-56}$ Recent work by Mallbris et al. in 200 patients with psoriasis at the onset of the disease supports the notion that lipid abnormalities in psoriasis are already present and probably genetically determined. ${ }^{57}$ However, this phenomenon needs further investigation and close monitoring.

\section{Long-term teratogenicity}

The main advantage of RAMBAs over acitretin lies in their inherent property towards long-term teratogenicity. Etretinate and acitretin have the disadvantage of being stored in subcutaneous adipose tissue from which they are slowly released into the plasma. This is, in view of the teratogenic potential, a real burden for women of child-bearing age as they are advised not to become pregnant for at least 2 (Europe) to 3 (US) years following acitretin treatment. Neither liarozole nor R115866 accumulate in plasma or tissues during treatment and both drugs are rapidly cleared from the body once treatment is stopped (within hours) as shown in chapters 4 and $8 .^{25,40,58}$ The elevated RA levels in plasma (still within physiological limits) and in tissue also rapidly return to baseline levels after discontinuation of the treatment which significantly minimizes the waiting period to become pregnant as compared to acitretin. ${ }^{17,24}$

\section{Conclusion}

The data presented in this thesis suggest that RAMBAs, compared to the oral retinoids available today, are at least equally effective treatments for hyperkeratotic disorders and they display a trend towards a more favourable safety profile. However, larger and longer studies will be needed to confirm these preliminary results.

Retinoids possess a remarkable range of activities and clinical uses. Other cutaneous disorders previously shown to be responsive to retinoids such as photoaging, dyspigmentation, actinic keratosis, etc. are likely to respond positively to RAMBAs too. As more insight is gained into the mechanism of action of retinoids and their intracellular metabolism, more opportunities will arise for RAMBAs. The latter form the object of a series of ongoing studies and research projects for the forthcoming years. 


\section{References}

1. Asselineau D, Darmon M. Retinoic acid provokes metaplasia of epithelium formed in vitro by adult human epidermal keratinocytes. Differentiation 1995; 58: 297-306.

2. Kopan R, Traska G, Fuchs E. Retinoids as important regulators of terminal differentiation: examining keratin expression in individual epidermal cells at various stages of keratinization. J Cell Biol 1987; 105: 427-40.

3. Soderlund MB, Sjoberg A, Svard G, et al. Biological variation of retinoids in man. Scand J Clin Lab Invest 2002; 62: 511-9.

4. Hartman S, Brors O, Bock J, et al. Exposure to retinyl esters, retinol and retinoic acids in non-pregnant women following increasing single and repeated oral doses of vitamin A. Ann Nutr Metab 2005; 49: 155-64.

5. Tang G, Russell RM. 13-cis Retinoic acid is an endogenous compound in human serum. J Lipid Res 1990; 31: 175-82.

6. Napoli JL, Pramanik BC, Williams JB, et al. Quantification of retinoic acid by gas-liquid chromatography-mass spectrometry: total versus all-trans-retinoic acid in human plasma. J Lipid Res 1985; 26: 387-92.

7. Kurlandsky SB, Gamble MV, Ramakrishnan R, et al. Plasma delivery of retinoic acid to tissues in the rat. J Biol Chem 1995; 270: 17850-7.

8. Napoli JL. Retinoic acid: its biosynthesis and metabolism. Prog Nucleic Acid Res Mol Biol 1999; 63: 139-88.

9. Napoli JL. Interactions of retinoid binding proteins and enzymes in retinoid metabolism. Biochim Biophys Acta 1999; 1440: 139-62.

10. Petkovich PM. Retinoic acid metabolism. J Am Acad Dermatol 2001; 45: S136-42.

11. Smith G, Wolf CR, Deeni YY, et al. Cutaneous expression of cytochrome P450 CYP2S1: individuality in regulation by therapeutic agents for psoriasis and other skin diseases. The Lancet 2003; 361: 1336-43.

12. Wolbach SB, Howe PR. Tissue changes following deprivation of fat-soluble vitamin A. J Exp Med 1925; 47: 753-77.

13. Orfanos CE, Zouboulis CC. Oral retinoids in the treatment of seborrhoea and acne. Dermatology 1998; 196: $140-7$.

14. Thielitz A, Krautheim A, Gollnick H. Update in retinoid therapy of acne. Dermatol Ther 2006; 9: 272-9.

15. David M, Hodak E, Lowe NJ. Adverse effects of retinoids. Medical Toxicology 1988; 3: 273-88.

16. Penniston KL, Tanumihardjo SA. The acute and chronic toxic effects of vitamin A. Am J Clin Nutr 2006; 83: 191-201.

17. Geiger JM, Baudin M, Saurat JH. Teratogenic risk with etretinate and acitretin treatment. Dermatology 1994; 189: 109-16.

18. Duell EA, Kang S, Voorhees JJ. Retinoic acid isomers applied to human skin in vivo each induce a 4hydroxylase that inactivates only trans retinoic acid. J Invest Dermatol. 1996; 106: 316-20.

19. Loudig O, Babichuk C, White J, et al. Cytochrome P450RAI (CYP26) promoter: a distinct composite retinoic acid response element underlies the complex regulation of retinoic acid metabolism. Mol Endocrinol 2000; 14: 1483-97.

20. Van Wauwe J, Coene MC, Goossens J, et al. Effects of cytochrome P-450 inhibition on the in vivo metabolism of all-trans-retinoic acid in rats. J Pharmacol Exp Ther 1990; 252: 365-9.

21. Van Wauwe J, Van Nyen G, Coene MC, et al. Liarozole, an inhibitor of retinoic acid metabolism, exerts retinoid-mimetic effects in vivo. J Pharmacol Exp Ther 1992; 261: 773-8. 
22. Kang S, Duell E, Kim K, et al. Liarozole inhibits human epidermal retinoic acid 4-hydroxylase activity and differentially augments human skin responses to retinoic acid and retinol in vivo. J Invest Dermatol 1996; 107: 183-7.

23. Stoppie $\mathrm{P}$, Borgers $\mathrm{M}$, Borghgraef $\mathrm{P}$, et al. R115866 Inhibits all-trans-retinoic acid metabolism and exerts retinoidal effects in rodents. J Pharmacol Exp Ther 2000; 293: 304-12.

24. Allen JG, Bloxham DP. The pharmacology and pharmacokinetics of the retinoids. Pharmacol Ther 1989; 40: $1-27$.

25. Cools M, Stoppie P, Cauwenbergh G, et al. Tolerability, safety and pharmacokinetics of single and multiple oral dosages of R115866 (Rambazole ${ }^{\mathrm{TM}}$ ) in healthy volunteers. Presented at Eur Acad Dermatol \& Venereol 2006, Rhodos, P035.22.

26. Dockx P, Decree J, Degreef H. Inhibition of the metabolism of endogenous retinoic acid as treatment for severe psoriasis: an open study with oral liarozole. Br J Dermatol 1995; 133: 426-32.

27. Berth-Jones J, Todd G, Hutchinson PE, et al. Treatment of psoriasis with oral liarozole: a dose-ranging study. Br J Dermatol 2000; 143: 1170-6.

28. Bhushan $\mathrm{M}$, Burden $\mathrm{AD}$, McElhone $\mathrm{K}$, et al. Oral liarozole in the treatment of palmoplantar pustular psoriasis: a randomized, double-blind, placebo-controlled study. Br J Dermatol 2001; 145: 546-53.

29. Neotigason ${ }^{\circledR}$ (Acitretin $10 \mathrm{mg}$ and $25 \mathrm{mg}$ capsules) Data Sheet. Available from URL: http://www.medsafe.govt.nz/profs/Datasheet/n/Neotigasoncap.htm. (Accessed on February 23rd, 2006)

30. Blanchet-Bardon C, Nazzaro V, Rognin C, et al. Acitretin in the treatment of severe disorders of keratinization. Results of an open study. JAAD 1991; 24: 982-6.

31. Lucker G, Heremans A, Boegheim P, et al. Oral treatment of ichthyosis by the cytochrome P-450 inhibitor liarozole. Br J Dermatol 1997; 136: 71-5.

32. Naldi L, Griffiths CME. Traditional therapies in the management of moderate to severe chronic plaque psoriasis: an assessment of the benefits and risks. Br J Dermatol 2005; 152: 597-615.

33. Nijsten T, Margolis DJ, Feldman SR, et al. Traditional systemic treatments have not fully met the needs of psoriasis patients: results from a national survey. J Am Acad Dematol 2005; 52: 434-4.

34. Soriatane ${ }^{\circledR}$ (acitretin) capsules, Medication Guide for Patients, 2004. Available from URL: http://www.fda.gov/cder/foi/label/2004/19821s011lbl.pdf (Accessed on February 23rd, 2006)

35. Allergan (US). Tazorac ${ }^{\circledR}$ (tazarotene topical cream): prescribing information 2001

36. Allergan (US). Tazorac ${ }^{\circledR}$ (tazarotene topical gel): prescribing information 2003 Dec.

37. Allergan Ltd (UK). Zorac $0.05 \%$ gel (online) Available from URL: http://emc.medicines.org.uk (Accessed February $15^{\text {th }}, 2006$ )

38. Allergan Ltd (UK). Zorac $0.1 \%$ gel (online) Available from URL: http://emc.medicines.org.uk (Accessed February $15^{\text {th }}, 2006$ )

39. http://www.fda.gov/ohrms/dockets/ac/04/slides/2004-4062S1_02_Allergan-Presentation_files/frame.htm (Accessed February $15^{\text {th }}, 2006$ )

40. Rambazole ${ }^{\mathrm{TM}}$ (R115866) Investigational Drug Brochure; version 4.0; Jun. 2006. Data on file at Barrier Therapeutics.

41. Stoppie P, Van Wauwe J, Wouters L, et al. Rambazole ${ }^{\mathrm{TM}}$, a potent inhibitor of all-trans-retinoic acid metabolism, applied topically to mouse tail skin exerts retinoid mimetic activity. J Invest Dermatol 2004; 122: A70(\#420)

42. Geiger JM. Efficacy of acitretin in severe psoriasis. Skin Therapy Lett 2003; 8: 1-3.

43. Murray HE, Anhalt AW, Lessard R, et al. A 12-month treatment of severe psoriasis with acitretin: Results of a Canadian open multicenter trial. J Am Acad Dermatol 1991; 24: 598-602. 
44. Kragballe K, Jansén CT, Geiger JM, et al. A double-blind comparison of acitretin and etretinate in the treatment of severe psoriasis. Results of a Nordic multicentre study. Acta Derm Venereol 1989; 69: $35-40$.

45. Bovenschen HJ, Otero ME, Langewouters AM, et al. Oral retinoic acid metabolism blocking agent rambazole for plaque psoriasis: an immunohistochemical study. Br J Dermatol 2007; 156: 263-70.

46. Pawin H, Beylot C, Chivot M, et al. Physiopathology of acne vulgaris: recent data, new understanding of the treatments. Eur J Dermatol 2004; 14: 4-12.

47. Gollnick H, Cunliffe W, Berson D, et al. Management of acne: a report from a Global Alliance to Improve Outcomes in Acne. J Am Acad Dermatol 2003; 49: S1-37.

48. Kunynetz RA. A review of systemic retinoid therapy for acne and related conditions. Skin Therapy Lett 2004; $9: 1-4$.

49. http://www.fda.gov/cder/foi/label/2005/018662s056lbl.pdf: Accutane (Oral isotretinoin capsules) prescribing information: accessed on July $31^{\text {st }} 2006$.

50. Cools M, Pavez-Lorie E, Borgers M, et al. Effect of topical R115866 (Rambazole ${ }^{\mathrm{TM}}$ ) gel on the expression of biomarkers in the skin of healthy volunteers. J Invest Dermatol 2006; 126: S40 (\#240).

51. Tan JKL, Lew-Kaya D, Walker PS. Oral tazarotene reduces comedones. JAAD 2004; 50: P20 (\#78)

52. Vandeplassche G, Verfaille CJ, Beger B, et al. Safety of oral liarozole in subjects with ichthyosis or psoriasis. J Eur Acad Dermatol Venereol 2004; 18 (Suppl. 2): 395-6.

53. Vahlquist C, Michaelson G, Vessby B. Serum lipoproteins in middle-aged men with psoriasis. Acta Derm Venereol 1987; 67: 12-5.

54. Vahlquist C, Selinus I, Vessby B. Serum lipids changes during acitretin (etretin) treatment of psoriasis and palmo-plantar pustulosis. Acta Derm Venereol 1988; 6: 300-5.

55. Piskin S, Gurkok F, Ekuklu G, et al. Serum lipids in psoriasis. Yonsei Med J 2003; 44: 24-6.

56. Hachem JP, Verfaille CJ, Coel M, et al. Oral R115866 (Rambazole ${ }^{\mathrm{TM}}$ ) in the treatment of facial acne vulgaris. Presented at Eur Acad Dermatol \& Venereol 2006, Rhodos, P001.65.

57. Mallbris L, Granath F, Hamsten A, et al. Psoriasis is associated with lipid abnormalities at the onset of skin disease. J Am Acad Dermatol 2006; 54: 614-20.

58. Barrett D, Bryla P, van de Velde, et al. Liarozole investigators' brochure, $2^{\text {nd }}$ edn, version 5.0, 22 February 2005. Data on file at Barrier Therapeutics. 



\section{Summary}

The outer layers of the human skin (epidermis) serve as the first line of defence between the internal body organs and the environment; it is a mechanical barrier that protects from pathogens, irritants and allergens whilst regulating the loss of water. Disturbance of the barrier can lead to significant water loss, the penetration of microbes and allergens and to the onset of inflammation. In order to produce and maintain that barrier function, the epidermis is a dynamic, continually renewing structure with a homeostasis that is carefully regulated. It is a stratifying epithelium consisting of stacked layers of keratinocytes connected by protein bridges called desmosomes. At the bottom, in the basal layers, are cells that continually divide and thereby regenerate the skin. As cells move outwards from the basal layer, they differentiate into their terminal state and desquamate. During this maturation process the physiology, chemical composition, shape and orientation of the keratinocytes changes. Under various pathophysiologic conditions, these orderly processes of growth and differentiation become disturbed and may lead to hyperkeratotic skin disorders like ichthyosis, psoriasis and acne. These three main hyperkeratotic disorders, their current and future treatment options are introduced in Chapter 1.

Hyperkeratosis (aberrant scaling) is mostly the result of an abnormal cell turnover caused by changes in the keratinocyte life-cycle, which may or may not be immunemediated. The best known example is psoriasis, where hyperkeratosis is associated with aberrant differentiation and inflammation caused by the release of cytokines into the epidermis by keratinocytes and lymphocytes. Hyperkeratosis is also one of the factors involved in the pathogenesis of acne. The keratinocytes lining the inside of a hair follicle normally detach from the lining, attach to the growing hair and die, while converting themselves into corneocytes and forming the hair cuticle. In hyperkeratinization, a number of these cells convert too fast, clumping together instead of attaching to the cuticle. When such a clump of cells blocks the follicle exit, it contributes to acne. Genetic abnormalities in structural cytoskeleton proteins or in 
enzymes responsible for the formation of the cornified cell envelope or the metabolism of the intercellular lipids are among the main causes of keratinization disorders such as ichthyosis. These, however, are relatively rare.

All-trans-retinoic acid (all-trans-RA), the naturally occurring derivative of vitamin $\mathrm{A}$ is one of the principal endogenous compounds that controls growth and differentiation of epithelial tissue. Since the discovery that vitamin A-deficiency leads to keratinizing metaplasia and hyperkeratosis, numerous studies have focused on the metabolism and pharmacological action of 'retinoids' in the skin which has led to the establishment of retinoid treatment for various skin diseases like psoriasis, ichthyosis and acne. The retinoids comprises the natural and synthetic compounds that share structural and/or functional similarity with vitamin A.

Although very effective, the use of oral retinoids is hampered by systemic toxicity and topical retinoids have not been proved a successful alternative because of skin irritation. A different clinical approach to administering retinoids is to modulate the retinoic acid concentrations at the cellular level by using a Retinoic Acid Metabolism Blocking Agent or RAMBA. RAMBAs (e.g. liarozole, R115866) are compounds that block a cytochrome P450-dependent enzyme i.e. the retinoic acid 4-hydroxylase (CYP26) responsible for the intracellular catabolism of all-trans-RA in specific target cells. This targeted selective increase in all-trans-RA is expected to result in a good therapeutic effect and a better safety profile compared to oral retinoids. The main objective of this work is to answer the question whether RAMBAs, liarozole and R115866 in particular, could represent an effective and safer therapeutic approach for hyperkeratotic disorders like ichthyosis, psoriasis and acne.The history and the mechanism of action of both the retinoids and the RAMBAs are elaborated in Chapter 1.

Chapter 2 describes the effect of 3 generations RAMBAs (ketoconazole, liarozole and R115866) on cell proliferation and viability of 3 major skin cell types i.e. keratinocytes, fibroblasts and endothelial cells. The in vitro comparison points out a different sensitivity of the cell types towards the RAMBAs with the keratinocytes being the most sensitive. In the light of a future topical development, the effect of R115866 on cell viability and skin permeability has been studied in vitro using human reconstituted epidermis as an alternative for animal testing. R115866 is found to be devoid of enhancing the permeation of $\mathrm{H}^{3}$-water through reconstructed skin epidermis or inducing morphological changes, see Chapter 3.

Interest in liarozole, the first RAMBA once in clinical development in the nineties for psoriasis and ichthyosis, has today received a boost because of its orphan drug status for congenital ichthyosis in Europe and the US. A review of liarozole's in vivo pharmacology related to dermatology is presented in Chapter $\mathbf{4}$ whilst the next two chapters cover 
its clinical use in several ichthyosis subtypes (XRI, LI and CBIE). The short (10 weeks) and long-term ( 72 weeks) clinical efficacy and safety of topical liarozole $5 \%$ cream is described in Chapter 5. After a 4 weeks double-blind treatment versus placebo, a significant unilateral improvement in extent and severity of skin lesions was observed in favour of the liarozole-treated side. The lesions further improved during the following 6 weeks open phase and 72 weeks open maintenance phase. Clinical side effects were only minimal and the treatment was well tolerated. These clinical findings justify consideration of liarozole cream as a front-line treatment for ichthyosis.

The results of a 12 week double-blind comparative trial between oral liarozole and acitretin, the only drug approved today for the treatment of congenital ichthyosis are discussed in Chapter 6. The data suggest that oral liarozole at a daily dose of $150 \mathrm{mg}$ is equally effective as $35 \mathrm{mg}$ acitretin daily but shows a trend towards a more favourable tolerability profile. Both the number of adverse events and the incidence of hypertriglyceridaemia in this trial are lower in the liarozole than in the acitretin group; however a larger trial will be needed to show statistical significance.

The clinical use of retinoids and RAMBAs in psoriasis is reviewed in Chapter 7. Specific information on the pharmacology and pharmacokinetics of R115866, the most selective and specific RAMBA, is also provided here.

Chapter 8 discusses the results of an 8 week exploratory study with oral R115866, 1 mg daily in patients with moderate to severe plaque-type psoriasis. Of the complete cases, 38\% had at least PASI50 at end of treatment and 54\% at follow-up which is comparable to efficacy data found on acitretin, the preferred systemic retinoid in the treatment of psoriasis for more than 10 years. A treatment duration extending 8 weeks may be needed to achieve optimal clinical efficacy. The kinetic data from this study reveal no accumulation of R115866 and a rapidly clearance from the body once treatment is stopped (within hours) which could significantly minimize the 'safe time' to conceive as compared to acitretin ( 2 years in EU). Throughout the study, the increases in plasma all-trans-RA levels remain within physiological limits. The data from this study suggest that R115866 may be an effective and well tolerated treatment for plaque type psoriasis which warrants further investigation.

Chapter 9 presents a 12-week exploratory study with oral R115866, $1 \mathrm{mg}$ daily in patients with moderate to severe facial acne vulgaris. The data indicate that R115866 could not only be an effective but also a well tolerated treatment for this skin disorder with equally good effects on inflammatory and non-inflammatory lesions. A significant mean reduction in inflammatory lesions of $77.4 \%(\mathrm{p}<0.001)$, in non-inflammatory lesions of $58.3 \%(p<0.001)$, and in total lesion count of $76 \%(p<0.001)$ is observed at the end of treatment compared to baseline. This improvement is still pronounced 4 
weeks after the last drug intake. Although the series of patients is small, it is worth mentioning that the reported side effects are low in incidence and severity and no elevated blood triglyceride levels are reported as adverse event.General considerations and future perspectives related to the treatment of hyperkeratotic disorders with RAMBAs are dealt with in Chapter 10. 


\section{Samenvatting}

De buitenste lagen van de huid, de epidermis, vormen een mechanische barrière tussen onze interne organen en de omgeving waarin we leven. Ze biedt bescherming tegen pathogenen, irriterende producten en allergenen terwijl ze het waterverlies regelt. Wanneer de epidermis beschadigd wordt, komt de barrièrefunctie in gevaar wat kan leiden tot waterverlies, het binnendringen van kiemen en allergenen en uiteindelijk tot ontstekingen. Om er voor te zorgen dat de barrièrefunctie intact blijft, wordt de epidermis voortdurend vernieuwd op een zorgvuldig gereguleerde manier. Het is een gestratifieerd epithelium d.w.z. het is opgebouwd uit verschillende lagen cellen met name keratinocyten, die met elkaar verbonden zijn door eiwitbruggen of desmosomen. De onderste of basale laag bevat cellen die zich continu delen en zodoende de epidermis hernieuwen. Vanuit deze basale lagen schuiven de cellen op naar bovenliggende lagen waar ze differentiëren tot verhoornde cellen (corneocyten) en uiteindelijk afschilferen. Tijdens dit maturatie- of rijpings-proces verandert niet alleen de fysiologie en de chemische compositie maar ook de vorm en de oriëntatie van de keratinocyten.

Onder bepaalde patho-fysiologische condities kan dit netjes geordend proces van groei en differentiatie verstoord worden en leiden tot hyperkeratiniserende huidziekten zoals ichthyosis, psoriasis en acne. In hoofdstuk 1 worden deze 3 belangrijke hyperkeratotische huidziekten samen met hun huidige en toekomstige behandelingen geïntroduceerd. Hyperkeratinisatie (overmatige hoorn/schilfervorming), is meestal het gevolg van een abnormale celvernieuwing veroorzaakt door veranderingen in de levenscyclus van de keratinocyten, al dan niet gestuurd door het immuunsysteem. Het meest bekende voorbeeld hiervan is psoriasis waar de hyperkeratosis samengaat met een aberante proliferatie/differentiatie en inflammatie die veroorzaakt wordt door de vrijstelling van cytokines in de epidermis door keratinocyten en lymfocyten. Hoewel niet onmiddellijk zichtbaar is hyperkeratinisatie ook één van de factoren betrokken in de pathogenese van acne. In normale omstandigheden komen de keratinocyten die zich aan de binnenkant van de haarfollikel bevinden los, hechten zich vast aan het groeiende haar en sterven af. Bij 
hyperkeratinisatie komt een groot deel van deze keratinocyten te snel los en klitten ze samen tot een klompje. Hierdoor treedt er een vernauwing op van de follikels waardoor de afvloeiing van talg wordt belemmerd en de ontwikkeling van acne wordt bewerkstelligd. Genetische afwijkingen in structurele eiwitten van het cytoskelet of in enzymen verantwoordelijk voor de vorming van de cornified envelope of het metaboliseren van de intracellulaire vetten liggen aan de basis van keratinisatiestoornissen zoals de ichthyosis, die eerder zeldzaam zijn.

All-trans-vitamine A zuur, een natuurlijk derivaat van vitamine A, is één van de belangrijkste endogene moleculen verantwoordelijk voor de groei en differentiatie van epitheliale weefsels. Sinds de ontdekking dat een tekort aan vitamine A o.a. leidt tot hyperkeratinisatie is er heel wat onderzoek geweest naar het metabolisme en het farmacologisch effect van vitamine A in de huid. Dit heeft geleid tot het ontwikkelen van tal van retinoiden (= natuurlijke en synthetische stoffen die structureel en/of functioneel verwant zijn met vitamine A) voor de behandeling van verschillende huidziekten als ichthyosis, psoriasis and acne. Hoewel ze heel efficiënt werken is het gebruik van orale retinoïden beperkt door een aantal storende neveneffecten. Topische retinoïden zijn minder toxisch maar hebben dan weer het nadeel dat ze irriterend zijn waardoor ze tot op heden nog geen volwaardig alternatief kunnen bieden.

Een alternatieve aanpak om retinoïden toe te dienen is de concentratie van het natuurlijke vitamine A zuur binnenin de cellen te verhogen door gebruik te maken van een Retinoic Acid Metabolism Blocking Agent of RAMBA. RAMBAs, zoals liarozole en R115866, zijn chemische stoffen die een bepaald enzyme blokkeren nl. het vitamine A zuur-4-hydroxylase, een cytochroom P450 afhankelijk enzyme dat verantwoordelijk is voor de afbraak van het vitamine A zuur in bepaalde cellen van het lichaam. Door het endogene all-trans-vitamine A zuur op een doelgerichte en selectieve manier te verhogen wordt niet alleen een betere doeltreffendheid maar vooral een beter veiligheidsprofiel verwacht in vergelijking tot orale retinoïden. Het hoofddoel van dit werk is het beantwoorden van de vraag of de RAMBAs, en met name liarozole en R115866, niet alleen een doeltreffende maar ook een veilige behandeling zouden kunnen zijn voor hyperkeratotische huidziekten zoals ichthyosis, psoriasis en acne.

De geschiedenis van de ontwikkeling van de retinoïden en de RAMBAs alsook hun werkingsmechanisme is samengevat in hoofdstuk 1.

In hoofdstuk 2 wordt het effect van 3 generaties RAMBAs (ketoconazole, liarozole en R115866) beschreven op celproliferatie en celviabiliteit en dit in de 3 voornaamste huidceltypes nl. keratinocyten, fibroblasten en endotheelcellen. De in vitro resultaten tonen aan dat de verschillende celtypes een verschillende gevoeligheid hebben t.o.v. de RAMBAs waarbij de keratinocyten de meest gevoelige zijn. Gezien de toekomstige 
ontwikkeling van R115866 als een topische geneesmiddel werd in hoofdstuk 3 het effect op celviabiliteit en huidpermeabiliteit bestudeerd in vitro gebruikmakend van menselijk gereconstrueerde epidermis als alternatief voor dierproeven. R115866 blijkt noch de doorlaatbaarheid van getritieerd water doorheen gereconstrueerde epidermis te beïnvloeden noch een effect te hebben op de morfologie.

Liarozole, de eerste RAMBA ooit in klinische ontwikkeling voor de behandeling van psoriasis in de jaren negentig heeft vandaag terug alle aandacht wegens het verkrijgen van de status van weesgeneesmiddel voor congenitale ichthyosis, zowel in Europa als in de U.S. De in vivo farmacologie van liarozole met betrekking tot dermatologie is samengevat in hoofdstuk 4, terwijl de volgende 2 hoofdstukken het klinisch gebruik van liarozole bespreken in verschillende ichthyosis subtypes zoals XRI, LI en CBIE.

De klinische efficiëntie en veiligheid van topische liarozole crème zowel op korte (10 weken) als lange (72 weken) termijn wordt beschreven in hoofdstuk 5. Na een 4 weken dubbel-blinde behandeling met $5 \%$ liarozole crème vs. placebo is er een unilaterale significante verbetering te zien van de huidletsels aan de zijde behandeld met liarozole. De huidletsels verminderen verder tijdens de daaropvolgende 6 weken open en de 72 weken onderhoudsbehandeling met liarozole crème. De neveneffecten zijn minimaal en de behandeling wordt goed verdragen. De klinische data bemoedigen een verdere ontwikkeling van liarozole crème als eerstelijnsbehandeling voor ichthyosis.

Hoofdstuk 6 behandelt de resultaten van een dubbel blinde studie waar orale liarozole wordt vergeleken met acitretin, het enige goedgekeurde geneesmiddel voor de behandeling van congenitale ichthyosis. De data suggereren dat een behandeling van 12 weken met liarozole (150 mg per dag) even efficiënt is als acitretin (35 mg per dag) maar dat liarozole een beter veiligheidsprofiel vertoont. Zowel het aantal nevenwerkingen als het aantal keren dat bij patiënten hypertriglyceridemie optreedt is lager in de liarozole groep dan in de acitretin groep maar gezien het beperkt aantal patiënten kon geen statistische significantie worden aangetoond.

Hoofdstuk 7 geeft een overzicht van het klinisch gebruik van retinoïden en RAMBAs in psoriasis. In dit hoofdstuk wordt ook dieper ingegaan op de farmacologie en de farmakokinetiek van R115866, de meest selectieve en specifieke RAMBA op dit moment.

De resultaten van een exploratieve klinische studie met oraal R115866, $1 \mathrm{mg}$ per dag gedurende 8 weken in patiënten met moderate tot severe plaque psoriasis worden besproken in hoofdstuk 8. Achtendertig procent van de patiënten die de volledige studie hebben doorlopen zien een verbetering van hun PASI van minstens $50 \%$ op het einde van de behandeling (week 8). Bij follow-up (week 10) zijn het er 54\% wat vergelijkbaar is met de efficaciteitsdata van acitretin, sinds 10 jaar het meest gebruikte retino- 
id voor de behandeling van psoriasis. Een behandeling van meer dan 8 weken zal waarschijnlijk nodig zijn om een grotere doeltreffendheid te bekomen. De kinetische data in deze studie tonen aan dat er geen opstapeling is van R115866 en dat na de laatste inname de molecule heel snel (binnen enkele uren) uit het lichaam verwijderd is. Dit betekent dat de sperperiode om zwanger te worden enorm kan worden gereduceerd in vergelijking met acitretin (2 jaar in Europa). Tijdens de behandeling blijven de verhogingen van all-trans-vitamine A zuur spiegels in het plasma binnen de fysiologische grenzen. De data van deze studie suggereren dat R115866 een doeltreffende en goed verdraagbare behandeling zou kunnen zijn voor plaque psoriasis wat uitnodigt voor verder onderzoek.

In hoofdstuk 9 worden de resultaten voorgesteld van een 12 week durende exploratieve studie met oraal R115866, $1 \mathrm{mg}$ per dag in moderate to severe acne vulgaris in het aangezicht. R115866 blijkt niet alleen een doeltreffende maar ook een goed verdraagbare behandeling te zijn voor deze huidziekte. R115866 grijpt aan op zowel de inflammatoire als niet-inflammatoire letsels. Op het eind van de behandeling wordt ten opzichte van de baseline een gemiddelde reductie behaald van $77 \%(\mathrm{p}<0.001)$ op de inflammatoire letsels, van 58\% $(\mathrm{p}<0.001)$ op de niet inflammatoire letsels en van $76 \%(\mathrm{p}<0.001)$ op de som van alle letsels samen. Vier weken na de laatste inname van R115866 is deze reductie nog steeds aanwezig. Ondanks het feit dat het hier om een kleine patiëntengroep gaat is het toch noodzakelijk om er op te wijzen dat zowel het aantal als de intensiteit van de nevenwerkingen in deze studie heel laag is en dat er geen verhoogde triglyceriden als een nevenwerking zijn gerapporteerd.

De algemene bevindingen en de toekomstplannen met betrekking tot het behandelen van hyperkeratotische huidziekten met RAMBAs zijn samengevat in hoofdstuk 10. 


\section{Colour Figures}
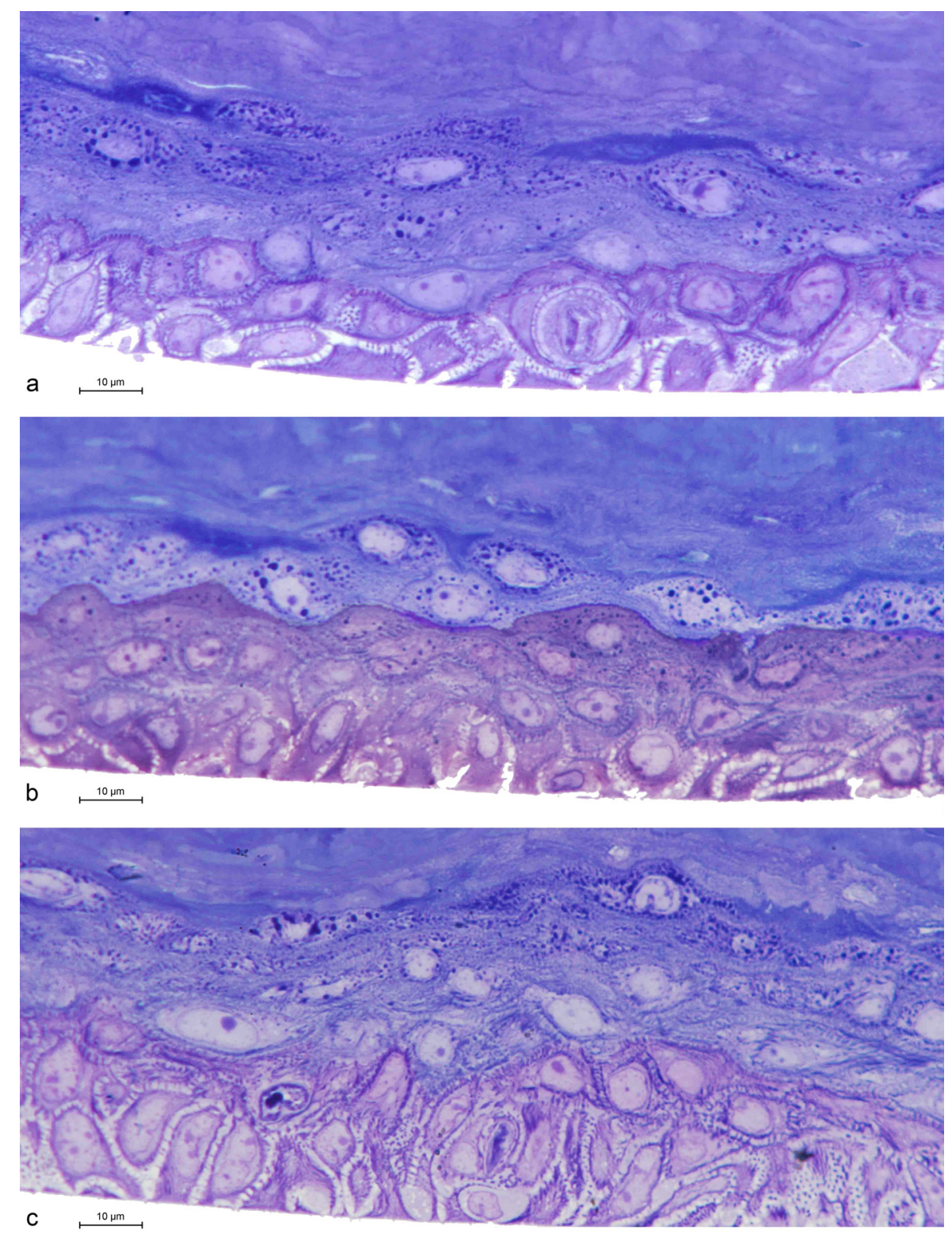

Figure 3.4 Light microscopical images of RHE treated with (a) Control (b) R115866, 10 $0^{-5} \mathrm{M}$ and (c) R116010, $10^{-5} \mathrm{M}$. 

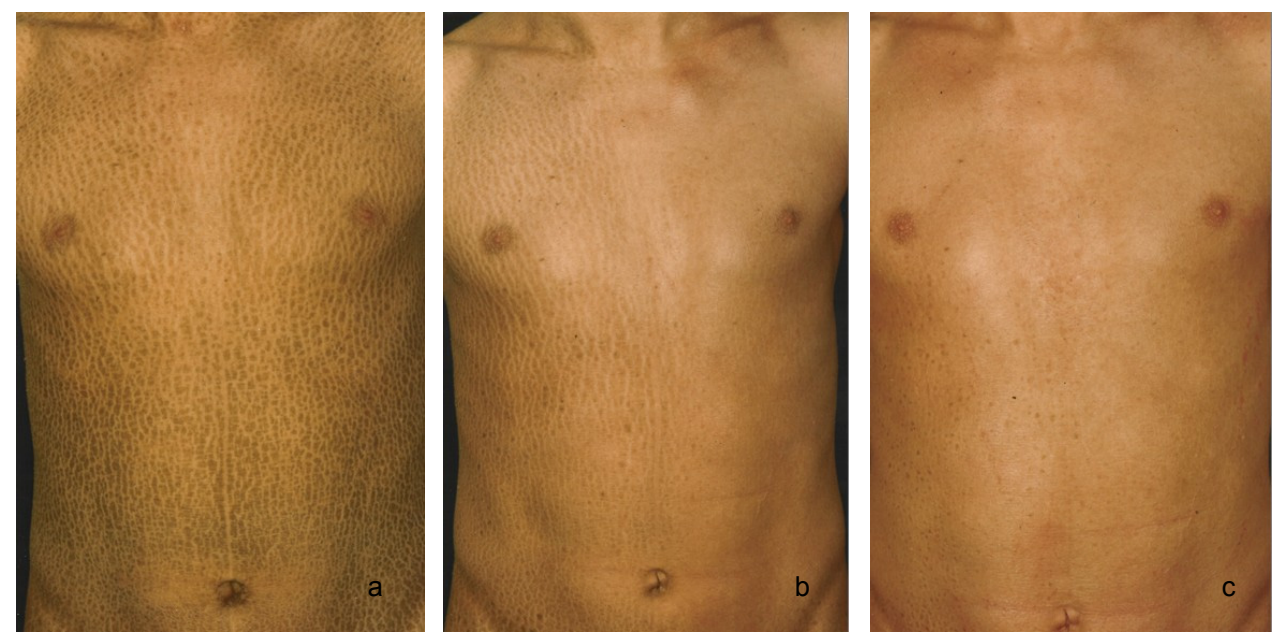

Figure 5.3 NELI patient: a) before treatment, exhibiting large brown scales covering a substantial part of the skin surface; b) at the end of the double-blind treatment, showing marked improvement at the liarozole treated side (left side of the person), whereas improvement at the cream-base treated side (right side of the person) is only small; c) after 6 weeks double-blind and 4 weeks open liarozole treatment, improvement is marked on both sides. At the previously cream-base treated right side, minimal scaling is still visible. 

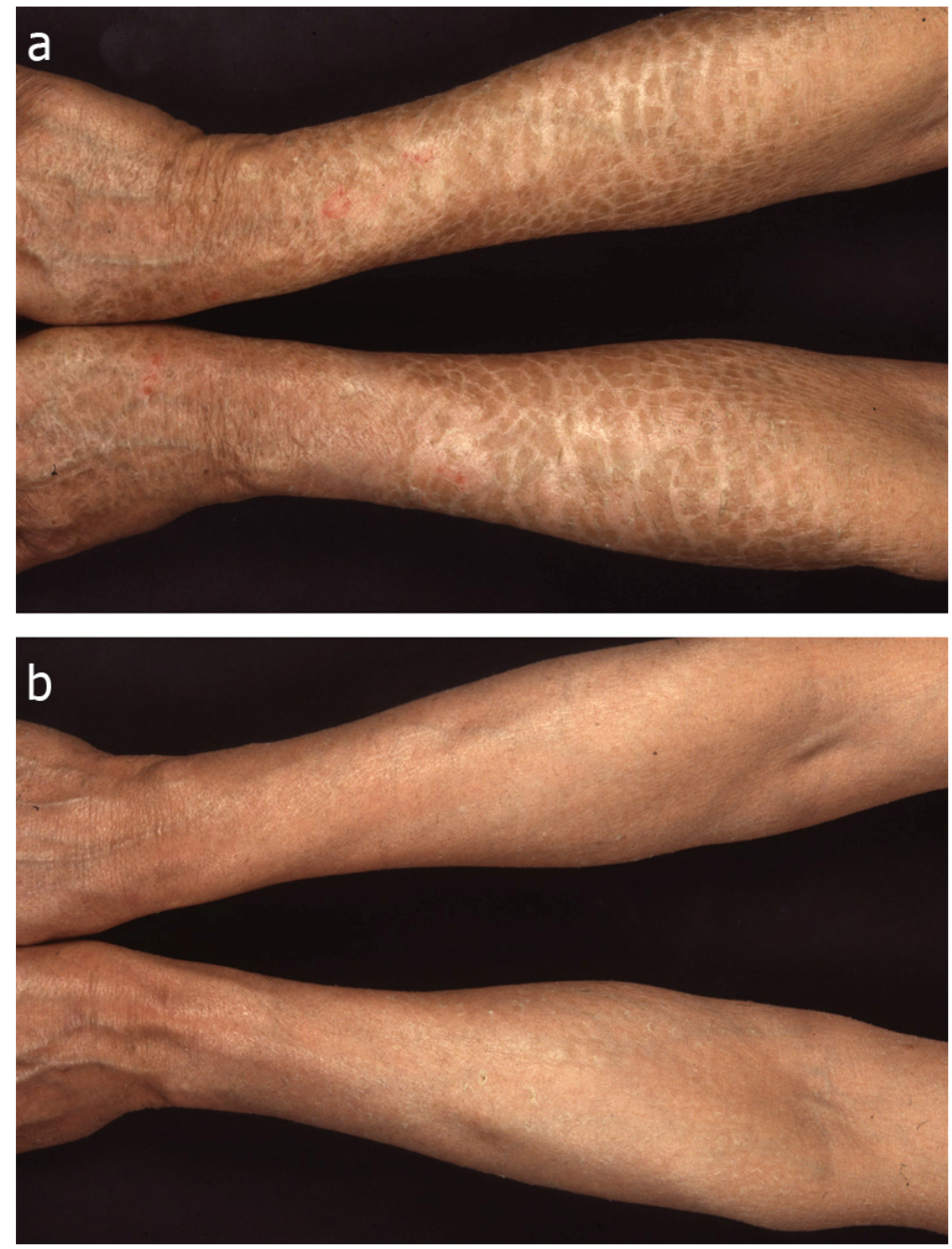

Figure 6.4 A patient with lamellar ichthyosis with the typical phenotype consisting of large brown scales covering the arm: (a) before treatment and (b) after 2 weeks of treatment with $75 \mathrm{mg}$ liarozole twice daily. 

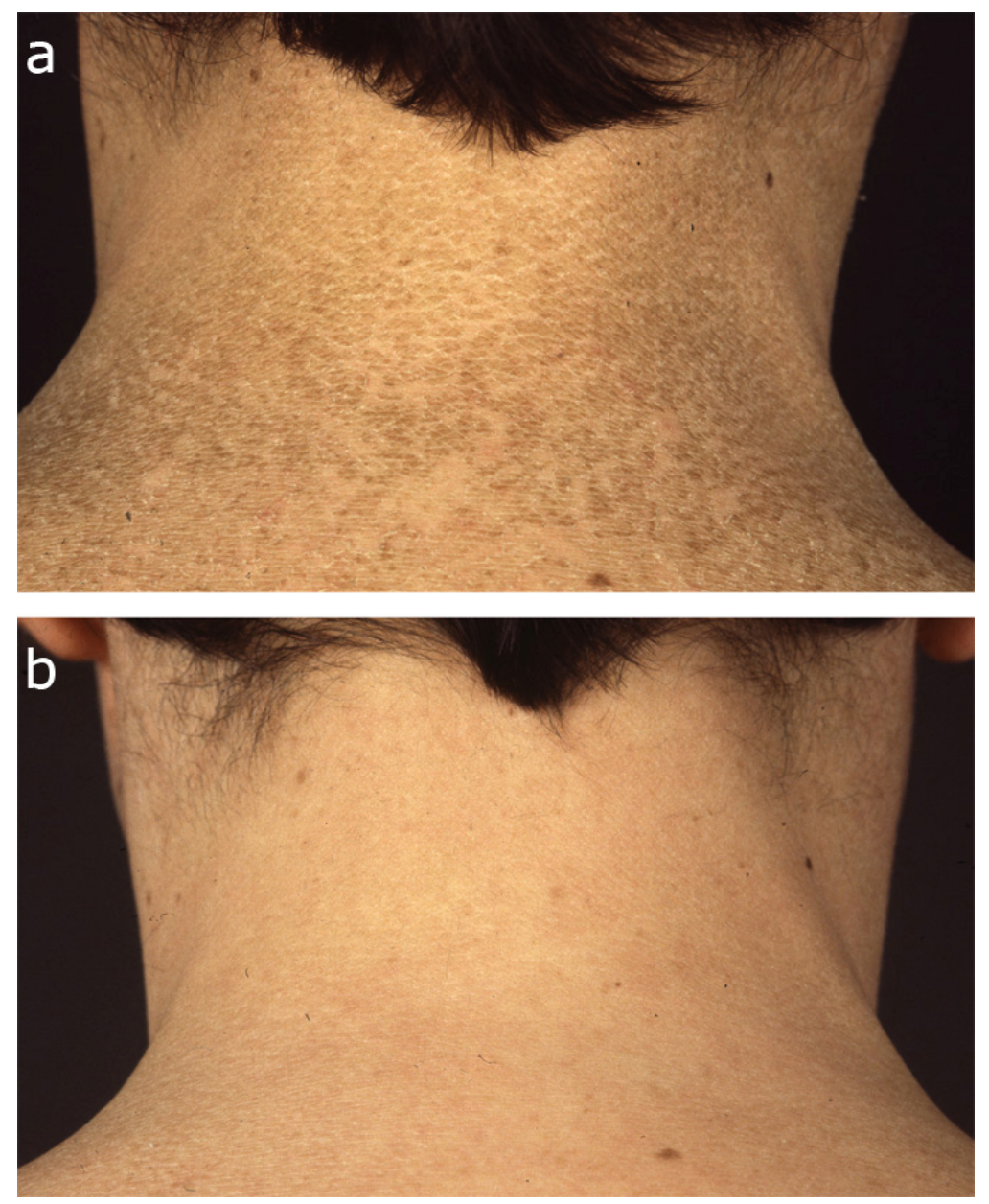

Figure 6.5 Typical hyperkeratosis in the neck of a patient with X-linked recessive ichthyosis which is giving the so-called 'dirty look' present before treatment with liarozole (a). Scaling is almost completely absent after treatment with liarozole (b). 

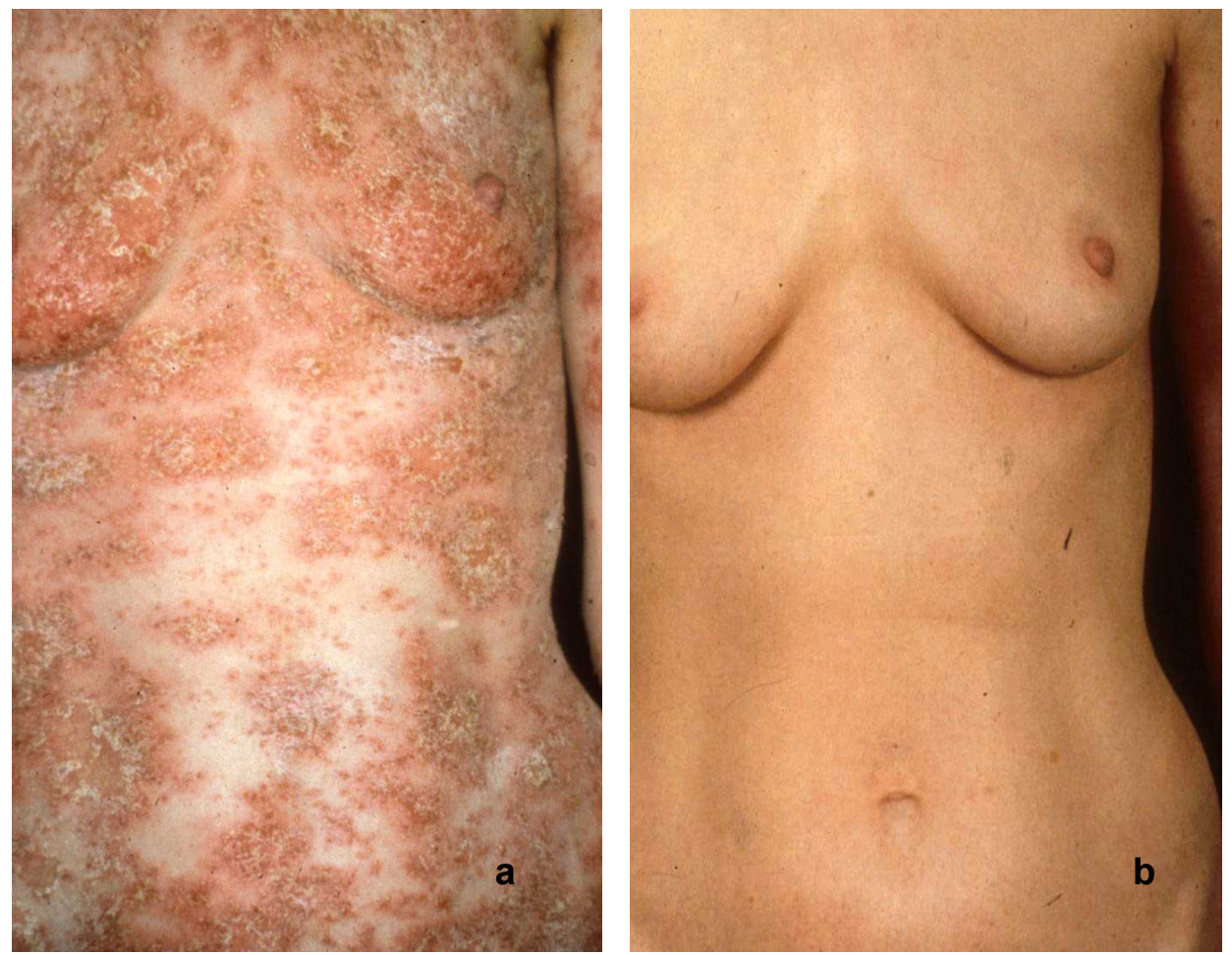

Figure 7.1 Clinical response to acitretin $(1 \mathrm{mg} / \mathrm{kg} /$ day $)$ in a patient with generalised pustular psoriasis (a) before and (b) after 4 weeks of treatment 


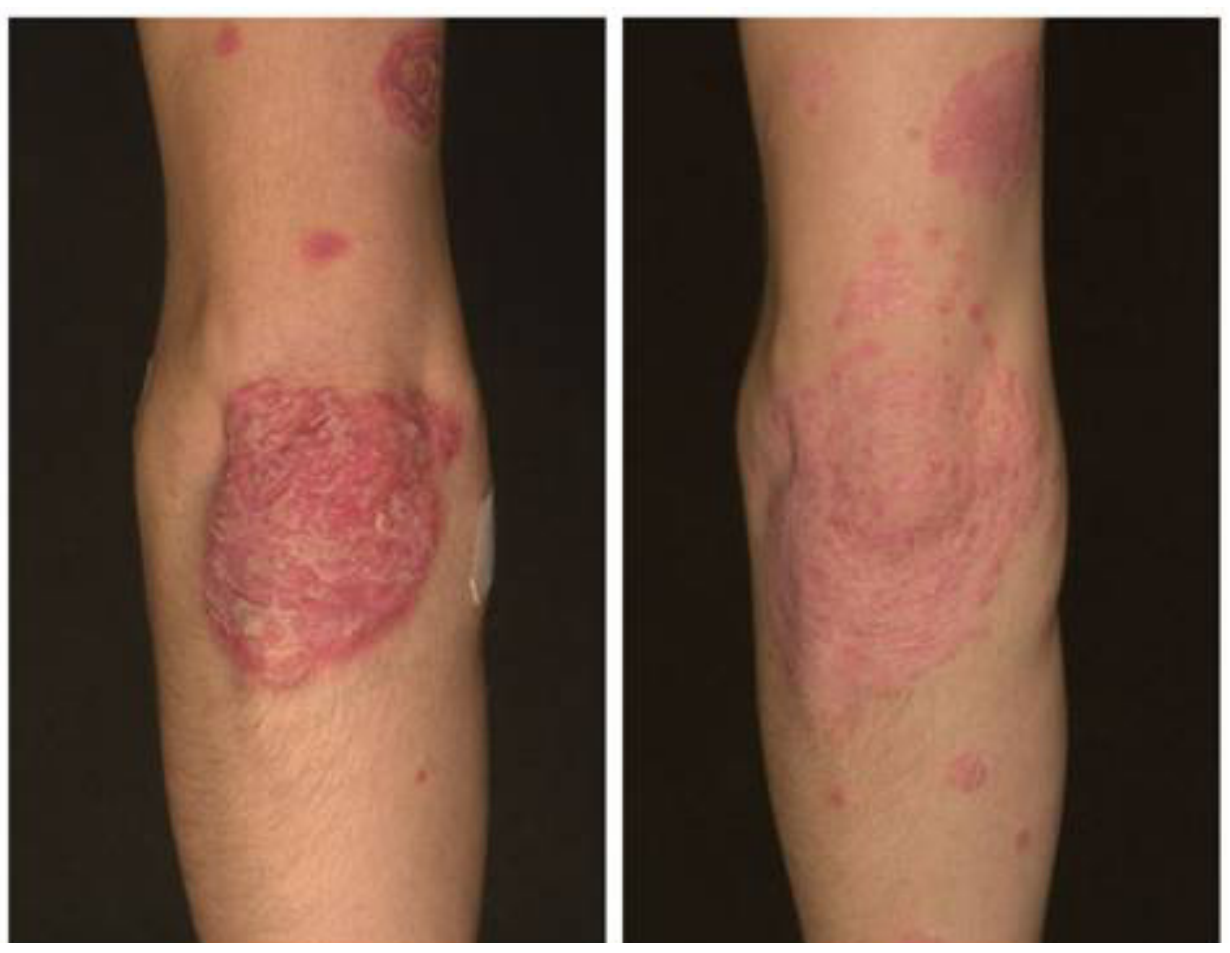

Figure 7.3 Clinical response to R115866 (1mg/ day) in a patient with moderate to severe plaque type psoriasis (a) before treatment and (b) after 10 weeks i.e. 8 week treatment +2 weeks treatment free follow-up. 

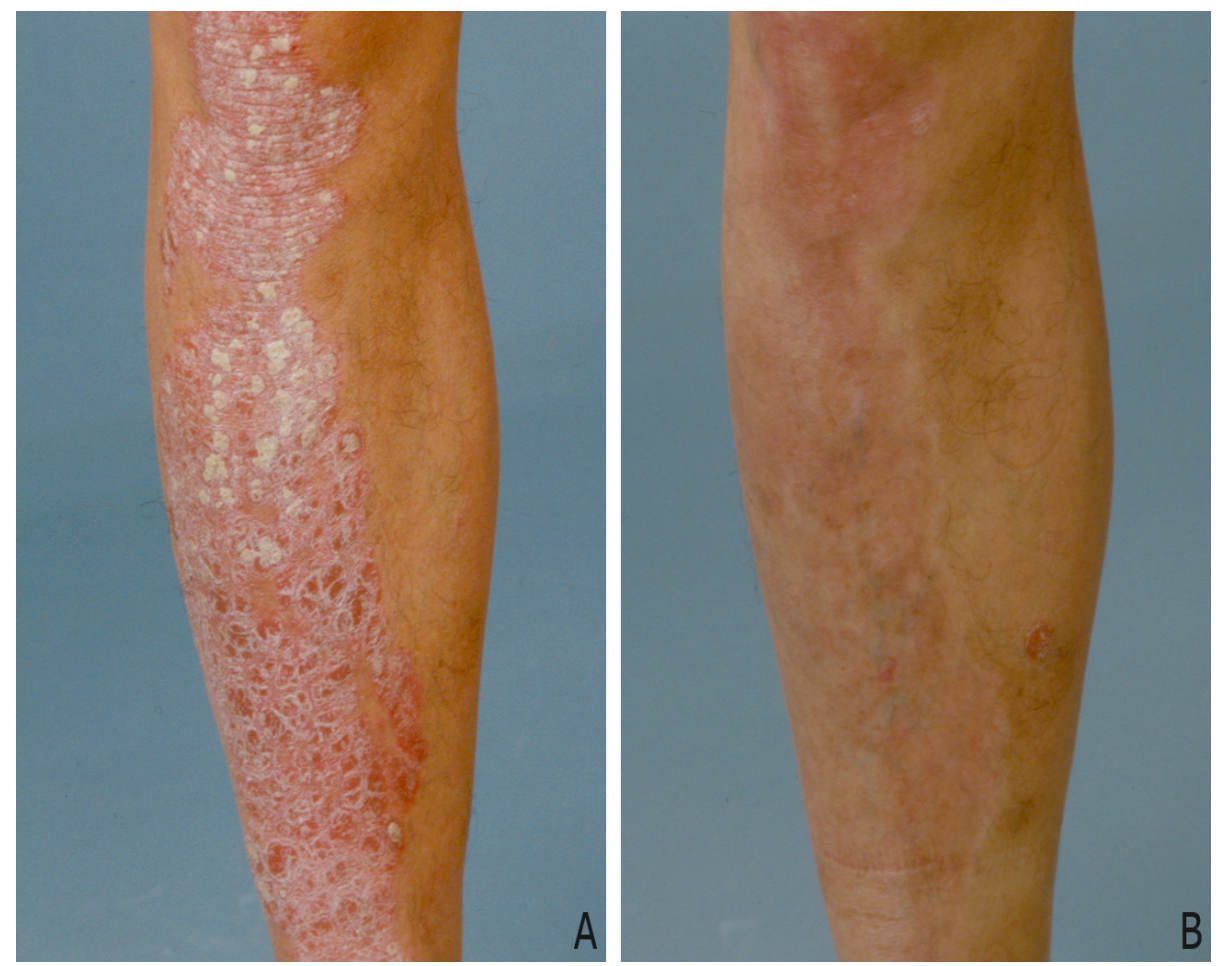

Figure 8.2 Plaque type psoriasis on lower leg of a patient (S206) before treatment (A) and after 8 weeks of treatment with $1 \mathrm{mg}$ R115866(B). 

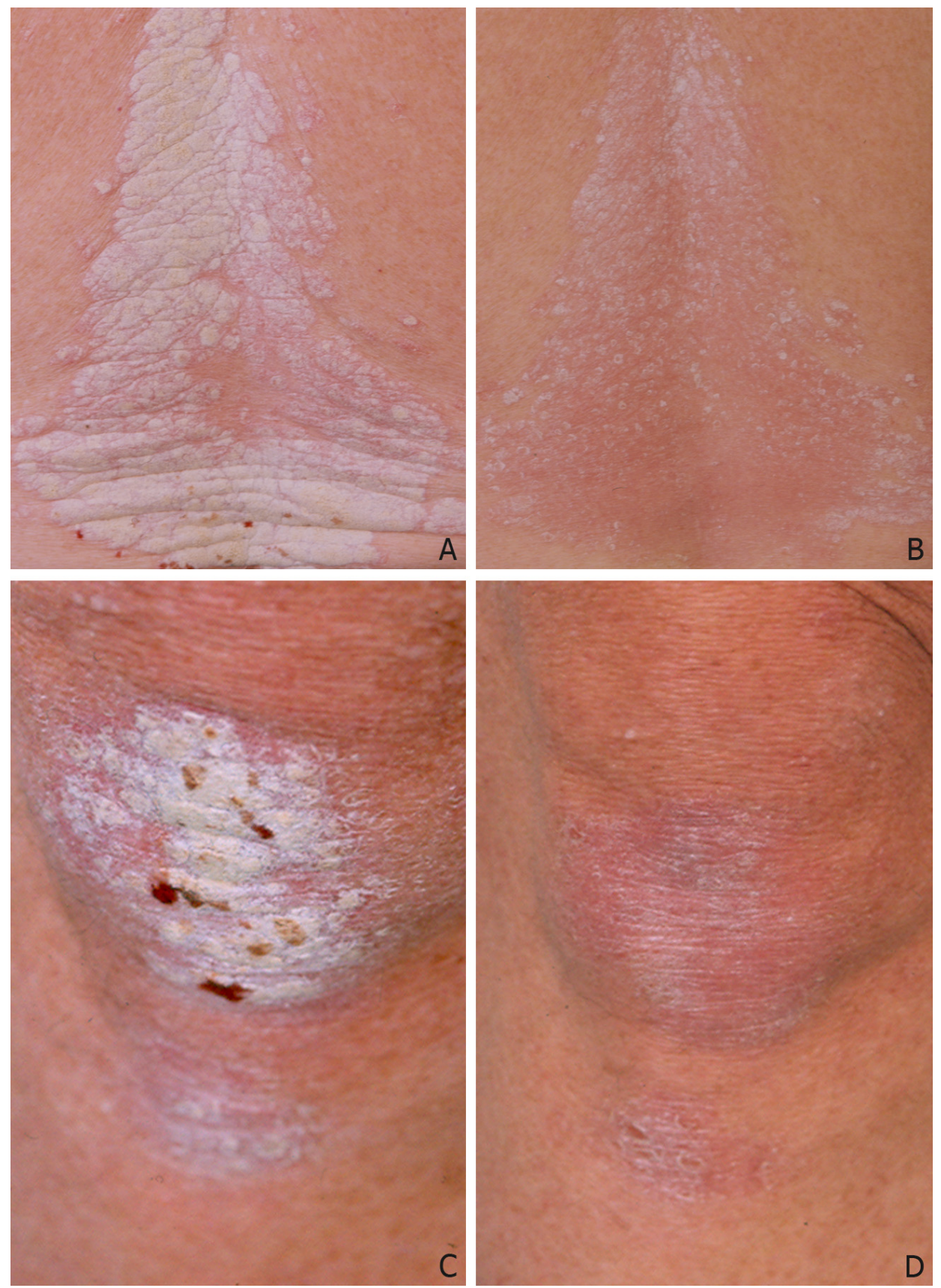

Figure 8.3 Plaque type psoriasis on back and knee of a patient (S226) at baseline (A and C) and after 8 weeks of treatment with $1 \mathrm{mg}$ R115866 (B and D). 

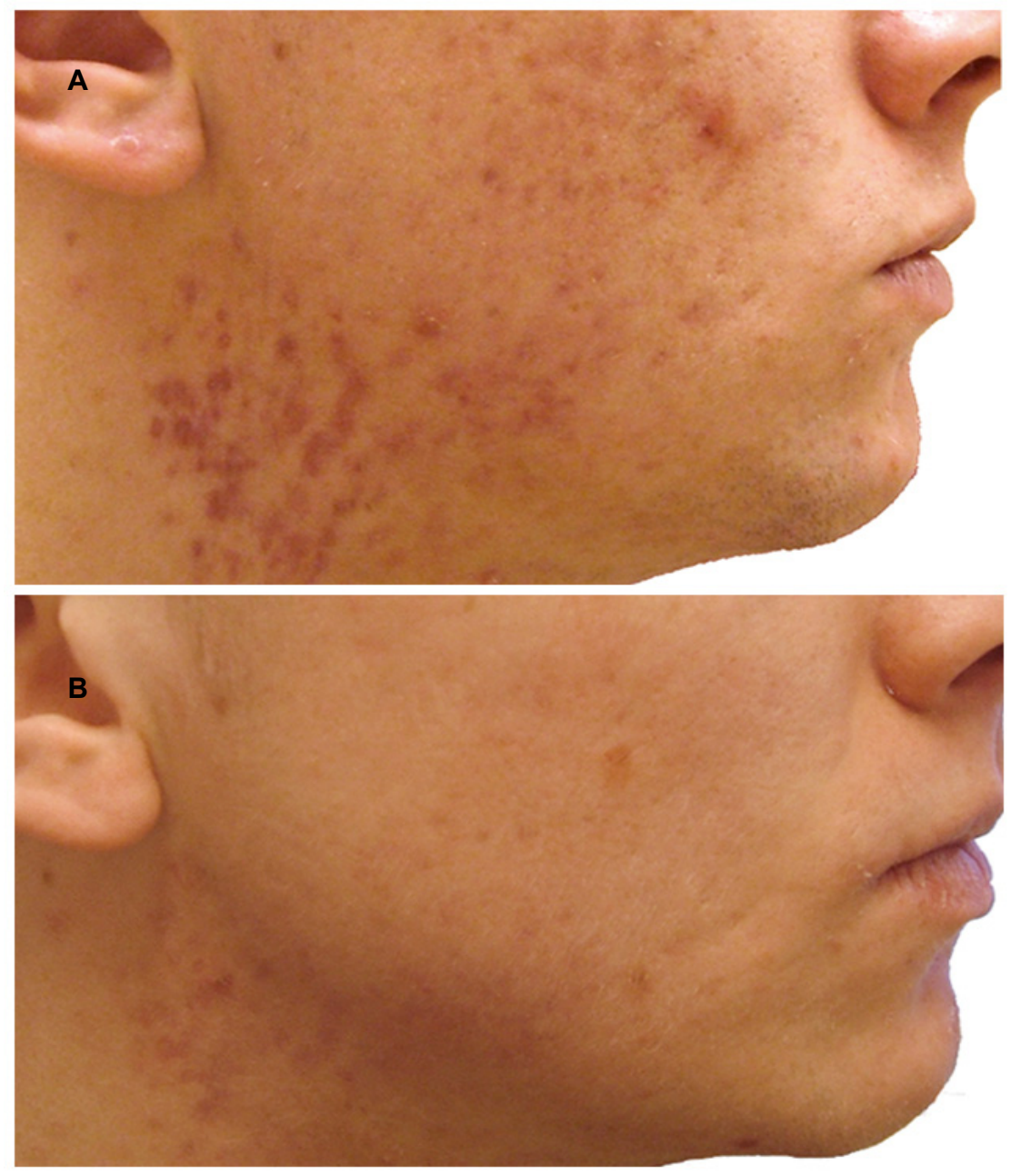

Figure 9.1 Healing of severe papular facial acne with some residual discolouring in the sub-mandibular area (A) before treatment and (B) after 12 weeks of treatment with 1mg R115866 daily. 

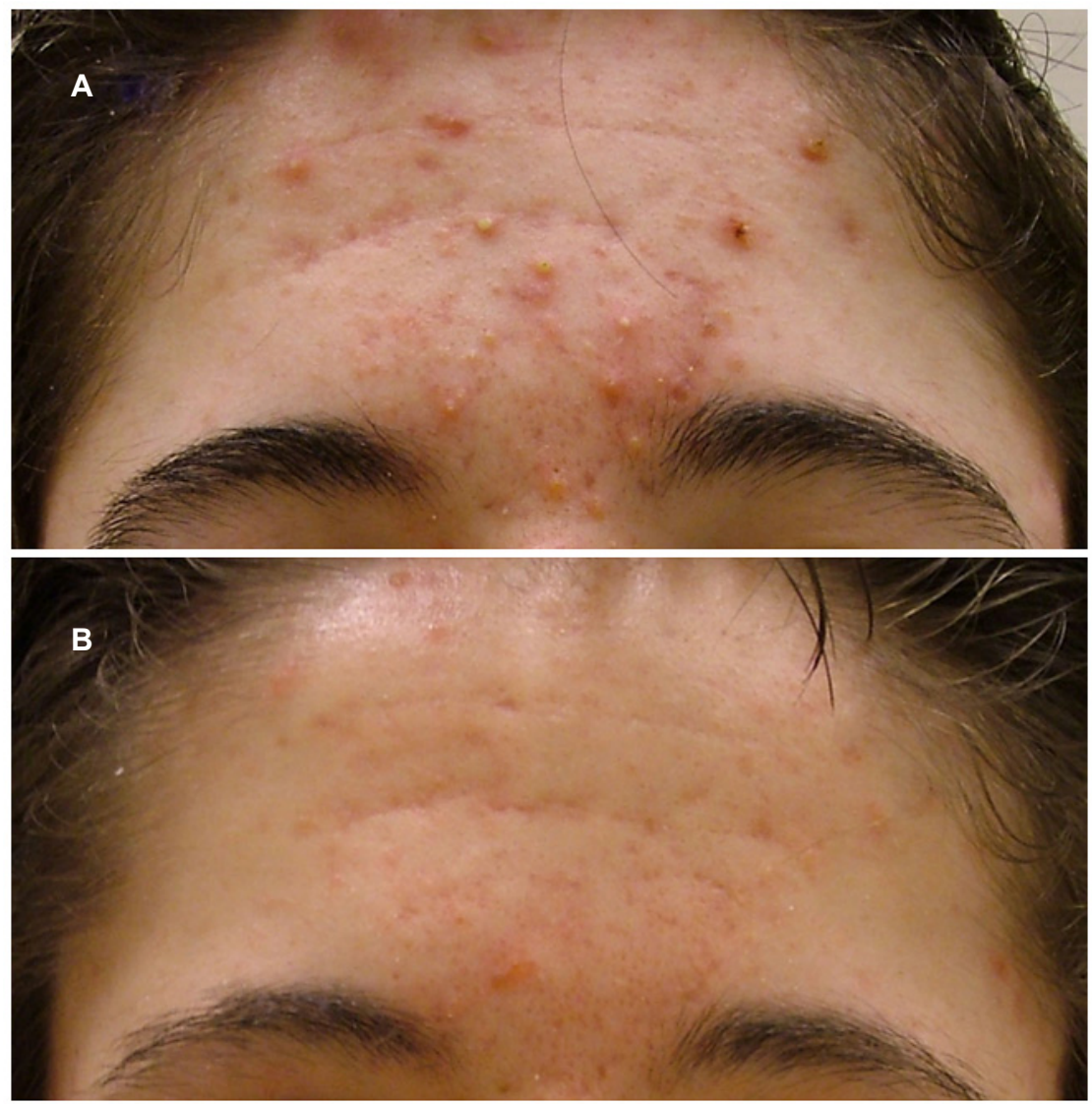

Figure 9.2 Case of moderate papulo-pustular acne almost completely cleared with minimal scarring after 12 weeks of treatment with $1 \mathrm{mg}$ R115866 daily: (A) before treatment, (B) after 12 weeks treatment. 


\section{Fiji Mermaid by Takeshi Yamada}

Takeshi Yamada, born in 1960, developed a fascination for the city's intricate culture and development as he grew up in Osaka, the third largest city in Japan. He moved to the United States when he was 23 years old, and lived in big cities such as Oakland, California; Baltimore, Maryland; Ann Arbor, Michigan; New Orleans, Louisiana; Chicago, Illinois and Brooklyn, NY, where he lives now. The similarities and differences among cities always fascinated him and therefore, he produced artworks based on what he saw, photographed, researched, interviewed and felt about the unique characteristics of cities, such as the city's physical, social, material, architectural and cultural development and people including their origin, evolution, costumes, beliefs, folkways, etc. in comparison to other cities. In this sense, he regards himself as a "Visual Anthropologist". With these unique artworks, as one of the most active and respected visual artists in America, he had over 350 fine art exhibitions including 40 solo art exhibitions internationally including Spain, The Netherlands, Japan and the United States.

His current series of super-realism artworks entitled "Museum of World Wonders: Coney Island Sideshow and Cabinet of Curiosities" reflect his investigation of the unique and distinctive culture where he lives in the Coney Island area of Brooklyn, NY. This special culture is called Coney Island Circus Sideshow. His series of artworks are simulations and re-interpretations of this rapidly disappearing unique and distinctive form of modern American pop culture, which originated and blossomed in Coney Island when Steeple Chase Park opened in 1879. He was particularly inspired by the series of artworks on display at the circus sideshow tents, which are called "gaffs". "Gaffs" are man-made objects simulating artifacts of wonder and oddities (some are completely fictional, such as "Fiji Mermaid" and "Jackalope"), with details great enough to fool the eyes and mind of the audience. His Circus Sideshow Gaffs celebrate the curiosity and passion of humanity, which never ceases to seek things of mystery and wonder of the universe. With these in mind, he created over 500 one-of-a-kind gaffs including Chupacabra, Fiji Mermaids, Giant Sea Serpents, Two-Headed Babies, Shrunken Human Head, Fossilized Fairies, Nuclear Radiation Giant Stag Beetles, Hairy Trout, King Piranhas, Mongolian Giant Death Worms, Two-headed Snakes, Four-legged Turkeys, Giant Vampire Bats, Chinese Flesh-Eating Mushrooms, Two-headed and Six-fingered 
Alchemist, artifacts of the Dreamland Fire of 1911 in Coney Island, relics of ancient civilizations, and alien artifacts/specimens collected by the Area 51 US Military Base, among others. Some of his gaffs reflect his investigation of today's technologies, and they are created with a digital camera, computer and photo-quality 7-color printer.

Takeshi Yamada regards his artworks as a "Visual Encyclopedia" equipped with a comprehensive description of each artwork, documentations and cross-cultural anthropological research behind them. It is his hope that his artworks are vehicles to please the eyes, uplift the spirit, stir the imagination and express conviction. It is his desire to promote a greater understanding and appreciation of the importance of the global nature of the world, its people and the bonds that mutually bind them. It is his sincere wish that his creativity and its products contribute to the advancement of the glorious culture based on the sanctity of life and true humanism.

Traditionally, a mermaid is a legendary/mythological creature with a female human head and torso and the tail of a fish, which inhabits the water. If it's male, it's called a merman. From the dawn of the humanity, across the world, sightings of mermaids are reported and documented. In Japan, Ningyo (人魚, human-fish) is an animal with tophalf is human and bottom-half is a fish. Ningyo can be male or female. There are many stories, legends, and mythologies of mermaids associated with Buddhism and Shintoism in Japan. There are many stories of mermaids helping or saving people. Some of the mummified mermaids are also enshrined at Buddhism temples as divine deity. Ningyo shinko (religion of mermaid) can be found many cities in Japan. The oldest record of mermaid in Japan is dated 619 AD in Nihonshoki (Historical Record of Japan) at the time of Suiko Emperor. Kuinji Temple in Fukui Prefecture is said to be the place of death of a woman (Buddhist nun called Yaobikuni, in her later life) who lived 800 years after eating the flesh of a mermaid, which was thought to have wondrous properties that could bring about immortality. Incidentally, a Japanese anime about this magical power of mermaid's flesh was recently released in America (bi-lingual format). It is entitled "Mermaid Forest: Quest for Death". It is a story of a boy who ate the flesh of mermaid became immortal, and lost being alone because people around him grow old and die one after another. He started his journey to find another mermaid, hoping to get her help to become mortal again.

In 2004, Takeshi Yamada created a three-dimensional life-like life-size super realistic large mermaid (49x12x8 inch). Part of the Fiji Mermaid is presented on the cover of this work. For Yamada, the mummified mermaid is the ultimate expression of humanity's curious mind to seek out mysteries and wonders of the universe.

More information of Takeshi Yamada and his artwork can be found on the web at http://sideshowworld.com/SSA-15.html 


\section{Dankwoord}

Na mijn afstudeerstage op de Life Sciences, Janssen Research Foundation, België, nu bijna 14 jaar geleden, werd mij door Prof. M. Borgers gevraagd of ik als AIO aan de Universiteit Maastricht nog enkele jaren verder wou studeren. Ik vond het een geweldig idee maar om allerhande redenen heb ik na veel twijfelen het aanbod afgeslagen. Er werd mij o.a. een boeiende job aangeboden binnen de Janssen Research Foundation op de afdeling neuropsychofarmacologie. Het omvatte vooral basisonderzoek, een combinatie van electrofysiologie en moleculaire biologie. Ondanks dat het onderzoek ontzettend gevarieerd was met veel interne en externe samenwerking en ik heel leuke collega's had, was ik toch niet helemaal tevreden. Door de vele contacten met $\mathrm{PhD}$ studenten werd ik er mij van bewust dat er diep van binnen nog een sluimerend verlangen zat om een $\mathrm{PhD}$ te halen.

Uiteindelijk werd de stap gezet, opnieuw gestimuleerd door Prof. M. Borgers, mijn promotor. Marcel, jij hebt van in het begin af aan in mij geloofd en nooit opgegeven. Bedankt voor dit jarenlange vertrouwen, voor je hulp en voor alles wat je mij hebt geleerd. Samen met Prof. Frans Ramaekers en Prof. Peter Steijlen, eveneens mijn promotoren, heb je er voor gezorgd dat ik de kans kreeg om te promoveren aan de Universiteit Maastricht. Frans en Peter, bedankt voor de begeleiding, het wetenschappelijk advies en het vertrouwen. Jullie hebben steeds moeite gedaan om mij zoveel mogelijk te betrekken bij het universitair gebeuren en mij te integreren in jullie beide vakgroepen waardoor ik steeds het gevoel had een interne AIO te zijn. Ik was altijd welkom en kon steeds op alle hulp en advies rekenen. Ook Dr. Maurice van Steensel, mijn copromotor heeft hiertoe bijgedragen. Maurice, bedankt voor jouw begeleiding, voor het kritisch doornemen van de manuscripten en voor je vriendschap. Het was altijd leuk en interessant te brainstormen over wetenschappelijke experimenten en nieuwe proof-ofconcept studies met de RAMBAs. Samen met Peter heb je mij als 'niet dermatoloog' ingeleid in de wereld van de geno-dermatologie en mijn interesse hiervoor aangewakkerd. Beste Frans, jou wil ik samen met Francine Teng nog even speciaal bedanken voor 
de organisatorische basis zoals het plannen en modereren van de meetings, bijhouden van timelines, de brieven en voor zoveel meer... Thank you for watching over me!

Marcel, jij hebt mij eveneens voorgesteld aan Dr. Geert Cauwenbergh waardoor ik de kans kreeg dit werk te voltooien binnen Barrier Therapeutics waarvoor mijn blijvende erkentelijkheid. Het was niet alleen een grote maar vooral een zeer boeiende uitdaging: een nieuwe job, een $\mathrm{PhD}$, de overstap van hersenen naar huid en van preklinisch naar klinisch onderzoek, een start-up bedrijf,... Het was heel druk, heel spannend maar ontzettend leerrijk. Jullie onuitputtelijk enthousiasme, positieve instelling, kennis en bruisende ideeën werkten ongelooflijk stimulerend. Jullie passie voor de RAMBAs was heel besmettelijk. Geert en Marcel, bedankt voor deze unieke ervaring!

Ook Nicole Eyben wil ik bedanken want zonder haar vertrouwen, haar hulp en steun zou dit boekje er ook niet geweest zijn. Nicole, bedankt!

Verder wil ik iedereen die op welke wijze dan ook heeft bijgedragen aan de totstandkoming van dit boekje bedanken. De leden van de beoordelingscommissie Prof. Dr. J.P.M. Geraedts, Prof. Dr. M.J.A.P. Daemen, Prof. Dr. H. Degreef, Prof. Dr. A.P. Oranje en Prof. Dr. H. van Loveren voor het kritisch doornemen van dit proefschrift.

Al mijn collega's bij Barrier Therapeutics voor het team-work, de wetenschappelijke discussies, de input, etc....maar vooral voor het begrip, de leuke momenten en de morele steun. In het bijzonder wil ik een woord van dank richten tot Kim Franssen en Dr. Paul Stoppie voor de hulp bij het preklinische werk en verder tot Johan Mertens, Luc Wouters, Dr. Paul Stoppie, Dr. Marina Cools en Dr. Koen van Rossem voor de input bij de klinische studies en publicaties rond R115866. Dr. Lieve Vandeplassche wil ik bedanken voor de begeleiding, de liarozole discussies, het kritisch doorlezen van de manuscripten maar ook voor de steun. Lieve, jij hebt mij heel veel bijgebracht op vlak van klinisch onderzoek, dank u wel! Dr. Geert Van Minnebruggen wil ik bedanken voor het overnemen van mijn werk tijdens deze laatste dagen, bedankt Geert.

Alle dermatologen, hun medische teams en de patiënten die hebben meegewerkt aan de klinische studies. Dank aan Dr. C. Blanchet-Bardon, Dr. I. Boersma, Dr. H.J. Bovenschen, Dr. M. Coel, Dr. J.P. Hachem, Dr. G.P.H. Lucker, Prof. Dr. D. Roseeuw, Prof. Dr. P.C.M. van de Kerkhof, Dr. M.A.M van Steensel, Prof. Dr. P.M. Steijlen en Dr. C.A. Thissen voor de goeie en leuke samenwerking. Bedankt voor de leerrijke protocolbesprekingen, jullie advies en het kritisch nalezen van de manuscripten.

Alle medewerkers van de vakgroep Moleculaire Celbiologie en Dermatologie van de Universiteit Maastricht en de medewerkers van Maia Scientific. In het bijzonder Francine, Marie-Hélène, Mieke, Fons, Ronald, Myriam, Michel, Valerie, Reno, Bieke, Marc, Luc en Johan: bedankt voor jullie gastvrijheid, voor het wetenschappelijk advies, de samenwerking in het lab en vooral voor jullie vriendschap. 
Alle excollega's bij Johnson \& Johnson Pharmaceutical Research and Development alsook iedereen die heeft bijgedragen tot mijn wetenschappelijke ontwikkeling en tot de ontwikkeling van de RAMBAs.

David Borgers voor de grafische hulp bij het maken van de posters en manuscripten.

Datawyse voor het drukken van dit boekje and I would like to thank Mr. Yamada Takeshi for allowing the use of his copyrighted picture of the beautiful Fiji Mermaid on the cover of my thesis.

Mijn paranimfen: Kim Franssen en Leen Raeymaekers, jullie weten wel waarom ik jullie persé aan mijn zijde wilde! Thanks!

Mijn ouders, broer en zussen, familie, schoonfamilie en vrienden voor hun liefde, morele steun en interesse. Ik beloof dat ik vanaf nu terug wat meer tijd voor jullie zal vrijmaken! Ik heb jullie vaak gemist! Uit het oog betekent niet uit het hart!

Frank, dat geldt ook voor jou want je hebt veel tijd zonder mij moeten doorbrengen wat niet altijd gemakkelijk was. Dankzij jou en dankzij onze vele rondreizen in Afrika en Latijns-Amerika heb ik geleerd te relativeren en te beseffen dat het leven mild voor mij is geweest en nog steeds is, bedankt.

\section{Christel}





\section{Curriculum Vitae}

Christel J. Verfaille werd geboren in Menen, België op 19 maart 1969. Nadat zij haar diploma van algemeen secundair onderwijs in de richting Latijn-Wetenschappen behaalde aan het Sint-Aloysiuscollege in Menen is ze naar Gent getrokken waar ze aan de Hogelschool Sint-Lieven de opleiding Farmaceutische en Biologische Technieken heeft gevolgd. De 6 maand-durende praktijkstage horende bij deze opleiding heeft ze volbracht op de afdeling Eiwitzuivering, Innogenetics N.V. in België waar ze de zuivering van recombinant humaan keratinocyt groei factor m.b.v. metaalaffiniteitschromatography heeft geoptimaliseerd. In datzelfde jaar vervolgde zij haar studie aan de Hogeschool West-Brabant in Nederland waar ze in 1993 afstudeerde met grootste onderscheiding als medisch ingenieur. Het daarbij horende afstudeerproject "Morfologische karakterisatie van gastro-intestinale motiliteitsstoornissen." heeft ze volbracht op de afdeling Life Sciences van de Janssen Research Foundation, Beerse, België .

Christel begon haar professionele carrière in oktober 1993 bij Johnson and Johnson Pharmaceutical Research and Development, een afdeling van Janssen Pharmaceutica nv, Beerse, België waar ze gedurende 9 jaar heeft gewerkt op de afdeling CNS. De eerste 7 jaar (1993-2000) was ze betrokken bij verschillende basisresearch projecten, ook buiten CNS. Ze heeft zich voornamelijk toelegd op de expressieklonering van receptoren en ionenkanalen in Xenopus laevis oocyten gebruik makend van de '2electrode voltage clamp' techniek en ontwikkelde een expertise in electrofysiologie and moleculaire biologie. Van 2000-2002 werkte ze aan projecten rond neurodegeneratie, stress en depressie en verbreedde ze haar expertise in diermodellen, morfologie (neuropathologie en neurodegeneratieve processen), histologie, immunohistochemie en receptorbinding-autoradiografie.

Sinds augustus 2002 is Christel werkzaam bij Barrier Therapeutics, een jong farmaceutisch bedrijf dat zich toespitst op de ontwikkeling van geneesmiddelen voor de dermatologie. Als project director heeft ze zich de voorbije jaren toegelegd op zowel de preklinische als klinische ontwikkeling van de Retinoic Acid Metabolism Blocking Agents (RAMBAs) met name liarozole en R115866. Naast haar job was Christel vanaf augus- 
tus 2002 tot november 2006 aangesteld als externe Assistent in Opleiding aan de afdelingen moleculaire celbiologie en dermatologie van de universiteit Maastricht o.l.v. Prof. M. Borgers, Prof. F.C. Ramaekers en Prof. P.M. Steijlen. Een deel van haar werk met de RAMBAs, wat volledig werd gefinancieerd door Barrier Therapeutics, vormt het onderwerp van deze $\mathrm{PhD}$ thesis.

Door de jaren heen heeft ze verschillende studenten opgeleid en begeleid en heeft ze deelgenomen aan menig nationale en internationale congressen. 


\section{About the author}

Christel J Verfaille was born in Menen, Belgium on March 19 $9^{\text {th }} 1969$. After completing her secondary school (Latin-Sciences) at the Sint-Aloysius College in Menen she went to Ghent where she obtained a Bachelors degree in Pharmaceutical and Biological Techniques at the Hogeschool St. Lieven. She received practical training at the department of Protein Purification, Innogenetics $n v$, Belgium where she optimized the purification of recombinant human Keratinocyte Growth Factor using metal-affinitychromatography. She continued her education in the Netherlands at the Hogeschool West-Brabant where she graduated in 1993 as an engineer in Medical Sciences. She completed a 6-month practical training at the department of Life Sciences, Janssen Research Foundation focussing on the morphological characterisation of gastrointestinal disorders.

Christel started her professional carrier in October 1993 at the department of CNS, Johnson and Johnson Pharmaceutical Research and Development, a division of Janssen Pharmaceutica $n v$, Beerse, Belgium where she worked for 9 years. The first 7 years (1993-2000) she was involved in various basic research projects (also outside the CNS field) focusing on the 'Expression cloning of receptors and ionchannels in Xenopus laevis oocytes using the 2-electrode voltage clamp technique'. During that time she developed an expertise in electrophysiology and molecular biology.

From 2000-2002, she worked on projects in the field of neurodegeneration, stress and depression and gained expertise in animal models, morphology (neuropathologyneurodegeneration processes), histology, immunohistochemistry and receptorbindingautoradiography.

Since august 2002, she joined Barrier Therapeutics, a young pharmaceutical company that develops and commercializes products in the field of dermatology. There she was appointed project director focussing on the preclinical and clinical development of the Retinoic Acid Metabolism Blocking Agents (RAMBAs) e.g. liarozole and R115866. Next to her job, she worked as an external PhD student from August 2002 till November 2006 at the departments of Molecular Cell Biology and Dermatology at the University of Maastricht under the supervision of Prof. M. Borgers, Prof. F.C. Ramaekers and Prof. P.M. Steijlen. Part of her work on the RAMBAs, which has been financially supported by Barrier Therapeutics, formed the basis of her research project which resulted in this thesis.

Over the years she trained and supervised undergraduate/graduate students and attended national and international meetings. 


\section{Publications}

\section{Papers}

Paulussen A, Yang P, Pangalos M, Verhasselt P, Marrannes R, Verfaille C, Vandenberk I, Crabbe R, Konings F, Luyten W, Armstrong M. Analysis of the Human KCNH2(HERG) Gene : Identification and Characterisation of a Novel Mutation Y667X Associated with Long QT Syndrome and a Non-Pathological 9bp Insertion. Hum Mutat 2000; 15: 483.

Lucker G, Verfaille CJ, Heremans A, Vanhoutte F, Boegheim J, Steijlen P. Topical liarozole in ichthyosis: a double-blind, left-right comparative study followed by a longterm open maintenance study. Br J Dermatol 2005; 152: 566-9.

Verfaille CJ, Bols L, Borgers M, Franssen K, Govaerts B, Moeremans M, Stoppie P, Geysen J. Analyse comparative de l'activité de 3 générations d'agents inhibiteurs du métabolisme de l'acide rétinoïque dans des cultures de kératinocytes épidermiques humains normaux. Actualités en Ingeniérie Cutanée 2006; 4: 287-9.

Verfaille CJ, Vanhoutte FP, Blanchet-Bardon C, van Steensel MAM, Steijlen PM. Oral liarozole versus acitretin in the treatment of ichthyosis: A phase II/III multicentre, double-blind, randomized, active-controlled study. $\mathrm{Br} J$ Dermatol 2007; DOI 10.1111/j.1365-2133.2006.07745.x.

Verfaille CJ, Thissen CACB, Bovenschen JH, Mertens J, Steijlen PM, van de Kerkhof PCM. Oral R115866 in the treatment of moderate to severe plaque type psoriasis. JEADV 2007; in press.

Verfaille CJ, Coel M, Boersma Y, Mertens J, Borgers M, Roseeuw D. Oral R115866 in the treatment of moderate to severe facial acne vulgaris: an exploratory study. $\mathrm{Br} J$ Dermatol 2007; in press.

Verfaille CJ, Stoppie P, Ramaekers FCS, Borgers M. Effects of R115866 on Reconstituted Human Epidermis (RHE). Submitted.

Verfaille CJ, Van Steensel MAM, van de Kerkhof PCM, Steijlen PM. Use of liarozole in ichthyosis. Submitted.

Verfaille CJ, Stoppie P, Ramaekers FCS, Borgers M. In vivo pharmacology of liarozole. Submitted. 


\title{
Book section
}

van de Kerkhof PCM and Verfaille CJ. Retinoids and RAMBAs in the treatment of psoriasis. In: Retinoids and Carotenoids in Dermatology. Valquist A \& Duvic M, eds., New York: Taylor and Francis Group, LLC; 2007: in press.

\begin{abstract}
s
Verfaille CJ, Bols L, Borgers M, Franssen K, Govaerts B, Moeremans M, Stoppie P, Geysen J. Comparative analysis of the activity of three generations of retinoic acid metabolism blocking agents in cultures of differentiating normal human epidermal keratinocytes. J Invest Dermatol 2004; 122 (3): A71.

Vandeplassche G, Verfaille CJ, Beger B, Wouters L, Snoeck E, Cauwenbergh G. Safety of oral liarozole in subjects with ichthyosis or psoriasis. $J$ Eur Acad Dermatol Venereol 2004; 18 (Suppl. 2): 395-6.

Verfaille CJ, Steijlen PM, Blanchet-Bardon C, Vandeplassche G, Vanhoutte FP, Cauwenbergh G. Phase II and III studies to evaluate the efficacy and safety of oral liarozole and acitretin in the treatment of severe ichthyosis. J Eur Acad Dermatol Venereol 2004;
\end{abstract} 18 (Suppl. 2): 145.

Mertens J, Verfaille CJ, Thissen CACM, Bovenschen HJ, Steijlen PM, van de Kerkhof PCM; Oral Rambazole ${ }^{\mathrm{TM}}$, in patients with moderate to severe plaque type psoriasis - A pilot trial. $14^{\text {th }} E A D V$, London, 2005. PO06.84

Mertens J, Verfaille CJ, Thissen CACM, Bovenschen HJ, Steijlen PM, van de Kerkhof PCM. Oral R115866 in patients with moderate to severe plaque type psoriasis - Safety evaluation from a phase IIa trial. JAAD 2006; 54: AB205, P2828.

Hachem JP, Verfaille CJ, Coel M, Boersma I, Mertens J, Borgers M, Roseeuw D. Oral $\mathrm{R} 115866$ in the treatment of facial acne vulgaris - a phase IIa trial. $15^{\text {th }} E A D V$, Rhodos, 2006. PO01.65. 